Portland State University

PDXScholar

Fall 1-1-2013

\title{
The Relationship Between Traffic Signals and Pedestrian, Bicyclist and Transit User Exposure in Urban Areas
}

Courtney Natasha Slavin

Portland State University

Follow this and additional works at: https://pdxscholar.library.pdx.edu/open_access_etds

Part of the Other Civil and Environmental Engineering Commons

Let us know how access to this document benefits you.

Recommended Citation

Slavin, Courtney Natasha, "The Relationship Between Traffic Signals and Pedestrian, Bicyclist and Transit User Exposure in Urban Areas" (2013). Dissertations and Theses. Paper 616.

https://doi.org/10.15760/etd.616

This Thesis is brought to you for free and open access. It has been accepted for inclusion in Dissertations and Theses by an authorized administrator of PDXScholar. Please contact us if we can make this document more accessible: pdxscholar@pdx.edu. 
The Relationship Between Traffic Signals and Pedestrian, Bicyclist and Transit User

Exposure in Urban Areas

by

Courtney Natasha Slavin

A thesis submitted in partial fulfillment of the requirements for the degree of

\author{
Master of Science \\ in \\ Civil and Environmental Engineering
}

Thesis Committee:

Miguel Figliozzi, Chair

Christopher Monsere

Peter Koonce

Portland State University

2012 
(C) 2012 Courtney Natasha Slavin 


\begin{abstract}
Improving the efficiency of traffic operations along arterials is currently a priority for many agencies as their roadway infrastructure is built out to the largest possible capacity within the urban environment. Many advanced systems are being implemented to optimize traffic signal timing. Air quality is typically not a consideration when these decisions are made. The relationship between exposure to air pollution and traffic signal timing has not been fully explored by other researchers. This study is the first research effort to combine detailed traffic signal timing data (at 5 second intervals) and air pollutant exposure data. Results show that longer green time along the busy arterial reduces pollutant levels, while increased volume per cycle increases pollutant levels. This research quantifies the factors that contribute to pedestrian, bicyclist, and transit user exposure at a busy intersection along an urban arterial. The factors include traffic signal timing, weather related variables, traffic volumes, and heavy vehicle and bus presence. Additionally, the impact of an adaptive traffic signal system on air quality is assessed to understand the implications of signal timing on air pollutant exposure.
\end{abstract}




\section{Dedication}

This thesis is dedicated to my family, my boyfriend, and his family for always supporting and believing in me, even when I didn't think that I could do it. Having such a wonderful support system helped me stay focused and finish my thesis. To my mom, dad, and sister, for constantly being my biggest supporters throughout my life, I thank you immensely. To my boyfriend Adam, for being the one person in this world that knows exactly how to get me through the hard times and put everything in perspective, I don't know how to thank you enough. To the Furman's, for wanting the best for me and helping me to achieve it. 


\section{Acknowledgements}

First and foremost I owe a special thank you to my advisor, Dr. Miguel Figliozzi, for his help throughout this process. Without his guidance, this thesis would not have been possible. I want to thank him for always finding ways to look at the data in a different way, when I found myself unsure of how to proceed. I especially want to thank him for reassuring me to keep going and reminding me that it would all work out in the end. Thank you to my committee members, Dr. Miguel Figliozzi, Dr. Chris Monsere and Peter Koonce, for careful review and assistance with my final thesis. Thank you to Peter Koonce and Willie Rotich at the City of Portland Bureau of Transportation for their help with traffic signal data and their involvement in the project. I would also like to thank TriMet for the bus characteristic data and for their willingness to help. I owe a thank you to the members of the data collection team, especially Eric Albright, for waking up early and braving the cold weather with me. Additionally, I gratefully acknowledge the Oregon

Transportation, Research and Education Consortium (OTREC) for sponsoring this research. 


\section{Table of Contents}

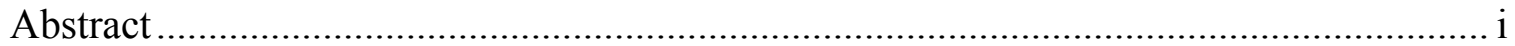

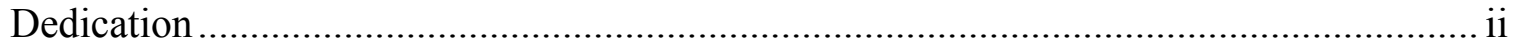

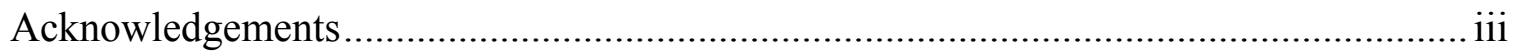

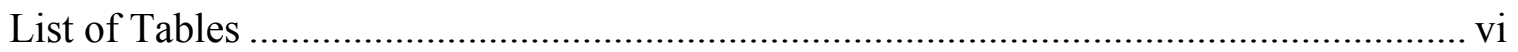

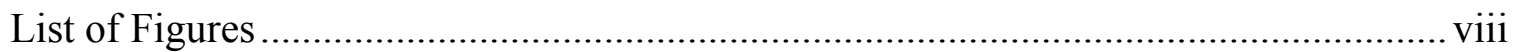

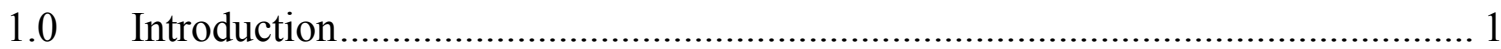

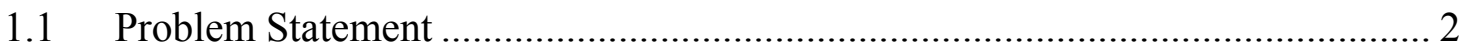

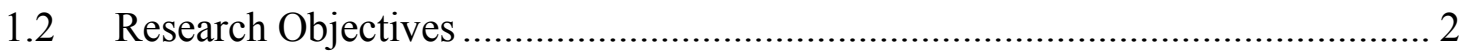

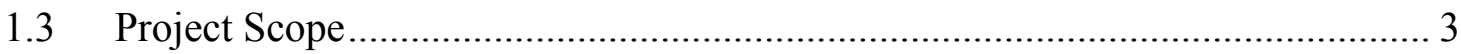

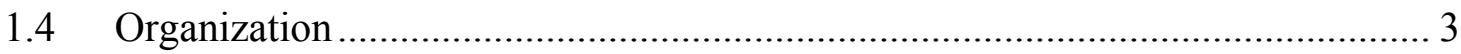

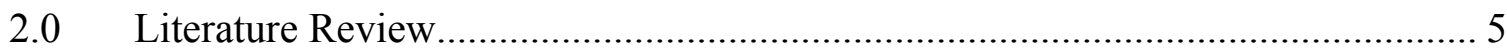

2.1 Air Pollutants, Regulations \& Health Effects ................................................ 5

2.2 Air Pollution and Atmospheric Impacts ......................................................... 9

2.3 Air Pollution Vehicular and Bus Impacts ...................................................... 9

2.4 Traffic Signal Impacts on Air Pollution ........................................................... 10

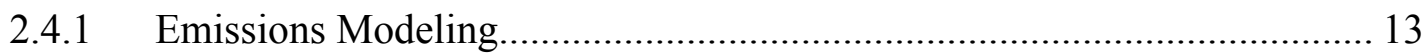

2.4.2 Air Quality Field Data Collection........................................................... 16

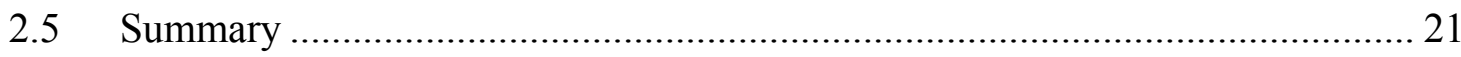

$3.0 \quad$ Data

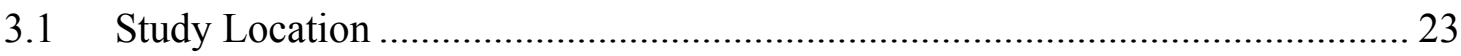

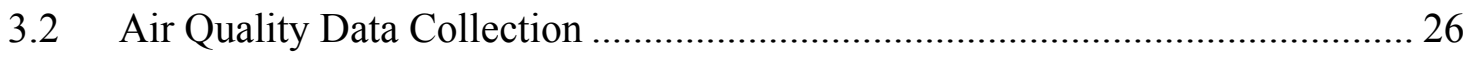

$3.3 \quad$ Traffic Related Data ...................................................................................... 31

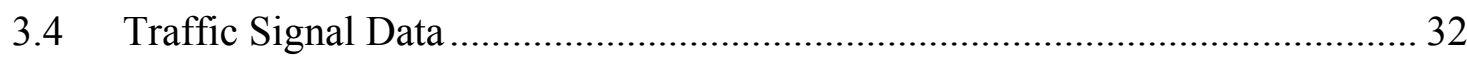

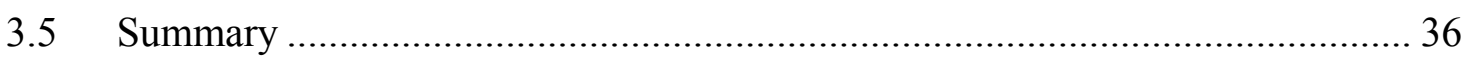

4.0 Exploratory Data Processing and Analysis ..................................................... 37

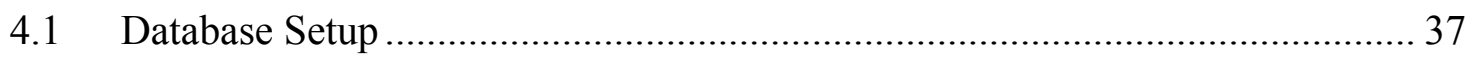

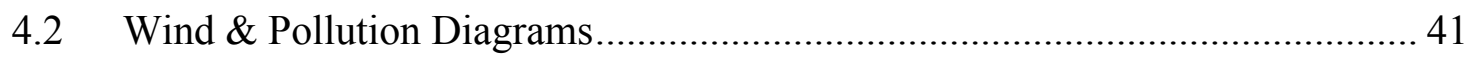

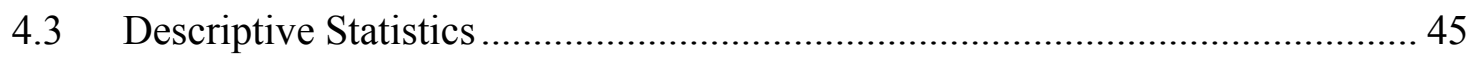

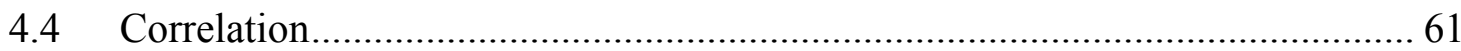

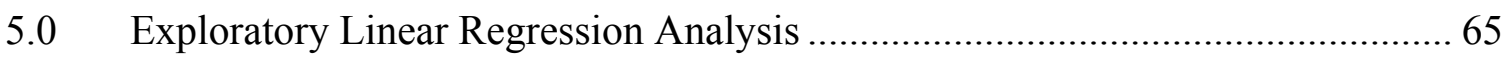

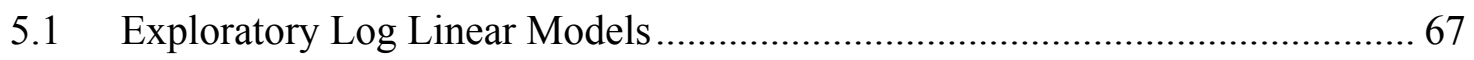


5.2 Exploratory Lagged Log Linear Models ..................................................... 78

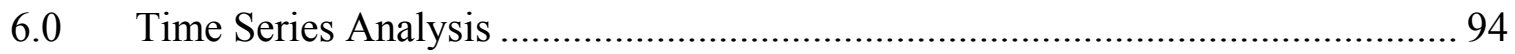

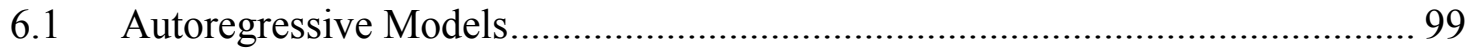

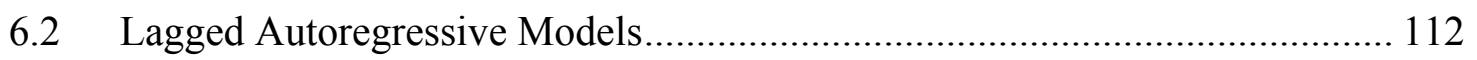

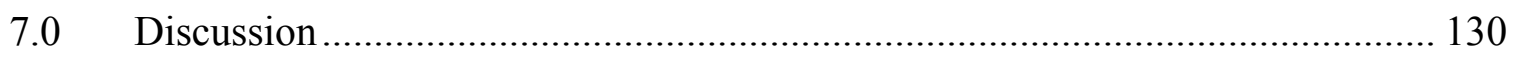

7.1 Comparison of Pollutants at NE Corner...................................................... 131

7.2 Comparison of Particulate Matter Between NE \& NW Corners ...................... 136

7.3 Vehicle Related Impacts.............................................................................. 141

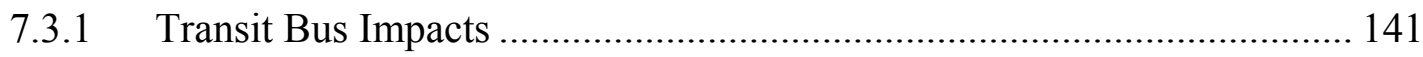

7.3.2 Heavy Vehicle Impacts ........................................................................... 143

7.3.3 Overall Traffic Impacts....................................................................... 144

7.4 Traffic Signal Timing Impacts ……...................................................... 145

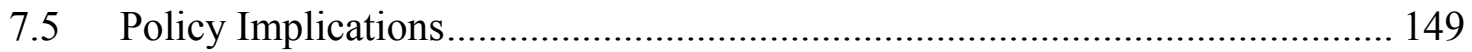

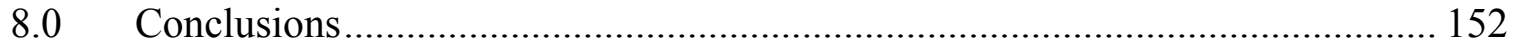

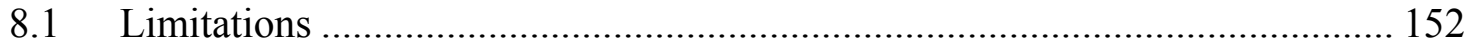

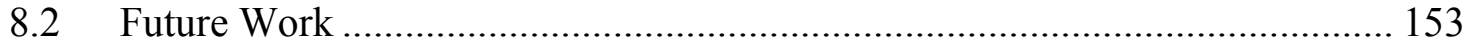

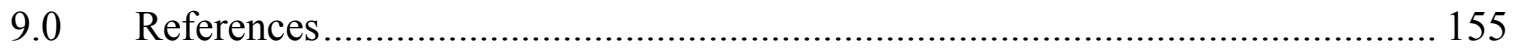

10.0 Appendix A: Exploratory Data Analysis ....................................................... 160

11.0 Appendix B: Exploratory Linear Regression Analysis......................................... 161

12.0 Appendix C: Time Series Analysis ................................................................... 166 


\section{List of Tables}

Table 1. National Ambient Air Quality Standards (EPA, 2011) …………………........... 8

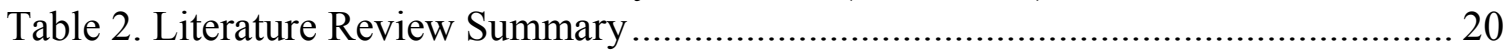

Table 3. Data Collection Equipment Summary ............................................................ 28

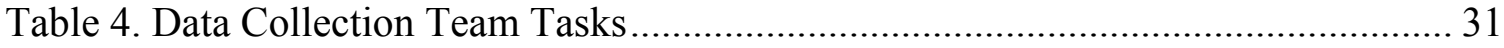

Table 5. Traffic Signal Phasing Legend ........................................................................ 36

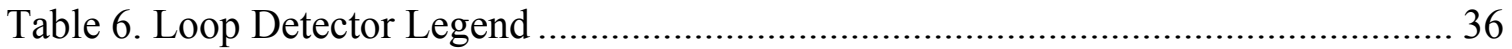

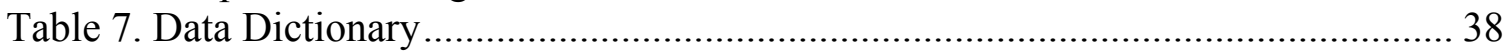

Table 8. Detectors Grouped by Movement................................................................... 40

Table 9. Descriptive Statistics - Atmospheric Factors ...................................................... 46

Table 10. Descriptive Statistics - Bus and Heavy Vehicle Traffic ................................... 47

Table 11. Descriptive Statistics - SCATS Inputs............................................................ 48

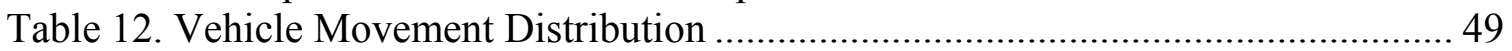

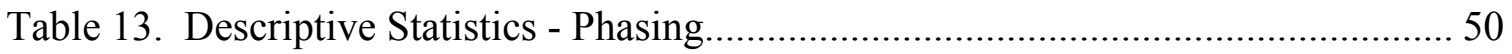

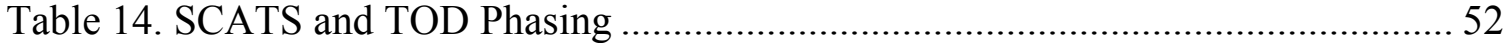

Table 15. Descriptive Statistics - Pollutant Concentrations.............................................. 54

Table 16. Correlation Between Weather, Traffic and Air Pollution................................. 62

Table 17. Correlation Among Traffic Variables.............................................................. 64

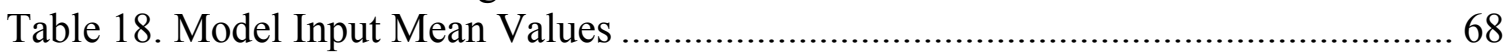

Table 19. NE Corner Log Linear Models - Particulate Matter ....................................... 68

Table 20. NE Corner Log Linear Model Interpretation - Particulate Matter..................... 69

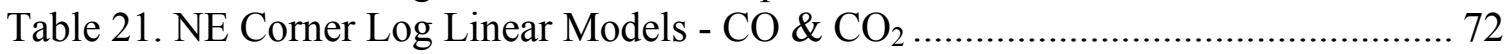

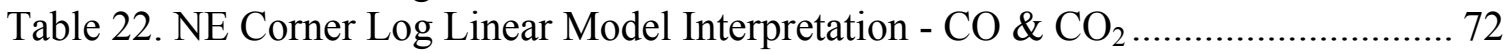

Table 23. NW Corner Log Linear Models - Particulate Matter........................................ 75

Table 24. NW Corner Log Linear Model Interpretation................................................... 76

Table 25. Compare Original and Lagged Log Linear Models........................................ 79

Table 26. UFP NE Lagged Log Linear Model ……….................................................. 80

Table 27. UFP NE Lagged Log Linear Model Interpretation........................................... 81

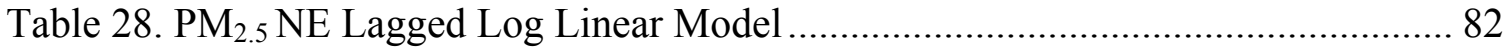

Table 29. $\mathrm{PM}_{2.5}$ NE Lagged Log Linear Model Interpretation ....................................... 84

Table 30. CO NE Lagged Log Linear Model …………............................................... 85

Table 31. CO NE Lagged Log Linear Model Interpretation ............................................ 86

Table 32. $\mathrm{CO}_{2}$ NE Lagged Log Linear Model......................................................... 88

Table 33. $\mathrm{CO}_{2} \mathrm{NE}$ Lagged Log Linear Model Interpretation .......................................... 89

Table 34. UFP NW Lagged Log Linear Model ........................................................... 90

Table 35. UFP NW Lagged Log Linear Model Interpretation ........................................ 91

Table 36. $\mathrm{PM}_{2.5}$ NW Lagged Log Linear Model........................................................... 92

Table 37. $\mathrm{PM}_{2.5}$ NW Lagged Log Linear Model Interpretation...................................... 93

Table 38. Autoregressive Model Specification.............................................................. 98

Table 39. UFP NE Log Linear \& AR1 Models .......................................................... 103

Table 40. $\mathrm{PM}_{2.5}$ NE Log Linear \& AR1 Models............................................................. 104

Table 41. NE Corner Autoregressive Model Interpretation - Particulate Matter ........... 105

Table 42. CO NE Log Linear \& AR 2 Models ............................................................. 106 
Table 43. $\mathrm{CO}_{2}$ NE Log Linear \& AR 1 Models ....................................................... 107

Table 44. NE Corner Autoregressive Model Interpretation - $\mathrm{CO} \& \mathrm{CO}_{2} \ldots \ldots \ldots \ldots \ldots \ldots . . . . . . . .108$

Table 45. UFP NW Log Linear \& AR 1 Models ......................................................... 109

Table 46. $\mathrm{PM}_{2.5}$ NW Log Linear \& AR 1 Models ....................................................... 110

Table 47. NW Corner Autoregressive Model Interpretation - Particulate Matter .......... 111

Table 48. Contribution from Autoregressive (AR) Terms......................................... 111

Table 49. UFP NE Lagged AR1 Model...................................................................... 115

Table 50. UFP NE Lagged AR1 Model Interpretation ............................................... 116

Table 51. $\mathrm{PM}_{2.5}$ NE Lagged AR1 Model ................................................................... 117

Table 52. $\mathrm{PM}_{2.5}$ NE Lagged AR1 Model Interpretation.............................................. 119

Table 53. CO NE Lagged AR 2 Model.................................................................... 120

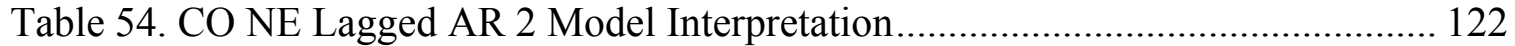

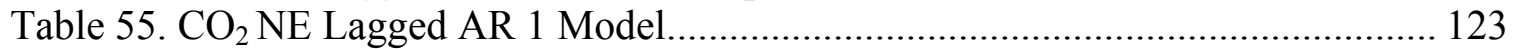

Table 56. $\mathrm{CO}_{2} \mathrm{NE}$ Lagged AR 1 Model Interpretation............................................... 124

Table 57. UFP NW Lagged AR1 Model ................................................................ 125

Table 58. UFP NW Lagged AR 1 Model Interpretation.............................................. 126

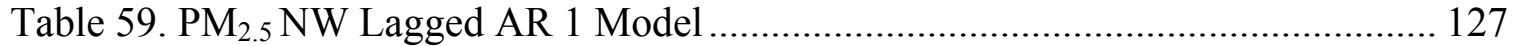

Table 60. $\mathrm{PM}_{2.5}$ NW Lagged AR 1 Model Interpretation........................................... 128

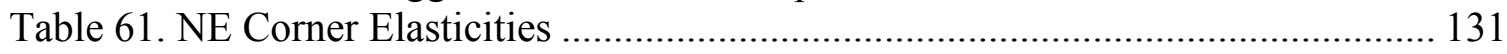

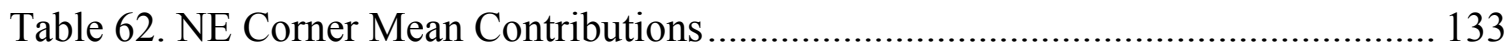

Table 63. NE Corner Lagged Elasticities ..................................................................... 134

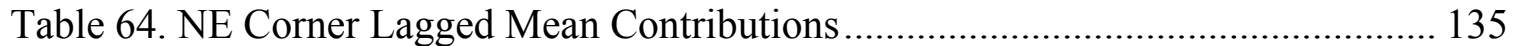

Table 65. NE \& NW Corners Elasticities ................................................................. 137

Table 66. NE \& NW Corners Mean Contributions....................................................... 138

Table 67. NE \& NW Corners Lagged Elasticities ......................................................... 139

Table 68. NE \& NW Corners Lagged Mean Contributions........................................... 140

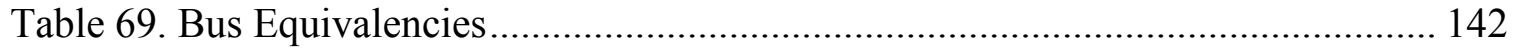

Table 70. Heavy Vehicle Equivalencies .................................................................. 144

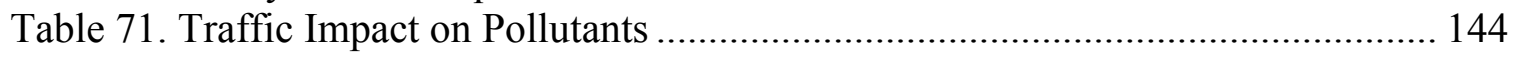

Table 72. Impact of Traffic Signal Timing on Pollutant Levels .................................. 146 


\section{List of Figures}

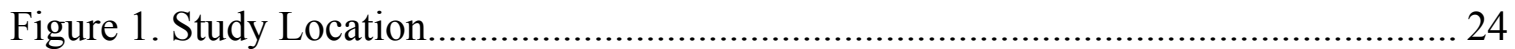

Figure 2. Powell Boulevard and $26^{\text {th }}$ Avenue - Land Use ........................................... 25

Figure 3. Data Collection Equipment Location ....................................................... 28

Figure 4. Data Collection Equipment Setup ............................................................. 30

Figure 5. SCATS Phasing \& Detector Locations ........................................................... 33

Figure 6. Ring and Barrier Diagram Before SCATS .................................................... 34

Figure 7. Ring and Barrier Diagrams After SCATS .................................................... 35

Figure 8. Wind Direction Bin Diagram ..................................................................... 38

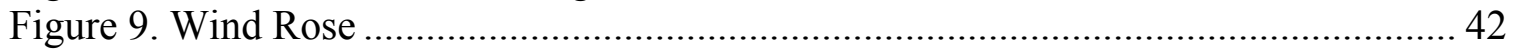

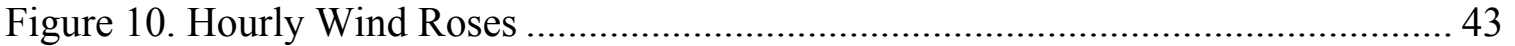

Figure 11. Polar Plots for Pollutants at NE \& NW Corners .......................................... 44

Figure 12. Phasing Bar Plots....................................................................................... 51

Figure 13. Adaptive Compared to Time of Day Cycle Length....................................... 53

Figure 14. Volume per Cycle and Cycle Length .......................................................... 53

Figure 15. UFP NE, NW \& SE Corners Scatterplots ................................................. 56

Figure 16. $\mathrm{PM}_{2.5}$ - NE, NW \& SE Corners Scatterplots............................................. 57

Figure 17. $\mathrm{CO} \& \mathrm{CO}_{2}$ - NE Corner Scatterplots ....................................................... 59

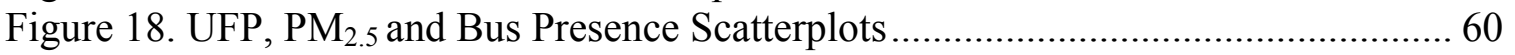

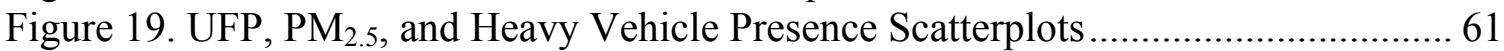

Figure 20. Log Linear Model Residual Plot - UFP NE............................................... 95

Figure 21. Log Linear Model Lag Plot - UFP NE ..................................................... 96

Figure 22. Log Linear Model ACF \& PACF Plots - UFP NE ..................................... 97

Figure 23. AR1 Residual Plot - UFP NE ............................................................. 100

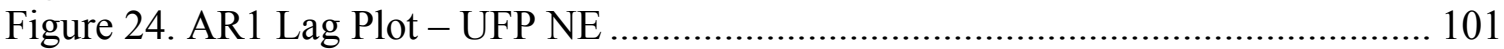

Figure 25. AR1 ACF \& PACF Plots - UFP NE ...................................................... 102

Figure 26. Cross Correlation Plots - UFP NE A ....................................................... 113

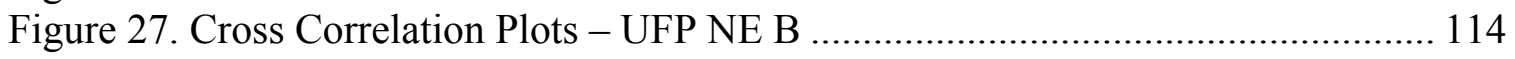

Figure 28. Fitted vs. Observed Plot ..................................................................... 129

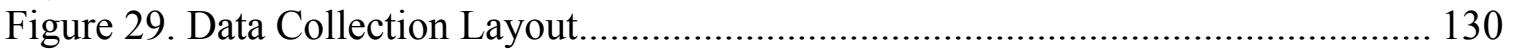

Figure 30. Volume Before and After SCATS .......................................................... 148 


\subsection{Introduction}

Air pollution is a growing concern in cities all over the United States. In urban areas the main contributor to air pollution is vehicle emissions on transportation facilities (Peters, McCourt, \& Hurtado, 2009). The United States Environmental Protection Agency (EPA) regulates air pollution by setting standards for various pollutants. There are regulations aimed at in-vehicle testing for tailpipe emissions in addition to regulations on ambient levels for criteria pollutants. These regulations are constantly being updated as research sheds new light on the relationship between pollutant levels and health effects.

Users of the transportation system are exposed to air pollution in urban areas regardless of their mode choice. Many urban arterials are multimodal in nature, facilitating travel by private vehicle, transit bus, bicycle, and walking. The operation of the traffic signals can greatly impact emissions in terms of the number of stops and the delay (Peters, McCourt, \& Hurtado, 2009). The efficiency of traffic operations on arterial roadways is greatly influenced by the traffic signal timing parameters. The relationship between traffic signal timing and pedestrian's exposure to emissions has not yet been fully explored. If this relationship can be more clearly understood, future traffic signal timing efforts will be able to reduce pedestrian exposure level to emissions.

This thesis studies emission and non-motorized exposure at an urban arterial called Powell Boulevard, located in Portland. Traffic and air quality data from peak travel periods are used for the analysis. This corridor implemented an adaptive traffic signal system, so the effects of this can be evaluated in comparison with time of day plans. Even 
though this study is only for one corridor, the results are generalizable and can be applied to similar intersections. Due to the importance of weather, the conditions must be similar to the ones from this study. The intersection must have similar volumes and operational characteristics for the model to be applied. In this case, traffic signal timing parameters can be used to predict changes in pollutant levels.

\subsection{Problem Statement}

Pedestrians, bicyclists, and transit users have not been included in research examining urban air quality and traffic signal timing. Air pollutants are typically not monitored near roadways, where the impact of traffic signals is near in proximity and where pedestrians and bicyclists travel. The Environmental Protection Agency (EPA) monitors air pollutant concentration levels and provides regulations that cities must comply with. However, they do not take measurements near roadways or pedestrian and bicycle travel areas, which are elevated compared to ambient urban levels. Hence, this research aims to fill this gap and understand the impact of traffic signal timing on pedestrian and transit exposure.

\subsection{Research Objectives}

Determine if there is an empirical connection between pedestrian, bicyclist, and transit user exposure to air pollutants at an intersection along an urban roadway and the traffic signal system performance. If an empirical relationship can be determined, air quality performance can be used as a factor in determination of traffic signal timing. Additionally, the significant factors in terms of explaining exposure will be identified and 
quantified. The results of this can help determine which traffic signal timing variables contribute the most to high exposure periods.

Previous research has examined exposure, while separate research has attempted to understand how traffic signal timing affects operational characteristics. This thesis attempts to link these two areas of research by providing a framework for linking exposure and traffic signal timing data to examine their relationship.

\subsection{Project Scope}

This research project uses data collected at one intersection on an urban arterial in Portland, Oregon to link air quality and traffic signal timing, while controlling for other factors that affect air pollution concentrations. These other factors include atmospheric factors, such as temperature, relative humidity, wind speed and direction, and traffic related factors, such as heavy vehicle, transit bus presence, and volumes. This research involved data collection and analysis in the scope.

\subsection{Organization}

This report is organized by first providing background information and summarizing current relevant research in Chapter 2 with the literature review. Chapter 3 is the data section, which goes over the various data sources, how they were collected, and what fields they include. Chapter 4 is an exploratory data analysis, which includes setting up the database, wind and pollution diagrams, descriptive statistics, and correlations. Chapter 5 provides the formulation and results for log linear regression models. Chapter 6 provides results of autoregressive models formed through the use of time series analysis. 
Chapter 7 includes a discussion of the results through use of comparisons, equivalencies, and assessments of the impacts of adaptive traffic signal timing relative to time of day plans. Policy implications are discussed related to transit buses, signal priority and operational strategies. The thesis concludes with Chapter 8, which describes limitations, overall conclusions and future work. 


\subsection{Literature Review}

Researchers have proven the link between changes in traffic signal timing and the number of stops, delay and fuel consumption. This has been widely researched. However, one step beyond this is establishing an empirical relationship between traffic signals and emissions. Changes in signalization and the effect on emissions is an important relationship to be researched. A challenge in minimizing air pollution is that not all pollutants are formed the same way or behave similarly. Due to this, there are tradeoffs in minimizing the different pollutants. In order to research this relationship, field data collection or modeling is commonly used to estimate pollutant levels. This research attempts to understand how air quality is affected by traffic signal timing by analyzing data collected on a test corridor located in Portland, Oregon.

The literature review provides background on air pollution, regulations, and health effects, how air quality is affected by atmospheric factors, vehicles, buses, and heavy vehicles. Additionally, case studies that examined air quality and traffic signal timing are discussed including research that used field data collection and modeling.

\subsection{Air Pollutants, Regulations \& Health Effects}

The United States Environmental Protection Agency (EPA), created in 1970, defines air pollution as "the presence of contaminants or pollutant substances in the air that interfere with human health or welfare, or produce other harmful environmental effects (Vallero, 2008)." Since the creation of the EPA, the number of laws concerning the regulation of air pollution has grown substantially. The EPA created the National Ambient Air Quality Standards (NAAQS), which regulates six pollutants: carbon monoxide, particulate matter, 
nitrogen oxide, sulfur oxide, smog, and lead (Vallero, 2008). Of the six pollutants, this research will include carbon monoxide and particulate matter. These two pollutants are from mobile sources. The EPA defines mobile sources as pollution sources that move, such as cars, trucks, snow blowers, bulldozers, and trains. Mobile sources are the main cause of air pollution in urban areas (EPA, 2007).

Carbon monoxide (CO), formed through incomplete combustion of fuel, is a poisonous gas that cannot be seen or smelled. The gas is inhaled and absorbed into the bloodstream, altering the typical process of inhaling $\mathrm{O}_{2}$ and releasing $\mathrm{CO}_{2}$. Instead carboxyhaemoglobin $(\mathrm{COHb})$ is formed after inhaling $\mathrm{CO}$, and the baseline level of $\mathrm{COHb}$ is about $0.5 \%$ for most people. After exposure to $\mathrm{CO}$, the $\mathrm{COHb}$ level is increased, where it should not exceed 2\%, or health effects can occur (Vallero, 2008).

Elevated levels of carbon monoxide in the bloodstream can cause a variety of symptoms, due to the reduction in oxygen delivery to the body's organs and tissues. These include: visual impairment, headache, and reduced work capacity. At high enough levels, carbon monoxide can cause death. For people with heart conditions, short-term exposure can cause chest pain (EPA, 2011). There are specific health concerns for pregnant women, such as low birth weight and an increase in deaths occurring immediately before and after birth (Vallero, 2008).

Particulate matter (PM) is a mixture of solid particles and liquid droplets found in the air that is defined by the particle size. It is made up of acids (such as nitrates and sulfates), organic chemicals, metals, and soil or dust particles. $\mathrm{PM}_{10}$ is defined as particles that are 
between $2.5 \mu \mathrm{m}$ and $10 \mu \mathrm{m}$ in diameter, $\mathrm{PM}_{2.5}$ is between $1.0 \mu \mathrm{m}$ and $2.5 \mu \mathrm{m}$, and $\mathrm{PM}_{1.0}$ is between $0.1 \mu \mathrm{m}$ and $1.0 \mu \mathrm{m}$, which are measured by mass, in micrograms per cubic meter $\left(\mu \mathrm{g} / \mathrm{m}^{3}\right)$. Ultrafine particles (UFP) are defined as being smaller than $0.1 \mu \mathrm{m}$ in diameter and are measured by particles per cubic centimeter ( $\mathrm{pt} / \mathrm{cc}$ ) because they are too small to be measured by mass concentration (EPA, 2012). Zhu et al. (Zhu, Hinds, Kim, Shen, \& Sioutas, 2002) found that UFP represent the majority of the number of particles in an urban area, but the heavier particles dominate the mass concentration measurements (Zhu, Hinds, Kim, Shen, \& Sioutas, 2002). Because of this, $\mathrm{PM}_{10}, \mathrm{PM}_{2.5}$, and $\mathrm{PM}_{1.0}$ are measured by mass concentration and ultrafine particulates are measured by number concentration.

The anatomy of the human lung enables smaller particles to travel deeper into the lung and can allow some particles to reach a person's bloodstream. Because of this, finer particles pose a greater health risk than coarse ones (EPA, 2012). There are several health effects that are related to the respiratory system from exposure to particulate matter, such as: wheezing and exacerbation of asthma, respiratory infections, cardiovascular disease, chronic bronchitis and chronic obstructive pulmonary disease (COPD) (Vallero, 2008).

The NAAQS is for criteria pollutants, including two types of standards, primary and secondary. Primary standards are for public health reasons, in order to protect populations that are more susceptible to the harmful effects of the pollutants, such as asthmatics, children, and the elderly. Secondary standards are for the general public in terms of visibility and the effect to the environment, including animals, plants, and buildings. 
Table 1 summarizes the relevant regulations, where the standards are in parts per million (ppm) or micrograms per cubic meter $\left(\mu \mathrm{g} / \mathrm{m}^{3}\right)(\mathrm{EPA}, 2011)$.

Table 1. National Ambient Air Quality Standards (EPA, 2011)

\begin{tabular}{|c|c|c|c|c|c|}
\hline \multicolumn{2}{|c|}{$\begin{array}{l}\text { Pollutant } \\
\text { [final rule year] }\end{array}$} & $\begin{array}{l}\text { Primary/ } \\
\text { Secondary }\end{array}$ & $\begin{array}{l}\text { Averaging } \\
\text { Time }\end{array}$ & Level & Form \\
\hline \multirow{2}{*}{\multicolumn{2}{|c|}{$\begin{array}{l}\text { Carbon Monoxide } \\
\text { [2011] }\end{array}$}} & \multirow{2}{*}{ Primary } & 8-hour & 9 ppm & \multirow{2}{*}{$\begin{array}{l}\text { Not to be exceeded more than } \\
\text { once per year }\end{array}$} \\
\hline & & & 1-hour & $35 \mathrm{ppm}$ & \\
\hline \multirow{3}{*}{$\begin{array}{l}\text { Particle } \\
\text { Pollution } \\
{[2006]}\end{array}$} & \multirow{2}{*}{$\mathrm{PM}_{2.5}$} & \multirow{2}{*}{$\begin{array}{l}\text { Primary and } \\
\text { Secondary }\end{array}$} & Annual* & $15 \mu \mathrm{g} / \mathrm{m}^{3}$ & $\begin{array}{l}\text { Annual mean, averaged over } 3 \\
\text { years }\end{array}$ \\
\hline & & & 24-hour & $35 \mu \mathrm{g} / \mathrm{m}^{3}$ & $\begin{array}{l}\text { 98th percentile, averaged over } \\
3 \text { years }\end{array}$ \\
\hline & $\mathrm{PM}_{10}$ & $\begin{array}{l}\text { Primary and } \\
\text { Secondary }\end{array}$ & 24-hour & $150 \mu \mathrm{g} / \mathrm{m}^{3}$ & $\begin{array}{l}\text { Not to be exceeded more than } \\
\text { once per year on average over } \\
3 \text { years }\end{array}$ \\
\hline
\end{tabular}

*Note: On June 29, 2012 EPA proposed a reduction in the annual $\mathrm{PM}_{2.5}$ standard to $12-13 \mu \mathrm{g} / \mathrm{m}^{3}$, which would result in a $13-20 \%$ reduction (EPA, 2012).

Ambient $\mathrm{CO}$ background concentrations are generally around $0.08-0.12 \mathrm{ppm}$. However, in urban areas around heavy traffic areas, such as intersections, there can be high shortterm peak values, up to $50 \mathrm{ppm}$ (WHO, 1999).

Ambient $\mathrm{PM}_{10}$ background concentrations, unaffected by roadway sources, range from 17 - $61 \mu \mathrm{g} / \mathrm{m}^{3}$ (Ballester, et al., 2008). Ambient $\mathrm{PM}_{2.5}$ background concentrations are generally below $16 \mu \mathrm{g} / \mathrm{m}^{3}$ (Bedada, et al., 2007). Particles that are finer than these, such as $\mathrm{PM}_{1.0}$ and UFP are unregulated by the EPA. Ambient urban UFP background concentrations range from a few thousand to 20 thousand particles $/ \mathrm{cm}^{3}$ (Morawska, Moore, \& Ristovski, 2004).

Although carbon dioxide $\left(\mathrm{CO}_{2}\right)$ is not a criteria pollutant, it is the most prevalent greenhouse gas and contributes to climate change. $\mathrm{CO}_{2}$ stays in the atmosphere for 50200 years, and about $30 \%$ of $\mathrm{CO}_{2}$ emissions are from transportation (EPA, 2012). Carbon 
dioxide was included in this research due to its link with traffic flows and its longevity in the environment. Due to its contribution to greenhouse gases, carbon dioxide is a pollutant of concern.

\subsection{Air Pollution and Atmospheric Impacts}

Vehicle exhaust is one process by which air pollutants are formed. However, there are other processes, which includes nucleation events, where particles coagulate with each other or condensation occurs. Various studies have found that the morning peak period typically has a higher number of particles than the afternoon for roadway environments (Holmes, 2007). Charron and Harrison (Charron \& Harrison, 2003) found a correlation between less nucleation events and higher temperature, meaning that in warmer weather less UFP is created (Charron \& Harrison, 2003).

A study done in Raleigh, North Carolina by Hagler et. al. (Hagler, et al., 2009) found elevated ambient UFP levels during the weekday morning commute period near the roadside. A study done by Zhu et. al. (Zhu, Kuhn, Mayo, \& Hinds, 2006) in Los Angeles compared UFP concentration measurements from daytime and nighttime data collections near a major highway. They found that the particle number concentration increased when the humidity increased and when the temperature decreased. In addition to this, temperature and relative humidity were inversely related with a strong correlation (Zhu, Kuhn, Mayo, \& Hinds, 2006). Therefore, UFP concentrations are significantly affected by atmospheric factors such as temperature, humidity, and time of day.

\subsection{Air Pollution Vehicular and Bus Impacts}


In urban areas, a large source of air pollution comes from vehicle and bus exhaust (Vallero, 2008). Pandian et. al. (Pandian, Gokhale, \& Ghoshal, 2009) evaluated factors that affect emissions near traffic intersections and listed parameters that play a role in air pollution. Heavy vehicles contribute to PM and the age and mileage of the vehicle have a positive effect on emissions. In addition to this, acceleration produces higher emissions than idling does, which makes an intersection and other areas with idling vehicles a critical location for the creation of air pollution (Pandian, Gokhale, \& Ghoshal, 2009).

Studies have found that near the roadway environment UFP coagulates and forms larger particles further away from the source of pollution and larger particles become more diluted. Due to the dilution and coagulation effects, there is a rapid decay with distance for particle number concentrations (Zhu, Hinds, Kim, Shen, \& Sioutas, 2002). This is crucial in terms of roadway exposure because the concentrations of particulate matter should be lower further away from the roadway.

\subsection{Traffic Signal Impacts on Air Pollution}

Time of day plans, which are associated to specific hours of the day due to fluctuations in demand, are the least expensive type of plan to design and require the least amount of hardware to operate. However, time of day plans are made, and used for years afterwards. Traffic conditions change over time, so time of day plans must be updated to meet new traffic conditions. The process of updating traffic signal plans is called signal retiming. Signal retiming optimizes the operation of signalized intersections by adjusting parameters associated with traffic signal timing. This process takes resources, such as 
time and money, in order to be completed. Even though there is a cost and time investment, there is potential for many benefits.

According to the Federal Highway Administration's (FHWA) Signal Timing Manual (STM), signal timing should be reviewed every three to five years to check for changes in traffic patterns. Often, there are significant differences, resulting in retiming being done every 3 to 5 years (Kittelson \& Associates, Inc., 2008). This is typically sufficient, however Sunkari, suggests that retiming should be done at least once a year to keep up with changes in traffic patterns (Sunkari, 2004).

The cost of signal retiming is about $\$ 2,500$ per intersection, which includes four timing plans. Even though there are costs, there are benefits associated with retiming, including: cost effectiveness, improved traffic flow, reduced delays and stops, improved safety, and reduced fuel consumption and emissions (Sunkari, 2004). These benefits are general and range per project.

In addition to retiming traffic signals by updating their time of day plans, there are other options for managing the system. Although it is more expensive to create, coordinated timing plans and adaptive systems can result in even larger improvements. There is a cost associated with coordinating traffic signals and updating plans. For non-recurring events, adaptive systems can be used to automatically adjust the timing plans to respond to the real traffic conditions. Signal timing can reduce harmful emissions by 5 to $10 \%$ (Peters, McCourt, \& Hurtado, 2009). 
There are a variety of adaptive traffic signal control systems on the market, which operate in different manners. This project specifically used the Sydney Coordinated Adaptive Traffic System (SCATS), which was developed in Australia in the early 1970's by the Road and Traffic Authority. It has successfully been used in Australia for the past 40 years. The system uses loop detection near the stop bars in addition to video cameras to detect vehicles enabling it to operate in real time conditions. Cycle lengths, phase splits, and offsets are optimized on a cycle by cycle basis. The degree of saturation is used to adjust the cycle length to maintain the highest allowable degree of saturation. SCATS selects offsets based on free flow travel time and degree of saturation, which aims to minimize stops for the vehicles on the main roadway (TransCore, 2011).

One case study has been done evaluating the impact of SCATS on emissions. The study was under the FAST-TRAC project in Oakland County, Michigan in 2008 for the M-59 corridor (Highland Road). The corridor runs in the eastbound and westbound direction and had pre-timed plans before SCATS. Data were collected for hydrocarbon, carbon monoxide, and nitrogen oxide emissions. The performance measures showed improvements for each of the peak periods generally in the eastbound direction, however the improvements were not statistically significant at the $95 \%$ confidence level. There were tradeoffs to the benefits from the implementation (Dutta, 2008).

The effect of traffic signal timing can be quantified through emissions and traffic modeling software or by using field measurements from data collection. 


\subsubsection{Emissions Modeling}

Air quality modeling is used as a cost effective method to assess air quality. Often, air quality modeling is used to test the effect of a change from a possible project. It is helpful to know that for example by giving additional green time to the mainline, queuing can be reduced, leading to reductions in pollutant levels. Results from air quality models can help policy makers make decisions. Many recent advances have been made with modeling techniques that make modeling an appealing method. Additionally, it is not always feasible to obtain field measurements.

EPA has been a leader in air quality modeling over the years. EPA first developed MOBILE, which is a model for highway vehicle emission factors in 1978. Every couple of years a new and improved MOBILE model has been released by EPA. The final MOBILE model was in 2004, which was MOBILE6.2. This model improved carbon monoxide emission factors, added emission factors for particulate matter, and added a spreadsheet output option (EPA, 2011).

MOBILE was replaced with MOVES (Motor Vehicle Emission Simulator) in order to meet the Clean Air Act requirements. The first MOVES model, MOVES2004, only included energy consumption and greenhouse gas impacts. After this, the Draft MOVES2009 was released, which included more air pollutants. This model was intended to receive input from users in order to make appropriate improvements. The result of these efforts is MOVES2010 which was released in December 2009; which takes millions of emission test results to make a model that estimates air pollution from on-road mobile sources, such as cars, trucks, motorcycles, and buses. MOVES2010 estimates the 
following air pollutants: VOCs (volatile organic compounds), $\mathrm{NO}_{\mathrm{x}}, \mathrm{CO}, \mathrm{PM}_{10}$, and $\mathrm{PM}_{2.5}$. In August 2010, MOVES2010a was released, which included minor upgrades (EPA, 2011).

MOVES is not simply an upgrade to MOBILE, it is an entirely different approach. MOBILE is based on numerous fixed driving cycles to simulate vehicle travel. However, MOVES2010 can compute emission factors for any drive cycle. MOVES2010 can compute emissions for the project scale for vehicles that are cruising, decelerating, idling, and accelerating. This makes it possible to compare the different parts of the drive cycle for each pollutant. Additionally, MOVES2010 takes into account differences among vehicle classifications, vehicle types, vehicle activity, and fuel used. According to Claggett, MOVES2010 particulate matter emission rates are sensitive to speed, temperature, and vehicle deterioration (Claggett, 2010). Not only can MOVES be used for smaller scale projects, but it can be applied at a regional, national or local level.

There are a couple of case studies that used modeling at the intersection level to attempt to understand the relationship between traffic control and emissions.

Papson, Hartley, and Kuo modeled $\mathrm{NO}_{\mathrm{x}}$ and $\mathrm{PM}$ emissions at congested and uncongested signalized intersections using MOVES2010. This research used MOVES2010 to estimate emissions with different traffic conditions and during various activity modes, including cruising, deceleration, idling, and acceleration. First, emission factors were calculated using MOVES2010 for each activity mode in grams per vehicle-second by using the project level analysis. Acceleration was the highest emission factor for both pollutants. 
Second, Synchro was used to simulate the control delay, queue length, and cycle length at the intersection. Webster's relationship of vehicles at signalized intersections was used to calculate the time-in-mode. The emission factors and the time in mode were used to calculate the total emissions for $\mathrm{NO}_{\mathrm{x}}$ and $\mathrm{PM}$ under the different volume scenarios (Papson, Hartley, \& Kuo, 2011).

$\mathrm{Li}, \mathrm{Wu}$, and $\mathrm{Zou}$ examined the impacts of signal timing on vehicle emissions at an isolated intersection by using three models with pre-timed signalization. The three models were optimized by: (a) minimizing delay, (b) minimizing stops, and (c) minimizing delay by limiting stops to a set value or constraint. The results of these models, which would be the delay and number of stops, are then used to calculate the emissions. Some of the inputs are: traffic volume, green time, lost time, cycle length, speed, deceleration rate, acceleration rate, and roadway grade. The results of this study showed that reducing the number of stops can reduce $\mathrm{CO}$ at the expense of slight increases in $\mathrm{CO}_{2}, \mathrm{HC}$, and $\mathrm{NO}_{\mathrm{x}}(\mathrm{Li}, \mathrm{Wu}, \& \mathrm{Zou}, 2011)$.

Li, Li, Pang, Yang, and Tian created a model for a signalized intersection that optimizes cycle length and green time by using integrated optimization of delay, fuel consumption, and emissions. Delay, fuel consumption, and emissions are given relative weights in the model. This model uses pedestrian green time as a constraint for the minimum green time allowed. This model was applied to an intersection in Nanjing City in China. Results show that the optimized signal timing yields reductions in delay and emissions $(\mathrm{Li}, \mathrm{Li}$, Pang, Yang, \& Tian, 2004). 
SCATSIM, which is an adaptive traffic network simulation model used to evaluate the SCATS algorithms, was used by Nguyen to compare adaptive traffic control to fixed timing. SCATSIM records fuel consumption, level of service, vehicle stops, and emission rates for $\mathrm{CO}, \mathrm{HC}$, and $\mathrm{NO}_{\mathrm{x}}$, which were used for comparison. It was found that under steady flow conditions, fixed-time performed slightly better than SCATS, however with unexpected conditions, SCATS showed a $25 \%$ reduction in $\mathrm{CO}$ and $\mathrm{HC}$ and a $15 \%$ reduction in $\mathrm{NO}_{\mathrm{x}}$ emissions (Nguyen, 1994).

Kergaye, Stevanovic, and Martin made a VISSIM model for 14 intersections in Park City, Utah using the SCATS algorithm. The model was validated to reflect field conditions through the use of turning movement counts and travel times so that there was no statistical difference between the model and field performance (Kergaye, Stevanovic, \& Martin, 2010). Upon completion of the VISSIM model, simulation was used to compare the operation of time of day plans to adaptive timing. Results showed that SCATS reduced the number of stops on the main arterials when compared to time of day plans. The Comprehensive Modal Emission Model (CMEM) was used to assess environmental impacts, including $\mathrm{CO}_{2}, \mathrm{CO}, \mathrm{HC}, \mathrm{NO}_{\mathrm{x}}$, and fuel consumption. The model results concluded that SCATS saved a significant amount of emissions (Stevanovic, Kergaye, \& Stevanovic, 2012).

There are a multitude of air quality/emissions models that can be used, however MOVES is the most commonly used model in the industry.

\subsubsection{Air Quality Field Data Collection}


Although air quality modeling has improved, it cannot perfectly represent real world conditions. To do this, air pollutant concentration levels must be measured in the field. However, air quality is difficult to measure for many reasons and is specific to a local environment. As previously discussed, there are many factors which can play a role in pollutant levels; these can be related to vehicular, transit, and or atmospheric factors. Vehicular factors can include traffic volumes, vehicle classifications, and vehicle speed. Transit factors can include transit vehicle volumes, age of vehicle, idling time, and the idling location near the intersection. Atmospheric factors can include temperature, relative humidity, wind speed and direction, and time of day. In addition to the challenge of accounting for all factors that could attribute to pollutant levels, there are challenges that are inherent to field data collection.

It is expensive to conduct data field measurements, and once the data are collected in the field, it must be processed and analyzed. Data are typically aggregated over a time period to make the data more usable. However, the more aggregated the data becomes; much of its value can be lost. Because of these reasons, field data collection is not done as often as desired.

Many studies have been done examining exposure at intersections in addition to taking measurements at varying distances from the roadway to understand dispersion effects. Although much research has been done, there has not been a study that looks at intersection level exposure in addition to the effect of traffic signal timing. It is not common to link these two types of data and research areas. 
However, there have been some studies related to signalization and emissions where field data were collected. The following relevant case studies took measurements while driving along a corridor by using on-road vehicle measurement devices. The results from these studies only apply to people who choose to drive as their transportation mode.

Unal et. al. (2003) examined the effect of signalization and level of service on vehicle emissions in Cary, North Carolina. This research used on-road vehicle measurement devices to collect emissions and traffic data for that trip on a particular roadway. Data were collected both before and after the corridors were signalized. The results indicated that in cases where the traffic flow significantly improved, emissions followed the same trend. Additionally, the highest emission rates were during acceleration, with idling being the lowest. This means that methods that reduce the number of stops would be more effective than reducing the amount of time a vehicle is stopped. Something to make note of is that these results are for the main corridor, which was being signalized. There may have been an opposite effect on the side street due to the changes in signal timing (Unal, Rouphail, \& Frey, 2003).

Parikh studied the effect of signal coordination on emission in the Dallas Fort Worth area by using a vehicle equipped with an on-board system. The system collects real-world emissions data every second including $\mathrm{CO}_{2}, \mathrm{NO}_{\mathrm{x}}, \mathrm{HC}, \mathrm{CO}$, engine rpm, vehicle speeds, temperature, and position data using GPS. Data were collected during the morning peak, afternoon peak and off-peak periods for two time periods. The first time period was before the signal retiming, while the second was done a year after during the same months. The results showed that there was a reduction in $\mathrm{NO}_{\mathrm{x}}$ and an increase in $\mathrm{CO}_{2}$ 
after signal coordination (Parikh, 2006). This study collected very detailed data concerning emissions and vehicle operations for one vehicle driving through the corridor. The research mentioned that atmospheric factors such as temperature and relative humidity could have been responsible for some of the differences, but these data were not collected.

Tao et. al. collected on-road data with two cars equipped with PEMS and GPS devices in Houston, Texas. PEMS collects real-world emissions data including $\mathrm{CO}_{2}, \mathrm{NO}_{\mathrm{x}}, \mathrm{HC}$, and CO. Data were collected during peak and off-peak periods in order to check for differences in the effect on emissions depending on traffic conditions. Coordinated timing was used in the field, so one of the cars represented coordinated, while the other was driven according to a set of rules to emulate non-coordinated conditions. The results showed that coordinated timing reduced emissions, but the effect was weakened during the peak periods, where the average speed decreased (Tao, Shi, \& Yu, 2011). While this study did collect field data, it compared coordinated to non-coordinated without actually changing the timing in the field. The results may have been different if data were collected with a true non-coordinated timing scheme.

A summary of the key studies using measured air quality data are included in Table 2, where all three are case studies that used on-road vehicle measurement devices along a corridor. 
Table 2. Literature Review Summary

\begin{tabular}{|c|c|c|c|}
\hline $\begin{array}{l}\text { Authors } \\
\text { (Year) }\end{array}$ & $\begin{array}{l}\text { Unal, Rouphail, Frey } \\
(2003)\end{array}$ & $\begin{array}{l}\text { Parikh } \\
(2006)\end{array}$ & $\begin{array}{l}\text { Tao, Shi, Yu. } \\
(2011)\end{array}$ \\
\hline Location & Cary, North Carolina & Dallas Fort Worth, Texas & Houston, Texas \\
\hline Methods & $\begin{array}{l}\text { - On-road vehicle } \\
\text { measurement devices } \\
\text { Data collected before } \\
\text { and after } \\
\text { coordination plans } \\
\text { for two corridors } \\
\text { - Collected emissions } \\
\text { and traffic data }\end{array}$ & $\begin{array}{ll}\text { - } & \text { On-road vehicle } \\
\text { measurement devices } \\
\text { - } & \text { Collect emissions and } \\
\text { traffic data } \\
\text { - } \\
\text { Before and after signal } \\
\text { retiming } \\
\text { During peak and off } \\
\text { peak periods }\end{array}$ & 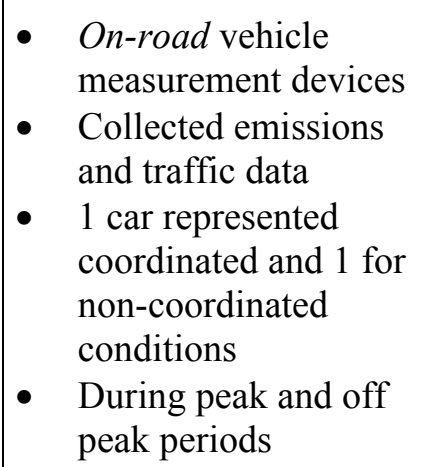 \\
\hline Data & $\begin{array}{ll}\text { - } & \text { CO, NOx, HC } \\
\text { - } & \text { Temperature and } \\
& \text { humidity } \\
\text { - } & \text { Travel time and } \\
& \text { speed } \\
\text { - } & \text { Vehicle information } \\
& \text { (make, model, } \\
\text { mileage, etc.) } \\
\text { - Events (entering } \\
\text { queue and crossing } \\
\text { intersections) }\end{array}$ & $\begin{array}{ll}\text { - } & \mathrm{CO}_{2} \text { and NOx } \\
\text { - } & \text { Temperature and } \\
& \text { humidity } \\
\text { - } & \text { Travel time and speed }\end{array}$ & $\begin{array}{ll}- & \mathrm{CO}, \mathrm{CO}_{2}, \mathrm{NOx}, \mathrm{HC} \\
- & \text { Travel time and speed } \\
- & \text { Vehicle information } \\
\text { (make, model, mileage, } \\
\text { etc.) }\end{array}$ \\
\hline Analysis & $\begin{array}{l}\mathrm{T} \text { tests to compare mean } \\
\text { before and after values }\end{array}$ & $\begin{array}{l}\mathrm{T} \text { tests to compare mean } \\
\text { before and after values } \\
\text { ANOVA to compare } \\
\text { groups }\end{array}$ & $\begin{array}{l}\% \text { reductions calculated } \\
\text { from coordinated to non- } \\
\text { coordinated values }\end{array}$ \\
\hline Results & $\begin{array}{l}\text { Highest emissions rates } \\
\text { during acceleration, } \\
\text { lowest during idling. } \\
\text { When traffic improved, } \\
\text { so did emissions. }\end{array}$ & $\begin{array}{l}\text { Reduction in } \mathrm{NOx}, \\
\text { increase in } \mathrm{CO}_{2} \text { after } \\
\text { signal coordination }\end{array}$ & $\begin{array}{l}\text { Coordinated timing } \\
\text { reduced emissions, but the } \\
\text { effect weakened during } \\
\text { peak periods. }\end{array}$ \\
\hline Gaps & $\begin{array}{l}\text { Did not examine effect } \\
\text { on side streets and } \\
\text { turning movements. } \\
\text { Did not incorporate all } \\
\text { measured predictors into } \\
\text { analysis. }\end{array}$ & $\begin{array}{l}\text { Did not examine effect on } \\
\text { side streets and turning } \\
\text { movements. } \\
\text { Did not incorporate all } \\
\text { measured predictors in } \\
\text { analysis. } \\
\text { Did not record events. }\end{array}$ & $\begin{array}{l}\text { The study corridor did not } \\
\text { actually change signal } \\
\text { timing. } \\
\text { Driver behavior affects } \\
\text { emissions. }\end{array}$ \\
\hline
\end{tabular}


The case studies examined in this literature review had a different goal than this research does. These studies focused on exposure for drivers, but they do not help to explain exposure other modes, such as walking, biking or taking transit. Drivers have much more control over their environment than pedestrians, cyclists, and transit users do. Bigazzi and Figliozzi (2011) found that one of the most effective mitigation strategies for freeway in vehicle UFP exposure is closing the vents, which provides the driver with $83-90 \%$ protection (Bigazzi \& Figliozzi, 2012). In-vehicle exposure can be relatively low with the windows and vents closed. Pedestrians, cyclists, and transit users do not have an option to protect themselves from poor air quality.

Although the case studies from the summary table are the most closely related research to this, there are many differences. The goal for this research is to examine exposure for pedestrians, bicyclists, and transit users by measuring air quality at a stationary location at a sidewalk, where transportation users wait. Whereas, the other studies took measurements while driving along a corridor, and focused on driver exposure. Additionally, these studies did not incorporate the effect of weather, heavy vehicles, transit vehicles, volume, and signal timing into their data collection and analysis, as this research has done.

\subsection{Summary}

This literature review has provided background on air pollution by defining the pollutants used in this study, discussing regulations, and health effects. Factors that have been established as having a relationship with air quality were mentioned, including vehicular, bus, and atmospheric conditions. This provided a baseline understanding before the 
relationship between air quality and traffic signals was introduced. Various traffic signal timing plans were mentioned to provide an understanding of the options available to agencies in managing their system. The impact of traffic signals on air quality has been assessed through field data collection and modeling techniques by other researchers. These relevant case studies were summarized along with gaps in the previous research highlighting issues that still need to be addressed. There is one key difference between research that has already been conducted and this research. Previous research has assessed exposure for drivers along a roadway, whereas this research quantifies exposure for pedestrians, bicyclists, and transit users on sidewalk facilities near the roadway environment.

The following Chapter will include specific information regarding the data used in this research. 


\subsection{Data}

Chapter 3 will provide background on the study location, the data collection procedure and descriptions of the various data sources used in the analysis. This is the first research to use data with this level of detail and from these sources that was simultaneously measured.

\subsection{Study Location}

Powell Boulevard is an urban arterial corridor located in Portland, Oregon that connects the Portland downtown and the City of Gresham. Powell Boulevard, also known as Highway US 26, has at least two lanes of traffic in each direction, and a center turn lane or median for left turns in some sections, and a variety of land uses. The street route runs east-west and includes the Ross Island Bridge which crosses over the Willamette River. The arterial is congested during peak traffic hours. The morning peak period is in the westbound direction, towards downtown Portland, while the afternoon peak period occurs in the eastbound direction. Improving the performance of this arterial is difficult due to the competing needs of different types of users such as pedestrians, transit, and private automobiles as well as balancing mobility and accessibility for a diverse array of activities and land uses along the corridor.

An adaptive traffic signal control system was implemented along Powell Boulevard in October of 2011, which makes it a perfect study location, because the effect of changing signalization can be quantified. In this case, the Sydney Coordinated Adaptive Traffic System (SCATS) was the adaptive system of choice by the City of Portland. The traffic signals previously operated on time of day plans that were unresponsive to real time 
traffic demands. The SCATS implementation extends from Milwaukie to $72^{\text {nd }}$. The study area is shown in Figure 1, where the icon is located at Powell and $26^{\text {th }}$, which is the intersection of focus for this research.

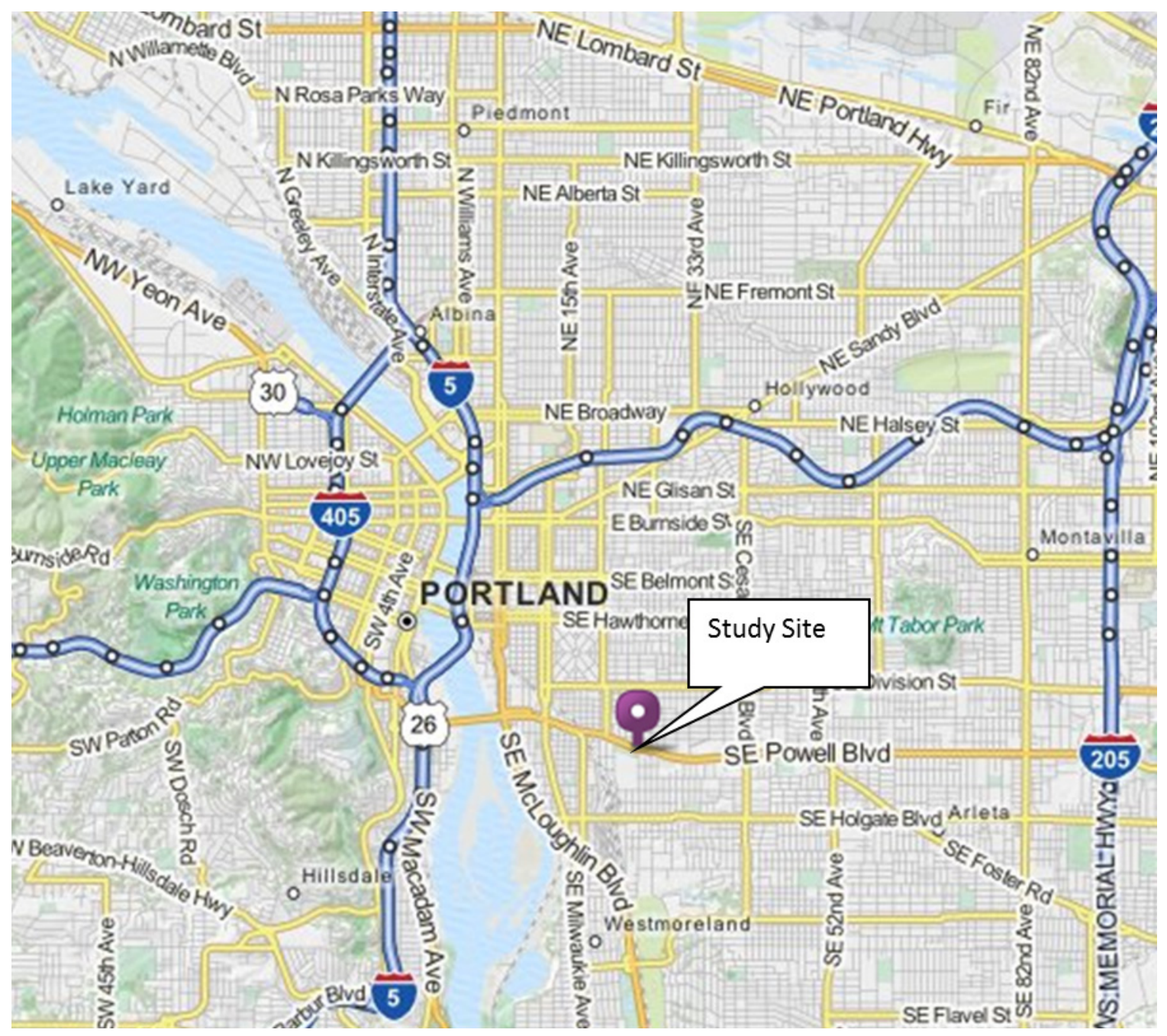

\section{Figure 1. Study Location}

Powell and $26^{\text {th }}$ is an ideal location for an air quality study for various reasons. The land use surrounding this intersection provides compelling reasons to measure the air pollution. At the northeast corner of the intersection is Cleveland High School, which serves about 1,600 students from grades nine to twelve. School is in attendance from 8:15 
am to 3:15 pm on typical school days (Portland Public Schools, 2010). The school brings high pedestrian, biking, and transit activity during school start and release times. At the southwest corner of the intersection is Powell Park, a publicly owned park that covers eight acres including a baseball field, basketball court, picnic area, restroom, playground, soccer field, and volleyball court (City of Portland, 2008). A variety of neighborhood residents use the park on a regular basis, which is located adjacent to the intersection. The other two corners of the intersection have businesses, in the northwest corner is a fast food restaurant and in the southeast corner is a multiuse retail building. The land use surrounding the intersection at Powell and $26^{\text {th }}$ is shown in Figure 2.

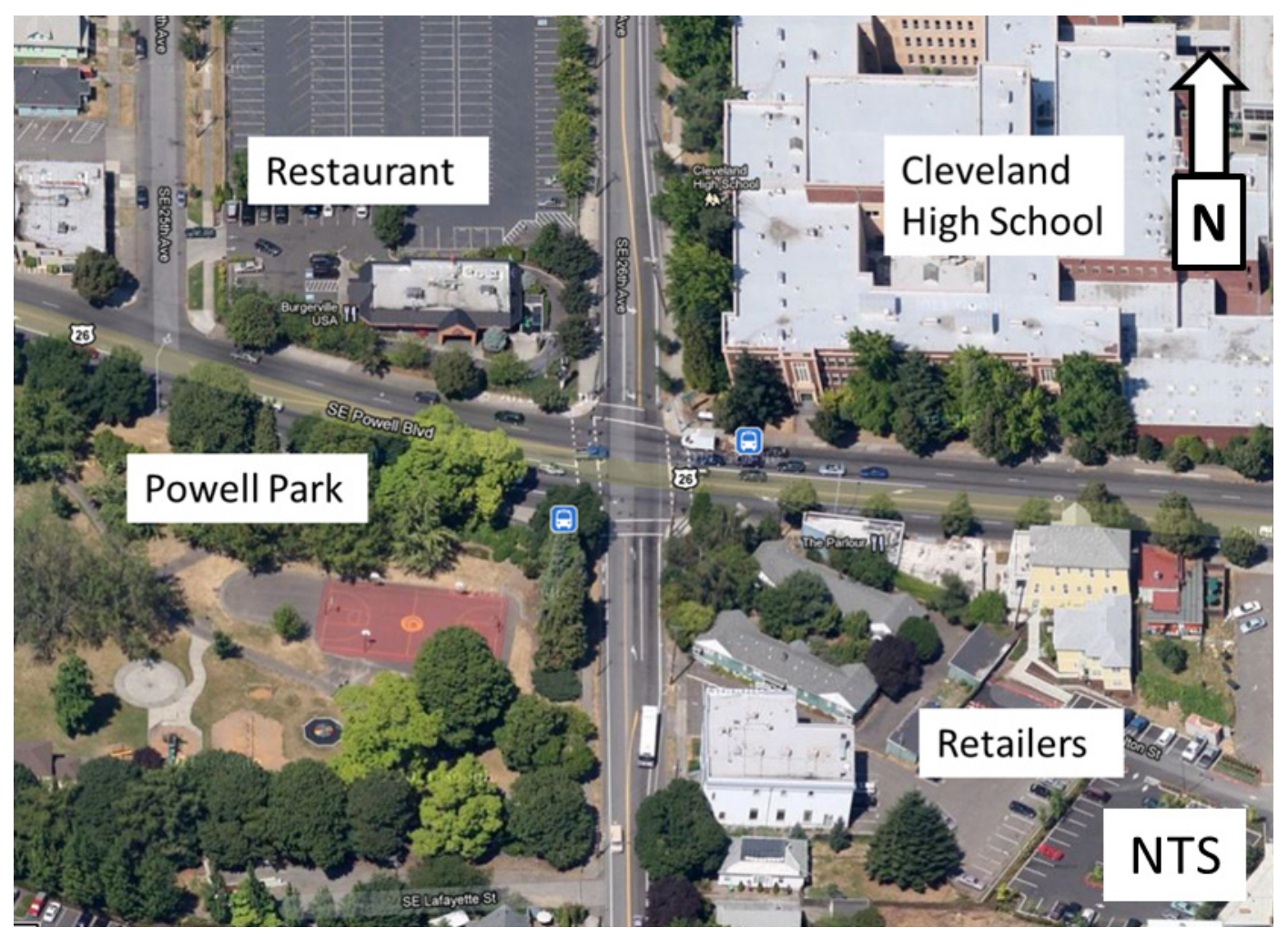

Figure 2. Powell Boulevard and $26^{\text {th }}$ Avenue - Land Use 
In addition to the land use items previously mentioned, this intersection is multimodal in nature. Powell is a heavily traveled corridor for private vehicles especially during peak commuting periods, in addition to being a key transit bus route. Alternately, $26^{\text {th }}$ is a more minor roadway in terms of vehicular volumes, but is a key bike route. In fall of 2011, bike boxes were installed at this intersection on the northbound and southbound approaches of $26^{\text {th }}$. The study location has high traffic volumes, public transit use, biking, and pedestrians competing for the right of way.

\subsection{Air Quality Data Collection}

Data collection was conducted by a team of three to five people during the fall of 2011, at Powell and $26^{\text {th }}$ measuring air quality, atmospheric factors, and traffic related data. Measurements were taken at three of the four corners of the intersection. Data were collected on Wednesday, October $26^{\text {th }}, 2011$ during the morning peak period, which was after SCATS was implemented. The morning peak period was used to capture one of the times during the day with the highest vehicular traffic, bicycle volumes, and pedestrian activity, in addition to the most frequent bus service. The morning peak period was seven to nine am, which was selected based on common practices used by other researchers and confirmation based on traffic data.

The data collection consisted of a two hour temporary setup of a variety of equipment owned by Portland State University. The P-Trak Particle Counter was used to take measurements of UFP concentration levels every second; this equipment is able to measure a concentration range of 0 to 500,000 particles per cubic centimeter (particles/cc). The Dusttrak Monitor was used to take measurements of the concentration 
levels of $\mathrm{PM}_{10}, \mathrm{PM}_{2.5}$, and $\mathrm{PM}_{1.0}$ every second. This equipment is able to measure a concentration range of 0.001 to 150 milligrams per cubic meter $\left(\mathrm{mg} / \mathrm{m}^{3}\right)$. The concentration levels of measurements exceeding the maximum value cannot be captured with this equipment. The Langan Model T15n was used to take measurements of CO concentration level and temperature every second, the concentration range is 0 to 200 parts per million (ppm). The Langan Model L26n was used to take $\mathrm{CO}_{2}$ measurements of the concentration level and temperature every second, the concentration range is 0 to 400 ppm. The two Langan pieces of equipment take temperature readings because of the technology's sensitivity to temperature to make post processing corrections to $\mathrm{CO}$ and $\mathrm{CO}_{2}$ possible. The Young Ultrasonic Anemometer was used to take measurements of wind speed and direction every five seconds. The range for wind speed is 0 to 40 meters per second $(\mathrm{m} / \mathrm{s})$ and the range for wind direction is 0 to 359.9 degrees. The HOBO Data Logger was used to take measurements of temperature and relative humidity every five seconds. The range for temperature is -4 to $158{ }^{\circ} \mathrm{F}$, while the range for relative humidity is 5 to $95 \%$.

Table 3 summarizes the data collection equipment, what it measures, the unit of measurement, how often measurements were taken, and the corners of the intersection where this equipment was located. 
Table 3. Data Collection Equipment Summary

\begin{tabular}{|l|l|l|l|l|}
\hline Equipment Name & Type of Data & Unit & Frequency & Corner \\
\hline $\begin{array}{l}\text { P-Trak Model 8525 } \\
\text { Ultrafine Particle Counter }\end{array}$ & UFP & particles $/ \mathrm{cm}^{3}$ & 1 second & $\begin{array}{l}\text { NE } \\
\text { NW } \\
\text { SE }\end{array}$ \\
\hline $\begin{array}{l}\text { TSI DUSTTRAK DRX } \\
\text { Aerosol Monitor 8533 }\end{array}$ & $\begin{array}{l}\mathrm{PM}_{10} \\
\mathrm{PM}_{2.5} \\
\mathrm{PM}_{1.0}\end{array}$ & $\mathrm{mg} / \mathrm{m}^{3}$ & 1 second & $\begin{array}{l}\text { NE } \\
\text { NW } \\
\text { SE }\end{array}$ \\
\hline Langan Model T15n & $\mathrm{CO}$ & $\mathrm{ppm}$ & 1 second & $\mathrm{NE}$ \\
\hline Langan Model L26n & $\mathrm{CO}_{2}$ & $\mathrm{ppm}$ & 1 second & $\mathrm{NE}$ \\
\hline $\begin{array}{l}\text { Young Ultrasonic } \\
\text { Anemometer Model 81000 }\end{array}$ & $\begin{array}{l}\text { Wind speed } \\
\text { Wind direction }\end{array}$ & $\begin{array}{l}\mathrm{m} / \mathrm{s} \\
\text { degrees }\end{array}$ & 5 seconds & NW \\
\hline $\begin{array}{l}\text { HOBO U12 } \\
\text { Temp/RH/External Data } \\
\text { Logger }\end{array}$ & $\begin{array}{l}\text { Temperature } \\
\text { Relative humidity }\end{array}$ & $\begin{array}{l}{ }^{\circ} \mathrm{C} \text { or }{ }^{\circ} \mathrm{F} \\
\%\end{array}$ & 5 seconds & NE \\
\hline
\end{tabular}

Corresponding to the summary table, the following diagram (Figure 3) shows the locations for each piece of equipment at Powell and $26^{\text {th }}$ during data collection periods including distances.

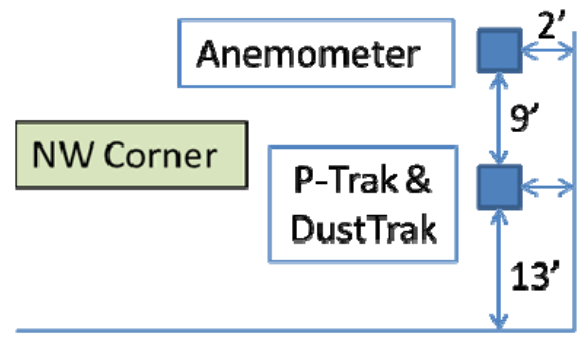

Powell Blvd.

SW Corner

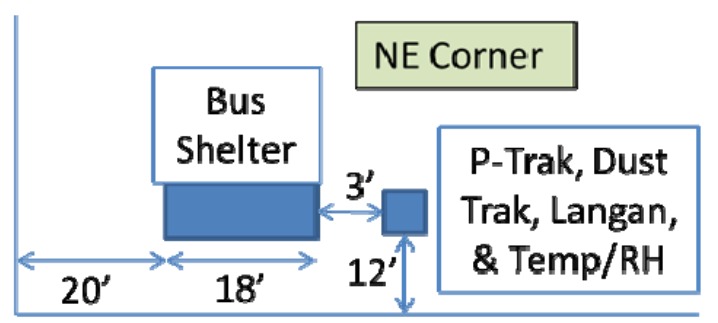

West

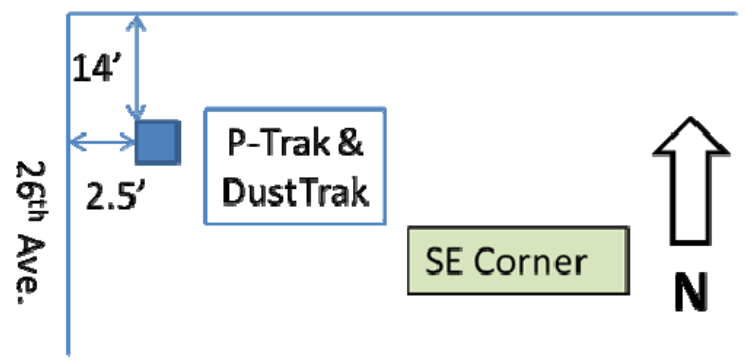

Figure 3. Data Collection Equipment Location 
More specifically, the equipment at the NE Corner was set on a cart that was located three feet from the side of the bus shelter and twelve feet from the curb (measurements were taken from the center of the cart). There was a tripod setup behind the cart to attach the tubing at a five foot height, which is a typical breathing height for most people. The equipment at both the NW and SE Corners was setup on equipment cases next to a streetlight pole with tubing attached to the pole at a five foot height. At the NW Corner, the equipment was located two feet from the curb on $26^{\text {th }}$ and thirteen feet from the center of the sidewalk ramp at the corner, along with the anemometer, which was located nine feet from the air quality equipment. The SE Corner was similarly located, where the equipment was two and a half feet from the curb on $26^{\text {th }}$ and fourteen feet from the center of the sidewalk ramp on the corner. The equipment location was located about the same distance away from Powell Boulevard, but was not at a similar distance from $26^{\text {th }}$ Avenue. The setup for each corner is shown in Figure 4. 


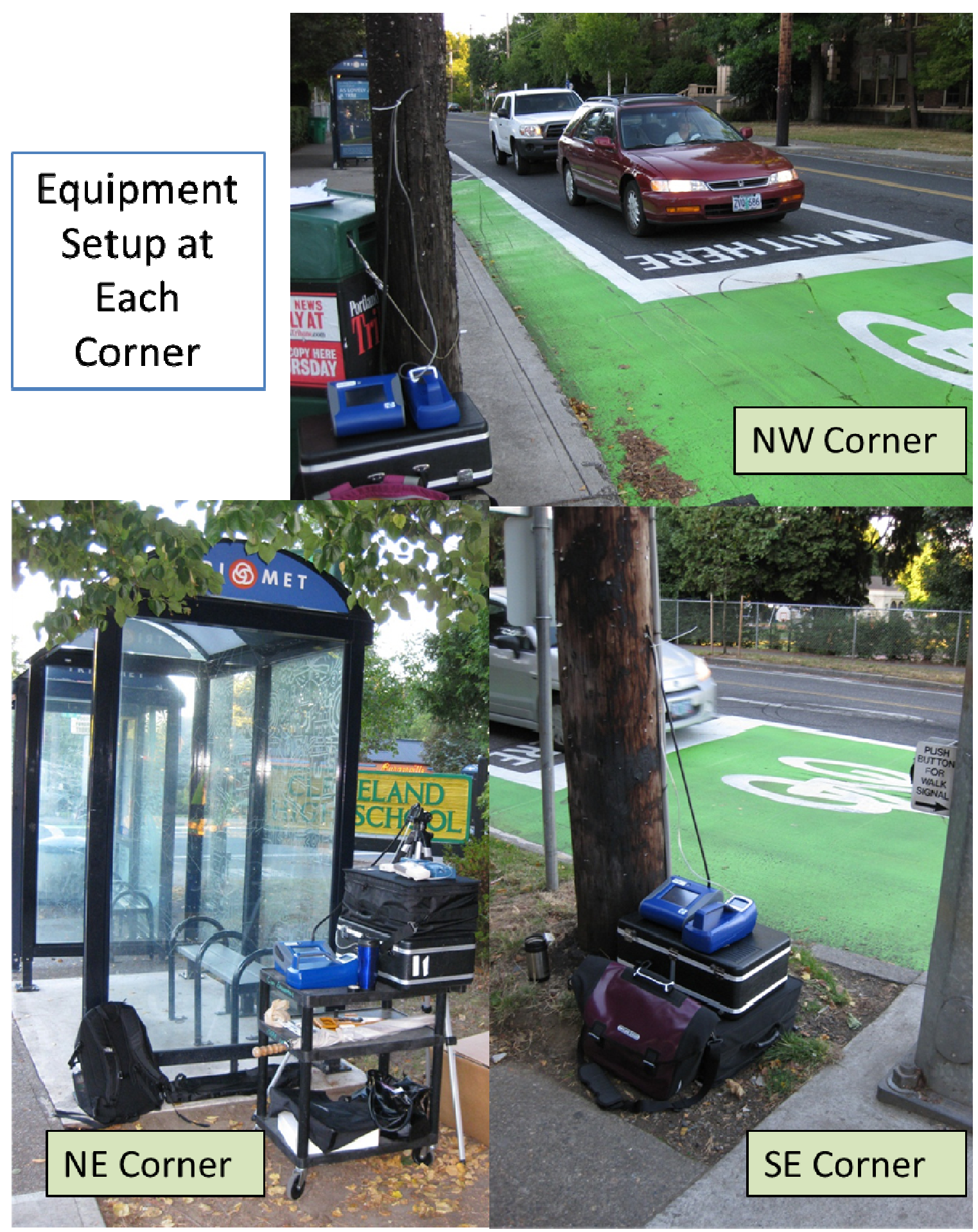

Figure 4. Data Collection Equipment Setup 


\subsection{Traffic Related Data}

In addition to the air quality and atmospheric data that were collected, traffic related factors were also measured. Team members were given a specific consistent role during data collection, as outlined in Table 4.

Table 4. Data Collection Team Tasks

\begin{tabular}{|l|l|l|l|l|}
\hline Location & \multicolumn{2}{|l|}{ NE Corner } & NW Corner & SE Corner \\
\hline Type of Data & $\begin{array}{l}\text { Bus } \\
\text { Presence }\end{array}$ & $\begin{array}{l}\text { Heavy Vehicle } \\
\text { Presence }\end{array}$ & Heavy Vehicles & Heavy Vehicles \\
\hline Team Member & $\begin{array}{l}\text { Eric } \\
\text { Albright }\end{array}$ & Courtney Slavin & $\begin{array}{l}\text { Pam Johnson } \\
\text { and/or Katie Bell }\end{array}$ & Brian Davis \\
\hline
\end{tabular}

At the NE corner, near the bus shelter, both bus presence and heavy vehicle presence were recorded. Bus presence data included the following:

- Arrival Time: the time that the bus arrived at the stop (accurate to one second)

- Dwell End Time: the time that the bus closed its doors and is ready to leave (accurate to one second)

- Departure Time: the time that the bus actually leaves the stop (accurate to one second)

- Stay Time: the difference between the departure time and the arrival time

- Red Light Duration: the time that the light is red after the bus doors shut, which is the departure time minus the dwell end time

- Route Number: either 9 or 66

- Bus Number: identification number specific to each bus

- Smell?: yes if there was a smell associated with the bus presence, no if not

- Tailpipe Orientation: angle of the tailpipe and a picture of the back of the bus to make an inventory

Heavy vehicle data presence included heavy vehicles within the first 50 feet of the queue in relation to the location of the air quality equipment were included. The exception to this, was if a heavy vehicle was visibly emitting or had a smell associated with it, it was 
recorded as well, even if it was not in the queue. Heavy vehicles that were recorded included both single unit and tractor-trailer configurations of any size and weight. This includes the following:

- Arrival Time: the time that the heavy vehicle joins the queue (accurate to one second)

- Departure Time: the time that the heavy vehicle starts moving (accurate to one second)

- Idling Time: the difference between the departure time and the arrival time

- License Plate \#: the license plate number of the heavy vehicle

- Smell?: yes if there was smell associated with the heavy vehicle presence, no if not

- Configuration: either single unit truck or tractor-trailer

- Lane: either adjacent, middle or far lane

- Age: either old or new looking in appearance

At the NW and SE corners, heavy vehicle presence was recorded, which included:

- Time: the time that the heavy vehicle drove by (accurate to one minute)

- Street: either Powell Boulevard or $26^{\text {th }}$ Avenue

- Lane: either adjacent or far lane

- Vehicle Type: description of vehicle and notes

\subsection{Traffic Signal Data}

Detailed data related to traffic signal timing plans had limited availability. Before the SCATS system was installed, the signal operated on time of day plans. After the system was installed, detailed traffic signal operation data were recorded, including the start and end time for each phase and the detector volumes. A graphic of Powell and $26^{\text {th }}$ showing the location and numbers for each detector, the phases, and the stages used by the SCATS system is shown in Figure 5. 
The phases before and after the SCATS system was installed follow the same standard numbering system, where phases two and six correspond to through movements on Powell Boulevard, the main street, and phase four is for through movements on $26^{\text {th }}$ Avenue.

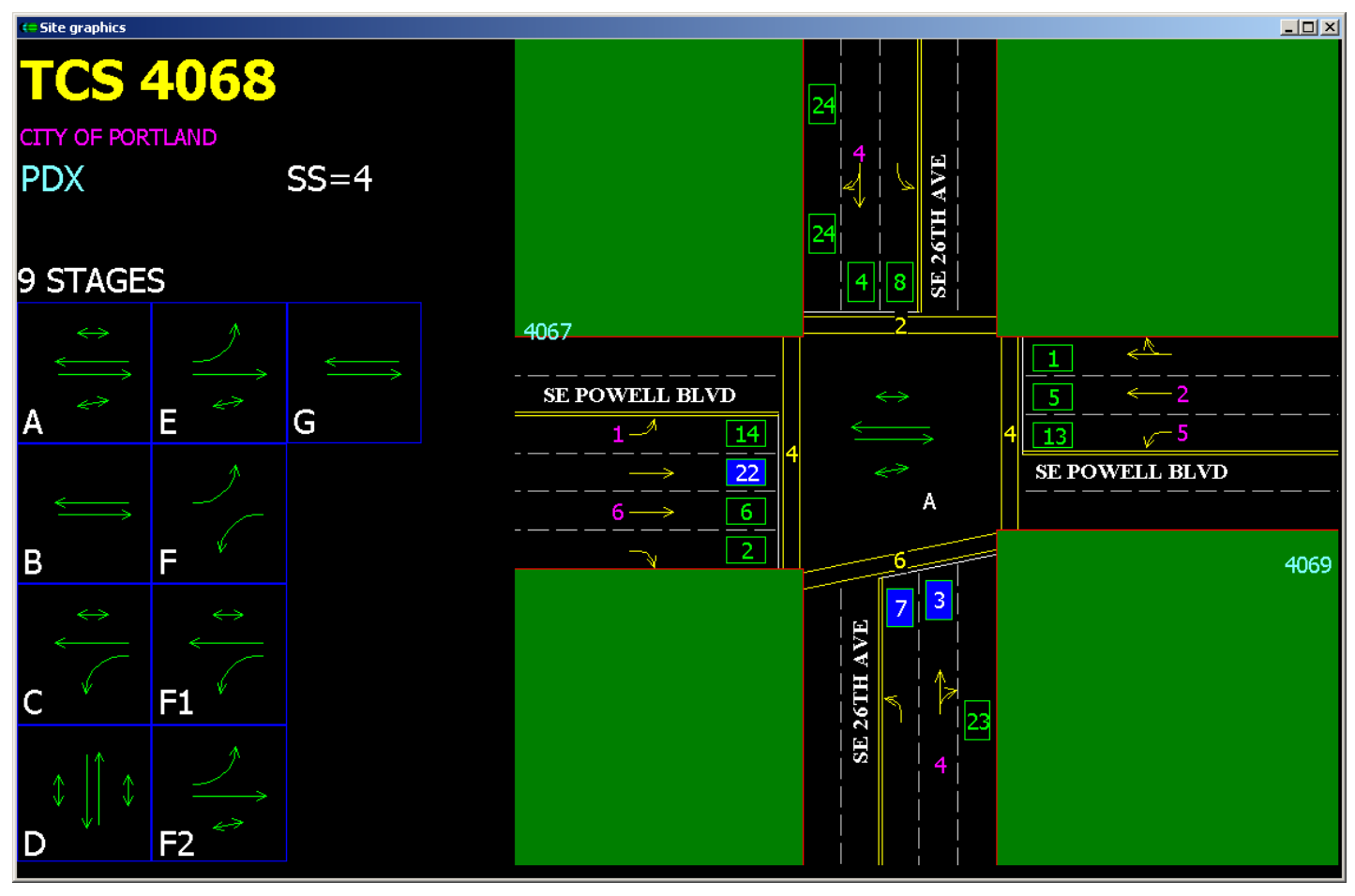

Figure 5. SCATS Phasing \& Detector Locations

Figure 6 is a ring and barrier diagram before SCATS was installed. There were leading protected left turns on Powell Boulevard, while all turning movements on $26^{\text {th }}$ were permissive. 


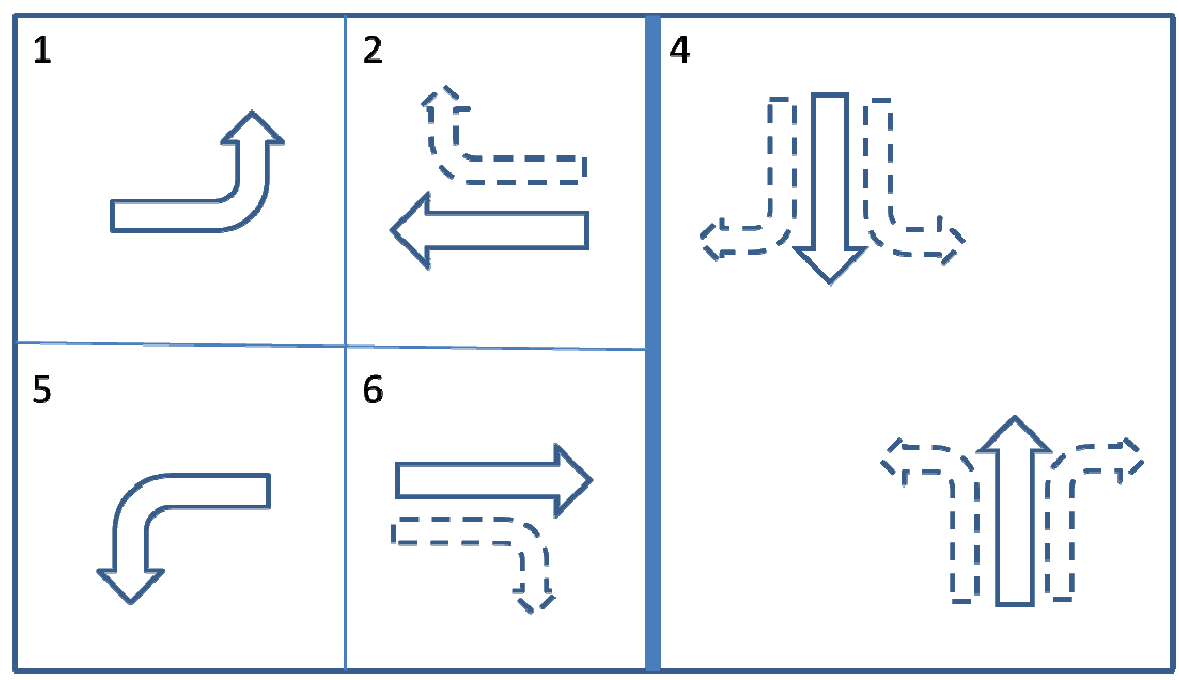

Figure 6. Ring and Barrier Diagram Before SCATS

After the SCATS system was installed, there were more options available for left turn movements depending on demand. Because of this, there are three options for the ring and barrier diagram, depending on which left turns are needed for each cycle. Shown in Figure 7 are the three options, the first one being the left turns in both the eastbound and westbound directions, which is the same as before SCATS, the second one being left turns only in the westbound direction, and the third for eastbound left turns only. 


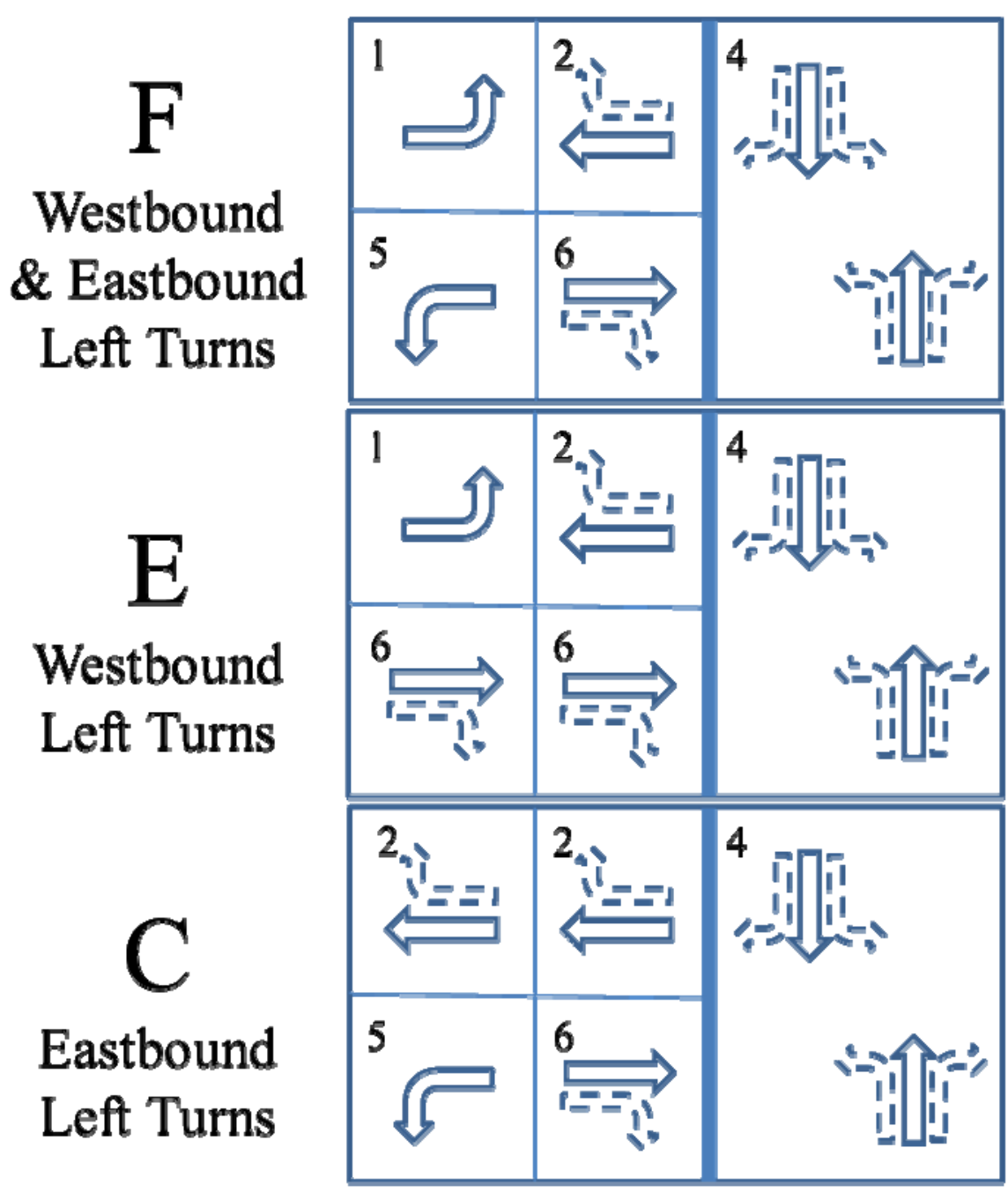

Note: The pedestrian phase was not included.

Figure 7. Ring and Barrier Diagrams After SCATS

The SCATS system assigns letters to the various options of phase groupings to provide further flexibility. Table 5 summarizes the phases and movements that go along with each letter designation. 
Table 5. Traffic Signal Phasing Legend

\begin{tabular}{|c|c|c|}
\hline & Phase(s) & Movements \\
\hline A & $2 \& 6$ & WBTH \& EBTH \\
\hline C & $2 \& 5$ & WBTH \& WBLT \\
\hline D & 4 & NBTH \& SBTH \\
\hline E & $1 \& 6$ & EBTH \& EBLT \\
\hline F & $1 \& 5$ & EBLT \& WBLT \\
\hline
\end{tabular}

In addition, detectors were installed at each stop bar as required by the SCATS system, these are listed in Table 6.

Table 6. Loop Detector Legend

\begin{tabular}{|c|c|}
\hline Detector Number & Movement \\
\hline 1 & WBTH/RT \\
\hline 2 & EBRT \\
\hline 3 & NBTH/RT \\
\hline 4 & SBTH/RT \\
\hline 5 & WBTH \\
\hline 6 & EBTH \\
\hline 7 & NBLT \\
\hline 8 & SBLT \\
\hline 13 & WBLT \\
\hline 14 & EBLT \\
\hline 22 & EBTH \\
\hline 23 & NB Bike \\
\hline 24 & SB Bike \\
\hline
\end{tabular}

\subsection{Summary}

This research includes an extensive amount of data, from a variety of sources. This section has described the origination of the data and what each dataset includes. However, all of the data sources must be tied together into one comprehensive database, this will be discussed next in Chapter 4 . 


\subsection{Exploratory Data Processing and Analysis}

To examine the relationship between traffic signals and air quality, all of the data sources previously mentioned were combined into one dataset. A detailed analysis was done focusing on one morning peak period data collection for Wednesday, October $26^{\text {th }}, 2011$.

\subsection{Database Setup}

First, a database was created for the morning peak period of October $26^{\text {th }}, 2011$, including all data sources available. This database includes the air pollutant concentrations, atmospheric factors, observed traffic, and SCATS related factors. Each row in the database represents a five second period. If the data source was taken per second then it was aggregated to five seconds to fit into the structure of the database. All of the air pollutant concentration levels were averaged over the five seconds. Additionally, particulate matter concentration levels were multiplied by one thousand, to convert the units from $\mathrm{mg} / \mathrm{m}^{3}$ to $\mu \mathrm{g} / \mathrm{m}^{3}$, which made the magnitudes easier for comparison during the analysis. In order to include wind direction, eight direction bins were created, including N, NE, E, SE, S, SW, W, and NW, as shown in degrees in Figure 8. 


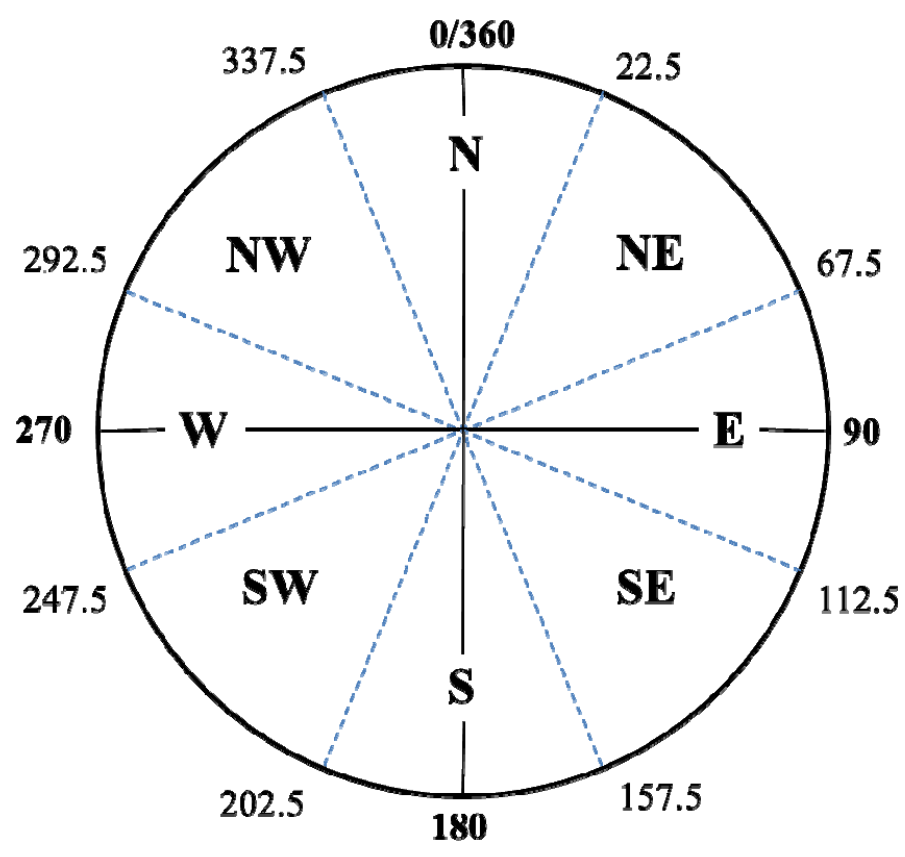

Figure 8. Wind Direction Bin Diagram

For observed traffic variables, the data collected at the NE corner were to the one second accuracy, whereas, the data collected at the NW and SE corners were to the one minute accuracy. The observed traffic variables at all three corners were converted into binary variables where a one meant bus or heavy vehicle presence and a zero if not. The data dictionary is shown in Table 7, including the name, description, data type, and the value or unit for each variable.

Table 7. Data Dictionary

\begin{tabular}{|l|l|c|c|}
\hline Name & Description & Data Type & Values or Units \\
\hline Air Pollutant Concentration \\
\hline UFPNE & Concentration measured at NE corner & Numeric & particles $/ \mathrm{cc}$ \\
\hline $\mathrm{PM}_{2.5} \mathrm{NE}$ & Concentration measured at NE corner & Numeric & $\mu \mathrm{g} / \mathrm{m}^{3}$ \\
\hline $\mathrm{CONE}$ & Concentration measured at NE corner & Numeric & $\mathrm{ppm}$ \\
\hline $\mathrm{CO}_{2} \mathrm{NE}$ & Concentration measured at NE corner & Numeric & $\mathrm{ppm}$ \\
\hline $\mathrm{UFPNW}^{\mathrm{N} N \mathrm{~m}}$ & Concentration measured at NW corner & Numeric & $\mathrm{particles} / \mathrm{cc}$ \\
\hline $\mathrm{PM}_{2.5} \mathrm{NW}$ & Concentration measured at NW corner & Numeric & $\mu \mathrm{g} / \mathrm{m}^{3}$ \\
\hline $\mathrm{UFPSE}^{3}$ & Concentration measured at SE corner & Numeric & $\mathrm{particles} / \mathrm{cc}$ \\
\hline $\mathrm{PM}_{2.5} \mathrm{SE}$ & Concentration measured at SE corner & Numeric & $\mu \mathrm{g} / \mathrm{m}^{3}$ \\
\hline
\end{tabular}




\begin{tabular}{|c|c|c|c|}
\hline Name & Description & Data Type & Values or Units \\
\hline \multicolumn{4}{|c|}{ Atmospheric Factors* } \\
\hline Temp & Temperature & Numeric & ${ }^{\circ} \mathrm{F}$ \\
\hline RH & Relative humidity & Numeric & $\%$ \\
\hline WindSpeed & Wind speed & Numeric & $\mathrm{m} / \mathrm{s}$ \\
\hline WindN & If the wind was in the north & Binary & $(0,1)$ \\
\hline WindNE & If the wind was in the northeast & Binary & $(0,1)$ \\
\hline WindE & If the wind was in the east & Binary & $(0,1)$ \\
\hline WindSE & If the wind was in the southeast & Binary & $(0,1)$ \\
\hline WindS & If the wind was in the south & Binary & $(0,1)$ \\
\hline WindSW & If the wind was in the southwest & Binary & $(0,1)$ \\
\hline WindW & If the wind was in the west & Binary & $(0,1)$ \\
\hline WindNW & If the wind was in the northwest & Binary & $(0,1)$ \\
\hline \multicolumn{4}{|c|}{ Observed Traffic ${ }^{* *}$} \\
\hline BusNE & $\begin{array}{l}\text { If there was a bus present at the bus } \\
\text { stop in the westbound direction }\end{array}$ & Binary & $(0,1)$ \\
\hline HVNE & $\begin{array}{l}\text { If there was a heavy vehicle within the } \\
\text { first } 50 \text { feet of the westbound queue }\end{array}$ & Binary & $(0,1)$ \\
\hline HVNW & $\begin{array}{l}\text { If there was a heavy vehicle traveling } \\
\text { westbound and/or southbound } \\
\end{array}$ & Binary & $(0,1)$ \\
\hline NVSE & $\begin{array}{l}\text { If there was a heavy vehicle traveling } \\
\text { eastbound and/or northbound }\end{array}$ & Binary & $(0,1)$ \\
\hline \multicolumn{4}{|c|}{ Traffic and Signal Timing $* * *$} \\
\hline EBTH & Eastbound through volume & Numeric & vehs/5 sec \\
\hline WBTH & Westbound through volume & Numeric & vehs/5 sec \\
\hline NBTH & Northbound through volume & Numeric & vehs/5 sec \\
\hline SBTH & Southbound through volume & Numeric & vehs/5 sec \\
\hline GreenA & Green time for Phase A & Numeric & seconds \\
\hline GreenC & Green time for Phase $\mathrm{C}$ & Numeric & seconds \\
\hline GreenF & Green time for Phase F & Numeric & seconds \\
\hline GreenE & Green time for Phase E & Numeric & seconds \\
\hline GreenD & Green time for Phase D & Numeric & seconds \\
\hline CycleLength & Length of cycle & Numeric & seconds \\
\hline VolCycle & Volume for the cycle & Numeric & vehs/cycle \\
\hline
\end{tabular}

*More details in Table 9

**More details in Table 10

****More details in Table 13

In order to incorporate the influence of both wind direction and wind speed on pollutant levels, interaction terms were created. The eight wind direction bins were multiplied by wind speed to create a new set of inputs. There are several benefits of using the product of wind direction and wind speed instead of keeping them as separate variables. First off, 
the magnitude of wind speed has a different effect depending on direction, and this method is able to include this. Second, the interpretation is clearer in a regression model. Wind direction bins as binary variables must be in reference to one direction, whereas the interacted wind direction and wind speed terms are numeric, and therefore do not need a reference group, which makes interpretation of coefficients from the model more intuitive.

The SCATS data were processed to fit into the database structure. The data had to be matched between two different file types. The phase start and end times were assigned to five second intervals in the database, and green times and cycle lengths were included. Detector volumes were assigned to their corresponding phase and converted into a volume per five seconds. Additionally, the detectors were grouped by movement, as shown in Table 8, where six total movements were included.

\section{Table 8. Detectors Grouped by Movement}

\begin{tabular}{|c|c|}
\hline Movement(s) & Detectors(s) \\
\hline WBTH & 1,5 \\
\hline WBLT & 13 \\
\hline EBTH & 6,22 \\
\hline EBLT & 14 \\
\hline SBTH & 4 \\
\hline NBTH & 3 \\
\hline
\end{tabular}

The SCATS data was coded in various ways to fit into the overall database. The phases were coded with three options:

1. Binary variable $(0=$ phase was not active, $1=$ phase was active $)$

2. Total green time for each phase

3. Incremental green time for each phase 
The volume was given by phase in the original data file, and therefore needed to be assigned to vehicle movements. The volume was assigned both incrementally and uniformly. For both the phases and volumes, the incremental assignment proved to have low explanatory power, and was not used in the final analysis.

\subsection{Wind \& Pollution Diagrams}

To understand the wind patterns during the data collection period, wind diagrams were created. These were done using the software $\mathrm{R}$ and a package called openair, which is an open-source tool for analyzing air pollution data (Carslaw, 2012).

First, a wind rose was created, as shown in Figure 9, which breaks the wind into eight directions, in the same manner that the bins were previously created (as shown in Table 9). The wind rose shows the percentage of time that wind was in a certain direction and in a certain speed range. These percentages agree with the mean values from Table 9, where the direction with the highest percentage was north, $22 \%$ of the time. South was a close second with $18 \%$ of the time. The advantage of a wind rose to descriptive statistics is that the wind speeds are assigned to direction bins. The wind rose illustrates that the wind in the north had a higher magnitude than south. In the south direction, the magnitude went from zero to one meter per second, whereas, in the north direction, the wind speed went up to almost two meters per second. 


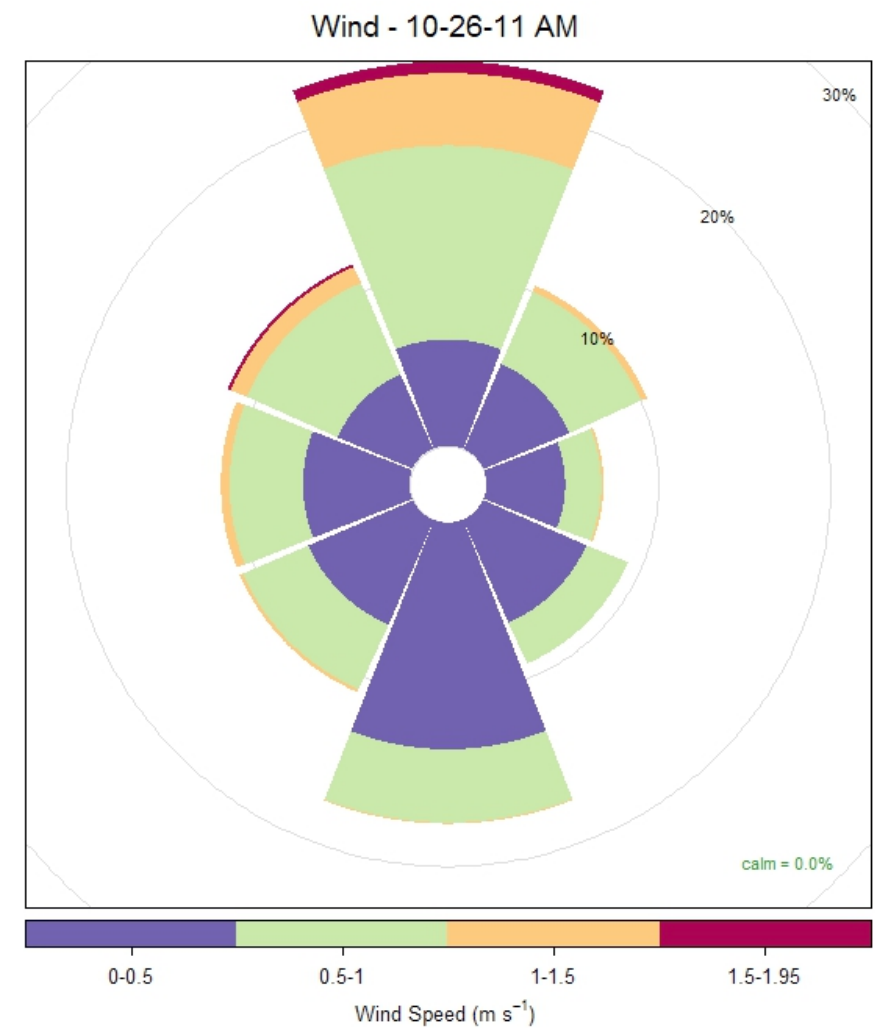

Figure 9. Wind Rose

While the previous wind rose was for the entire two-hour data collection period, another one was made that was broken up by the hour, as shown in Figure 10. This shows that during the first hour (from seven to eight am) the wind was more in the south direction, and switched to the north direction during the second hour (from eight to nine am). 


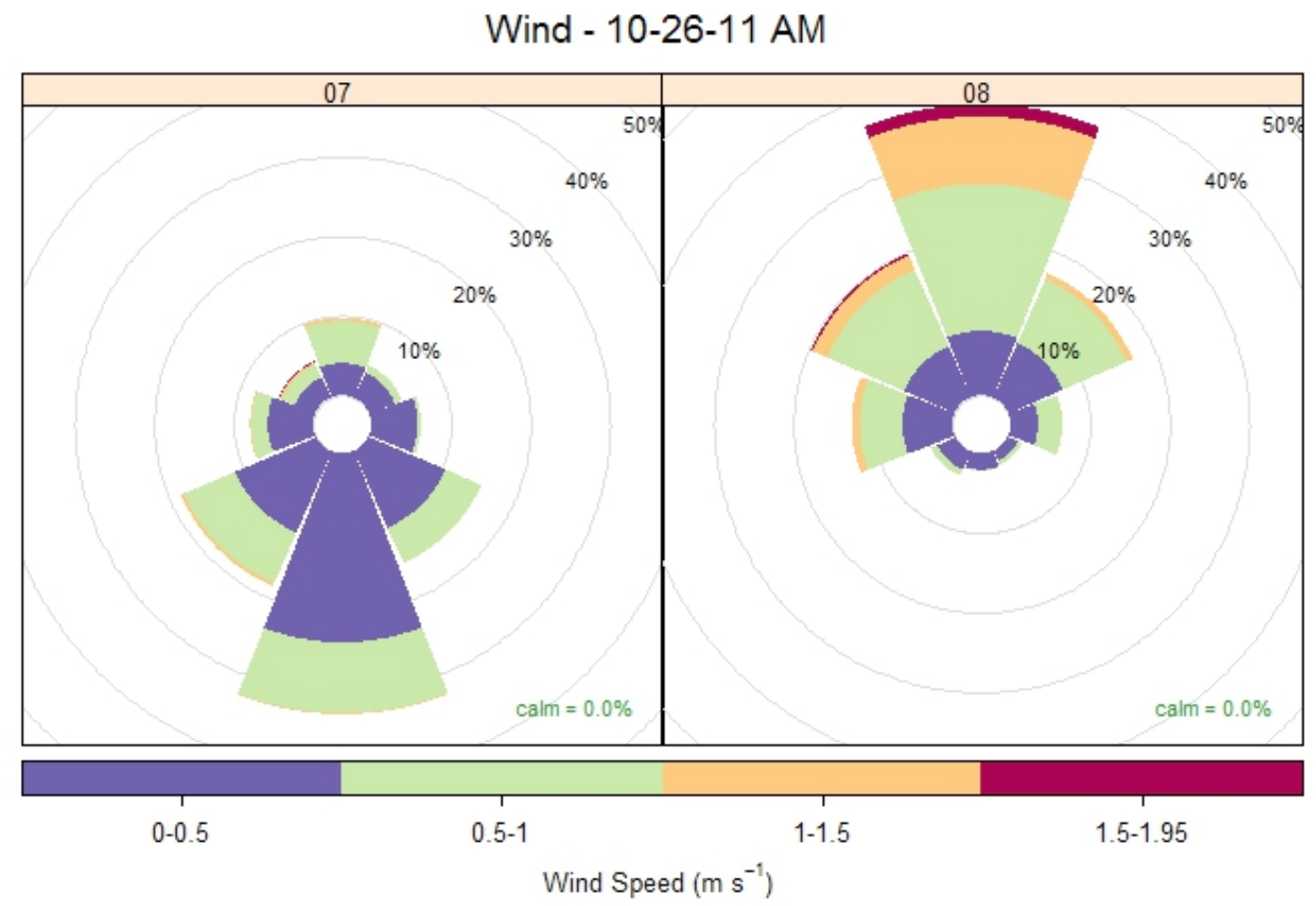

Figure 10. Hourly Wind Roses

Next, the polarPlot function was used to calculate a surface through modeling and smoothing techniques from the wind speed, wind direction, and concentration level. This function uses the mean as the default. These plots are shown for UFP, $\mathrm{PM}_{2.5}, \mathrm{CO}$, and $\mathrm{CO}_{2}$ at the NE corner, along with UFP and $\mathrm{PM}_{2.5}$ at the NW corner in Figure 11. 

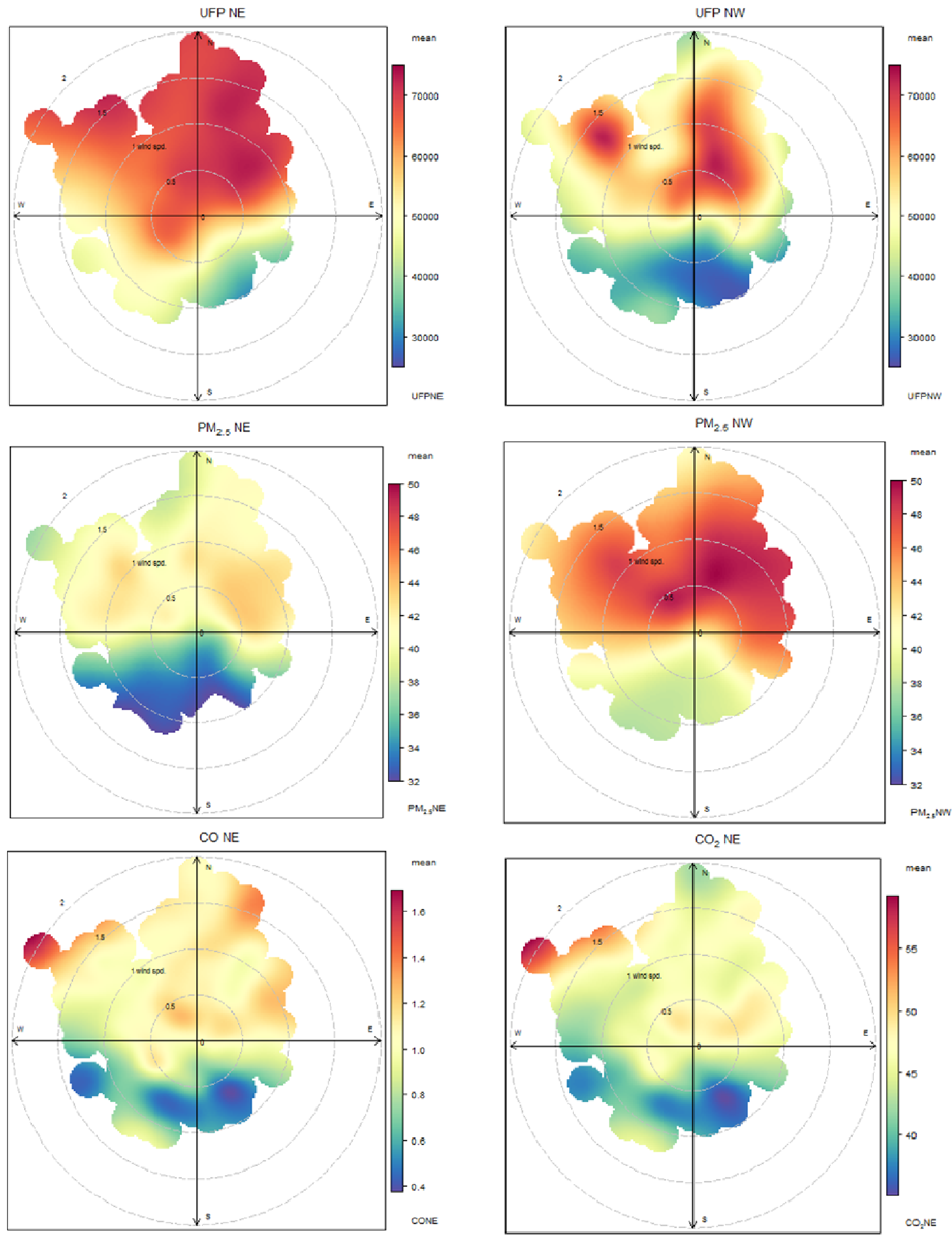

Figure 11. Polar Plots for Pollutants at NE \& NW Corners 
This shows that for all four pollutants at the NE and NW corners, the lowest concentration levels (blue color) are mostly in the south direction, whereas the higher concentration levels (red color) are mostly in the north direction.

The wind diagrams helped to understand the impact of wind direction and speed on pollutant levels at the NE and NW corners of the intersection.

\subsection{Descriptive Statistics}

After the database was setup, exploratory analysis was conducted using descriptive statistics and plots to obtain a preliminary understanding of the data.

Descriptive statistics for atmospheric related factors, such as temperature, relative humidity, wind speed and direction are included in Table 9. The wind interaction terms are shown with the units of meters per second $(\mathrm{m} / \mathrm{s})$. These include the minimum, mean, standard deviation, maximum, and the sample size for each variable. Additionally, whether or not the variable was included in the final analysis is listed in the table. 
Table 9. Descriptive Statistics - Atmospheric Factors

\begin{tabular}{|c|c|c|c|c|c|c|c|}
\hline Name & Type & Min & Mean & St Dev & Max & $\mathbf{N}$ & $\begin{array}{c}\text { Used in } \\
\text { Analysis? }\end{array}$ \\
\hline Temp & \multirow{3}{*}{ Continuous } & 39.31 & 39.94 & 0.3486 & 41.04 & 1591 & \multirow[t]{2}{*}{ Yes } \\
\hline $\mathrm{RH}$ & & 74.66 & 78.92 & 1.06 & 80.97 & 1591 & \\
\hline WindSpeed & & 0.04 & 0.5247 & 0.3117 & 1.95 & 1568 & \multirow[t]{9}{*}{ No } \\
\hline WindN & \multirow[t]{8}{*}{ Binary } & 0.00 & 0.2239 & 0.4170 & 1.00 & \multirow{8}{*}{1568} & \\
\hline WindNE & & 0.00 & 0.1040 & 0.3053 & 1.00 & & \\
\hline WindE & & 0.00 & 0.0682 & 0.2522 & 1.00 & & \\
\hline WindSE & & 0.00 & 0.0918 & 0.2889 & 1.00 & & \\
\hline WindS & & 0.00 & 0.1754 & 0.3804 & 1.00 & & \\
\hline WindSW & & 0.00 & 0.1097 & 0.3126 & 1.00 & & \\
\hline WindW & & 0.00 & 0.1097 & 0.3126 & 1.00 & & \\
\hline WindNW & & 0.00 & 0.1173 & 0.3219 & 1.00 & & \\
\hline wsN & \multirow[t]{8}{*}{ Continuous } & 0.00 & 0.1665 & 0.3530 & 1.81 & \multirow{8}{*}{1568} & \multirow[t]{8}{*}{ Yes } \\
\hline wsNE & & 0.00 & 0.0524 & 0.1731 & 1.12 & & \\
\hline wsE & & 0.00 & 0.02702 & 0.1218 & 1.42 & & \\
\hline wsSE & & 0.00 & 0.03612 & 0.1285 & 0.87 & & \\
\hline wsS & & 0.00 & 0.06651 & 0.1643 & 1.09 & & \\
\hline wsSW & & 0.00 & 0.05035 & 0.1629 & 1.13 & & \\
\hline wsW & & 0.00 & 0.0526 & 0.1773 & 1.48 & & \\
\hline wsNW & & 0.00 & 0.07316 & 0.2327 & 1.95 & & \\
\hline
\end{tabular}

The variability in temperature and relative humidity during the two hours was very small.

The wind speed was relatively low, only going up to about two meters per second. This shows that the magnitude of wind was the highest in the northwest and north directions, whereas the lowest magnitude was in the southeast direction.

Descriptive statistics were calculated for observed traffic, including transit bus and heavy vehicle presence as shown in Table 10. This includes several variables related to bus presence, such as the length of time at the red light, if the bus has an EMP engine cooling system, if the bus has a DPF particulate filter, and if the bus's tailpipe was angled away from the street compared to being oriented backwards. Heavy vehicle presence is included at the NE, NW, and SE corners, where the queuing duration of the heavy vehicle 
is included for the NE corner. These include the minimum, mean, standard deviation, and maximum for each variable.

Table 10. Descriptive Statistics - Bus and Heavy Vehicle Traffic

\begin{tabular}{|l|c|c|c|c|c|}
\hline Name & Min & Mean & St Dev & Max & Mean During Bus or HV Presence \\
\hline BusNE & 0 & 0.074 & 0.262 & 1 & 11.853 \\
\hline BusRedLight & 0 & 0.877 & 5.606 & 45 & 0.276 \\
\hline EMP & 0 & 0.020 & 0.141 & 1 & 0.664 \\
\hline DPF & 0 & 0.049 & 0.216 & 1 & 0.034 \\
\hline TPAngled & 0 & 0.003 & 0.051 & 1 & 29.271 \\
\hline HVNE & 0 & 0.031 & 0.172 & 1 & \\
\hline HVNETime & 0 & 0.896 & 5.289 & 45 & \\
\hline HVNW & 0 & 0.398 & 0.490 & 1 & \\
\hline HVSE & 0 & 0.299 & 0.458 & 1 & \\
\hline
\end{tabular}

A transit bus was at the stop on the NE corner $7.4 \%$ of the time during the two hour period. The largest amount of time that a bus was waiting at the red light after serving the transit riders and closing their doors was 45 seconds. The average amount of a bus was waiting at a red light during bus presence periods was 11.85 seconds. During bus presence periods, buses were equipped with the engine cooling system $28 \%$ of the time, a particulate filter $66 \%$ of the time and $3 \%$ of the time the tailpipe was angled.

There were heavy vehicles queuing in the eastbound direction $3.1 \%$ of the time during the data collection. The longest amount of time that a heavy vehicle was in the queue was 45 seconds, and the mean time during heavy vehicle presence periods was 29 seconds. Heavy vehicles were present at the other corners from $30-40 \%$ of the time because this included all heavy vehicles driving by the location, not just queued vehicles like the NE corner variable. 
Summarized in Table 11 are the descriptive statistics for the variables related to the SCATS data. This includes which phases were active and the number of vehicles per five seconds during each phase.

Table 11. Descriptive Statistics - SCATS Inputs

\begin{tabular}{|c|c|c|c|c|c|}
\hline Name & Description & Movements & Min & Mean & Max \\
\hline PhaseA & \multirow{5}{*}{$\begin{array}{l}1 \text { if the phase was } \\
\text { active, } 0 \text { if not }\end{array}$} & WBTH \& EBTH & 0 & 0.626 & 1 \\
\hline PhaseC & & WBTH \& WBLT & 0 & 0.048 & 1 \\
\hline PhaseD & & NBTH \& SBTH & 0 & 0.249 & 1 \\
\hline PhaseE & & EBTH \& EBLT & 0 & 0.016 & 1 \\
\hline PhaseF & & WBLT \& EBLT & 0 & 0.060 & 1 \\
\hline WBTH & \multirow{6}{*}{\multicolumn{2}{|c|}{$\begin{array}{l}\text { Number of vehicles during the phase } \\
\text { per } 5 \text { seconds }\end{array}$}} & 0 & 1.967 & 4.25 \\
\hline WBLT & & & 0 & 0.116 & 2.50 \\
\hline EBTH & & & 0 & 1.250 & 4.00 \\
\hline EBLT & & & 0 & 0.071 & 2.33 \\
\hline SBTH & & & 0 & 0.229 & 2.00 \\
\hline NBTH & & & 0 & 0.077 & 1.00 \\
\hline PowellVol & \multicolumn{2}{|c|}{ Sum of WBTH \& EBTH } & 0 & 3.212 & 7.00 \\
\hline
\end{tabular}

Note: Vehicle movements were allocated in 5 second intervals by assigning a uniform distribution of vehicles to the active phase.

The phase with the largest split is Phase A, where the Powell Boulevard through movements (westbound and eastbound) are served, using $62.6 \%$ of the time during the two hour period. The second largest split is Phase D, with $24.9 \%$, where $26^{\text {th }}$ Avenue (northbound and southbound) is being served. Among the phases including left turning options, Phase F is the most common, which serves westbound and eastbound left turns, using $6 \%$ of the total time. Phase $\mathrm{C}$ used $4.8 \%$ of the time and served westbound through and left turns. With the smallest amount of time used is Phase E with $1.6 \%$ for eastbound through and left turns. 
The distribution of vehicles by movement was calculated, as shown in Table 12, where the percent of total volume is shown. The total volume is 3.7 vehicles per 5 seconds, which is the summation of the average number of vehicles per 5 seconds for each movement (from Table 11). The westbound through movement had $53 \%$ of the total volume, which was the highest movement. When the through movement on Powell Boulevard is added together, it makes up almost $87 \%$ of the total volume.

\section{Table 12. Vehicle Movement Distribution}

\begin{tabular}{|c|c|}
\hline Vehicle Movement & Percent of Total Volume \\
\hline WBTH & $53.02 \%$ \\
\hline WBLT & $3.13 \%$ \\
\hline EBTH & $33.69 \%$ \\
\hline EBLT & $1.91 \%$ \\
\hline SBTH & $6.17 \%$ \\
\hline NBTH & $2.08 \%$ \\
\hline PowellVol & $86.58 \%$ \\
\hline
\end{tabular}

The other way that volume was included in the analysis was by using the volume per cycle, instead of my movement. The average volume per cycle (as shown in Table 13) is 96 and the average cycle length is 115 seconds, which equates to 4.2 vehicles per 5 seconds. This is similar to the average number of vehicles calculated from the vehicles by movement data, with around 4 vehicles per 5 seconds.

In addition to cycle length and volume per cycle, the green time for each phase was added to the database. The descriptive statistics for the cycles and phases are included in the summary table, shown in Table 13, including the minimum, median, mean, standard deviation, coefficient of variation, maximum and the number of cycles each phase was active for. 
Table 13. Descriptive Statistics - Phasing

\begin{tabular}{|c|c|c|c|c|c|c|c|}
\hline Name & Min & Median & Mean & Std Dev & CV & Max & Frequency \\
\hline Phase A & 56 & 70 & 72.05 & 10.32 & 0.14 & 120 & 63 \\
\hline Phase C & 5 & 13 & 12.57 & 4.19 & 0.33 & 22 & 30 \\
\hline Phase E & 9 & 13 & 12.63 & 2.00 & 0.16 & 15 & 8 \\
\hline Phase F & 10 & 13 & 13.42 & 2.16 & 0.16 & 20 & 31 \\
\hline Phase D & 12 & 33 & 29.05 & 6.51 & 0.22 & 33 & 63 \\
\hline Cycle Length & 80 & 116 & 115.29 & 14.29 & 0.12 & 168 & - \\
\hline $\begin{array}{c}\text { Volume per } \\
\text { Cycle }\end{array}$ & 50 & 95 & 95.94 & 20.01 & 0.21 & 137 & - \\
\hline
\end{tabular}

The descriptive statistics summarized in Table 13 are shown in Figure 12 in the form of bar plots. While Phase A has the largest standard deviation, it actually has the smallest coefficient of variation, because it has the largest mean value. 

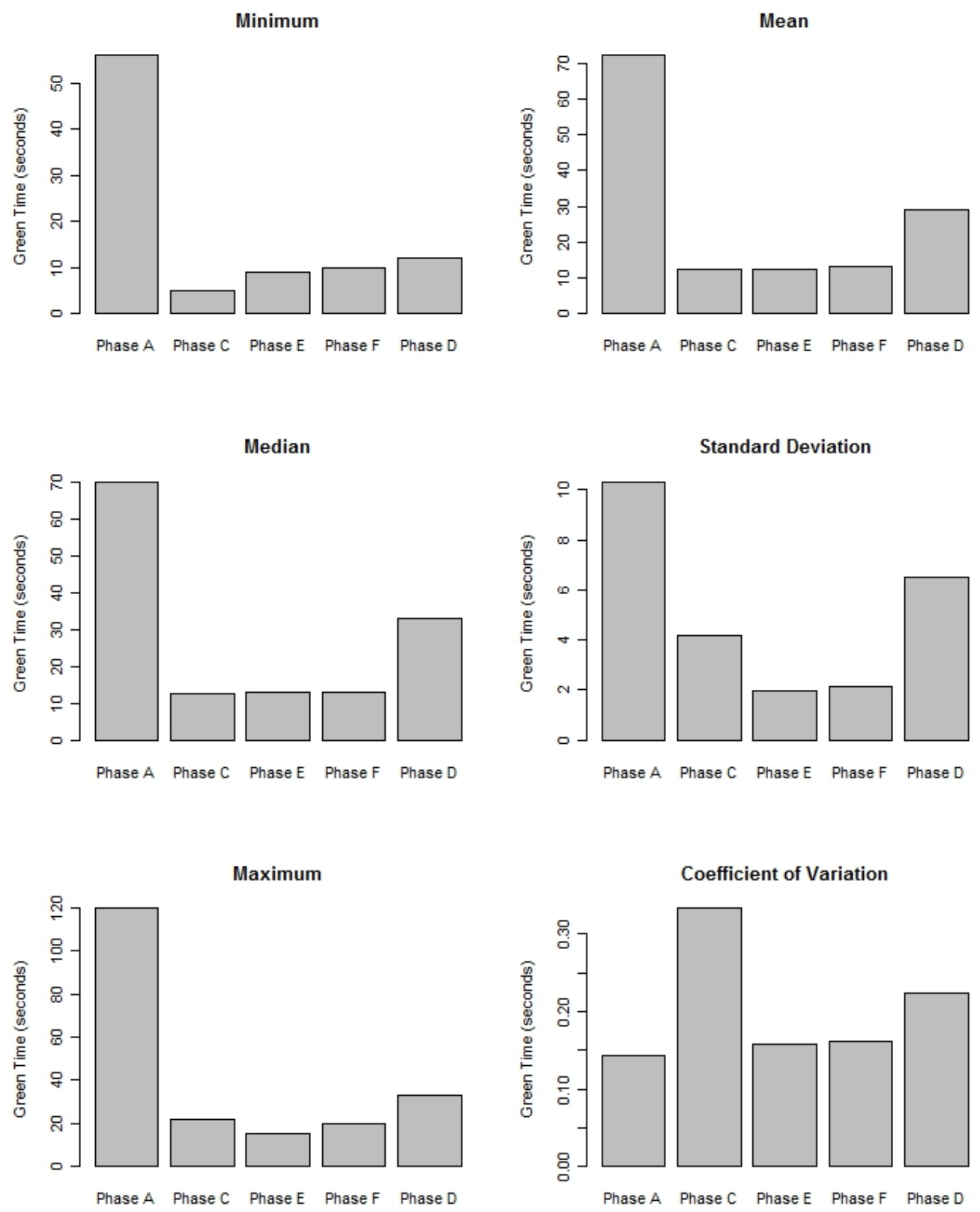

\section{Figure 12. Phasing Bar Plots}

The descriptive statistics the phasing and cycle length can be compared to the time of day plans to evaluate the effect of adaptive timing, this is shown in Table 14. 
Table 14. SCATS and TOD Phasing

\begin{tabular}{|c|c|c|c|}
\hline Name & $\begin{array}{c}\text { SCATS Median } \\
\text { (seconds) }\end{array}$ & $\begin{array}{c}\text { SCATS Mean } \\
\text { (seconds) }\end{array}$ & $\begin{array}{c}\text { Time of Day Plans } \\
\text { (seconds) }\end{array}$ \\
\hline Phase A & 70 & 72.05 & 60 \\
\hline Phase C & 13 & 12.57 & - \\
\hline Phase E & 13 & 12.63 & - \\
\hline Phase F & 13 & 13.42 & 20 \\
\hline Phase D & 33 & 29.05 & 32 \\
\hline Cycle Length & 116 & 115.29 & 110 \\
\hline
\end{tabular}

The time allocated to Phase $\mathrm{A}$ is about ten additional seconds after SCATS was implemented. The time for Phase $\mathrm{D}$ is about the same with both plans. The left turn phases are shorter after SCATS by about seven seconds due to the ability to respond to demand. Overall, the cycle length is about five seconds longer than before, where the median and mean cycle length after SCATS is about 116 seconds, and with the time of day plans it was 110 seconds per cycle during the morning peak period from 5:30 to 9:00 AM. Although the mean cycle length is similar before and after, the splits are different and there is more fluctuation than there was with the time of day plans. This is shown in Figure 13, where the red horizontal line at 110 seconds is the time of day plans and the black hollow circles are the cycle lengths for the morning of October $26^{\text {th }}, 2011$. 


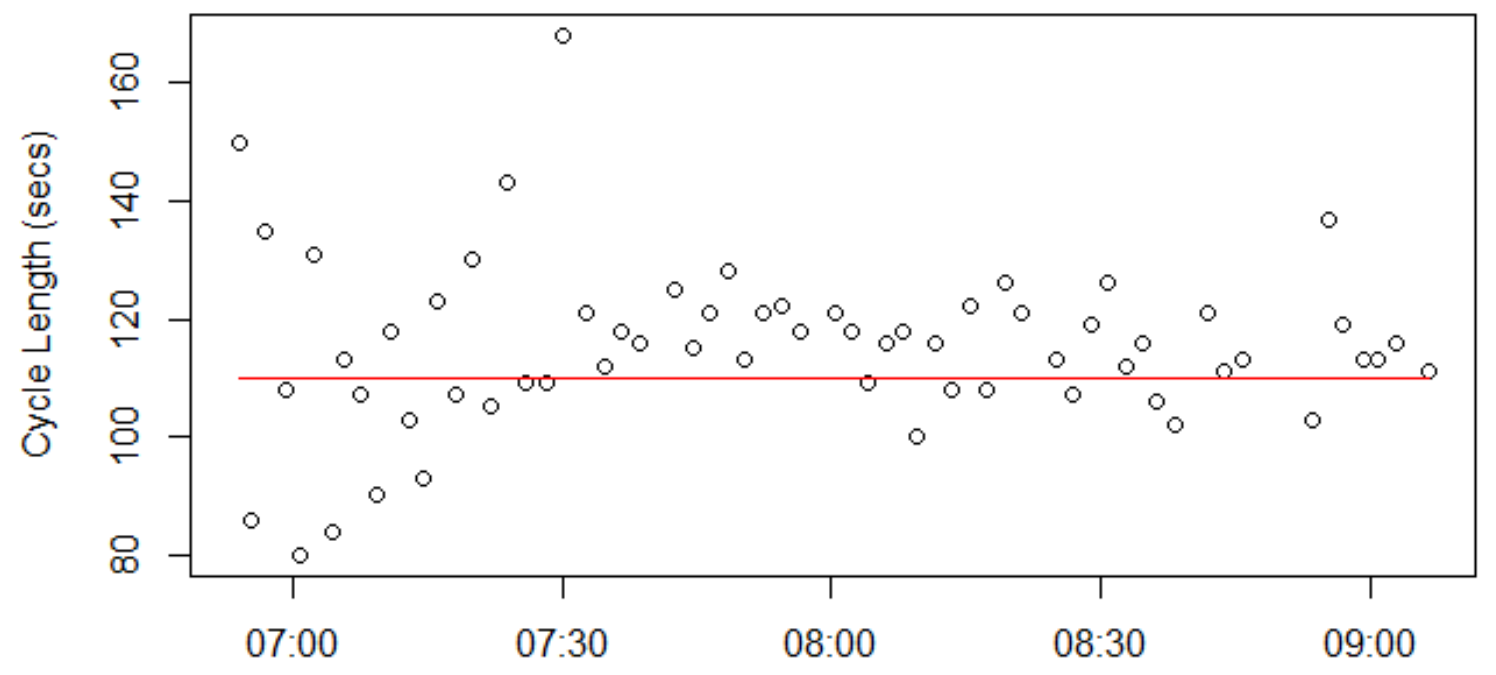

October 26, 2011

Figure 13. Adaptive Compared to Time of Day Cycle Length

Volume per cycle was plotted with the cycle length, showing similar trends. Volume per cycle is shown as black filled circles and cycle length is shown as red hollow triangles. The SCATS system is responsive to demand, which is clearly demonstrated in Figure 14.

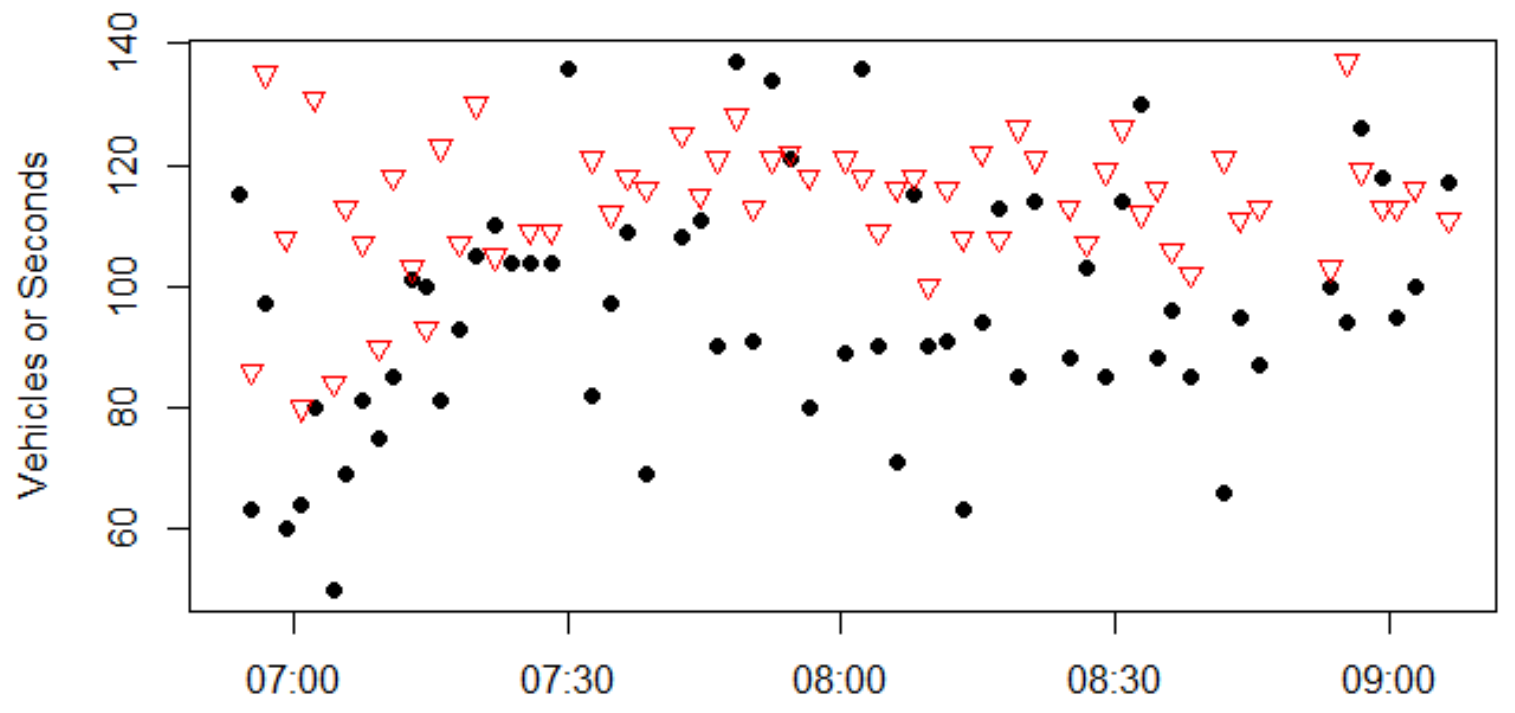

Figure 14. Volume per Cycle and Cycle Length 
The exploratory analysis of the entire dataset, including pollutant concentrations, bus and heavy vehicles, atmospheric factors, SCATS inputs, and traffic signal phasing, provided an overview of the behavior of the data and relationships among variables. One relationship that is especially difficult to visualize is wind direction and speed with pollutant levels. The following section will address this issue and include plots to understand this relationship more clearly.

Descriptive statistics for pollutant levels of UFP, $\mathrm{PM}_{2.5}, \mathrm{CO}$, and $\mathrm{CO}_{2}$ were calculated for all corners of the intersection that had data available. This is shown in Table 15, including the minimum, mean, standard deviation, maximum, and sample size for each variable. Additionally, ambient levels from Section 2.1 are included to provide a reference point for concentration levels.

Table 15. Descriptive Statistics - Pollutant Concentrations

\begin{tabular}{|c|c|c|c|c|c|c|c|}
\hline Name & Units & Min & Mean & St Dev & Max & $\mathbf{N}$ & Ambient Level \\
\hline UFPNE & \multirow{3}{*}{$\mathrm{pt} / \mathrm{cc}$} & 24,820 & 64,683 & 29,484 & 245,000 & 1591 & \multirow{3}{*}{20,000} \\
\hline UFPNW & & 21,160 & 53,971 & 34,831 & 461,800 & 1473 & \\
\hline UFPSE & & 27,160 & 57,614 & 44,657 & 500,000 & 1431 & \\
\hline $\mathrm{PM}_{2.5} \mathrm{NE}$ & \multirow{3}{*}{$\mu \mathrm{g} / \mathrm{m}^{3}$} & 27.40 & 38.78 & 6.63 & 114.80 & 1591 & \multirow{3}{*}{20} \\
\hline $\mathrm{PM}_{2.5} \mathrm{NW}$ & & 32 & 44.83 & 15.52 & 391.6 & 1473 & \\
\hline $\mathrm{PM}_{2.5} \mathrm{SE}$ & & 34.6 & 46.64 & 18.92 & 483.4 & 1431 & \\
\hline CONE & \multirow{2}{*}{ ppm } & 0.1587 & 0.9678 & 0.3859 & 2.7313 & 1591 & 0.10 \\
\hline $\mathrm{CO}_{2} \mathrm{NE}$ & & 22.58 & 44.64 & 7.86 & 73.62 & 1591 & $\mathrm{~N} / \mathrm{A}$ \\
\hline
\end{tabular}

The descriptive statistics show that the SE corner had the highest maximum UFP and $\mathrm{PM}_{2.5}$ levels, with the NW corner in second and the NE corner having the lowest peak values. At the SE corner, the maximum UFP reading was 500,000, which is the highest reading the equipment is capable of, indicating that there could have been even higher levels of UFP than what was measured. Even though the NE corner had the lowest peak 
UFP level, it had the highest mean. Ambient levels were typically around the minimum values from the field measured data.

Scatterplots were made to examine trends in pollutant levels and the predominant wind direction. Figure 15 shows UFP concentrations at the NE, NW, and SE corners of the intersection along with wind speed in the south and north direction. The same plot is made for $\mathrm{PM}_{2.5}$, as shown in Figure 16. 
UFP NE
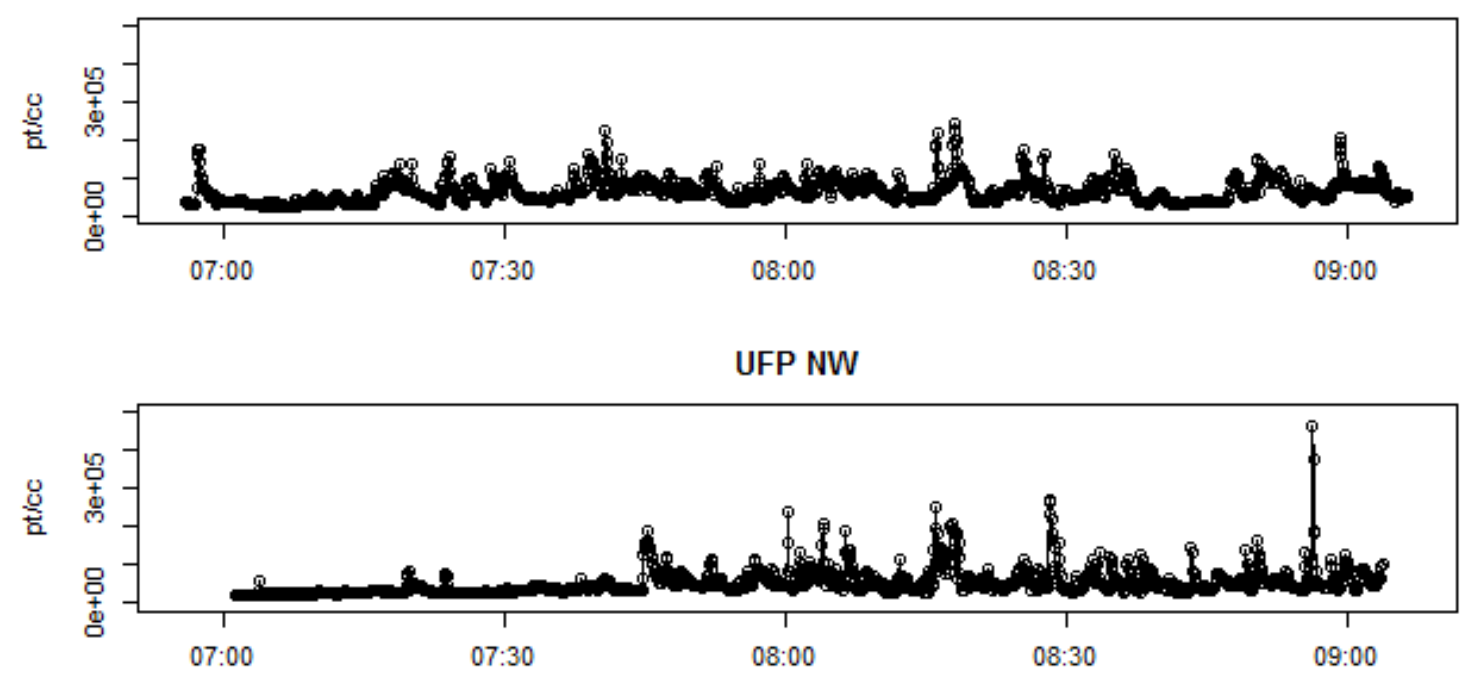

UFP SE

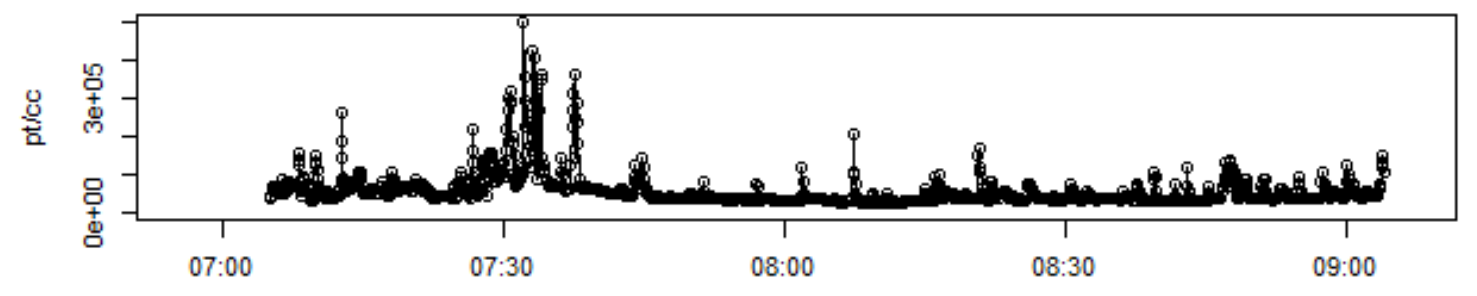

Wind Speed - South

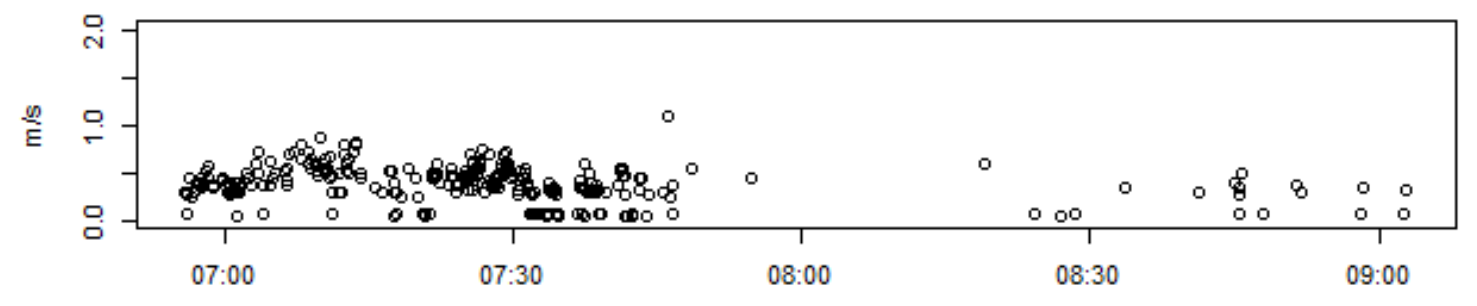

Wind Speed - North

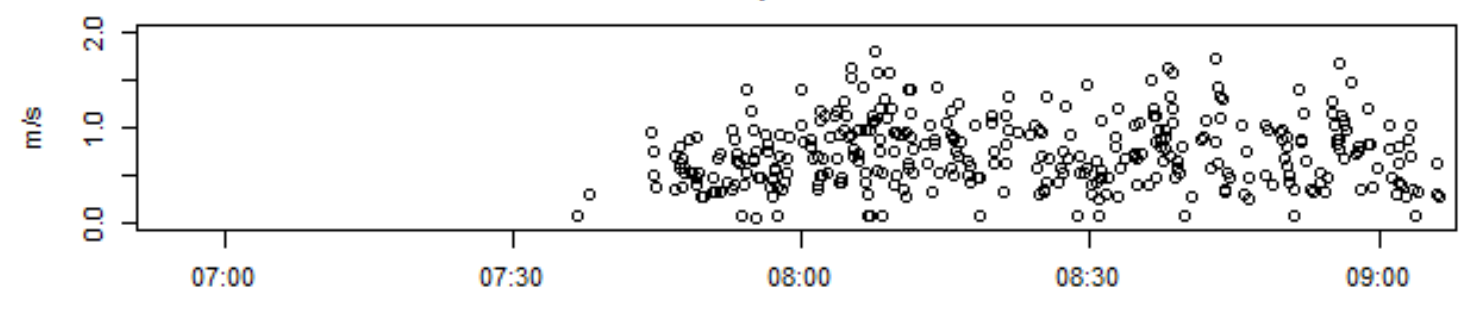

Figure 15. UFP NE, NW \& SE Corners Scatterplots 

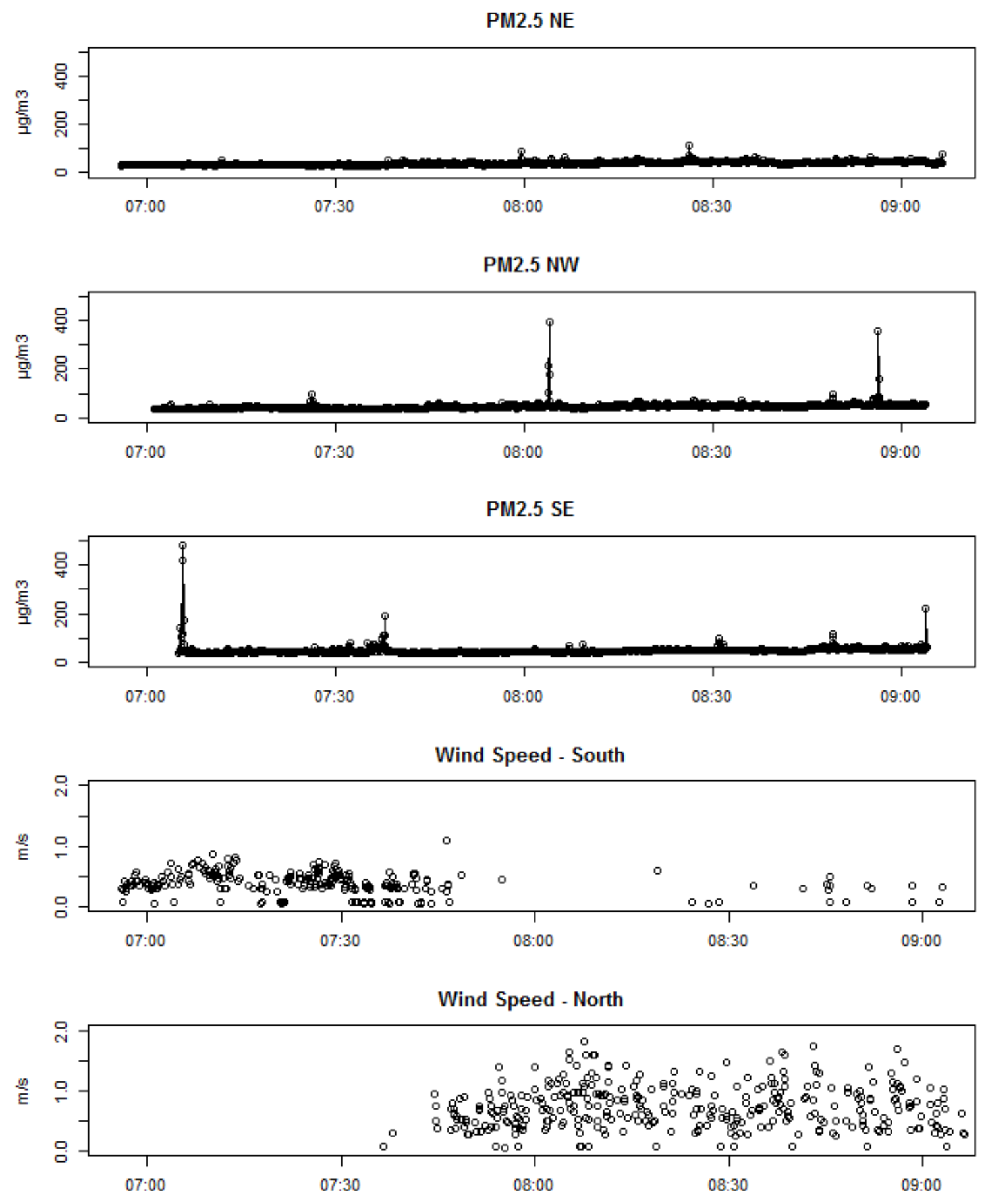

Figure 16. $P M_{2.5}-\mathrm{NE}$, NW \& SE Corners Scatterplots 
These plots help to illustrate that while the NW and SE corners have higher peaks, they are consistently lower on average than the NE corner. It is worth noting that these peaks do not occur at the same time at different corners of the intersection. The importance of wind direction is illustrated in these figures. The wind switched direction around 7:45 am, almost halfway through the data collection period, from the south to the north. It is clear from the scatterplots that UFP measured at the SE corner is the highest during the time when the wind was in the south, and UFP at the NW corner is highest after the wind switched to the north. This same trend holds for $\mathrm{PM}_{2.5}$, mostly corresponding to when the largest peak values occurred.

From the descriptive statistics, it was observed that the maximum values for pollutant levels were considerably higher than the mean values, ranging from three to ten times larger in magnitude. This is confirmed by examination of the scatterplots, where it is clear that presence of heavy polluters contributes to extremely high pollutant levels for a short period of time. The implications of this are extremely important in terms of pedestrian, bicyclist, and transit user exposure. Depending on the corner of the intersection that a person is located, their exposure could be completely different. For example at 7:30 am, UFP levels are around the mean at the NW corner, whereas the SE corner is around ten times that level, meaning that the person at the SE corner is exposed to ten times that of the person at the NW corner at the same exact time.

$\mathrm{CO}$ and $\mathrm{CO}_{2}$ are compared over time in Figure 17, where it can be seen that there is not as much variation and not as high of peak values in these pollutants as compared to particulate matter. 

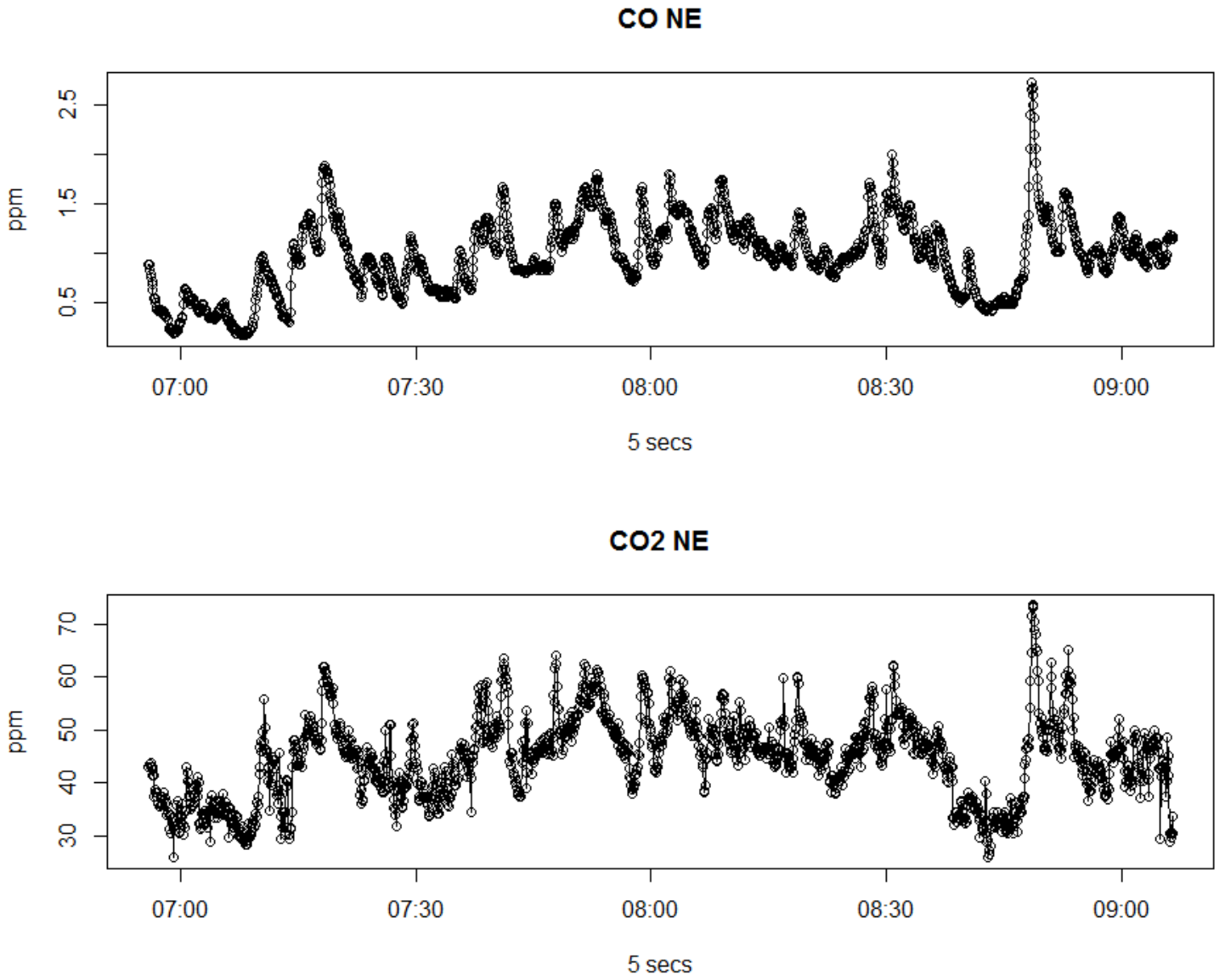

Figure 17. $\mathrm{CO} \& \mathrm{CO}_{2}-\mathrm{NE}$ Corner Scatterplots

Scatterplots for particulate matter (UFP and $\mathrm{PM}_{2.5}$ ) at the NE corner were made including periods of transit bus and heavy vehicle presence. Figure 18 shows bus presence in blue vertical lines for the entire duration of time spent at the bus stop on the NE corner of the intersection. Periods of long bus presence have thick vertical lines associated with the duration. There are a couple of times where there are large peaks in pollutant levels during bus presence. 

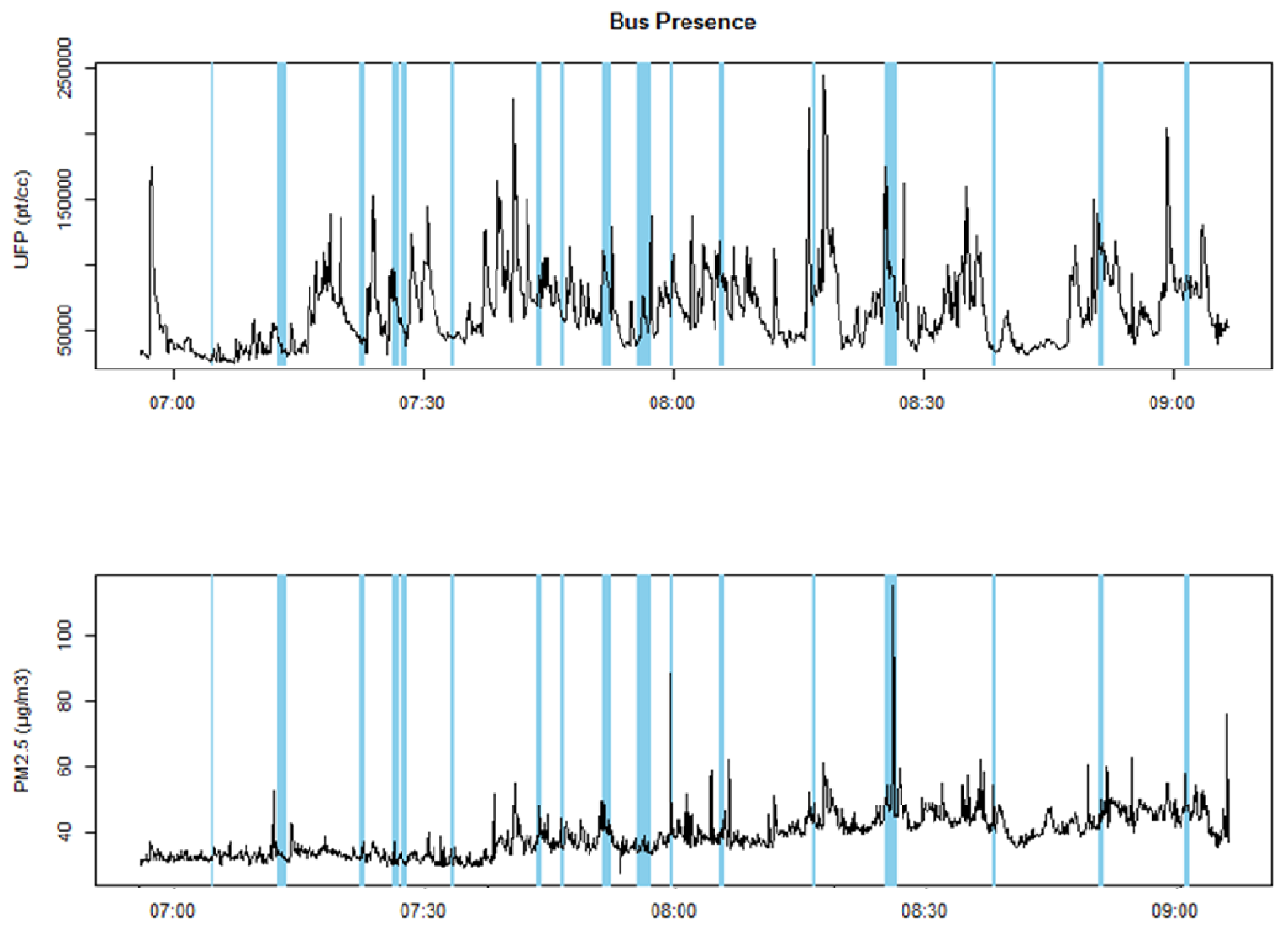

Figure 18. UFP, $\mathrm{PM}_{2.5}$ and Bus Presence Scatterplots

Scatterplots for heavy vehicle presence are shown in Figure 19, where periods of heavy vehicle idling while waiting in a queue near the NE corner of the intersection are represented by yellow vertical lines. There are a few occasions where peak pollutant values line up in time with heavy vehicle presence periods. 

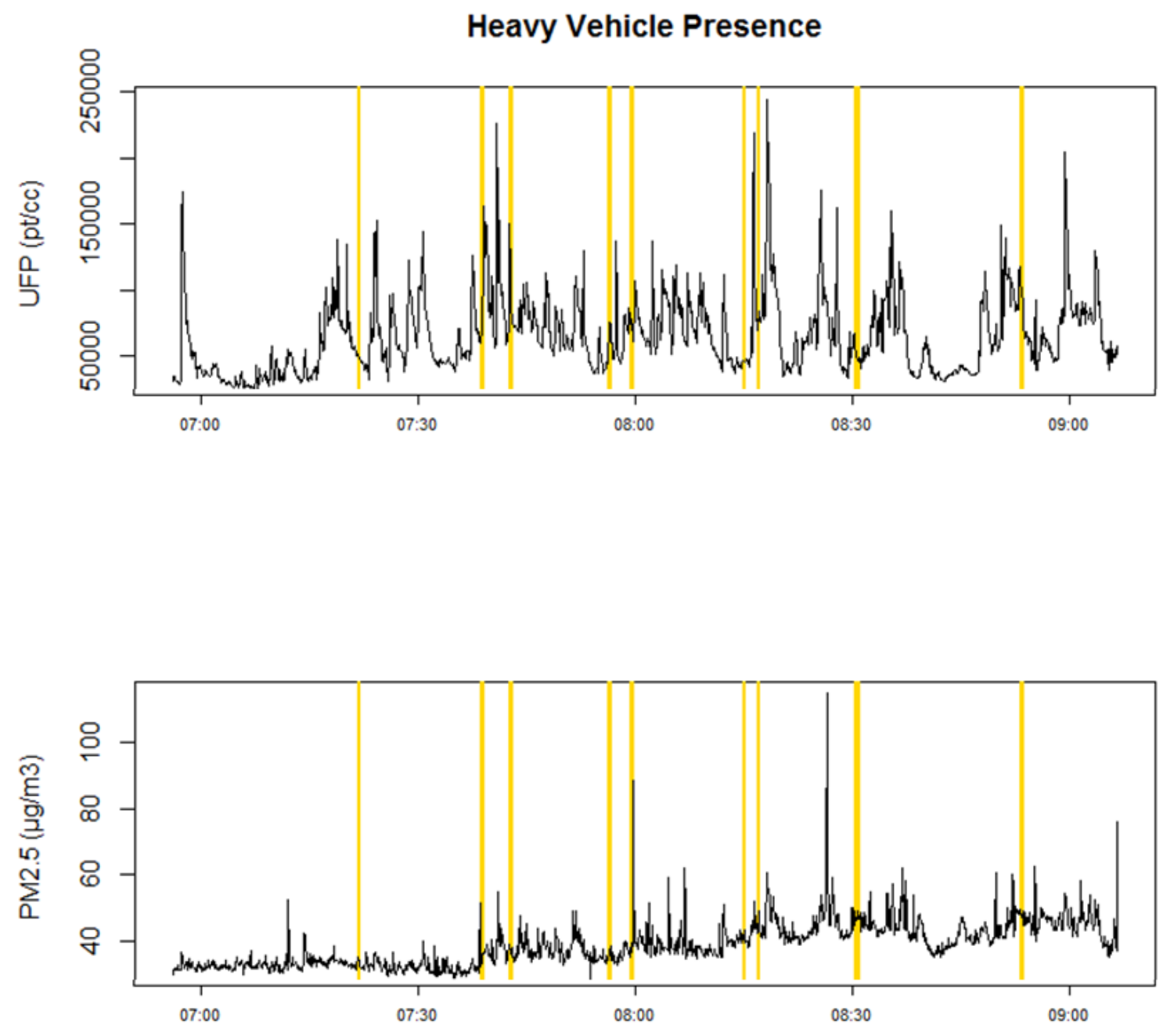

Figure 19. UFP, $\mathrm{PM}_{2.5}$, and Heavy Vehicle Presence Scatterplots

After examining the descriptive statistics and plotting pollutant levels at different corners of the intersection, it is clear that there is variability by location in terms of how outside factors impact pollutant levels at each corner.

\subsection{Correlation}

The Pearson correlation, a measure of the linear relationship between two variables, was calculated between various weather and traffic related variables and pollutant levels. The 
values fall within -1 and 1 , indicating either a negative or positive correlation. The closer the value is to one indicates a strong relationship, whereas zero indicates no relationship. The correlations were calculated in $\mathrm{R}$ (version 2.14.0) using the cor (correlation) function from the stats package. A summary table is provided including the strongest relationships with correlations over 0.15 shown as bolded in Table 16 (Table 73 in Appendix A includes all variables).

Table 16. Correlation Between Weather, Traffic and Air Pollution

\begin{tabular}{|l|r|r|r|r|r|r|}
\hline \multirow{2}{*}{} & \multicolumn{4}{|c|}{ NE Corner } & \multicolumn{2}{c|}{ NW Corner } \\
\cline { 2 - 7 } & \multicolumn{1}{|c|}{ UFP } & \multicolumn{1}{c|}{ PM $_{2.5}$} & \multicolumn{1}{c|}{ CO } & \multicolumn{1}{c|}{$\mathrm{CO}_{2}$} & \multicolumn{1}{c|}{ UFP } & \multicolumn{1}{|c|}{$\mathrm{PM}_{2.5}$} \\
\hline RH & $\mathbf{0 . 5 3}$ & $\mathbf{0 . 1 6}$ & $\mathbf{0 . 5 8}$ & $\mathbf{0 . 5 5}$ & $\mathbf{0 . 3 4}$ & 0.11 \\
Temp & 0.06 & $\mathbf{- 0 . 1 9}$ & $\mathbf{0 . 1 8}$ & $\mathbf{0 . 3 1}$ & 0.12 & $\mathbf{- 0 . 2 0}$ \\
wSN & 0.08 & $\mathbf{0 . 2 1}$ & $\mathbf{0 . 1 7}$ & 0.10 & $\mathbf{0 . 2 3}$ & $\mathbf{0 . 2 0}$ \\
wSNE & 0.07 & $\mathbf{0 . 2 0}$ & 0.09 & 0.08 & $\mathbf{0 . 1 6}$ & 0.12 \\
wsSE & $\mathbf{- 0 . 2 6}$ & $\mathbf{- 0 . 2 2}$ & $\mathbf{- 0 . 3 3}$ & $\mathbf{- 0 . 2 5}$ & $\mathbf{- 0 . 2 5}$ & $\mathbf{- 0 . 1 7}$ \\
wsS & -0.09 & $\mathbf{- 0 . 3 3}$ & $\mathbf{- 0 . 2 4}$ & $\mathbf{- 0 . 1 8}$ & $\mathbf{- 0 . 3 2}$ & $\mathbf{- 0 . 2 4}$ \\
wsSW & -0.03 & $\mathbf{- 0 . 1 8}$ & -0.11 & -0.05 & $\mathbf{- 0 . 1 8}$ & $\mathbf{- 0 . 1 5}$ \\
wsNW & 0.07 & $\mathbf{0 . 1 6}$ & 0.12 & 0.08 & 0.12 & 0.13 \\
BusRedLight & $\mathbf{0 . 1 5}$ & $\mathbf{0 . 1 8}$ & 0.07 & 0.08 & 0.07 & 0.03 \\
HVNW & $\mathbf{0 . 1 9}$ & 0.05 & $\mathbf{0 . 1 5}$ & 0.13 & $\mathbf{0 . 1 9}$ & 0.04 \\
GreenA & -0.01 & $\mathbf{- 0 . 2 4}$ & -0.09 & -0.08 & $\mathbf{- 0 . 1 8}$ & $\mathbf{- 0 . 2 3}$ \\
GreenC & -0.03 & $\mathbf{- 0 . 2 3}$ & $\mathbf{- 0 . 1 7}$ & -0.10 & $\mathbf{- 0 . 1 9}$ & $\mathbf{- 0 . 1 7}$ \\
GreenF & 0.09 & 0.11 & 0.13 & 0.10 & $\mathbf{0 . 2 0}$ & $\mathbf{0 . 1 5}$ \\
GreenE & 0.02 & $\mathbf{0 . 2 1}$ & 0.08 & 0.05 & $\mathbf{0 . 1 8}$ & 0.14 \\
GreenD & $\mathbf{0 . 1 6}$ & $\mathbf{0 . 2 1}$ & $\mathbf{0 . 2 5}$ & 0.11 & $\mathbf{0 . 2 1}$ & 0.14 \\
VolCycle & $\mathbf{0 . 2 4}$ & 0.13 & $\mathbf{0 . 3 1}$ & $\mathbf{0 . 2 4}$ & $\mathbf{0 . 1 5}$ & 0.08 \\
\hline
\end{tabular}

Wind speed in the SE direction is the only variable that is strongly associated with all pollutants at both locations, whereas most variables are correlated with only some pollutants or only at one corner of the intersection. Either relative humidity or temperature are strongly correlated with all pollutants. The signs are consistent for wind direction, where all directions in the north are positive, and those in the south are 
negative. Bus red light only shows up as an important variable at the NE corner only, which makes sense since that corresponds to the location of the stop. The green time for Phase A seems to be most important for $\mathrm{PM}_{2.5}$ compared to other pollutants, whereas volume per cycle has a stronger relationship with $\mathrm{CO}$ and $\mathrm{CO}_{2}$. UFP has a strong relationship with volume per cycle at the NE corner, and has strong relationship with all signal timing parameters at the NW corner. Examining the correlation between variables is an important step in exploratory data analysis to understand which variables explain the most.

Additionally, it is necessary to understand the correlation among variables. The correlation between relative humidity and temperature is -0.09 , meaning that they are inversely related. The correlation was also calculated among traffic related variables, at a five minute interval after aggregating the data. This was done to account for different units of time in the vehicle movements (vehicles per 5 seconds) and signal timing and volume per cycle (around 2 minutes). Table 17 shows the correlation among traffic related variables including vehicle movements, phase green times, cycle length, and volume per cycle. Correlations over 0.50 in magnitude are bolded in the table below. 
Table 17. Correlation Among Traffic Variables

\begin{tabular}{|l|r|r|r|r|r|r|r|r|r|r|}
\hline & \multicolumn{1}{l|}{$\begin{array}{l}\text { EB } \\
\text { TH }\end{array}$} & $\begin{array}{l}\text { WB } \\
\text { TH }\end{array}$ & $\begin{array}{l}\text { SB } \\
\text { TH }\end{array}$ & $\begin{array}{l}\text { NB } \\
\text { TH }\end{array}$ & $\begin{array}{l}\text { Green } \\
\text { A }\end{array}$ & $\begin{array}{l}\text { Green } \\
\text { C }\end{array}$ & $\begin{array}{l}\text { Green } \\
\text { F }\end{array}$ & $\begin{array}{l}\text { Green } \\
\text { E }\end{array}$ & $\begin{array}{l}\text { Green } \\
\text { D }\end{array}$ & $\begin{array}{l}\text { Cycle } \\
\text { Length }\end{array}$ \\
\hline WBTH & -0.27 & & & & & & & & & \\
SBTH & -0.22 & 0.21 & & & & & & & & \\
NBTH & $\mathbf{- 0 . 6 0}$ & 0.16 & -0.04 & & & & & & & \\
GreenA & -0.14 & 0.18 & $\mathbf{0 . 5 4}$ & 0.05 & & & & & & \\
GreenC & 0.08 & -0.18 & 0.39 & -0.24 & $\mathbf{0 . 7 0}$ & & & & & \\
GreenF & 0.58 & -0.13 & 0.04 & -0.37 & 0.06 & 0.10 & & & & \\
GreenE & -0.36 & 0.33 & -0.09 & 0.35 & -0.10 & -0.35 & -0.49 & & & \\
GreenD & -0.46 & 0.08 & 0.02 & 0.16 & 0.19 & -0.08 & $\mathbf{- 0 . 6 6}$ & 0.02 & & \\
Cycle & & & & & & & & & & \\
Length & -0.27 & 0.45 & 0.36 & 0.49 & 0.44 & -0.15 & -0.07 & 0.22 & 0.01 & \\
Volume/ & & & & & & & & & & \\
Cycle & -0.20 & 0.39 & 0.41 & 0.32 & 0.49 & 0.07 & -0.10 & 0.05 & 0.26 & $\mathbf{0 . 5 5}$ \\
\hline
\end{tabular}

The traffic related correlations show that the northbound movement is inversely related to eastbound, due to being conflicting movements. Green time for Phase A is strongly correlated to the southbound vehicle movement. Green time for Phase A and F are strongly inversely correlated, meaning that when one increases, the other decreases. Cycle length and volume per cycle are strongly correlated because additional times allows for a higher number of vehicles to travel through the intersection. The variables that are strongly correlated with each other cannot be used in the same models because they explain the same thing. 


\subsection{Exploratory Linear Regression Analysis}

Multiple linear regression was used to make a model for the dependent variable $\mathrm{Y}$ as a linear function of a series of independent variables, $\mathrm{X}_{1}, \mathrm{X}_{2}, \ldots, \mathrm{X}_{\mathrm{k}}$, and an error term.

The model is written as:

$$
Y_{i}=\beta_{1}+\beta_{2} X_{2 i}+\beta_{3} X_{3 i} \ldots+\beta_{k} X_{k i}+\varepsilon_{i} \quad \text { (Equation 1) }
$$

$\beta_{1}$ is the constant or intercept of the equation. The regression coefficients measure the change in the dependent variable associated with a unit change in the predictor. The predictors are able to explain changes in the outcome variable.

The following are the assumptions for multiple linear regression:

1. The relationship between $\mathrm{Y}$ and $\mathrm{X}$ is linear and given by Equation 1 .

2. The X's are nonstochastic variables. In addition, no exact linear relationship exists between two or more independent variables.

3. The error term has zero expected value for all observations.

4. The error term has constant variance for all observations.

5. Errors corresponding to different observations are independent and therefore uncorrelated.

6. The error term is normally distributed.

The model notation and list of assumptions were taken from Econometric Models and Economic Forecasts (Pindyck \& Rubinfeld, 1998).

Log linear regression models were used, where the outcome variable was log transformed using natural log. This transformation made the pollutant data more normally distributed and increased the adjusted $\mathrm{r}$ square for all models. The model is written as:

$$
\ln \left(Y_{i}\right)=\beta_{1}+\beta_{2} X_{2 i}+\beta_{3} X_{3 i} \ldots+\beta_{k} X_{k i}+\varepsilon_{i}(\text { Equation 2) }
$$


This section will include the results from each model that was made along with interpretation. Creating log linear models makes it possible to quantify the effect of various factors on air quality using elasticities.

The process of building the models was done by creating separate models for: (1) only weather related variables, (2) only traffic related variables, (3) weather and traffic together. Each model was made by including the variables listed above and removing insignificant variables until only significant variables remained. Weather and traffic variables were examined separately at first, to make sure that only the variables with the most explanatory power remain in the final models. The variance inflation factor (VIF) was checked each time a change was made to the model to avoid multicollinearity (where two variables are included and only one is needed to explain the same changes in pollutant levels). The model building process was done in $\mathrm{R}$ (version 2.14.0) using the $\mathrm{lm}$ (linear model) function from the stats package. The VIF was checked using the vif (variance inflation factor) function from the $\mathrm{HH}$ package (Statistical Analysis and Data Display: Heiberger and Holland).

The model interpretation will be different than typical linear regression because the outcome variable is transformed (Pindyck \& Rubinfeld, 1998). There are three methods of interpretation that will be included:

1. \% Change per Unit Change in $\mathbf{X}$ : Exponentiation of regression coefficient and subtract one from it $\left(\mathrm{e}^{\beta}-1\right)$.

2. \% Change per 1\% Change in $\mathrm{X}$ : Elasticity for each parameter at their mean value. It is the percent change in $\mathrm{Y}$ divided by the percent change in $\mathrm{X}$. 
3. \% Average Contribution Relative to Baseline: Contribution to $\mathrm{Y}$ using mean values of $X$, where the constant, relative humidity and temperature were summed to provide a baseline condition.

The unit change can be somewhat misleading since the units are on different scales between the various predictors for real or continuous variables. The elasticity is particularly useful because it is a unit-free measure. The second and third methods make interpretation more intuitive because the units of the model input do not affect the results. For the following tables including the three methods of interpretation, the highest values will be bolded within the table following these guidelines: (1) if the percent change per unit change in the predictor is greater than or equal to $\mathbf{1 0 \%},(2)$ if the elasticity is greater than or equal to $\mathbf{1 \%}$, and (3) if the percent average contribution relative to the baseline conditions is greater than or equal to $\mathbf{5 \%}$.

\subsection{Exploratory Log Linear Models}

A model was made for each pollutant measured at the NE corner, including UFP, $\mathrm{PM}_{2.5}$, $\mathrm{CO}$, and $\mathrm{CO}_{2}$, and at the $\mathrm{NW}$ corner, including UFP and $\mathrm{PM}_{2.5}$. Variables related to atmospheric conditions, transit buses, heavy vehicles, traffic, and signal timing were included as independent variables to account for the variation in pollutant levels. The following are the model inputs including their mean values as shown in Table 18. 
Table 18. Model Input Mean Values

\begin{tabular}{|l|r|l|l|r|l|}
\hline \multicolumn{3}{|c|}{ Atmospheric Factors } & \multicolumn{3}{c|}{ Traffic Related Factors } \\
\hline Model Input & Mean Value & Units & Model Input & Mean Value & Units \\
\hline Constant & 1.000 & & HVNW & 0.398 & unitless \\
RH & 78.971 & $\%$ & BusRedLight & 0.877 & seconds \\
Temp & 39.920 & ${ }^{\circ} \mathrm{F}$ & DPF & 0.049 & unitless \\
wsN & 0.167 & $\mathrm{~m} / \mathrm{s}$ & TPAngled & 0.003 & unitless \\
wsNE & 0.052 & $\mathrm{~m} / \mathrm{s}$ & EMP & 0.020 & unitless \\
wsSE & 0.036 & $\mathrm{~m} / \mathrm{s}$ & GreenA & 71.891 & seconds \\
wsS & 0.067 & $\mathrm{~m} / \mathrm{s}$ & GreenE & 1.841 & seconds \\
wsSW & 0.050 & $\mathrm{~m} / \mathrm{s}$ & GreenF & 6.631 & seconds \\
wsW & 0.053 & $\mathrm{~m} / \mathrm{s}$ & GreenC & 5.784 & seconds \\
wsNW & 0.073 & $\mathrm{~m} / \mathrm{s}$ & GreenD & 29.422 & seconds \\
HVNE & 0.031 & unitless & VolCycle & 96.519 & vehicles \\
HVNETime & 0.896 & seconds & CycleLength & 115.570 & seconds \\
\hline
\end{tabular}

The final models for particulate matter are shown in Table 19 for the NE corner of the intersection, where only significant variables at the 0.05 level remain in the models. Weather and traffic related variables were able to explain $27 \%$ of the variation in UFP and $44 \%$ for $\mathrm{PM}_{2.5}$.

Table 19. NE Corner Log Linear Models - Particulate Matter

\begin{tabular}{|l|rrr|rrr|}
\hline Pollutant & \multicolumn{3}{|c|}{$\ln ($ UFP) } & \multicolumn{3}{c|}{$\ln \left(\mathbf{P M}_{2.5}\right)$} \\
$\mathrm{R}^{2}$ & & $27.68 \%$ & & & $44.63 \%$ & \\
Adj ${ }^{2}$ & & $27.35 \%$ & & & $44.14 \%$ & \\
\hline & $\mathrm{B}$ & $\mathrm{SE}_{\mathrm{B}}$ & P-Value & $\mathrm{B}$ & $\mathrm{SE}_{\mathrm{B}}$ & P-Value \\
\hline Constant & -2.8178 & 0.7717 & 0.0003 & 1.6358 & 0.4768 & 0.0006 \\
RH & 0.1737 & 0.0099 & 0.0000 & 0.0069 & 0.0034 & 0.0447 \\
Temp & & & & -0.1348 & 0.0092 & 0.0000 \\
wsN & & & & 0.0554 & 0.0097 & 0.0000 \\
wsNE & & & & 0.1157 & 0.0186 & 0.0000 \\
wsSE & -0.3871 & 0.0751 & 0.0000 & -0.1950 & 0.0268 & 0.0000 \\
wsS & & & & -0.2482 & 0.0209 & 0.0000 \\
wsSW & & & & -0.1405 & 0.0198 & 0.0000 \\
\hline
\end{tabular}




\begin{tabular}{|l|rrr|rrr|}
\hline Pollutant & \multicolumn{3}{|c|}{$\ln (\mathbf{U F P})$} & \multicolumn{3}{c|}{$\ln \left(\mathbf{P M}_{\mathbf{2 . 5}}\right)$} \\
\hline & $\mathrm{B}$ & $\mathrm{SE}_{\mathrm{B}}$ & $\mathrm{P}-$ Value & $\mathrm{B}$ & $\mathrm{SE}_{\mathrm{B}}$ & P-Value \\
\hline wsW & -0.1160 & 0.0511 & 0.0234 & & & \\
wsNW & & & & 0.0761 & 0.0139 & 0.0000 \\
BusRedLight & 0.0076 & 0.0016 & 0.0000 & 0.0050 & 0.0005 & 0.0000 \\
$H V N E$ & & & & 0.0780 & 0.0174 & 0.0000 \\
GreenA & -0.0026 & 0.0009 & 0.0053 & -0.0028 & 0.0003 & 0.0000 \\
GreenE & & & & 0.0049 & 0.0007 & 0.0000 \\
GreenC & 0.0027 & 0.0014 & 0.0483 & & & \\
GreenD & & & & 0.0025 & 0.0006 & 0.0000 \\
VolCycle & 0.0029 & 0.0005 & 0.0000 & 0.0006 & 0.0002 & 0.0002 \\
\hline
\end{tabular}

The following Table 20 is a summary table for particulate matter at the NE corner using all three of the interpretation methods previously discussed.

Table 20. NE Corner Log Linear Model Interpretation - Particulate Matter

\begin{tabular}{|c|c|c|c|c|c|c|}
\hline \multirow[t]{3}{*}{ Model Input } & \multicolumn{6}{|c|}{ NE Corner Particulate Matter } \\
\hline & \multicolumn{2}{|c|}{$\begin{array}{l}\% \text { Change per Unit } \\
\text { Change in X }\end{array}$} & \multicolumn{2}{|c|}{$\begin{array}{l}\% \text { Change per } 1 \% \\
\text { Change in } \mathrm{X}\end{array}$} & \multicolumn{2}{|c|}{$\begin{array}{c}\% \text { Average Contribution } \\
\text { to Baseline* }\end{array}$} \\
\hline & UFP & $\mathrm{PM}_{2.5}$ & UFP & $\mathrm{PM}_{2.5}$ & UFP & $\mathrm{PM}_{2.5}$ \\
\hline RH & $18.97 \%$ & $0.69 \%$ & $14.705 \%$ & $0.548 \%$ & & \\
\hline Temp & & $-12.61 \%$ & & $-5.239 \%$ & & \\
\hline wsN & & $5.70 \%$ & & $0.009 \%$ & & $0.93 \%$ \\
\hline wsNE & & $12.27 \%$ & & $0.006 \%$ & & $0.61 \%$ \\
\hline wsSE & $-32.10 \%$ & $-17.72 \%$ & $-0.014 \%$ & $-0.007 \%$ & $-1.39 \%$ & $-0.70 \%$ \\
\hline wsS & & $-21.98 \%$ & & $-0.017 \%$ & & $-1.64 \%$ \\
\hline wsSW & & $-13.11 \%$ & & $-0.007 \%$ & & $-0.71 \%$ \\
\hline wsW & $-10.95 \%$ & & $-0.006 \%$ & & $-0.61 \%$ & \\
\hline wsNW & & $7.90 \%$ & & $0.006 \%$ & & $0.56 \%$ \\
\hline BusRedLight & $0.77 \%$ & $0.50 \%$ & $0.007 \%$ & $0.004 \%$ & $0.67 \%$ & $0.44 \%$ \\
\hline$H V N E$ & & $8.12 \%$ & & & & $0.24 \%$ \\
\hline GreenA & $-0.26 \%$ & $-0.28 \%$ & $-0.188 \%$ & $-0.204 \%$ & $-17.16 \%$ & $-18.49 \%$ \\
\hline GreenE & & $0.49 \%$ & & $0.009 \%$ & & $0.91 \%$ \\
\hline GreenC & $0.27 \%$ & & $0.015 \%$ & & $1.56 \%$ & \\
\hline GreenD & & $0.26 \%$ & & $0.075 \%$ & & $7.79 \%$ \\
\hline VolCycle & $0.29 \%$ & $0.06 \%$ & $0.279 \%$ & $0.063 \%$ & $32.16 \%$ & $6.45 \%$ \\
\hline
\end{tabular}

*Baseline is the sum of constant, $\mathrm{RH}$, and temp 
First off, atmospheric factors play a large role in explaining pollutant levels. An increase in relative humidity increases higher pollutant levels, where each additional percentage of relative humidity has an increase of 19 and $0.7 \%$, for UFP and $\mathrm{PM}_{2.5}$, respectively. As temperature increases, lower levels are predicted for $\mathrm{PM}_{2.5}$, with no significant effect for UFP. Various wind speed bins explain pollutant levels, where winds in the NW, N, and NE directions increase the $\mathrm{PM}_{2.5}$ levels at the NE corner. The $\mathrm{E}$ wind is not significant in any of the cases. Wind in the SE, S, SW, and W directions decreases pollutant levels in the NE corner. The south winds are pushing the air away from the measurement device, whereas the north winds are pushing the air into the device.

Second, several of the observed traffic variables significantly help to explain pollutant levels. For every additional second that the transit bus is waiting at the red light after the doors have shut, there is an increase of $0.77 \%$ in UFP and $0.5 \%$ for $\mathrm{PM}_{2.5}$. For every heavy vehicle presence at the NE corner, there is an increase in $\mathrm{PM}_{2.5}$ of $8 \%$.

Third, there are various factors related to traffic signal timing that remain in the models. In all cases, longer green times for Phase A, which consists of through eastbound and westbound movements on Powell, reduces pollutant levels from $0.26 \%$ to $0.28 \%$ per additional second of green time. All other phase green times do not have consist signs between the different pollutants. Each additional vehicle per cycle results in an increase of $0.3 \%$ and $0.1 \%$ for UFP and $\mathrm{PM}_{2.5}$, respectively, after controlling for all other variables. 
In terms of elasticity, a $1 \%$ increase in relative humidity results in $15 \%$ and $0.5 \%$ higher UFP and $\mathrm{PM}_{2.5}$ levels, respectively. A $1 \%$ increase in temperature results in $5 \%$ lower $\mathrm{PM}_{2.5}$ levels. The other predictors with the highest elasticity values are volume per cycle and green time during Phase A. Where a $1 \%$ increase in volume per cycle, results in increases of $0.1-0.3 \%$ for particulate matter. A $1 \%$ increase green time for Phase A results in decreases of about $0.2 \%$. The rest of the predictors have elasticity values lower than $0.1 \%$.

For the mean contribution, the largest contribution to UFP levels is volume per cycle with an average contribution of $32 \%$ with mean values for all other inputs. The second highest was green time for Phase A with a 17\% reduction in UFP. The remaining variables each contributed less than two percent, with green time for Phase D, wind in the SE direction, wind in the $\mathrm{W}$ direction, and bus red light time. The largest contribution to $\mathrm{PM}_{2.5}$ is $8 \%$ from green time for Phase D. The largest reduction in $\mathrm{PM}_{2.5}$ is $19 \%$ from green time for Phase A.

The final models for $\mathrm{CO}$ and $\mathrm{CO}_{2}$ are shown in Table 21 for the NE corner of the intersection, where only significant variables at the 0.05 level remain in the models. Weather and traffic related variables were able to explain $54 \%$ of the variation in $\mathrm{CO}$ and $40 \%$ for $\mathrm{CO}_{2}$. 
Table 21. NE Corner Log Linear Models - $\mathrm{CO} \& \mathrm{CO}_{2}$

\begin{tabular}{|c|c|c|c|c|c|c|}
\hline $\begin{array}{l}\text { Pollutant } \\
\mathrm{R}^{2} \\
\text { Adj } \mathrm{R}^{2}\end{array}$ & & $\begin{array}{l}\operatorname{In}(\mathbf{C O}) \\
54.65 \% \\
54.30 \%\end{array}$ & & & $\begin{array}{l}\operatorname{In}\left(\mathbf{C O}_{2}\right) \\
40.43 \% \\
39.97 \%\end{array}$ & \\
\hline & B & $\mathrm{SE}_{\mathrm{B}}$ & P-Value & B & $\mathrm{SE}_{\mathrm{B}}$ & P-Value \\
\hline Constant & -19.9166 & 0.7321 & 0.0000 & -3.4549 & 0.3149 & 0.0000 \\
\hline RH & 0.2567 & 0.0095 & 0.0000 & 0.0945 & 0.0041 & 0.0000 \\
\hline wsSE & -0.7524 & 0.0728 & 0.0000 & -0.1980 & 0.0313 & 0.0000 \\
\hline wsS & -0.5358 & 0.0558 & 0.0000 & -0.1464 & 0.0240 & 0.0000 \\
\hline wsSW & -0.3068 & 0.0527 & 0.0000 & -0.0717 & 0.0227 & 0.0016 \\
\hline wsW & -0.1265 & 0.0469 & 0.0071 & -0.0611 & 0.0202 & 0.0025 \\
\hline$D P F$ & -0.1249 & 0.0379 & 0.0010 & & & \\
\hline$H V N E$ & 0.1788 & 0.0474 & 0.0002 & 0.0822 & 0.0204 & 0.0001 \\
\hline GreenA & -0.0033 & 0.0017 & 0.0499 & -0.0025 & 0.0004 & 0.0000 \\
\hline GreenE & & & & -0.0032 & 0.001 & 0.0015 \\
\hline GreenF & -0.0106 & 0.0017 & 0.0000 & -0.0049 & 0.0008 & 0.0000 \\
\hline GreenC & -0.0091 & 0.0017 & 0.0000 & -0.0036 & 0.0008 & 0.0000 \\
\hline GreenD & & & & -0.0036 & 0.0007 & 0.0000 \\
\hline VolCycle & 0.0054 & 0.0005 & 0.0000 & 0.0015 & 0.0002 & 0.0000 \\
\hline CycleLength & -0.0047 & 0.0014 & 0.0005 & & & \\
\hline
\end{tabular}

The following Table 22 is a summary table for carbon monoxide and dioxide at the NE corner using all three of the interpretation methods.

Table 22. NE Corner Log Linear Model Interpretation - $\mathrm{CO} \& \mathrm{CO}_{2}$

\begin{tabular}{|c|c|c|c|c|c|c|}
\hline \multirow[t]{3}{*}{ Model Input } & \multicolumn{6}{|c|}{$\mathrm{NE}$ Corner $\mathrm{CO} \& \mathrm{CO}_{2}$} \\
\hline & \multicolumn{2}{|c|}{$\begin{array}{c}\text { \% Change per Unit } \\
\text { Change in X }\end{array}$} & \multicolumn{2}{|c|}{$\begin{array}{c}\% \text { Change per } 1 \% \\
\text { Change in X }\end{array}$} & \multicolumn{2}{|c|}{$\begin{array}{c}\% \text { Average Contribution } \\
\text { to Baseline* }\end{array}$} \\
\hline & $\mathrm{CO}$ & $\mathrm{CO}_{2}$ & $\mathrm{CO}$ & $\mathrm{CO}_{2}$ & $\mathrm{CO}$ & $\mathrm{CO}_{2}$ \\
\hline RH & $29.26 \%$ & $9.91 \%$ & $22.469 \%$ & $7.747 \%$ & & \\
\hline wsSE & $-52.88 \%$ & $-17.96 \%$ & $-0.027 \%$ & $-0.007 \%$ & $-2.68 \%$ & $-0.71 \%$ \\
\hline wsS & $-41.48 \%$ & $-13.62 \%$ & $-0.036 \%$ & $-0.010 \%$ & $-3.50 \%$ & $-0.97 \%$ \\
\hline wsSW & $-26.42 \%$ & $-6.92 \%$ & $-0.015 \%$ & $-0.004 \%$ & $-1.53 \%$ & $-0.36 \%$ \\
\hline wsW & $-11.88 \%$ & $-5.93 \%$ & $-0.007 \%$ & $-0.003 \%$ & $-0.66 \%$ & $-0.32 \%$ \\
\hline$D P F$ & $-11.74 \%$ & & & & $-0.61 \%$ & \\
\hline$H V N E$ & $19.57 \%$ & $8.57 \%$ & & & $0.55 \%$ & $0.25 \%$ \\
\hline
\end{tabular}




\begin{tabular}{|l|c|c|c|c|c|r|}
\hline \multirow{2}{*}{} & \multicolumn{2}{|c|}{$\begin{array}{c}\text { \% Change per Unit } \\
\text { Change in } \mathrm{X}\end{array}$} & \multicolumn{2}{c|}{$\begin{array}{c}\text { \% Change per } 1 \% \\
\text { Change in } \mathrm{X}\end{array}$} & \multicolumn{2}{c|}{$\begin{array}{c}\text { Average Contribution } \\
\text { to Baseline* }\end{array}$} \\
\cline { 2 - 7 } & $\mathrm{CO}$ & $\mathrm{CO}_{2}$ & $\mathrm{CO}$ & $\mathrm{CO}_{2}$ & $\mathrm{CO}$ & \multicolumn{1}{c|}{$\mathrm{CO}_{2}$} \\
\hline GreenA & $-0.33 \%$ & $-0.25 \%$ & $-0.237 \%$ & $-0.180 \%$ & $\mathbf{- 2 1 . 0 9 \%}$ & $\mathbf{- 1 6 . 4 8 \%}$ \\
GreenE & & $-0.32 \%$ & & $-0.006 \%$ & & $-0.59 \%$ \\
GreenF & $-1.05 \%$ & $-0.49 \%$ & $-0.070 \%$ & $-0.033 \%$ & $\mathbf{- 6 . 7 6 \%}$ & $-3.20 \%$ \\
GreenC & $-0.90 \%$ & $-0.36 \%$ & $-0.052 \%$ & $-0.021 \%$ & $\mathbf{- 5 . 1 1 \%}$ & $-2.05 \%$ \\
GreenD & & $-0.36 \%$ & & $-0.107 \%$ & & $\mathbf{- 1 0 . 1 6 \%}$ \\
VolCycle & $0.54 \%$ & $0.15 \%$ & $0.519 \%$ & $0.147 \%$ & $\mathbf{6 7 . 7 6 \%}$ & $\mathbf{1 5 . 7 9 \%}$ \\
CycleLength & $-0.47 \%$ & & $-0.545 \%$ & & $\mathbf{- 4 2 . 0 8 \%}$ & \\
\hline
\end{tabular}

*Baseline is the sum of constant, $\mathrm{RH}$, and temp

Relative humidity plays a large role in explaining pollutant levels, where an additional percentage of relative humidity yields an increase of $29 \%$ and $10 \%$ for $\mathrm{CO}$ and $\mathrm{CO}_{2}$, respectively. Temperature is not a significant factor for either $\mathrm{CO}$ or $\mathrm{CO}_{2}$, due to relative humidity already accounting for the variation in weather. Various wind speed bins explain pollutant levels, where wind in the SE, S, SW, and W directions decreases pollutant levels in the NE corner. The other wind variables were not significant.

For every bus presence with a DPF particulate filter, $\mathrm{CO}$ is reduced by $12 \%$. For every heavy vehicle presence at the $\mathrm{NE}$ corner, there is an increase in $\mathrm{CO}$ and $\mathrm{CO}_{2}$, ranging from 8 to $20 \%$. In all cases, longer green times for Phase A reduces pollutant levels from $0.25 \%$ to $0.33 \%$ per additional second of green time. Each additional vehicle per cycle results in an increase of $0.5 \%$ and $0.2 \%$ for $\mathrm{CO}$ and $\mathrm{CO}_{2}$, respectively. Longer cycle lengths decreases $\mathrm{CO}$ by $0.5 \%$ per additional second.

For the elasticity values, a $1 \%$ increase in relative humidity results in $22 \%$ and $8 \%$ higher $\mathrm{CO}$ and $\mathrm{CO}_{2}$ levels, respectively. The other predictors with the highest elasticity values are volume per cycle, cycle length, and green time during Phase A. Where a 1\% increase 
in volume per cycle, results in increases of $0.5 \%$ and $0.15 \%$ in $\mathrm{CO}$ and $\mathrm{CO}_{2}$ levels, respectively. A $1 \%$ increase in cycle length results in $0.5 \%$ lower CO levels. A $1 \%$ increase green time for Phase A results in decreases of about $0.2 \%$. The rest of the predictors have elasticity values lower than $0.1 \%$.

Regarding the mean contribution, for both $\mathrm{CO}$ and $\mathrm{CO}_{2}$, the largest contribution is from volume per cycle with $68 \%$ and $16 \%$ respectively. For both, the largest reduction is from green time for Phase A, with $21 \%$ and $17 \%$ respectively for $\mathrm{CO}$ and $\mathrm{CO}_{2}$.

Other than atmospheric factors, which play a significant role in explaining pollutant levels, there are four main inputs that have the largest impact on air quality. When interpreting the log linear models with average contributions relative to the baseline atmospheric conditions, the most significant factors at the NE corner of the intersection were green time for Phase A, green time for Phase D, volume per cycle and cycle length.

The final models for particulate matter are shown in Table 23 for the NW corner of the intersection, where only significant variables at the 0.05 level remain in the models. Weather and traffic related variables were able to explain $34 \%$ of the variation in UFP and $27 \%$ for $\mathrm{PM}_{2.5}$. 
Table 23. NW Corner Log Linear Models - Particulate Matter

\begin{tabular}{|c|c|c|c|c|c|c|}
\hline $\begin{array}{l}\text { Pollutant } \\
\mathrm{R}^{2} \\
\text { Adj } \mathrm{R}^{2}\end{array}$ & \multicolumn{3}{|c|}{$\begin{array}{c}\ln (\mathbf{U F P}) \\
34.36 \% \\
33.73 \%\end{array}$} & \multicolumn{3}{|c|}{$\begin{array}{c}\ln \left(\mathbf{P M}_{2.5}\right) \\
27.48 \% \\
26.73 \% \\
\end{array}$} \\
\hline & B & $\mathrm{SE}_{\mathrm{B}}$ & P-Value & B & $\mathrm{SE}_{\mathrm{B}}$ & P-Value \\
\hline Constant & 1.5633 & 1.1354 & 0.1688 & 9.0763 & 0.6298 & 0.0000 \\
\hline RH & 0.1182 & 0.0147 & 0.0000 & 0.0225 & 0.0058 & 0.0001 \\
\hline Temp & & & & -0.1736 & 0.0141 & 0.0000 \\
\hline wsN & 0.1732 & 0.0614 & 0.0049 & 0.0656 & 0.0130 & 0.0000 \\
\hline wsNE & 0.0841 & 0.0311 & 0.0069 & 0.0670 & 0.0250 & 0.0074 \\
\hline wsSE & -0.5673 & 0.0942 & 0.0000 & -0.1459 & 0.0378 & 0.0001 \\
\hline wsS & -0.6880 & 0.0709 & 0.0000 & -0.1857 & 0.0287 & 0.0000 \\
\hline wsSW & -0.4755 & 0.0688 & 0.0000 & -0.1349 & 0.0278 & 0.0000 \\
\hline wsNW & & & & 0.0792 & 0.0189 & 0.0000 \\
\hline BusRedLight & 0.0043 & 0.0018 & 0.0172 & & & \\
\hline TPAngled & & & & -0.1974 & 0.0783 & 0.0118 \\
\hline$H V N W$ & 0.0894 & 0.0219 & 0.0000 & & & \\
\hline WBTH & -0.0148 & 0.0074 & 0.0464 & -0.0148 & 0.0040 & 0.0003 \\
\hline ЕВТН & & & & 0.0118 & 0.0054 & 0.0292 \\
\hline GreenA & -0.0068 & 0.0011 & 0.0000 & -0.0035 & 0.0004 & 0.0000 \\
\hline GreenE & 0.0128 & 0.0025 & 0.0000 & 0.00278 & 0.001 & 0.0038 \\
\hline GreenF & 0.0055 & 0.0017 & 0.0012 & & & \\
\hline GreenD & 0.0056 & 0.0020 & 0.0060 & 0.0020 & 0.0008 & 0.0127 \\
\hline VolCycle & 0.0017 & 0.0006 & 0.0051 & 0.0005 & 0.0002 & 0.0320 \\
\hline
\end{tabular}

The following Table 24 is a summary table for particulate matter at the NW corner using all three of the interpretation methods. 
Table 24. NW Corner Log Linear Model Interpretation

\begin{tabular}{|c|c|c|c|c|c|c|}
\hline \multirow[t]{3}{*}{ Model Input } & \multicolumn{6}{|c|}{ NW Corner } \\
\hline & \multicolumn{2}{|c|}{$\begin{array}{l}\text { \% Change per Unit } \\
\text { Change in X }\end{array}$} & \multicolumn{2}{|c|}{$\begin{array}{l}\% \text { Change per } 1 \% \\
\text { Change in } \mathrm{X}\end{array}$} & \multicolumn{2}{|c|}{$\begin{array}{c}\% \text { Average Contribution } \\
\text { to Baseline* }\end{array}$} \\
\hline & UFP & $\mathrm{PM}_{2.5}$ & UFP & $\mathrm{PM}_{2.5}$ & UFP & $\mathrm{PM}_{2.5}$ \\
\hline RH & $12.55 \%$ & $2.28 \%$ & $9.784 \%$ & $1.796 \%$ & & \\
\hline Temp & & $-15.93 \%$ & & $-6.694 \%$ & & \\
\hline wsN & & & $0.014 \%$ & $0.011 \%$ & $1.41 \%$ & $1.10 \%$ \\
\hline wsNE & $18.91 \%$ & $6.93 \%$ & $0.009 \%$ & $0.004 \%$ & $0.91 \%$ & $0.35 \%$ \\
\hline wsSE & $-43.30 \%$ & $-13.58 \%$ & $-0.020 \%$ & $-0.005 \%$ & $-2.03 \%$ & $-0.53 \%$ \\
\hline wsS & $-49.74 \%$ & $-16.94 \%$ & $-0.046 \%$ & $-0.012 \%$ & $-4.47 \%$ & $-1.23 \%$ \\
\hline wsSW & $-37.84 \%$ & $-12.62 \%$ & $-0.024 \%$ & $-0.007 \%$ & $-2.37 \%$ & $-0.68 \%$ \\
\hline wsNW & & $8.25 \%$ & & $0.006 \%$ & & $0.58 \%$ \\
\hline BusRedLight & $0.43 \%$ & & $0.004 \%$ & & $0.38 \%$ & \\
\hline TPAngled & & $-17.91 \%$ & & & & $-0.05 \%$ \\
\hline$H V N W$ & $9.36 \%$ & & & & $0.27 \%$ & \\
\hline WBTH & $-1.46 \%$ & $-1.47 \%$ & $-0.029 \%$ & $-0.029 \%$ & $-2.86 \%$ & $-2.86 \%$ \\
\hline EBTH & & $1.19 \%$ & & $0.015 \%$ & & $1.49 \%$ \\
\hline GreenA & $-0.68 \%$ & $-0.35 \%$ & $-0.488 \%$ & $-0.252 \%$ & $-38.67 \%$ & $-22.30 \%$ \\
\hline GreenE & $1.29 \%$ & $0.28 \%$ & $0.024 \%$ & $0.005 \%$ & $2.38 \%$ & $0.51 \%$ \\
\hline GreenF & $0.55 \%$ & & $0.036 \%$ & & $3.68 \%$ & \\
\hline GreenD & $0.56 \%$ & $0.20 \%$ & $0.164 \%$ & $0.058 \%$ & $17.83 \%$ & $5.99 \%$ \\
\hline VolCycle & $0.17 \%$ & $0.05 \%$ & $0.163 \%$ & $0.050 \%$ & $17.75 \%$ & $5.08 \%$ \\
\hline
\end{tabular}

*Baseline is the sum of constant, $\mathrm{RH}$, and temp

An increase in relative humidity yields higher pollutant levels, where each additional percentage of relative humidity yields an increase of 13 and $2 \%$, for UFP and $\mathrm{PM}_{2.5}$, respectively. As temperature increases, $16 \%$ lower levels are predicted for $\mathrm{PM}_{2.5}$, with no significant effect for UFP. Various wind speed bins explain pollutant levels, where winds in the NW, N, and NE directions increase UFP and $\mathrm{PM}_{2.5}$ levels at the NW corner. Wind in the SE, S, SW, and W directions decreases pollutant levels in the NE corner. The signs for atmospheric factors for the NW corner are consistent with results from the NE corner. 
Several of the observed traffic variables significantly help to explain pollutant levels. For every additional second that the transit bus is waiting at the red light after the doors have shut, there is an increase of $0.4 \%$ in UFP. For every bus presence with an angled tailpipe there is a reduction in $\mathrm{PM}_{2.5}$ of $18 \%$. For every heavy vehicle that drove by the NW corner, there is an increase in UFP of $9 \%$. In all cases, longer green times for Phase A, reduced pollutant levels from $0.35 \%$ to $0.68 \%$ per additional second of green time. Each additional vehicle per cycle results in an increase of $0.2 \%$ and $0.1 \%$ for UFP and $\mathrm{PM}_{2.5}$, respectively.

In terms of elasticity, a $1 \%$ increase in relative humidity results in $10 \%$ and $2 \%$ higher UFP and $\mathrm{PM}_{2.5}$ levels, respectively. A 1\% increase in temperature results in $7 \%$ lower $\mathrm{PM}_{2.5}$ levels. The other predictor with the highest elasticity is green time during Phase A, where a $1 \%$ increase in green time for Phase A, results in decreases of $0.25-0.5 \%$ for particulate matter. The rest of the predictors have elasticity values lower than $0.2 \%$.

For the mean contribution, the largest reduction in UFP levels is green time for Phase A with an average contribution of $38 \%$ with mean values for all other inputs. Wind in the south had a reduction of $5 \%$, which is more significant than at the NE corner. The largest contribution is a tie between green time for Phase D and volume per cycle, both with an $18 \%$ contribution to UFP. The remaining variables each contributed less than two percent. The largest contribution is a tie between green time for Phase $\mathrm{D}$ and volume per cycle, both with a 5-6\% contribution to $\mathrm{PM}_{2.5}$. The largest reduction in $\mathrm{PM}_{2.5}$ is $22 \%$ from green time for Phase A. 
Other than atmospheric factors, which play a significant role in explaining pollutant levels, there are three main inputs that have the largest impact on air quality. When interpreting the log linear models with average contributions relative to the baseline atmospheric conditions, the most significant factors at the NW corner of the intersection were green time for Phase A, green time for Phase D and volume per cycle.

\subsection{Exploratory Lagged Log Linear Models}

Often there is period of time that passes before an impact is observed or noticed from a change in a predictor. The previous log linear models examined how various predictors can explain changes in the outcome. However, this does not take into account the lagged time effect that occurs. To incorporate this into the analysis, the distributed lag model was used, which is written as (Pindyck \& Rubinfeld, 1998):

$$
Y_{t}=\alpha+\beta_{0} X_{t}+\beta_{1} X_{t-1}+\beta_{2} X_{t-2}+\cdots=\alpha+\sum_{s=0}^{\infty} \beta_{s} X_{t-s}+\varepsilon_{t} \text { (Equation 3) }
$$

Note: Where t-1 is a period 1 lag earlier, which is 5 seconds before in this case

Traffic related variables were lagged and included in the original linear regression models for each pollutant at the NE and NW corners in order to determine if the effect from these variables took time to show up in the pollutant levels. Traffic variables were selected because emissions can take time to travel from the roadway to the sidewalk around the intersection. Bus, heavy vehicle and vehicles per movement were lagged up to two minutes, while the volume per cycle was lagged up to five minutes. These lag numbers were selected based on traffic operations, where one cycle is around two minutes in length. 
Lagged variables were created in $\mathrm{R}$ (version 2.14.0) by defining the lagmatrix function as: lagmatrix $<-$ function(x,max.lag) embed(c(rep(NA,max.lag), x), max.lag+1). This function was used to create lagged versions of all traffic variables, which were then included in the same model building process previously described for the original models.

The following summary table compares the original and lagged models by their r-square (\%) and adjusted r-square (\%) as shown in Table 25.

Table 25. Compare Original and Lagged Log Linear Models

\begin{tabular}{|l|l|c|c|c|c|c|c|}
\hline \multicolumn{2}{|c|}{} & \multicolumn{4}{|c|}{ NE Corner } & \multicolumn{2}{c|}{ NW Corner } \\
\cline { 3 - 8 } \multicolumn{2}{|c|}{} & UFP & $\mathrm{PM}_{2.5}$ & $\mathrm{CO}$ & $\mathrm{CO}_{2}$ & UFP & $\mathrm{PM}_{2.5}$ \\
\hline Original & $\mathrm{R}^{2}$ & 27.68 & 44.63 & 56.65 & 40.43 & 34.36 & 27.48 \\
& Adj R $^{2}$ & 27.35 & 44.14 & 54.30 & 39.97 & 33.73 & 26.73 \\
\hline Lagged & $\mathrm{R}^{2}$ & 41.64 & 53.52 & 58.89 & 46.02 & 39.82 & 33.86 \\
& Adj R $^{2}$ & 41.05 & 52.43 & 58.26 & 45.37 & 38.91 & 32.67 \\
\hline
\end{tabular}

By adding lagged versions of the traffic related variables, more of the variation in pollutant levels was explained in all cases. The addition of lagged traffic variables not only improved the power of the models in terms of the adjusted r-square value, but it changed the significance of some of the predictors. However, the signs of the significant variables remained the same between the original and lagged models. The improvements from adding lagged variables in terms of the power of the model was larger at the NE corner. The adjusted r-square increased by $14 \%$ at the NE corner, but only increased $5 \%$ at the NW corner. The same applies for $\mathrm{PM}_{2.5}$, but is not as significant of a difference, where there was an increase of $8 \%$ at the NE corner and $5 \%$ at the NW corner. The NE 
corner is more affected by traffic related variables because there is more queuing by the NE corner than the NW corner.

For all lagged log linear models, a weighted average lag is shown if more than one lag for the same traffic related variable was significant in the model. The full results are shown in Appendix B. In addition, the three methods of interpretation were summed within each lagged variable that was the same within a model to provide the overall effect from lagging that variable. The effect from each separate lag can be found in Appendix B. The model results for UFP at the NE corner including lagged traffic variables is shown in Table 26. This table includes the regression coefficients, standard errors, and p-values for each predictor. For the lagged variables, the number of lags, in seconds and minutes is included to show how far back the impact is extended.

Table 26. UFP NE Lagged Log Linear Model

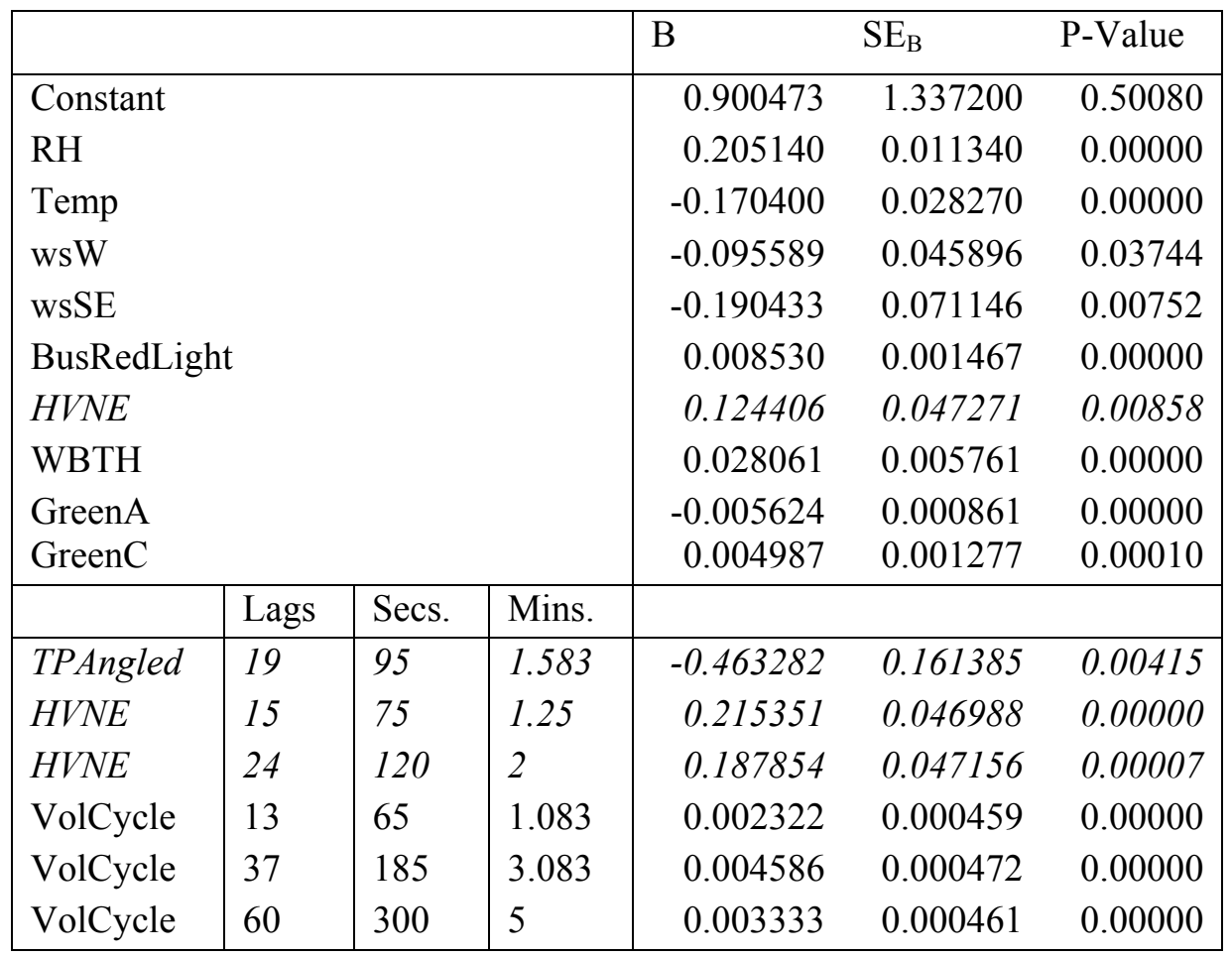


Temperature, heavy vehicle presence on the NE corner and westbound through volumes became significant in the lagged model, where they were not included in the original model. The signs of the regression coefficients between the two models are consistent.

The following Table 27 is a summary table of the \% change in UFP NE per unit change in predictor, $\%$ change in UFP NE per $1 \%$ change in predictor and the $\%$ average contribution to the baseline condition, including the lagged variables.

Table 27. UFP NE Lagged Log Linear Model Interpretation

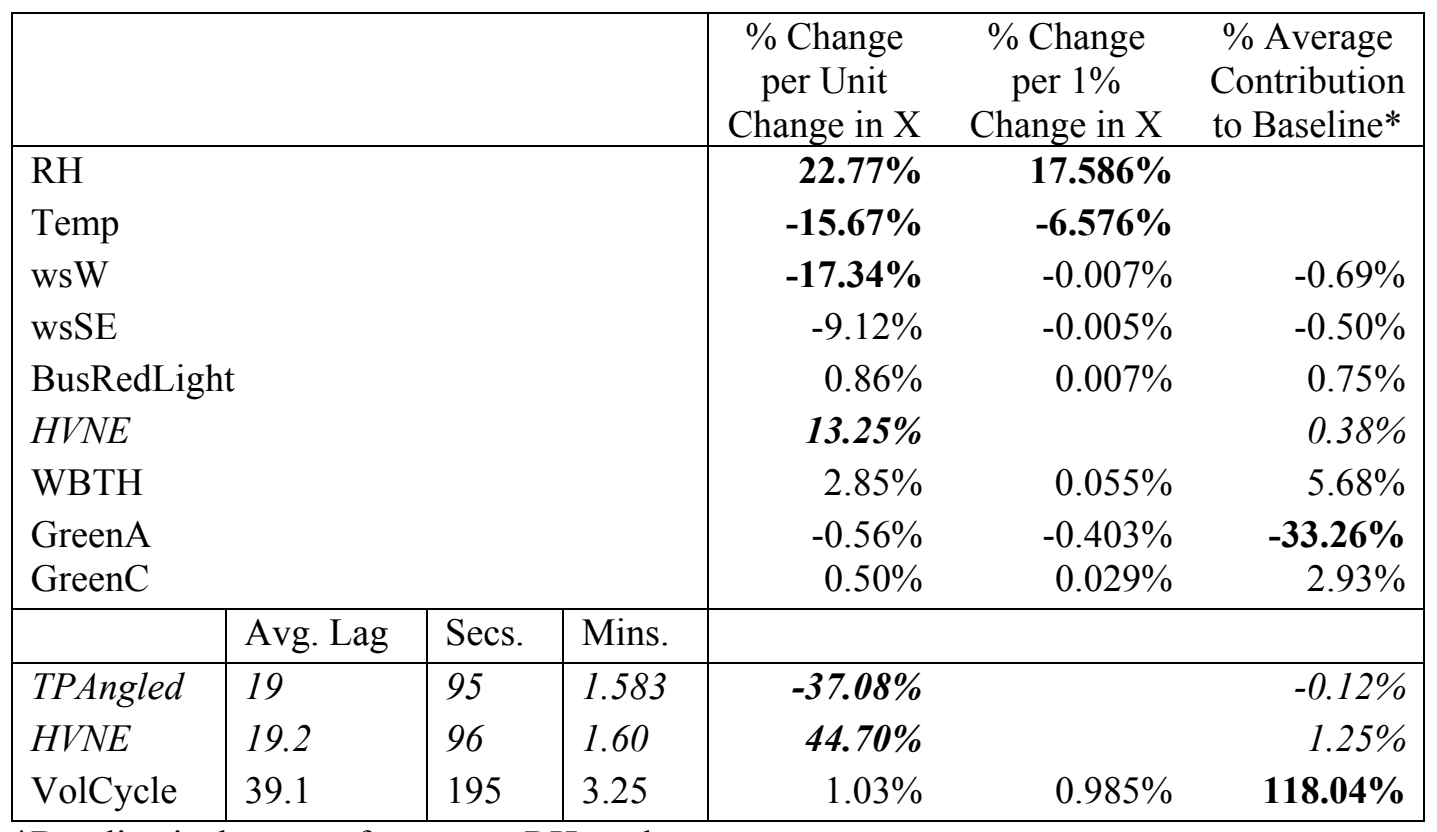

*Baseline is the sum of constant, RH, and temp

In terms of the lagged effect, bus presence that occurred a minute and half beforehand for a bus with an angled tailpipe reduces UFP levels by $38 \%$ compared to a backwards oriented tailpipe. Heavy vehicle presence on the NE corner a minute and a half earlier on average increased UFP by $45 \%$. For every additional volume per cycle three minutes earlier, there is an increase in UFP levels of $1 \%$. The bus and heavy vehicle related 
lagged variables have less than a $1 \%$ average contribution compared to the baseline, whereas volume per cycle contributes $120 \%$, having a much larger impact on UFP at the NE corner.

The model results for $\mathrm{PM}_{2.5}$ at the $\mathrm{NE}$ corner including lagged traffic variables is shown in Table 28. This table includes the regression coefficients, standard errors, and p-values for each predictor. For the lagged variables, the number of lags, in seconds and minutes is included to show how far back the impact is extended.

Table 28. $\mathrm{PM}_{2.5}$ NE Lagged Log Linear Model

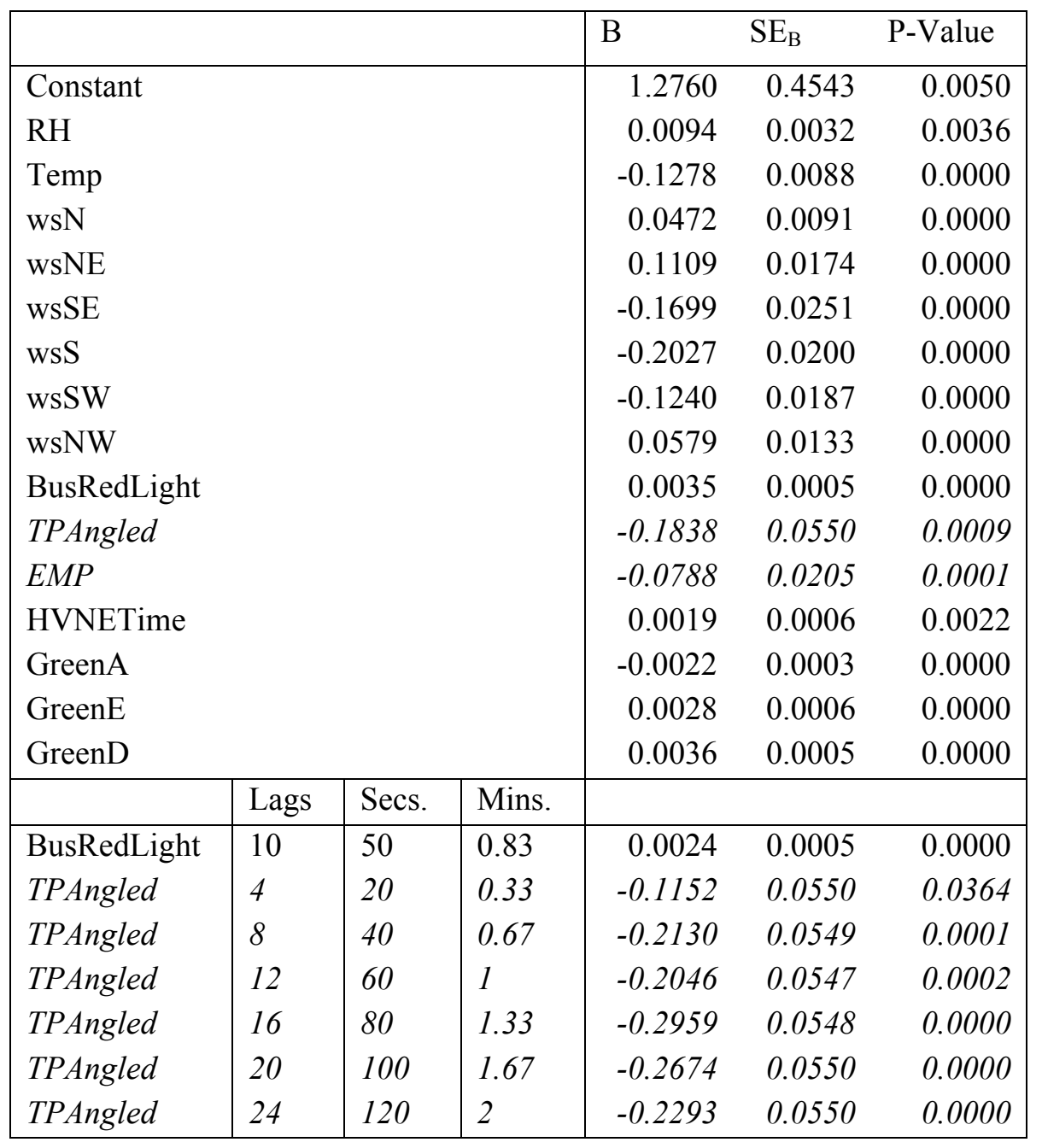




\begin{tabular}{|l|l|l|l|rll|}
\hline & Lags & Secs. & Mins. & & & \\
\hline EMP & 15 & 75 & 1.25 & -0.0764 & 0.0205 & 0.0002 \\
$H V N E$ & 18 & 90 & 1.5 & 0.0491 & 0.0163 & 0.0027 \\
$H V N E$ & 24 & 120 & 2 & 0.0677 & 0.0165 & 0.0000 \\
HVNETime & 3 & 15 & 0.25 & 0.0014 & 0.0006 & 0.0268 \\
HVNETime & 10 & 50 & 0.833 & 0.0011 & 0.0005 & 0.0442 \\
EBTH & 12 & 60 & 1 & 0.0183 & 0.0038 & 0.0000 \\
WBTH & 5 & 25 & 0.417 & -0.0064 & 0.0025 & 0.0105 \\
WBTH & 9 & 45 & 0.75 & -0.0093 & 0.0028 & 0.0008 \\
WBTH & 11 & 55 & 0.917 & -0.0112 & 0.0031 & 0.0004 \\
WBTH & 13 & 65 & 1.083 & -0.0104 & 0.0031 & 0.0009 \\
WBTH & 15 & 75 & 1.25 & -0.0105 & 0.0031 & 0.0006 \\
WBTH & 17 & 85 & 1.417 & -0.0071 & 0.0028 & 0.0132 \\
WBTH & 20 & 100 & 1.67 & -0.0075 & 0.0026 & 0.0034 \\
WBTH & 24 & 120 & 2 & -0.0122 & 0.0025 & 0.0000 \\
\hline
\end{tabular}

Bus tailpipe orientation, bus EMP engine cooling system, and heavy vehicle idling time at the NE corner became significant in the lagged model, where they were not included in the original model. The signs of the regression coefficients between the two models are consistent.

The following Table 29 is a summary table of the \% change in $\mathrm{PM}_{2.5} \mathrm{NE}$ per unit change in predictor, \% change in $\mathrm{PM}_{2.5} \mathrm{NE}$ per $1 \%$ change in predictor and the $\%$ average contribution to the baseline condition. 
Table 29. $\mathrm{PM}_{2.5}$ NE Lagged Log Linear Model Interpretation

\begin{tabular}{|c|c|c|c|c|c|c|}
\hline & & & & $\begin{array}{c}\text { \% Change } \\
\text { per Unit } \\
\text { Change in } \mathrm{X} \\
\end{array}$ & $\begin{array}{c}\% \text { Change } \\
\text { per } 1 \% \\
\text { Change in } \mathrm{X} \\
\end{array}$ & $\begin{array}{l}\text { \% Average } \\
\text { Contribution } \\
\text { to Baseline* }\end{array}$ \\
\hline RH & & & & $0.94 \%$ & $0.741 \%$ & \\
\hline Temp & & & & $-12.00 \%$ & $-4.975 \%$ & \\
\hline wsN & & & & $4.83 \%$ & $0.008 \%$ & $0.79 \%$ \\
\hline wsNE & & & & $11.72 \%$ & $0.006 \%$ & $0.58 \%$ \\
\hline wsSE & & & & $-15.62 \%$ & $-0.006 \%$ & $-0.61 \%$ \\
\hline wsS & & & & $-18.35 \%$ & $-0.013 \%$ & $-1.34 \%$ \\
\hline wsSW & & & & $-11.66 \%$ & $-0.006 \%$ & $-0.62 \%$ \\
\hline wsNW & & & & $5.96 \%$ & $0.004 \%$ & $0.42 \%$ \\
\hline BusRedLight & & & & $0.35 \%$ & $0.003 \%$ & $0.30 \%$ \\
\hline TPAngled & & & & $-16.79 \%$ & & $-0.05 \%$ \\
\hline$E M P$ & & & & $-7.57 \%$ & & $-0.16 \%$ \\
\hline HVNETime & & & & $0.19 \%$ & $0.002 \%$ & $0.17 \%$ \\
\hline GreenA & & & & $-0.22 \%$ & $-0.155 \%$ & $-14.34 \%$ \\
\hline GreenE & & & & $0.28 \%$ & $0.005 \%$ & $0.52 \%$ \\
\hline GreenD & & & & $0.36 \%$ & $0.105 \%$ & $11.07 \%$ \\
\hline & Avg. Lag & Secs. & Mins. & & & \\
\hline BusRedLight & 10 & 50 & 0.83 & $0.24 \%$ & $0.002 \%$ & $0.22 \%$ \\
\hline TPAngled & 15.2 & 76 & 1.27 & $-118.14 \%$ & & $-0.34 \%$ \\
\hline$E M P$ & 15 & 75 & 1.25 & $-7.35 \%$ & & $-0.16 \%$ \\
\hline$H V N E$ & 21.5 & 107 & 1.79 & $12.03 \%$ & & $0.36 \%$ \\
\hline HVNETime & 6.1 & 30 & 0.51 & $0.24 \%$ & $0.002 \%$ & $0.22 \%$ \\
\hline EBTH & 12 & 60 & 1 & $1.85 \%$ & $0.023 \%$ & $2.32 \%$ \\
\hline WBTH & 14.7 & 73 & 1.22 & $-7.43 \%$ & $-0.147 \%$ & $-14.60 \%$ \\
\hline
\end{tabular}

*Baseline is the sum of constant, $\mathrm{RH}$, and temp

In terms of the lagged effect, longer bus red light time that occurred in the previous minute increases $\mathrm{PM}_{2.5}$ levels by $0.24 \%$. About one minute previously, buses present with an angled tailpipe reduced $\mathrm{PM}_{2.5}$ levels by $120 \%$ compared to a backwards oriented tailpipe. Heavy vehicle presence on the NE corner two minutes earlier increases $\mathrm{PM}_{2.5}$ by $12 \%$. More heavy vehicle idling time half a minute earlier increases $\mathrm{PM}_{2.5}$ by $0.24 \%$. Eastbound through volume on Powell from a minute before increases pollutant levels, while westbound through volume on Powell a minute earlier decreases pollutant levels. 
All lagged variables have less than a 3\% average contribution relative to the baseline, except for westbound through volumes, which is almost a $15 \%$ reduction.

The model results for $\mathrm{CO}$ at the $\mathrm{NE}$ corner including lagged traffic variables is shown in Table 30. This table includes the regression coefficients, standard errors, and p-values for each predictor. For the lagged variables, the number of lags, in seconds and minutes is included to show how far back the impact is extended.

Table 30. CO NE Lagged Log Linear Model

\begin{tabular}{|c|c|c|c|c|c|c|}
\hline \multicolumn{4}{|l|}{ 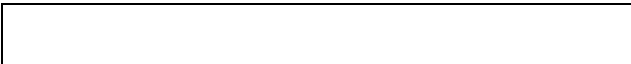 } & B & $\mathrm{SE}_{\mathrm{B}}$ & P-Value \\
\hline \multicolumn{4}{|l|}{ Constant } & -16.9100 & 0.8136 & 0.0000 \\
\hline \multicolumn{4}{|l|}{ RH } & 0.2044 & 0.0106 & 0.0000 \\
\hline \multicolumn{4}{|l|}{ wsW } & -0.0873 & 0.0425 & 0.0403 \\
\hline \multicolumn{4}{|l|}{ wsSW } & -0.2287 & 0.0479 & 0.0000 \\
\hline \multicolumn{4}{|l|}{ wsS } & -0.4521 & 0.0497 & 0.0000 \\
\hline \multicolumn{4}{|l|}{ wsSE } & -0.5497 & 0.0665 & 0.0000 \\
\hline \multicolumn{4}{|l|}{ TPAngled } & -0.8115 & 0.1507 & 0.0000 \\
\hline \multicolumn{4}{|l|}{$D P F$} & -0.0969 & 0.0358 & 0.0068 \\
\hline \multicolumn{4}{|l|}{ HVNETime } & 0.0081 & 0.0014 & 0.0000 \\
\hline \multicolumn{4}{|l|}{ GreenA } & -0.0080 & 0.0008 & 0.0000 \\
\hline \multicolumn{4}{|l|}{ GreenF } & -0.0067 & 0.0012 & 0.0000 \\
\hline \multicolumn{4}{|l|}{ VolCycle } & 0.0020 & 0.0005 & 0.0000 \\
\hline & Lags & Secs. & Mins. & & & \\
\hline BusNE & 24 & 120 & 2 & 0.1525 & 0.0284 & 0.0000 \\
\hline TPAngled & 4 & 20 & 0.33 & -0.8944 & 0.1471 & 0.0000 \\
\hline TPAngled & 17 & 85 & 1.417 & -0.4927 & 0.1478 & 0.0009 \\
\hline TPAngled & 21 & 105 & 1.75 & -0.3846 & 0.1508 & 0.0108 \\
\hline HVNETime & 6 & 30 & 0.5 & 0.0067 & 0.0014 & 0.0000 \\
\hline EBTH & 24 & 120 & 2 & 0.0202 & 0.0076 & 0.0077 \\
\hline NBTH & 5 & 25 & 0.417 & -0.1598 & 0.0439 & 0.0003 \\
\hline NBTH & 12 & 60 & 1 & -0.2360 & 0.0462 & 0.0000 \\
\hline VolCycle & 15 & 75 & 1.25 & 0.0044 & 0.0005 & 0.0000 \\
\hline VolCycle & 34 & 170 & 2.83 & 0.0026 & 0.0007 & 0.0006 \\
\hline VolCycle & 39 & 195 & 3.25 & 0.0038 & 0.0007 & 0.0000 \\
\hline VolCycle & 60 & 300 & 5 & 0.0010 & 0.0004 & 0.0292 \\
\hline
\end{tabular}


Bus tailpipe orientation, bus DPF particulate filter, and heavy vehicle idling time at the NE corner became significant in the lagged model, where they were not included in the original model. The signs of the regression coefficients between the two models are consistent.

The following Table 31 is a summary table of the \% change in CO NE per unit change in predictor, $\%$ change in $\mathrm{CO} \mathrm{NE}$ per $1 \%$ change in predictor and the $\%$ average contribution to the baseline condition.

Table 31. CO NE Lagged Log Linear Model Interpretation

\begin{tabular}{|c|c|c|c|c|c|c|}
\hline & & & & $\begin{array}{c}\% \text { Change } \\
\text { per Unit } \\
\text { Change in } \mathrm{X}\end{array}$ & $\begin{array}{c}\% \text { Change } \\
\text { per } 1 \% \\
\text { Change in } \mathrm{X}\end{array}$ & $\begin{array}{l}\% \text { Average } \\
\text { Contribution } \\
\text { to Baseline* }\end{array}$ \\
\hline \multicolumn{4}{|l|}{$\mathrm{RH}$} & $22.68 \%$ & $17.518 \%$ & \\
\hline \multicolumn{4}{|l|}{ wsW } & $-8.36 \%$ & $-0.005 \%$ & $-0.46 \%$ \\
\hline \multicolumn{4}{|l|}{ wsSW } & $-20.44 \%$ & $-0.012 \%$ & $-1.14 \%$ \\
\hline \multicolumn{4}{|l|}{ wsS } & $-36.37 \%$ & $-0.030 \%$ & $-2.96 \%$ \\
\hline \multicolumn{4}{|l|}{ wsSE } & $-42.29 \%$ & $-0.020 \%$ & $-1.97 \%$ \\
\hline \multicolumn{4}{|l|}{ TPAngled } & $-55.58 \%$ & & $-0.21 \%$ \\
\hline \multicolumn{4}{|l|}{$D P F$} & $-9.24 \%$ & & $-0.47 \%$ \\
\hline \multicolumn{4}{|l|}{ HVNETime } & $0.82 \%$ & $0.007 \%$ & $0.73 \%$ \\
\hline \multicolumn{4}{|l|}{ GreenA } & $-0.80 \%$ & $-0.576 \%$ & $-43.85 \%$ \\
\hline \multicolumn{4}{|l|}{ GreenF } & $-0.66 \%$ & $-0.044 \%$ & $-4.31 \%$ \\
\hline \multicolumn{4}{|l|}{ VolCycle } & $0.20 \%$ & $0.196 \%$ & $21.67 \%$ \\
\hline & Avg. Lag & Secs. & Mins. & & & \\
\hline BusNE & 24 & 120 & 2 & $16.47 \%$ & & $1.15 \%$ \\
\hline TPAngled & 11.3 & 57 & 0.94 & $-129.94 \%$ & & $-0.45 \%$ \\
\hline HVNETime & 6 & 30 & 0.5 & $0.67 \%$ & $0.006 \%$ & $0.61 \%$ \\
\hline EBTH & 24 & 120 & 2 & $2.04 \%$ & $0.025 \%$ & $2.53 \%$ \\
\hline NBTH & 9.2 & 46 & 0.76 & $-35.79 \%$ & $-0.030 \%$ & $-2.96 \%$ \\
\hline VolCycle & 30.6 & 153 & 2.55 & $1.18 \%$ & $1.132 \%$ & $134.82 \%$ \\
\hline
\end{tabular}

*Baseline is the sum of constant, $\mathrm{RH}$, and temp 
In terms of the lagged effect, bus presence occurring two minutes prior increases $\mathrm{CO}$ levels by $16.5 \%$. One minute earlier, buses present with an angled tailpipe reduced CO levels by $130 \%$ compared to a backwards oriented tailpipe. More heavy vehicle idling time half a minute earlier increases $\mathrm{CO}$ by $0.7 \%$. Eastbound through volume on Powell two minutes before increases $\mathrm{CO}$ by $2 \%$, while northbound volume on $26^{\text {th }}$ for minute to a minute decreases $\mathrm{CO}$ from $36 \%$. With increased volumes per cycle two and a half minutes previous, there is an increase in CO levels of 1.2\%. Lagged volume per cycle had the largest $\%$ average contribution relative to the baseline, and was the only one over $3 \%$, with $135 \%$.

The model results for $\mathrm{CO}_{2}$ at the NE corner including lagged traffic variables is shown in Table 32. This table includes the regression coefficients, standard errors, and p-values for each predictor. For the lagged variables, the number of lags, in seconds and minutes is included to show how far back the impact is extended. 
Table 32. $\mathrm{CO}_{2} \mathrm{NE}$ Lagged Log Linear Model

\begin{tabular}{|c|c|c|c|c|c|c|}
\hline \multicolumn{4}{|l|}{ 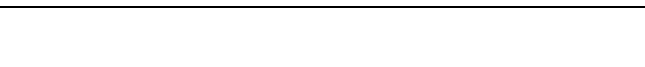 } & B & $\mathrm{SE}_{\mathrm{B}}$ & P-Value \\
\hline \multicolumn{4}{|l|}{ Constant } & -3.716358 & 0.358272 & 0.00000 \\
\hline \multicolumn{4}{|l|}{ RH } & 0.093499 & 0.004669 & 0.00000 \\
\hline \multicolumn{4}{|l|}{ wsS } & -0.079787 & 0.022166 & 0.00033 \\
\hline \multicolumn{4}{|l|}{ wsSE } & -0.060489 & 0.029558 & 0.04089 \\
\hline \multicolumn{4}{|l|}{$H V N E$} & 0.100968 & 0.019811 & 0.00000 \\
\hline \multicolumn{4}{|l|}{ GreenA } & -0.003505 & 0.000364 & 0.00000 \\
\hline \multicolumn{4}{|l|}{ GreenE } & -0.001613 & 0.000789 & 0.04100 \\
\hline \multicolumn{4}{|l|}{ GreenF } & -0.002706 & 0.000543 & 0.00000 \\
\hline \multicolumn{4}{|l|}{ VolCycle } & 0.000597 & 0.000219 & 0.00655 \\
\hline & Lags & Secs. & Mins. & & & \\
\hline BusRedLight & 16 & 80 & 1.33 & 0.001914 & 0.000650 & 0.00329 \\
\hline BusRedLight & 24 & 120 & 2 & 0.002030 & 0.000649 & 0.00179 \\
\hline$E M P$ & 24 & 120 & 2 & 0.077126 & 0.023814 & 0.00123 \\
\hline HVNETime & 5 & 25 & 0.417 & 0.002383 & 0.000695 & 0.00062 \\
\hline HVNETime & 9 & 45 & 0.75 & 0.001845 & 0.000685 & 0.00716 \\
\hline ЕВТН & 15 & 75 & 1.25 & 0.010008 & 0.003307 & 0.00250 \\
\hline NBTH & 8 & 40 & 0.67 & -0.072583 & 0.019901 & 0.00027 \\
\hline VolCycle & 13 & 65 & 1.083 & 0.000983 & 0.000220 & 0.00001 \\
\hline VolCycle & 37 & 185 & 3.083 & 0.001793 & 0.000251 & 0.00000 \\
\hline VolCycle & 46 & 230 & 3.83 & 0.000537 & 0.000247 & 0.02962 \\
\hline
\end{tabular}

No additional predictors became significant in the lagged model that were not already included in the original model. The signs of the regression coefficients between the two models are consistent.

The following Table 33 is a summary table of the $\%$ change in $\mathrm{CO}_{2} \mathrm{NE}$ per unit change in predictor, \% change in $\mathrm{CO}_{2} \mathrm{NE}$ per $1 \%$ change in predictor and the $\%$ average contribution to the baseline condition. 
Table 33. $\mathrm{CO}_{2} \mathrm{NE}$ Lagged Log Linear Model Interpretation

\begin{tabular}{|c|c|c|c|c|c|c|}
\hline & & & & $\begin{array}{l}\text { \% Change per } \\
\text { Unit Change } \\
\text { in X }\end{array}$ & $\begin{array}{c}\% \text { Change } \\
\text { per } 1 \% \\
\text { Change in } \mathrm{X}\end{array}$ & $\begin{array}{l}\% \text { Average } \\
\text { Contribution } \\
\text { to Baseline* }\end{array}$ \\
\hline RH & & & & $9.80 \%$ & $7.663 \%$ & \\
\hline wsS & & & & $-7.67 \%$ & $-0.005 \%$ & $-0.53 \%$ \\
\hline wsSE & & & & $-5.87 \%$ & $-0.002 \%$ & $-0.22 \%$ \\
\hline HVNE & & & & $10.62 \%$ & & $0.31 \%$ \\
\hline GreenA & & & & $-0.35 \%$ & $-0.252 \%$ & $-22.28 \%$ \\
\hline GreenE & & & & $-0.16 \%$ & $-0.003 \%$ & $-0.30 \%$ \\
\hline GreenF & & & & $-0.27 \%$ & $-0.018 \%$ & $-1.78 \%$ \\
\hline VolCycle & & & & $0.06 \%$ & $0.058 \%$ & $5.93 \%$ \\
\hline & Avg. Lag & Secs. & Mins. & & & \\
\hline BusRedLight & 20.1 & 101 & 1.68 & $0.39 \%$ & $0.004 \%$ & $0.35 \%$ \\
\hline$E M P$ & 24 & 120 & 2 & $8.02 \%$ & & $0.16 \%$ \\
\hline HVNETime & 6.8 & 34 & 0.56 & $0.42 \%$ & $0.004 \%$ & $0.38 \%$ \\
\hline EBTH & 15 & 75 & 1.25 & $1.01 \%$ & $0.012 \%$ & $1.26 \%$ \\
\hline NBTH & 8 & 40 & 0.67 & $-7.00 \%$ & $-0.006 \%$ & $-0.55 \%$ \\
\hline VolCycle & 31.3 & 157 & 2.61 & $0.33 \%$ & $0.318 \%$ & $33.99 \%$ \\
\hline
\end{tabular}

*Baseline is the sum of constant, RH, and temp

In terms of the lagged effect, bus red light time a minute and a half prior increases $\mathrm{CO}_{2}$ levels by $0.4 \%$ per second. Buses from two minutes ago with an EMP engine cooling system reduce $\mathrm{CO}_{2}$ levels by $8 \%$. More heavy vehicle idling time half a minute earlier increases $\mathrm{CO}_{2}$ by $0.4 \%$. Eastbound through volume on Powell a little over a minute before increases $\mathrm{CO}_{2}$ by $1 \%$, while northbound volume on $26^{\text {th }}$ less than a minute before decreases $\mathrm{CO}_{2}$ from 7\%. With increased volumes per cycle two and a half minutes previously, there is an increase in $\mathrm{CO}_{2}$ levels of $0.33 \%$. The largest mean contribution was from lagging volume per cycle, with an overall contribution of $34 \%$.

The model results for UFP at the NW corner including lagged traffic variables is shown in Table 34. This table includes the regression coefficients, standard errors, and p-values 
for each predictor. For the lagged variables, the number of lags, in seconds and minutes is included to show how far back the impact is extended.

Table 34. UFP NW Lagged Log Linear Model

\begin{tabular}{|c|c|c|c|c|c|c|}
\hline \multicolumn{4}{|l|}{ 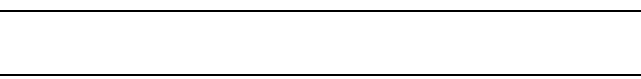 } & B & $\mathrm{SE}_{\mathrm{B}}$ & P-Value \\
\hline & 1.1618 & 1.0990 & 0.2906 \\
\hline & 0.1242 & 0.0142 & 0.0000 \\
\hline \multicolumn{4}{|l|}{ wsNE } & 0.1874 & 0.0593 & 0.0016 \\
\hline \multicolumn{4}{|l|}{ wsN } & 0.0937 & 0.0299 & 0.0018 \\
\hline \multicolumn{4}{|l|}{ wsSW } & -0.3533 & 0.0673 & 0.0000 \\
\hline \multicolumn{4}{|l|}{ wsS } & -0.5144 & 0.0703 & 0.0000 \\
\hline \multicolumn{4}{|l|}{ wsSE } & -0.4133 & 0.0918 & 0.0000 \\
\hline \multicolumn{4}{|l|}{$H V N W$} & 0.1271 & 0.0217 & 0.0000 \\
\hline \multicolumn{4}{|l|}{ GreenA } & -0.0047 & 0.0011 & 0.0000 \\
\hline \multicolumn{4}{|l|}{ GreenD } & 0.0077 & 0.0019 & 0.0001 \\
\hline \multicolumn{4}{|l|}{ GreenE } & 0.0089 & 0.0024 & 0.0002 \\
\hline \multicolumn{4}{|l|}{ GreenF } & 0.0047 & 0.0016 & 0.0030 \\
\hline \multicolumn{4}{|l|}{ VolCycle } & 0.0011 & 0.0006 & 0.0584 \\
\hline & Lags & Secs. & Mins. & & & \\
\hline BusRedLight & 24 & 120 & 2.00 & 0.0037 & 0.0017 & 0.0360 \\
\hline EBTH & 9 & 45 & 0.75 & 0.0397 & 0.0131 & 0.0024 \\
\hline EBTH & 18 & 90 & 1.50 & 0.0367 & 0.0129 & 0.0046 \\
\hline EBTH & 24 & 120 & 2.00 & 0.0292 & 0.0143 & 0.0413 \\
\hline WBTH & 9 & 45 & 0.75 & -0.0302 & 0.0099 & 0.0023 \\
\hline WBTH & 12 & 60 & 1.00 & -0.0312 & 0.0090 & 0.0005 \\
\hline WBTH & 15 & 75 & 1.25 & -0.0359 & 0.0092 & 0.0001 \\
\hline WBTH & 19 & 95 & 1.58 & -0.0412 & 0.0099 & 0.0000 \\
\hline WBTH & 22 & 110 & 1.83 & -0.0270 & 0.0101 & 0.0076 \\
\hline WBTH & 24 & 120 & 2.00 & -0.0470 & 0.0116 & 0.0001 \\
\hline
\end{tabular}

No additional predictors became significant in the lagged model that were not already included in the original model. The signs of the regression coefficients between the two models are consistent. 
The following Table 35 is a summary table of the \% change in UFP NW per unit change in predictor, $\%$ change in UFP NW per $1 \%$ change in predictor and the $\%$ average contribution to the baseline condition.

Table 35. UFP NW Lagged Log Linear Model Interpretation

\begin{tabular}{|c|c|c|c|c|c|c|}
\hline & & & & $\begin{array}{c}\text { \% Change per } \\
\text { Unit Change } \\
\text { in X }\end{array}$ & $\begin{array}{c}\% \text { Change per } \\
1 \% \text { Change in } \\
X\end{array}$ & $\begin{array}{l}\text { \% Average } \\
\text { Contribution } \\
\text { to Baseline* }\end{array}$ \\
\hline \multicolumn{4}{|l|}{$\mathrm{RH}$} & $13.22 \%$ & $10.304 \%$ & \\
\hline \multicolumn{4}{|l|}{ wsNE } & $20.61 \%$ & $0.010 \%$ & $0.99 \%$ \\
\hline \multicolumn{4}{|l|}{$\mathrm{wsN}$} & $9.82 \%$ & $0.016 \%$ & $1.57 \%$ \\
\hline \multicolumn{4}{|l|}{ wsSW } & $-29.77 \%$ & $-0.018 \%$ & $-1.76 \%$ \\
\hline \multicolumn{4}{|l|}{ wsS } & $-40.22 \%$ & $-0.034 \%$ & $-3.36 \%$ \\
\hline \multicolumn{4}{|l|}{ wsSE } & $-33.85 \%$ & $-0.015 \%$ & $-1.48 \%$ \\
\hline \multicolumn{4}{|l|}{$H V N W$} & $13.55 \%$ & & $5.19 \%$ \\
\hline \multicolumn{4}{|l|}{ GreenA } & $-0.47 \%$ & $-0.338 \%$ & $-28.70 \%$ \\
\hline \multicolumn{4}{|l|}{ GreenD } & $0.77 \%$ & $0.226 \%$ & $25.39 \%$ \\
\hline \multicolumn{4}{|l|}{ GreenE } & $0.90 \%$ & $0.016 \%$ & $1.66 \%$ \\
\hline \multicolumn{4}{|l|}{ GreenF } & $0.48 \%$ & $0.031 \%$ & $3.19 \%$ \\
\hline \multicolumn{4}{|l|}{ VolCycle } & $0.11 \%$ & $0.107 \%$ & $11.24 \%$ \\
\hline & Lags & Secs. & Mins. & & & \\
\hline BusRedLight & 24 & 120 & 2.00 & $0.37 \%$ & $0.003 \%$ & $0.33 \%$ \\
\hline ЕВTH & 16.3 & 81.4 & 1.36 & $10.75 \%$ & $0.131 \%$ & $13.41 \%$ \\
\hline WBTH & 17.4 & 86.8 & 1.45 & $-20.87 \%$ & $-0.419 \%$ & $-40.45 \%$ \\
\hline
\end{tabular}

*Baseline is the sum of constant, $\mathrm{RH}$, and temp

In terms of the lagged effect, every additional second that the bus was waiting at a red light two minutes earlier adds $0.4 \%$ to UFP at the NW corner. Each additional eastbound through vehicle per five second period adds $11 \%$ to UFP a minute and a half earlier, whereas westbound though traffic is a $21 \%$ decrease. Additional vehicles up to two minutes earlier for the westbound through movements reduces UFP at the NW corner, most likely due to the reaction from the traffic signal to higher volumes, by allocating more time on Powell Boulevard. The largest average contributions are from eastbound and westbound lagged traffic. 
The model results for $\mathrm{PM}_{2.5}$ at the NW corner including lagged traffic variables is shown in Table 36. This table includes the regression coefficients, standard errors, and p-values for each predictor. For the lagged variables, the number of lags, in seconds and minutes is included to show how far back the impact is extended.

Table 36. PM $_{2.5}$ NW Lagged Log Linear Model

\begin{tabular}{|c|c|c|c|c|c|c|}
\hline \multicolumn{4}{|l|}{ 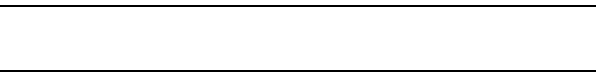 } & B & $\mathrm{SE}_{\mathrm{B}}$ & P-Value \\
\hline \multicolumn{4}{|l|}{ Constant } & 8.9669 & 0.6068 & 0.0000 \\
\hline \multicolumn{4}{|l|}{ RH } & 0.0289 & 0.0056 & 0.0000 \\
\hline \multicolumn{4}{|l|}{ Temp } & -0.1809 & 0.0135 & 0.0000 \\
\hline \multicolumn{4}{|l|}{ wsN } & 0.0554 & 0.0126 & 0.0000 \\
\hline \multicolumn{4}{|l|}{ wsNE } & 0.0573 & 0.0239 & 0.0167 \\
\hline \multicolumn{4}{|l|}{ wsSE } & -0.1319 & 0.0361 & 0.0003 \\
\hline \multicolumn{4}{|l|}{ wsS } & -0.1430 & 0.0278 & 0.0000 \\
\hline \multicolumn{4}{|l|}{ wsSW } & -0.1050 & 0.0270 & 0.0001 \\
\hline \multicolumn{4}{|l|}{ wsNW } & 0.0622 & 0.0183 & 0.0007 \\
\hline \multicolumn{4}{|c|}{ BusRedLight } & -0.1884 & 0.0753 & 0.0125 \\
\hline \multicolumn{4}{|l|}{ GreenA } & -0.0027 & 0.0004 & 0.0000 \\
\hline \multicolumn{4}{|l|}{ GreenD } & 0.0027 & 0.0007 & 0.0002 \\
\hline & Lags & Secs. & Mins. & & & \\
\hline TPAngled & 4 & 20 & 0.33 & -0.1501 & 0.0755 & 0.0471 \\
\hline TPAngled & 8 & 40 & 0.67 & -0.1793 & 0.0753 & 0.0175 \\
\hline TPAngled & 12 & 60 & 1.00 & -0.1823 & 0.0752 & 0.0155 \\
\hline TPAngled & 16 & 80 & 1.33 & -0.2632 & 0.0751 & 0.0005 \\
\hline TPAngled & 20 & 100 & 1.67 & -0.2732 & 0.0753 & 0.0003 \\
\hline TPAngled & 24 & 120 & 2.00 & -0.2333 & 0.0753 & 0.0020 \\
\hline EBTH & 16 & 80 & 1.33 & 0.0249 & 0.0050 & 0.0000 \\
\hline EBTH & 24 & 120 & 2.00 & 0.0167 & 0.0056 & 0.0028 \\
\hline WBTH & 5 & 25 & 0.42 & -0.0111 & 0.0035 & 0.0016 \\
\hline WBTH & 9 & 45 & 0.75 & -0.0101 & 0.0037 & 0.0060 \\
\hline WBTH & 12 & 60 & 1.00 & -0.0083 & 0.0040 & 0.0387 \\
\hline WBTH & 14 & 70 & 1.17 & -0.0141 & 0.0040 & 0.0004 \\
\hline WBTH & 18 & 90 & 1.50 & -0.0176 & 0.0038 & 0.0000 \\
\hline WBTH & 21 & 105 & 1.75 & -0.0144 & 0.0037 & 0.0001 \\
\hline WBTH & 24 & 120 & 2.00 & -0.0198 & 0.0043 & 0.0000 \\
\hline
\end{tabular}


No additional predictors became significant in the lagged model that were not already included in the original model. The signs of the regression coefficients between the two models are consistent.

The following Table 37 is a summary table of the \% change in $\mathrm{PM}_{2.5} \mathrm{NW}$ per unit change in predictor, \% change in $\mathrm{PM}_{2.5} \mathrm{NW}$ per $1 \%$ change in predictor and the $\%$ average contribution to the baseline condition.

Table 37. $\mathrm{PM}_{2.5}$ NW Lagged Log Linear Model Interpretation

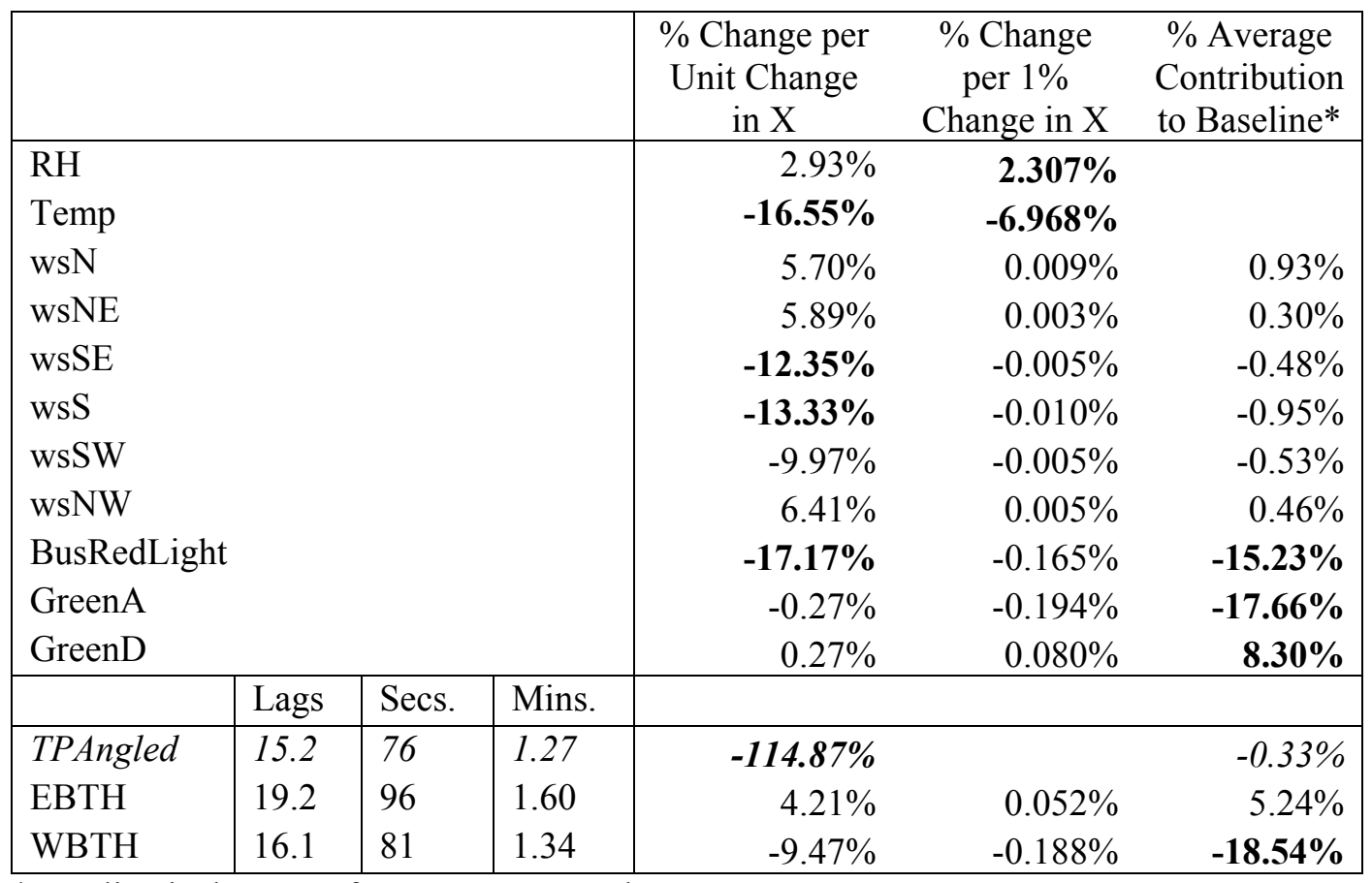

*Baseline is the sum of constant, $\mathrm{RH}$, and temp

In terms of the lagged effect, a minute beforehand when the bus tailpipe is angled during bus presence, $\mathrm{PM}_{2.5}$ at the $\mathrm{NW}$ corner is $115 \%$ lower than other orientations. Additional eastbound through vehicles a minute and a half earlier increases $\mathrm{PM}_{2.5}$ by $4.21 \%$ per vehicle during five seconds, whereas westbound through vehicles decreases by $9.5 \%$. 


\subsection{Time Series Analysis}

It is common with pollution data that the observations are not independent from one another. One of the assumptions of linear regression models is that the residuals are independent. Time series data typically violates this assumption, which is why other types of models are used in these situations. In order to determine if the previous log linear models are sufficient or if time series analysis must be used, the Durbin Watson test was conducted. The Durbin Watson (DW) test determines if there is autocorrelation in the residuals from the model. Durbin Watson values range from zero to four, where positive serial correlation is evident when the value is less than two. The Durbin Watson statistic was calculated for the log linear models previously discussed, as recapped in Table 38. The DW values indicate positive serial correlation.

To confirm this several plots were made. First, the residuals were plotted over time, which examines the trends in the residuals. If there was no autocorrelation, the residuals would appear random. However, as shown in Figure 20, there is a trend in the residuals for the log linear model for UFP at the NE corner and they are not randomly scattered about the line at zero. The remaining residual plots for the log linear models are shown in in Appendix $\mathrm{C}$ in Figure 31. All residual plots demonstrate trends and signs of positive serial correlation. 


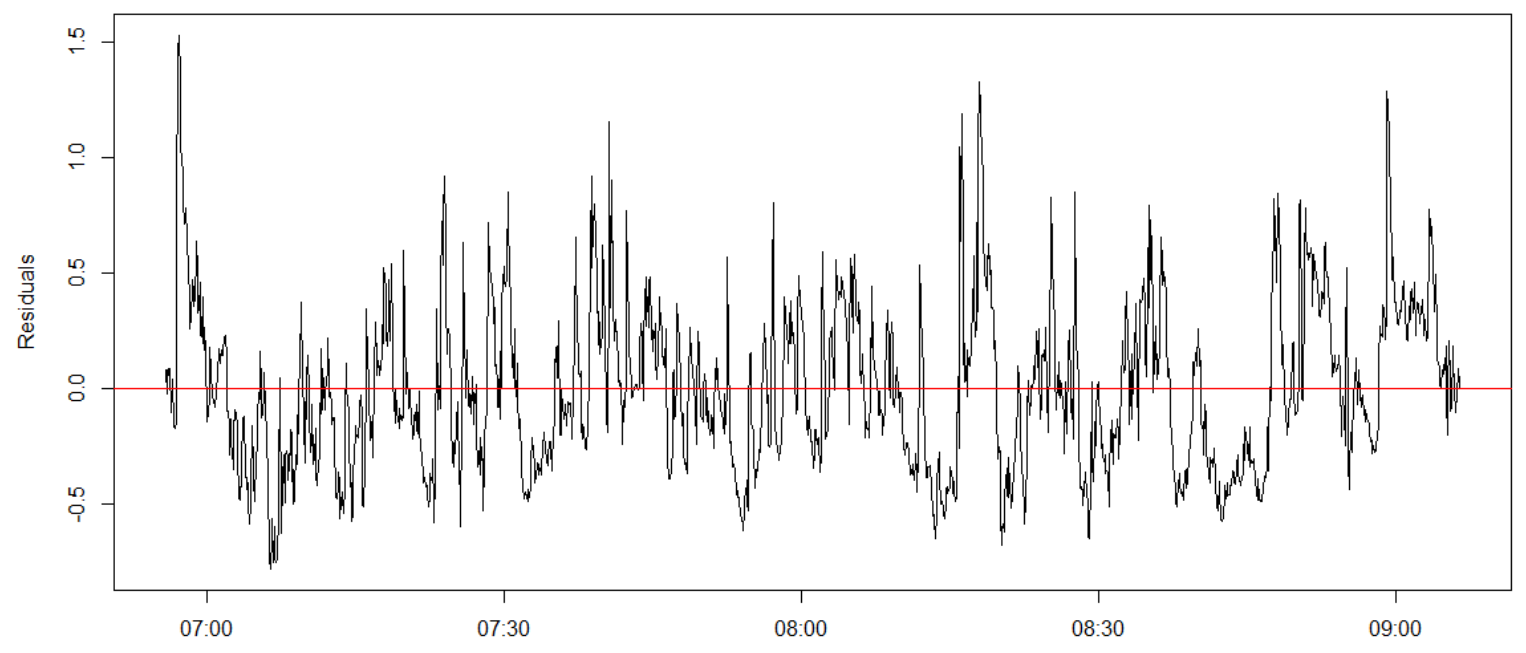

Figure 20. Log Linear Model Residual Plot - UFP NE

Second, lag plots were made to examine the relationship between the measurements and their previous measurement (lag 1). This plot would look shapeless if there was no autocorrelation. In this case, there is a clear positive linear trend as demonstrated in Figure 21 for UFP at the NE corner. The remaining lag plots for the other pollutants are shown in Figure 32 in the Appendix C. All of them exhibit the same trends as the one shown for UFP at the NE corner. 


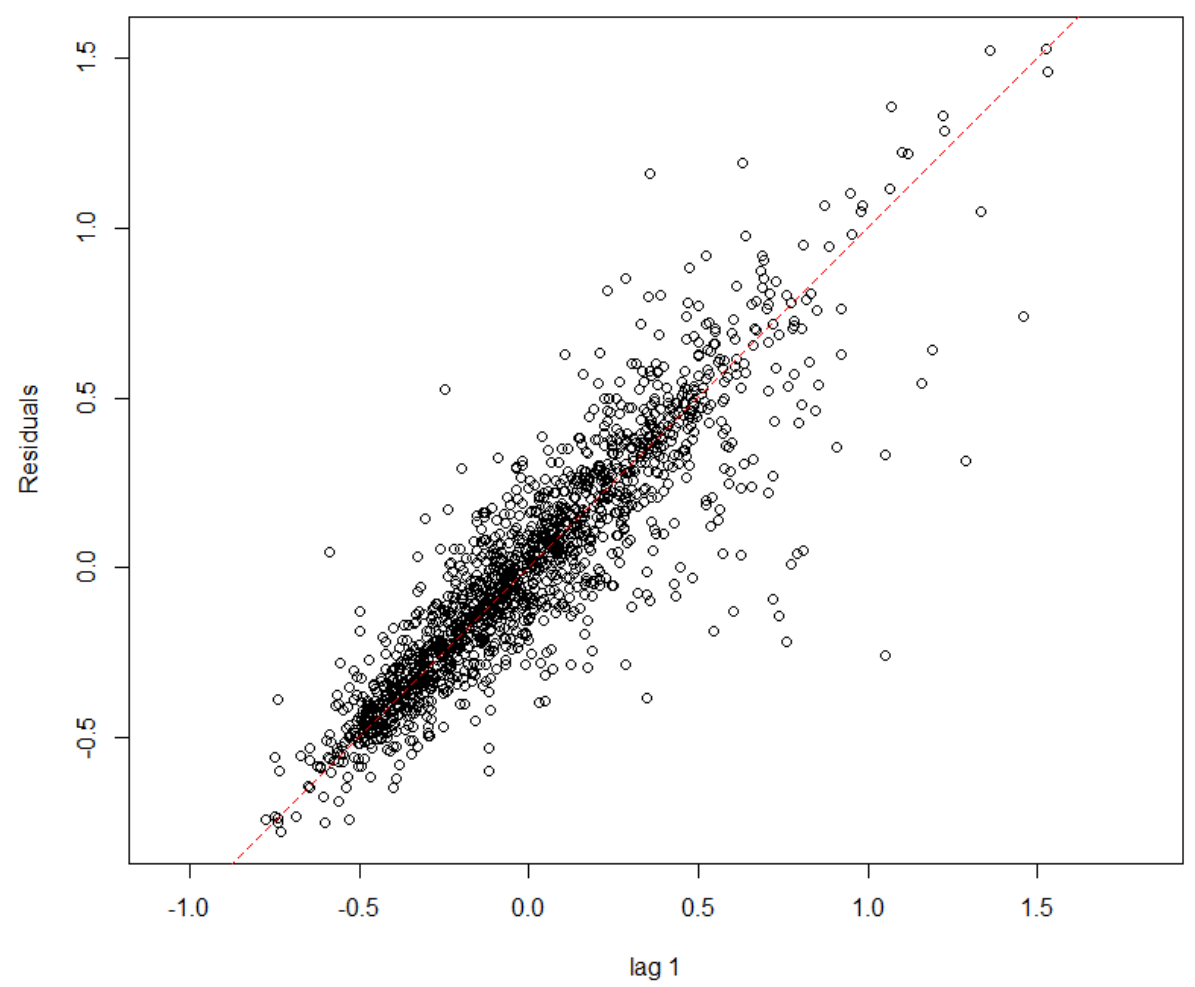

Figure 21. Log Linear Model Lag Plot - UFP NE

Third, the autocorrelation function (acf) and partial autocorrelation function (pacf) were plotted to help determine the best type of model to use.

The autocorrelation function (acf) is defined as:

$\hat{\rho}_{k}=\frac{\sum_{t=1}^{T-k}\left(y_{t}-\bar{y}\right)\left(y_{t+k}-\bar{y}\right)}{\sum_{t=1}^{T}\left(y_{t}-\bar{y}\right)^{2}}($ Equation 4)

Note: Where $\rho$ is the autocorrelation value and $\mathrm{k}$ is number of lags

The partial autocorrelation function (pacf) is defined as the autocorrelation between the current observation and future (k lags) observation that is not accounted for by any of the observations in between these two. It can be written as: 
$\alpha=\operatorname{Cor}\left(y_{t+k}-P_{t, k}\left(y_{t+k}\right), y_{t}-P_{t, k}\left(y_{t}\right)\right)$, for $k \geq 2 \quad$ (Equation 5)

Note: Where $\alpha$ is the partial autocorrelation, $\mathrm{k}$ is the number of lags and $\mathrm{P}$ is the projection

These plots are shown in Figure 22 for UFP at the NE corner, where the ACF plot tails off and the PACF plot cuts off quickly. These plots demonstrate that an AR model should be tested to correct for the autocorrelation. The remaining ACF \& PACF plots are shown the NE Corner in Figure 33 and for the NW Corner in Figure 34 in the Appendix C.
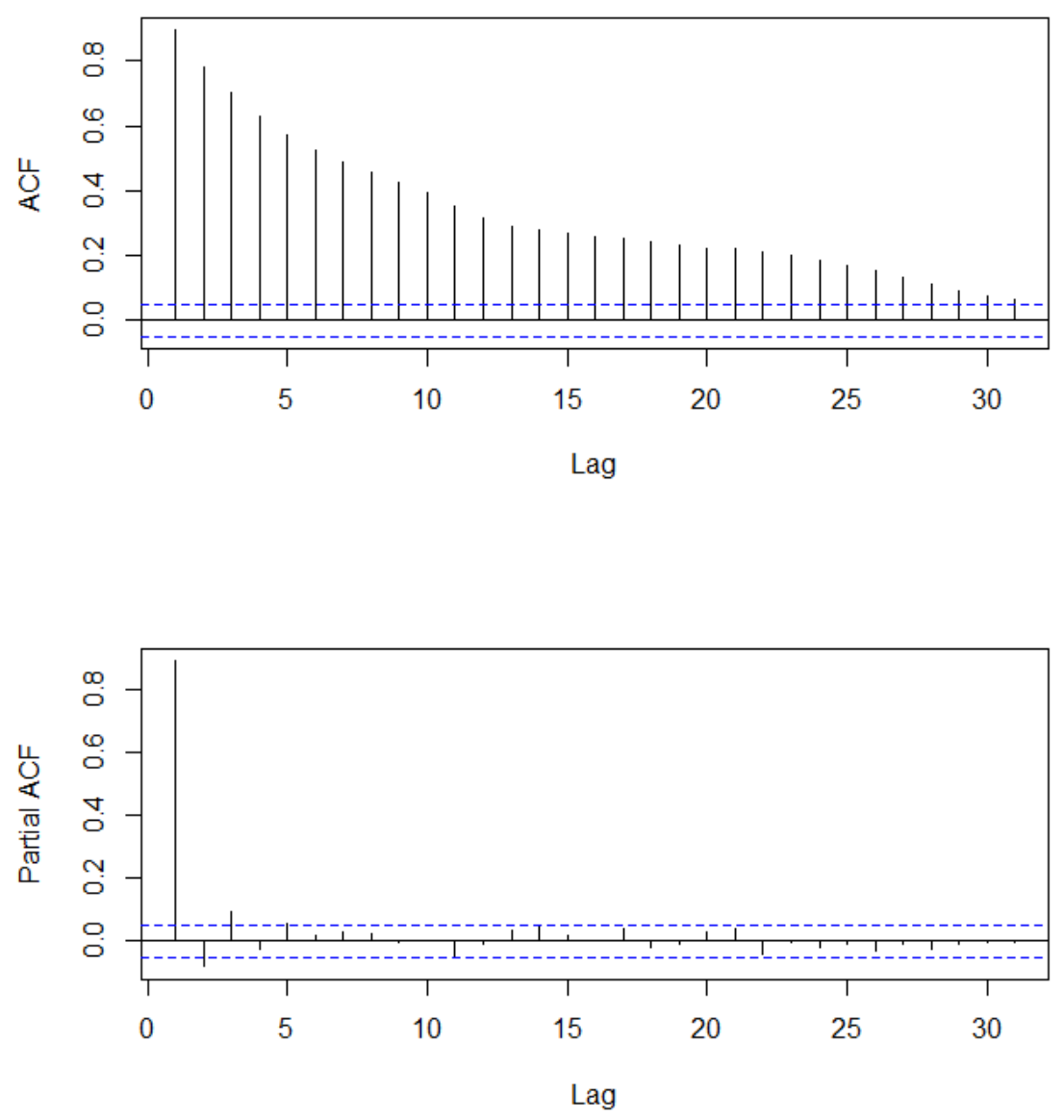

Figure 22. Log Linear Model ACF \& PACF Plots - UFP NE

The Autoregressive Integrated Moving Average (ARIMA) model is the most general form for time series. ARIMA models consist of (p, $d, q$ ) which refers to the order of the 
autoregressive, integrated, and moving average parts, respectively. The model is specified by determining values for $\mathrm{p}, \mathrm{d}$, and $\mathrm{q} . \mathrm{P}$ and $\mathrm{q}$ can be determined from the acf and pacf plots. To determine if differencing (the $\mathrm{d}$ term in the ARIMA model) is needed, the data is tested for stationarity. The Augmented Dickey-Fuller test is used, where it is determined if the unit root is present or not. This indicates if differencing is needed. Table 38, shown below, summarizes the tests and diagnostic plots previously described that were used to specify the ARIMA models for the four pollutants at the NE corner and the two pollutants at the NW corner.

Table 38. Autoregressive Model Specification

\begin{tabular}{|l|c|c|c|c|c|c|}
\hline & \multicolumn{5}{|c|}{ NE Corner } & \multicolumn{2}{c|}{ NW Corner } \\
\hline & UFP & $\mathrm{PM}_{2.5}$ & $\mathrm{CO}$ & $\mathrm{CO}_{2}$ & UFP & $\mathrm{PM}_{2.5}$ \\
\hline DW & 0.213 & 0.643 & 0.134 & 0.225 & 0.371 & 0.582 \\
P-Value & $2.2 \mathrm{e}-16$ & $2.2 \mathrm{e}-16$ & $2.2 \mathrm{e}-16$ & $2.2 \mathrm{e}-16$ & $2.2 \mathrm{e}-16$ & $2.2 \mathrm{e}-16$ \\
Autocorrelated? & $\checkmark$ & $\checkmark$ & $\checkmark$ & $\checkmark$ & $\checkmark$ & $\checkmark$ \\
ACF plot & Tails off & Tails off & Tails off & Tails off & Tails off & Tails off \\
PACF plot & Cuts off & Cuts off & Cuts off & Cuts off & Cuts off & Cuts off \\
Model type & AR & AR & AR & AR & AR & AR \\
Dickey-Fuller & -7.0625 & -6.0774 & -6.9363 & -5.9742 & -7.7878 & -7.7953 \\
P-Value & $<0.01$ & $<0.01$ & $<0.01$ & $<0.01$ & $<0.01$ & $<0.01$ \\
Stationary? & $\checkmark$ & $\checkmark$ & $\checkmark$ & $\checkmark$ & $\checkmark$ & $\checkmark$ \\
\hline
\end{tabular}

The diagnostics lead to a recommendation of autoregressive models. The log linear models previously made do not estimate the standard errors of the coefficients correctly because an assumption was violated. 


\subsection{Autoregressive Models}

Autoregressive models use past observations to explain current observations. The general form for autoregressive models is written as follows:

$y_{t}=\varphi_{1} y_{t-1}+\varphi_{2} y_{t-2}+\cdots+\varphi_{p} y_{t-p}+\delta+\varepsilon_{t}$ (Equation 6)

Note: Where $\varphi$ is the autoregressive parameter, $\mathrm{y}_{\mathrm{t}-1}$ is the previous observation, $\delta$ is the constant, and $\varepsilon$ is the error term

The weather and traffic related variables that were tested in the log linear models were included in various AR models. First, an autoregressive model using one term (AR1) was tested. If this did not raise the DW, then an additional autoregressive term was added, making at an AR2 model. Autoregressive models were constructed for each pollutant, where only the predictors significant at the 0.05 level remained. The autoregressive models were made in R (version 2.14.0) using the TSA (Time Series Analysis) package.

In order to check for autocorrelation in the ARIMA model, various plots were made, including the residuals over time, lag plots, ACF \& PACF plots, in addition to conducting the Durbin Watson test.

As an example of the process used for all four pollutants at the NE corner, UFP is used to illustrate how the ARIMA $(1,0,0)$ or AR1 model was selected.

First off, a residual plot was made were the residuals were plotted over time for the AR1 model shown in Figure 23. This plot can be compared to that of Figure 20, where it can be seen that more of the residuals are grouped closer to zero in the AR1 model and there 
is less variability than there was before. The remaining residuals plots for the other pollutants are shown in Figure 35 in the Appendix C.

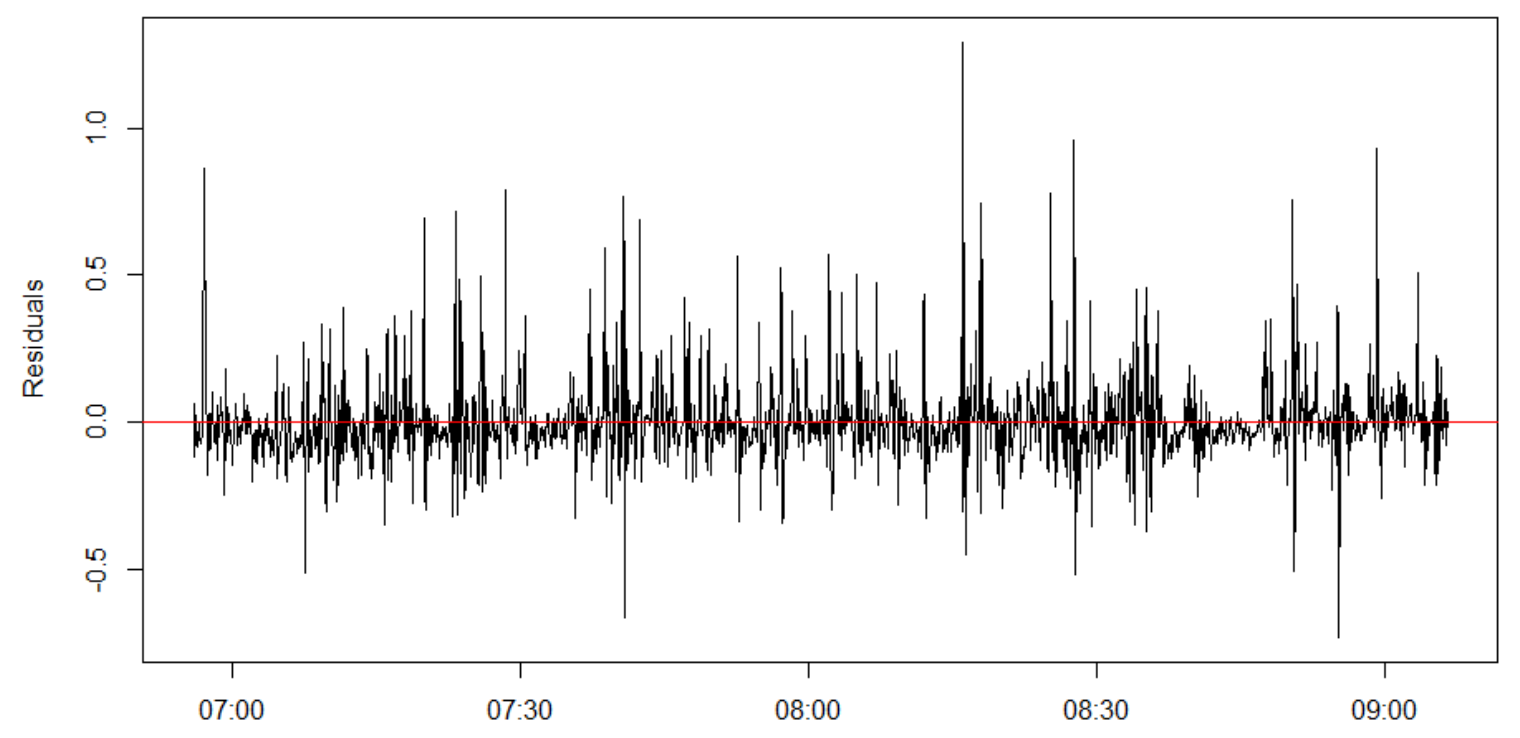

Figure 23. AR1 Residual Plot - UFP NE

Second, a lag plot was made as shown in Figure 24, where there is no distinctive trend shown as there used to be in Figure 21. The remaining lag plots for the other pollutants are shown in Figure 36 in the Appendix C. 


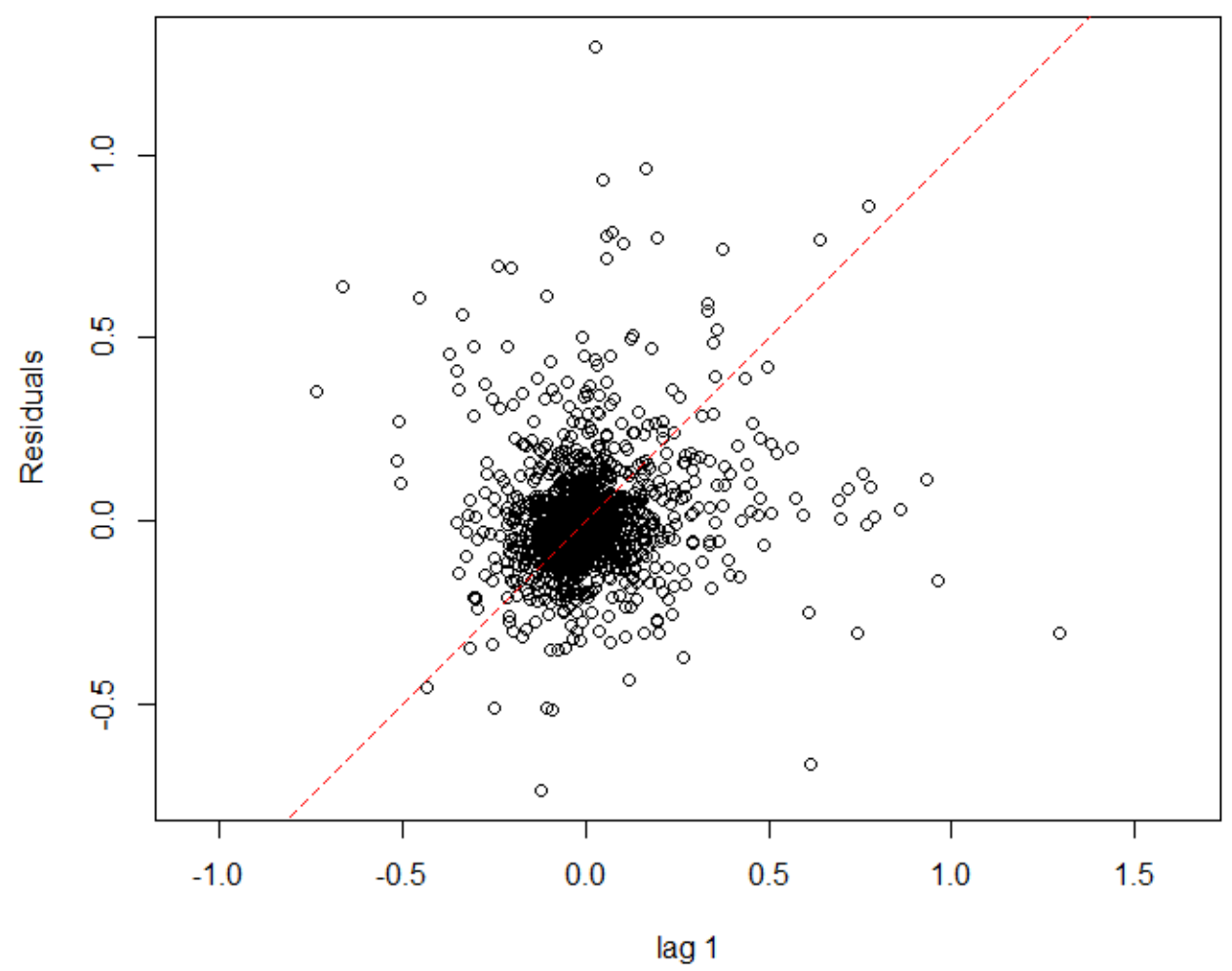

Figure 24. AR1 Lag Plot - UFP NE

Third, the ACF and PACF were plotted as shown in Figure 25, where the maximum autocorrelation is around 0.10 . This is improved upon the log linear model as shown in Figure 22, where the maximum autocorrelation was a little over 0.80 . Most values now fall within the dashed range shown on the plot, which would indicate random variation. The remaining ACF and PACF plots are shown in Figure 37 for the NE corner and Figure 38 for the NW corner. 

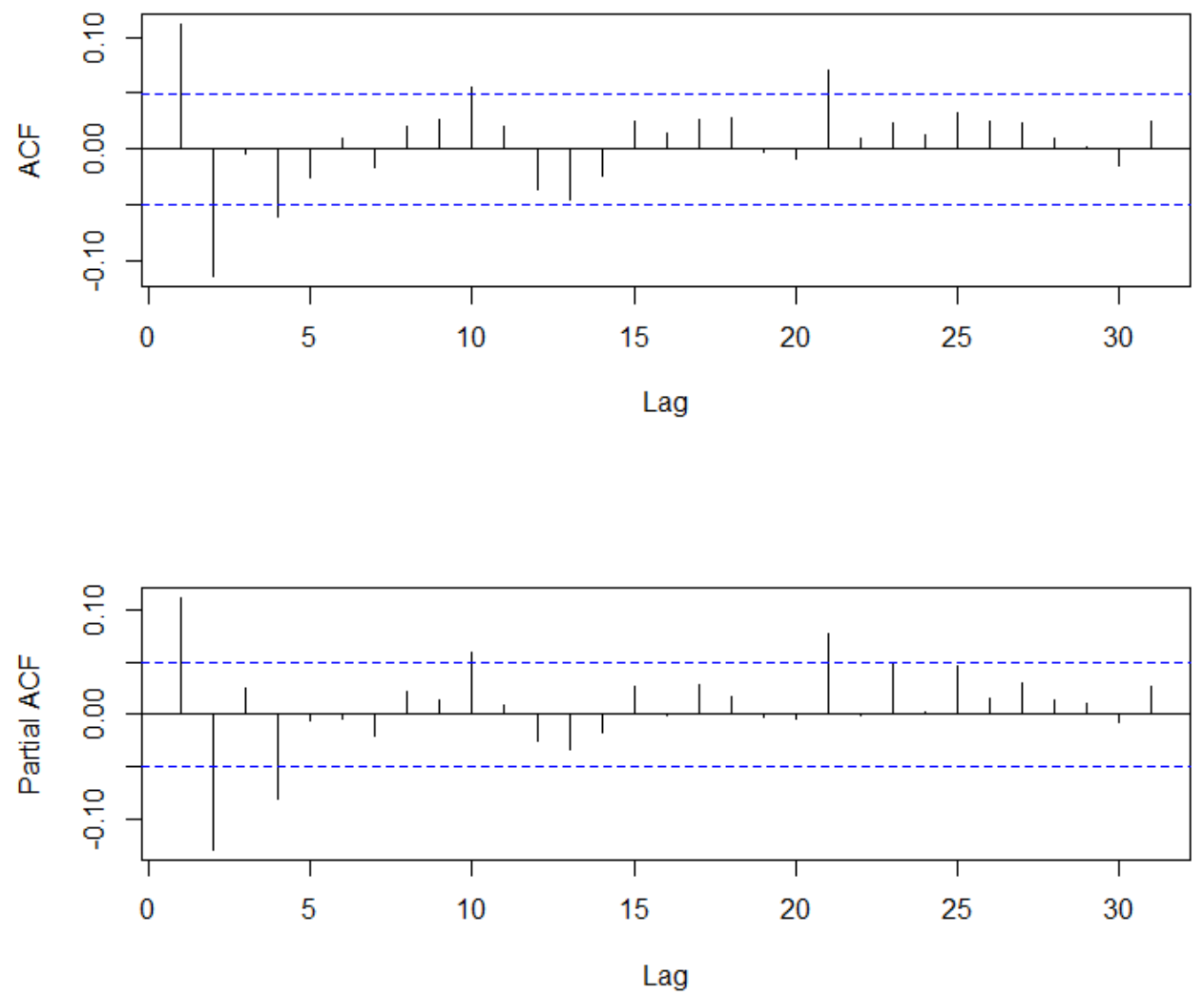

Figure 25. AR1 ACF \& PACF Plots - UFP NE

It has been demonstrated that for UFP at the NE corner, an AR1 model corrects for the autocorrelation and passes the diagnostic tests. Additionally, the Durbin Watson statistic is improved from the log linear model. The final model for UFP at the NE corner of the intersection is shown in Table 39, where only significant variables at the 0.05 level remain in the models. 
Table 39. UFP NE Log Linear \& AR1 Models

\begin{tabular}{|c|c|c|c|c|c|c|}
\hline & \multicolumn{3}{|c|}{ Linear Model } & \multicolumn{3}{|c|}{$\operatorname{ARIMA}(1,0,0)$} \\
\hline $\mathrm{R}^{2}$ & \multicolumn{3}{|c|}{$27.68 \%$} & \multicolumn{3}{|c|}{$87.00 \%$} \\
\hline Sigma $^{2}$ & & & & \multicolumn{3}{|c|}{0.02270} \\
\hline Log Likelihood & & & & \multicolumn{3}{|c|}{741.90} \\
\hline AIC & & & & \multicolumn{3}{|c|}{-1469.80} \\
\hline Durbin Watson & \multicolumn{3}{|c|}{0.2132} & \multicolumn{3}{|c|}{1.7763} \\
\hline & B & $\mathrm{SE}_{\mathrm{B}}$ & P-Value & B & $\mathrm{SE}_{\mathrm{B}}$ & P-Value \\
\hline ar1 & & & & 0.9153 & 0.0105 & 0.0000 \\
\hline constant & -2.8178 & 0.7717 & 0.0003 & 2.6101 & 1.9401 & 0.0446 \\
\hline $\mathrm{RH}$ & 0.1737 & 0.0099 & 0.0000 & 0.1059 & 0.0246 & 0.0000 \\
\hline wsSE & -0.3871 & 0.0751 & 0.0000 & & & \\
\hline wsW & -0.1160 & 0.0511 & 0.0234 & & & \\
\hline wsNW & & & & -0.0178 & 0.0148 & 0.0571 \\
\hline BusRedLight & 0.0076 & 0.0016 & 0.0000 & 0.0051 & 0.0017 & 0.0008 \\
\hline$H V N E$ & & & & 0.0754 & 0.0368 & 0.0100 \\
\hline WBTH & & & & 0.0087 & 0.0043 & 0.0108 \\
\hline GreenA & -0.0026 & 0.0009 & 0.0053 & & & \\
\hline GreenC & 0.0027 & 0.0014 & 0.0483 & & & \\
\hline VolCycle & 0.0029 & 0.0005 & 0.0000 & & & \\
\hline
\end{tabular}

Many variables from the log linear model became insignificant in the autoregressive model. However, the signs between the ones that did remain were consistent.

The final model for $\mathrm{PM}_{2.5}$ at the NE corner of the intersection is shown in Table 40, where only significant variables at the 0.05 level remain in the models. 
Table 40. PM 2.5 NE Log Linear \& AR1 Models

\begin{tabular}{|c|c|c|c|c|c|c|}
\hline & \multicolumn{3}{|c|}{ Linear Model } & \multicolumn{3}{|c|}{$\operatorname{ARIMA}(1,0,0)$} \\
\hline $\mathrm{R}^{2}$ & \multirow{4}{*}{\multicolumn{3}{|c|}{$44.63 \%$}} & \multicolumn{3}{|c|}{$76.38 \%$} \\
\hline Sigma $^{2}$ & & & & \multicolumn{3}{|c|}{0.00587} \\
\hline Log Likelihood & & & & \multicolumn{3}{|c|}{1803.34} \\
\hline AIC & & & & \multicolumn{3}{|c|}{-3576.68} \\
\hline Durbin Watson & \multicolumn{3}{|c|}{0.6426} & \multicolumn{3}{|c|}{2.2445} \\
\hline & $\mathrm{B}$ & $\mathrm{SE}_{\mathrm{B}}$ & P-Value & B & $\mathrm{SE}_{\mathrm{B}}$ & P-Value \\
\hline ar1 & & & & 0.8238 & 0.0163 & 0.0000 \\
\hline constant & 1.6358 & 0.4768 & 0.0006 & 6.4178 & 1.5291 & 0.0000 \\
\hline RH & 0.0069 & 0.0034 & 0.0447 & 0.0174 & 0.0092 & 0.0148 \\
\hline Temp & -0.1348 & 0.0092 & 0.0000 & -0.1045 & 0.0322 & 0.0003 \\
\hline wsSE & -0.1950 & 0.0268 & 0.0000 & -0.0260 & 0.0197 & 0.0466 \\
\hline wsS & -0.2482 & 0.0209 & 0.0000 & -0.0267 & 0.0155 & 0.0214 \\
\hline wsSW & -0.1405 & 0.0198 & 0.0000 & -0.0264 & 0.0135 & 0.0125 \\
\hline BusRedLight & 0.0050 & 0.0005 & 0.0000 & 0.0013 & 0.0009 & 0.0343 \\
\hline$E M P$ & & & & -0.0395 & 0.0280 & 0.0396 \\
\hline$H V N E$ & 0.0780 & 0.0174 & 0.0000 & & & \\
\hline PowellVol & & & & 0.0034 & 0.0015 & 0.0052 \\
\hline GreenA & -0.0028 & 0.0003 & 0.0000 & -0.0017 & 0.0007 & 0.0048 \\
\hline GreenE & 0.0049 & 0.0007 & 0.0000 & 0.0029 & 0.0015 & 0.0126 \\
\hline GreenF & & & & 0.0016 & 0.0010 & 0.0326 \\
\hline GreenD & 0.0025 & 0.0006 & 0.0000 & 0.0027 & 0.0011 & 0.0040 \\
\hline VolCycle & 0.0006 & 0.0002 & 0.0002 & 0.0005 & 0.0004 & 0.0359 \\
\hline
\end{tabular}

The following Table 41 is a summary table for particulate matter at the NE corner using all three of the interpretation methods previously discussed. 
Table 41. NE Corner Autoregressive Model Interpretation - Particulate Matter

\begin{tabular}{|c|c|c|c|c|c|c|}
\hline \multirow[t]{3}{*}{ Model Input } & \multicolumn{6}{|c|}{ NE Corner Particulate Matter } \\
\hline & \multicolumn{2}{|c|}{$\begin{array}{l}\text { \% Change per Unit } \\
\text { Change in X }\end{array}$} & \multicolumn{2}{|c|}{$\begin{array}{l}\% \text { Change per } 1 \% \\
\text { Change in } \mathrm{X}\end{array}$} & \multicolumn{2}{|c|}{$\begin{array}{c}\% \text { Average Contribution } \\
\text { to Baseline* }\end{array}$} \\
\hline & UFP & $\mathrm{PM}_{2.5}$ & UFP & $\mathrm{PM}_{2.5}$ & UFP & $\mathrm{PM}_{2.5}$ \\
\hline RH & $11.17 \%$ & $1.75 \%$ & $8.721 \%$ & $1.381 \%$ & & \\
\hline Temp & & $-9.93 \%$ & & $-4.088 \%$ & & \\
\hline wsSE & & $-2.56 \%$ & & $-0.001 \%$ & & $-0.09 \%$ \\
\hline wsS & & $-2.63 \%$ & & $-0.002 \%$ & & $-0.18 \%$ \\
\hline wsSW & & $-2.61 \%$ & & $-0.001 \%$ & & $-0.13 \%$ \\
\hline wsNW & $-1.77 \%$ & & $-0.001 \%$ & & $-0.13 \%$ & \\
\hline BusRedLight & $0.51 \%$ & $0.13 \%$ & $0.004 \%$ & $0.001 \%$ & $0.45 \%$ & $0.11 \%$ \\
\hline$E M P$ & & $-3.87 \%$ & & & & $-0.08 \%$ \\
\hline$H V N E$ & $7.84 \%$ & & & & $0.23 \%$ & \\
\hline WBTH & $0.88 \%$ & & $0.017 \%$ & & $1.73 \%$ & \\
\hline PowellVol & & $0.34 \%$ & & $0.011 \%$ & & $1.09 \%$ \\
\hline GreenA & & $-0.17 \%$ & & $-0.122 \%$ & & $-11.47 \%$ \\
\hline GreenE & & $0.30 \%$ & & $0.005 \%$ & & $0.54 \%$ \\
\hline GreenF & & $0.16 \%$ & & $0.010 \%$ & & $1.04 \%$ \\
\hline GreenD & & $0.27 \%$ & & $0.079 \%$ & & $8.25 \%$ \\
\hline VolCycle & & $0.05 \%$ & & $0.051 \%$ & & $5.26 \%$ \\
\hline
\end{tabular}

*Baseline is the sum of constant, RH, and temp

For the mean contribution, the largest reduction in UFP levels is green time for Phase A with an average contribution of $11 \%$ with mean values for all other inputs. The largest contributions are $8 \%$ for green time for Phase D and 5\% for volume per cycle.

When interpreting the log linear models with average contributions relative to the baseline atmospheric conditions, there were no large contributions to UFP, but there were a couple for $\mathrm{PM}_{2.5}$ at the $\mathrm{NE}$ corner of the intersection including green time for Phase A, green time for Phase D and volume per cycle.

The final model for $\mathrm{CO}$ at the NE corner of the intersection is shown in Table 42, where only significant variables at the 0.05 level remain in the models. 
Table 42. CO NE Log Linear \& AR 2 Models

\begin{tabular}{|c|c|c|c|c|c|c|}
\hline & \multicolumn{3}{|c|}{ Linear Model } & \multicolumn{3}{|c|}{$\operatorname{ARIMA}(2,0,0)$} \\
\hline $\mathrm{R}^{2}$ & \multirow{4}{*}{\multicolumn{3}{|c|}{$54.65 \%$}} & \multicolumn{3}{|c|}{$98.95 \%$} \\
\hline Sigma $^{2}$ & & & & & 0.00237 & \\
\hline Log Likelihood & & & & & 2510.57 & \\
\hline AIC & & & & & -4997.13 & \\
\hline Durbin Watson & \multicolumn{3}{|c|}{0.1342} & & 2.1191 & \\
\hline & B & $\mathrm{SE}_{\mathrm{B}}$ & P-Value & B & $\mathrm{SE}_{\mathrm{B}}$ & P-Value \\
\hline ar1 & & & & 1.43656 & 0.02282 & 0.00000 \\
\hline ar2 & & & & -0.44678 & 0.02280 & 0.00000 \\
\hline constant & -19.9166 & 0.7321 & 0.0000 & -1.24835 & 0.75238 & 0.02427 \\
\hline RH & 0.2567 & 0.0095 & 0.0000 & 0.01469 & 0.00942 & 0.02972 \\
\hline wsSE & -0.7524 & 0.0728 & 0.0000 & -0.00944 & 0.00806 & 0.06046 \\
\hline wsS & -0.5358 & 0.0558 & 0.0000 & & & \\
\hline wsSW & -0.3068 & 0.0527 & 0.0000 & -0.00881 & 0.00557 & 0.02854 \\
\hline wsW & -0.1265 & 0.0469 & 0.0071 & & & \\
\hline BusRedLight & 0.0050 & 0.0005 & 0.0000 & & & \\
\hline$D P F$ & -0.1249 & 0.0379 & 0.0010 & & & \\
\hline$E M P$ & & & & -0.01849 & 0.01598 & 0.06183 \\
\hline$H V N E$ & 0.1788 & 0.0474 & 0.0002 & & & \\
\hline EBTH & & & & 0.00288 & 0.00211 & 0.04291 \\
\hline WBTH & & & & -0.00374 & 0.00150 & 0.00316 \\
\hline GreenA & & & & -0.00060 & 0.00040 & 0.04750 \\
\hline GreenF & -0.0106 & 0.0017 & 0.0000 & 0.00090 & 0.00080 & 0.06830 \\
\hline GreenC & -0.0091 & 0.0017 & 0.0000 & 0.00110 & 0.00080 & 0.03770 \\
\hline VolCycle & 0.0054 & 0.0005 & 0.0000 & & & \\
\hline ActualCL & -0.0047 & 0.0014 & 0.0005 & & & \\
\hline
\end{tabular}

The final model for $\mathrm{CO}_{2}$ at the NE corner of the intersection is shown in Table 43, where only significant variables at the 0.05 level remain in the models. 
Table 43. $\mathrm{CO}_{2} \mathrm{NE}$ Log Linear \& AR 1 Models

\begin{tabular}{|c|c|c|c|c|c|c|}
\hline & \multicolumn{3}{|c|}{ Linear Model } & \multicolumn{3}{|c|}{ ARIMA $(1,0,0)$} \\
\hline $\mathrm{R}^{2}$ & \multicolumn{3}{|c|}{$40.43 \%$} & \multicolumn{3}{|c|}{$89.97 \%$} \\
\hline Sigma $^{2}$ & & & & \multicolumn{3}{|c|}{0.00319} \\
\hline Log Likelihood & & & & \multicolumn{3}{|c|}{2280.26} \\
\hline AIC & & & & \multicolumn{3}{|c|}{-4542.53} \\
\hline Durbin Watson & \multicolumn{3}{|c|}{0.2252} & \multicolumn{3}{|c|}{2.2183} \\
\hline & B & $\mathrm{SE}_{\mathrm{B}}$ & P-Value & B & $\mathrm{SE}_{\mathrm{B}}$ & P-Value \\
\hline ar1 & & & & 0.9369 & 0.0095 & 0.0000 \\
\hline constant & -3.4549 & 0.3149 & 0.0000 & 1.3355 & 0.7980 & 0.0236 \\
\hline $\mathrm{RH}$ & 0.0945 & 0.0041 & 0.0000 & 0.0319 & 0.0101 & 0.0004 \\
\hline wsN & & & & & & \\
\hline wsNE & & & & & & \\
\hline wsE & & & & -0.0176 & 0.0116 & 0.0319 \\
\hline wsSE & -0.1980 & 0.0313 & 0.0000 & -0.0167 & 0.0135 & 0.0540 \\
\hline wsS & -0.1464 & 0.0240 & 0.0000 & -0.0154 & 0.0095 & 0.0263 \\
\hline wsSW & -0.0717 & 0.0227 & 0.0016 & & & \\
\hline wsW & -0.0611 & 0.0202 & 0.0025 & & & \\
\hline$H V N E$ & 0.0822 & 0.0204 & 0.0001 & & & \\
\hline NBTH & & & & 0.0461 & 0.0154 & 0.0007 \\
\hline SBTH & & & & -0.0081 & 0.0063 & 0.0497 \\
\hline GreenA & -0.0025 & 0.0004 & 0.0000 & -0.0010 & 0.0005 & 0.0137 \\
\hline GreenE & -0.0032 & 0.0010 & 0.0015 & & & \\
\hline GreenF & -0.0049 & 0.0008 & 0.0000 & & & \\
\hline GreenC & -0.0036 & 0.0008 & 0.0000 & & & \\
\hline GreenD & -0.0036 & 0.0007 & 0.0000 & & & \\
\hline VolCycle & 0.0015 & 0.0002 & 0.0000 & & & \\
\hline
\end{tabular}

The following Table 44 is a summary table for carbon monoxide and dioxide at the NE corner using all three of the interpretation methods previously discussed. 
Table 44. NE Corner Autoregressive Model Interpretation - $\mathrm{CO} \& \mathrm{CO}_{2}$

\begin{tabular}{|c|c|c|c|c|c|c|}
\hline \multirow[t]{3}{*}{ Model Input } & \multicolumn{6}{|c|}{ NE Corner $\mathrm{CO} \& \mathrm{CO}_{2}$} \\
\hline & \multicolumn{2}{|c|}{$\begin{array}{l}\% \text { Change per Unit } \\
\text { Change in X }\end{array}$} & \multicolumn{2}{|c|}{$\begin{array}{l}\% \text { Change per } 1 \% \\
\text { Change in } \mathrm{X}\end{array}$} & \multicolumn{2}{|c|}{$\begin{array}{c}\% \text { Average Contribution } \\
\text { to Baseline* }\end{array}$} \\
\hline & $\mathrm{CO}$ & $\mathrm{CO}_{2}$ & $\mathrm{CO}$ & $\mathrm{CO}_{2}$ & $\mathrm{CO}$ & $\mathrm{CO}_{2}$ \\
\hline RH & $1.48 \%$ & $3.25 \%$ & $1.167 \%$ & $2.555 \%$ & & \\
\hline wsE & & $-1.75 \%$ & & $0.000 \%$ & & $-0.05 \%$ \\
\hline wsSE & $-0.94 \%$ & $-1.65 \%$ & $0.000 \%$ & $-0.001 \%$ & $-0.03 \%$ & $-0.06 \%$ \\
\hline wsS & & $-1.53 \%$ & & $-0.001 \%$ & & $-0.10 \%$ \\
\hline wsSW & $-0.88 \%$ & & $0.000 \%$ & & $-0.04 \%$ & \\
\hline$E M P$ & $-1.83 \%$ & & & & $-0.04 \%$ & \\
\hline EBTH & $0.29 \%$ & & $0.004 \%$ & & $0.36 \%$ & \\
\hline WBTH & $-0.37 \%$ & & $-0.007 \%$ & & $-0.73 \%$ & \\
\hline NBTH & & $4.72 \%$ & & $0.004 \%$ & & $0.36 \%$ \\
\hline SBTH & & $-0.80 \%$ & & $-0.002 \%$ & & $-0.18 \%$ \\
\hline GreenA & $-0.06 \%$ & $-0.10 \%$ & $-0.041 \%$ & $-0.074 \%$ & $-4.04 \%$ & $-7.10 \%$ \\
\hline GreenF & $0.09 \%$ & & $0.006 \%$ & & $0.58 \%$ & \\
\hline GreenC & $0.11 \%$ & & $0.007 \%$ & & $0.66 \%$ & \\
\hline
\end{tabular}

For the mean contribution, the largest reduction in $\mathrm{CO}_{2}$ levels is green time for Phase A with an average contribution of $7 \%$ with mean values for all other inputs. This was the only large contribution, and there were no large contributions to $\mathrm{CO}$.

The final model for UFP at the NW corner of the intersection is shown in Table 45, where only significant variables at the 0.05 level remain in the models. 
Table 45. UFP NW Log Linear \& AR 1 Models

\begin{tabular}{|c|c|c|c|c|c|c|}
\hline & \multicolumn{3}{|c|}{ Linear Model } & \multicolumn{3}{|c|}{$\operatorname{ARIMA}(1,0,0)$} \\
\hline $\mathrm{R}^{2}$ & \multicolumn{3}{|c|}{$34.36 \%$} & \multicolumn{3}{|c|}{$82.36 \%$} \\
\hline Sigma $^{2}$ & & & & \multicolumn{3}{|c|}{0.04051} \\
\hline Log Likelihood & & & & \multicolumn{3}{|c|}{270.45} \\
\hline AIC & & & & \multicolumn{3}{|c|}{-524.90} \\
\hline Durbin Watson & \multicolumn{3}{|c|}{0.3712} & \multicolumn{3}{|c|}{1.7475} \\
\hline & $\mathrm{B}$ & $\mathrm{SE}_{\mathrm{B}}$ & P-Value & $\mathrm{B}$ & $\mathrm{SE}_{\mathrm{B}}$ & P-Value \\
\hline ar1 & & & & 0.8891 & 0.0125 & 0.0000 \\
\hline constant & 1.5633 & 1.1354 & 0.1688 & 5.2547 & 2.6890 & 0.0127 \\
\hline RH & 0.1182 & 0.0147 & 0.0000 & 0.0688 & 0.0341 & 0.0109 \\
\hline wsNE & 0.1732 & 0.0614 & 0.0049 & & & \\
\hline wsN & 0.0841 & 0.0311 & 0.0069 & & & \\
\hline wsSW & -0.4755 & 0.0688 & 0.0000 & & & \\
\hline wsS & -0.6880 & 0.0709 & 0.0000 & & & \\
\hline wsSE & -0.5673 & 0.0942 & 0.0000 & & & \\
\hline BusRedLight & 0.0043 & 0.0018 & 0.0172 & & & \\
\hline$H V N W$ & 0.0894 & 0.0219 & 0.0000 & & & \\
\hline WBTH & -0.0148 & 0.0074 & 0.0464 & -0.0096 & 0.0060 & 0.0269 \\
\hline GreenA & -0.0068 & 0.0011 & 0.0000 & -0.0029 & 0.0020 & 0.0377 \\
\hline GreenD & 0.0056 & 0.0020 & 0.0060 & & & \\
\hline GreenE & 0.0128 & 0.0025 & 0.0000 & 0.0102 & 0.0042 & 0.0040 \\
\hline GreenF & 0.0055 & 0.0017 & 0.0012 & 0.0105 & 0.0030 & 0.0001 \\
\hline VolCycle & 0.0017 & 0.0006 & 0.0051 & 0.0021 & 0.0010 & 0.0110 \\
\hline
\end{tabular}

The final model for $\mathrm{PM}_{2.5}$ at the NW corner of the intersection is shown in Table 46, where only significant variables at the 0.05 level remain in the models. 
Table 46. $\mathrm{PM}_{2.5}$ NW Log Linear \& AR 1 Models

\begin{tabular}{|c|c|c|c|c|c|c|}
\hline & \multicolumn{3}{|c|}{ Linear Model } & \multicolumn{3}{|c|}{$\operatorname{ARIMA}(1,0,0)$} \\
\hline $\mathrm{R}^{2}$ & \multirow{4}{*}{\multicolumn{3}{|c|}{$27.48 \%$}} & \multicolumn{3}{|c|}{$67.32 \%$} \\
\hline Sigma $^{2}$ & & & & \multicolumn{3}{|c|}{0.01077} \\
\hline Log Likelihood & & & & \multicolumn{3}{|c|}{1246.76} \\
\hline AIC & & & & \multicolumn{3}{|c|}{-2471.51} \\
\hline Durbin Watson & \multicolumn{3}{|c|}{0.582} & \multicolumn{3}{|c|}{2.116} \\
\hline & $\mathrm{B}$ & $\mathrm{SE}_{\mathrm{B}}$ & P-Value & B & $\mathrm{SE}_{\mathrm{B}}$ & P-Value \\
\hline ar1 & & & & 0.7826 & 0.0164 & 0.0000 \\
\hline constant & 9.0763 & 0.6298 & 0.0000 & 8.7908 & 1.6217 & 0.0000 \\
\hline RH & 0.0225 & 0.0058 & 0.0001 & & & \\
\hline Temp & -0.1736 & 0.0141 & 0.0000 & -0.1247 & 0.0406 & 0.0005 \\
\hline wsN & 0.0656 & 0.0130 & 0.0000 & & & \\
\hline wsNE & 0.0670 & 0.0250 & 0.0074 & & & \\
\hline wsSE & -0.1459 & 0.0378 & 0.0001 & -0.0459 & 0.0246 & 0.0155 \\
\hline wsS & -0.1857 & 0.0287 & 0.0000 & & & \\
\hline wsSW & -0.1349 & 0.0278 & 0.0000 & & & \\
\hline wsNW & 0.0792 & 0.0189 & 0.0000 & 0.0155 & 0.0108 & 0.0381 \\
\hline TPAngled & -0.1974 & 0.0783 & 0.0118 & & & \\
\hline$H V N W$ & & & & 0.0159 & 0.0123 & 0.0495 \\
\hline WBTH & -0.0148 & 0.0040 & 0.0003 & -0.0055 & 0.0040 & 0.0407 \\
\hline ЕВТН & 0.0118 & 0.0054 & 0.0292 & 0.0082 & 0.0056 & 0.0358 \\
\hline GreenA & -0.0035 & 0.0004 & 0.0000 & -0.0030 & 0.0009 & 0.0001 \\
\hline GreenE & 0.0028 & 0.0010 & 0.0038 & & & \\
\hline GreenF & & & & 0.0027 & 0.0013 & 0.0091 \\
\hline GreenD & 0.0020 & 0.0008 & 0.0127 & 0.0054 & 0.0015 & 0.0001 \\
\hline VolCycle & 0.0005 & 0.0002 & 0.0320 & & & \\
\hline
\end{tabular}

The following Table 47 is a summary table for particulate matter at the NW corner using all three of the interpretation methods previously discussed. 
Table 47. NW Corner Autoregressive Model Interpretation - Particulate Matter

\begin{tabular}{|c|c|c|c|c|c|c|}
\hline \multirow[t]{3}{*}{ Model Input } & \multicolumn{6}{|c|}{ NW Corner Particulate Matter } \\
\hline & \multicolumn{2}{|c|}{$\begin{array}{l}\% \text { Change per Unit } \\
\text { Change in X }\end{array}$} & \multicolumn{2}{|c|}{$\begin{array}{l}\% \text { Change per } 1 \% \\
\text { Change in } \mathrm{X}\end{array}$} & \multicolumn{2}{|c|}{$\begin{array}{c}\% \text { Average Contribution } \\
\text { to Baseline* }\end{array}$} \\
\hline & UFP & $\mathrm{PM}_{2.5}$ & UFP & $\mathrm{PM}_{2.5}$ & UFP & $\mathrm{PM}_{2.5}$ \\
\hline RH & $7.12 \%$ & & $5.584 \%$ & & & \\
\hline Temp & & $-11.72 \%$ & & $-4.855 \%$ & & \\
\hline wsSE & & $-4.49 \%$ & & $-0.002 \%$ & & $-0.17 \%$ \\
\hline wsNW & & $1.56 \%$ & & $0.001 \%$ & & $0.11 \%$ \\
\hline$H V N W$ & & $1.60 \%$ & & & & $0.05 \%$ \\
\hline WBTH & $-0.96 \%$ & $-0.55 \%$ & $-0.019 \%$ & $-0.011 \%$ & $-1.88 \%$ & $-1.08 \%$ \\
\hline ЕВТН & & $0.83 \%$ & & $0.010 \%$ & & $1.03 \%$ \\
\hline GreenA & $-0.29 \%$ & $-0.30 \%$ & $-0.207 \%$ & $-0.219 \%$ & $-18.73 \%$ & $-19.67 \%$ \\
\hline GreenE & $1.02 \%$ & & $0.019 \%$ & & $1.89 \%$ & \\
\hline GreenF & $1.05 \%$ & $0.27 \%$ & $0.070 \%$ & $0.018 \%$ & $7.21 \%$ & $1.78 \%$ \\
\hline GreenD & & $0.54 \%$ & & $0.158 \%$ & & $17.06 \%$ \\
\hline VolCycle & $0.21 \%$ & & $0.203 \%$ & & $22.46 \%$ & \\
\hline
\end{tabular}

For the mean contribution, the largest reduction in UFP and $\mathrm{PM}_{2.5}$ levels at the NW corner was green time for Phase A with an average contribution of $19-20 \%$ with mean values for all other inputs. The largest contributions are $22 \%$ for volume per cycle and $7 \%$ for green time for Phase F for UFP, whereas for $\mathrm{PM}_{2.5}$ it is $17 \%$ for green time for Phase D.

The contribution from the autoregressive term(s) in each model was calculated and is shown below in Table 48. This illustrates the importance of previous measurements on each pollutant.

Table 48. Contribution from Autoregressive (AR) Terms

\begin{tabular}{|l|c|c|c|c|c|c|}
\hline \multirow{2}{*}{$\begin{array}{l}\text { Contribution } \\
\text { from AR }\end{array}$} & \multicolumn{4}{|c|}{ NE Corner } & \multicolumn{2}{c|}{ NW Corner } \\
\cline { 2 - 7 } Terms & $\mathrm{UFP}$ & $\mathrm{PM}_{2.5}$ & $\mathrm{CO}$ & $\mathrm{CO}_{2}$ & UFP & $\mathrm{PM}_{2.5}$ \\
\cline { 2 - 7 } & $8.94 \%$ & $3.90 \%$ & $3.25 \%$ & $3.76 \%$ & $10.83 \%$ & $4.06 \%$ \\
\hline
\end{tabular}


The autoregressive term contributed the most to UFP with almost $9 \%$ at the NE Corner and almost $11 \%$ at the NW Corner. The other three pollutants had a 3 to $4 \%$ contribution from the autoregressive term(s). These contributions take into account variable that occurs due to the previous conditions. The most that the autoregressive terms are able to explain is $10 \%$, indicating that other variables are explaining the total adjusted $r$-square values, ranging from 67 to $98 \%$.

\subsection{Lagged Autoregressive Models}

The time series models previously discussed examine the time series relationships occurring at the same point in time. However, it is common for time series to have a delayed response. In order to find out if this is true with the dataset, cross correlation plots were used. These plots were used to determine the proper lags for traffic related variables for the models with each pollutant. Spurious correlation is not an issue because all predictors and outcomes are stationary (they do not have unit roots).

Cross correlation plots (ccf's) are made for each traffic related variable and UFP, totaling twelve plots, shown in Figure 26 and Figure 27. The cross correlation function (ccf) is defined as:

$r=\frac{\sum_{i}\left(x_{i}-\bar{x}\right)\left(y_{i-k}-\bar{y}\right)}{\sqrt{\sum_{i}\left(x_{i}-\bar{x}\right)^{2}} \sqrt{\sum_{i}\left(y_{i-k}-\bar{y}\right)^{2}}}($ Equation 7)

The ccf's show up to two minutes before and after time zero for bus related variables, including bus presence, bus red light duration, EMP (engine cooling system), DPF (particulate filter) and angled tailpipe, where 24 lags is equal to two minutes. Volume per 
cycle includes five minutes before and after time zero, where 60 lags is equal to five minutes. Two minutes was also selected for heavy vehicle presence and time in queue. Vehicle movements including eastbound, westbound, southbound and northbound through, are also shown up to two minutes.
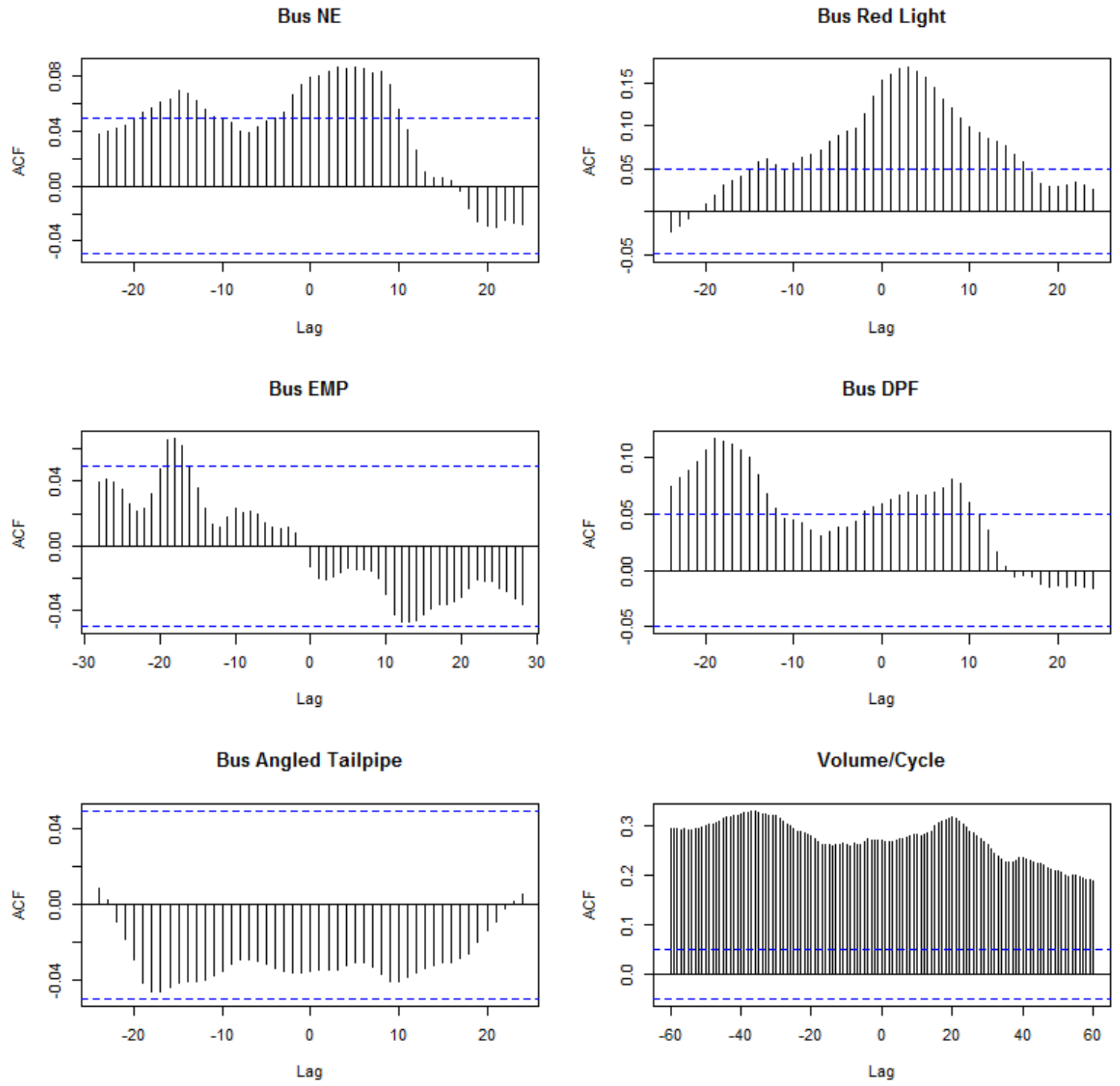

Figure 26. Cross Correlation Plots - UFP NE A 

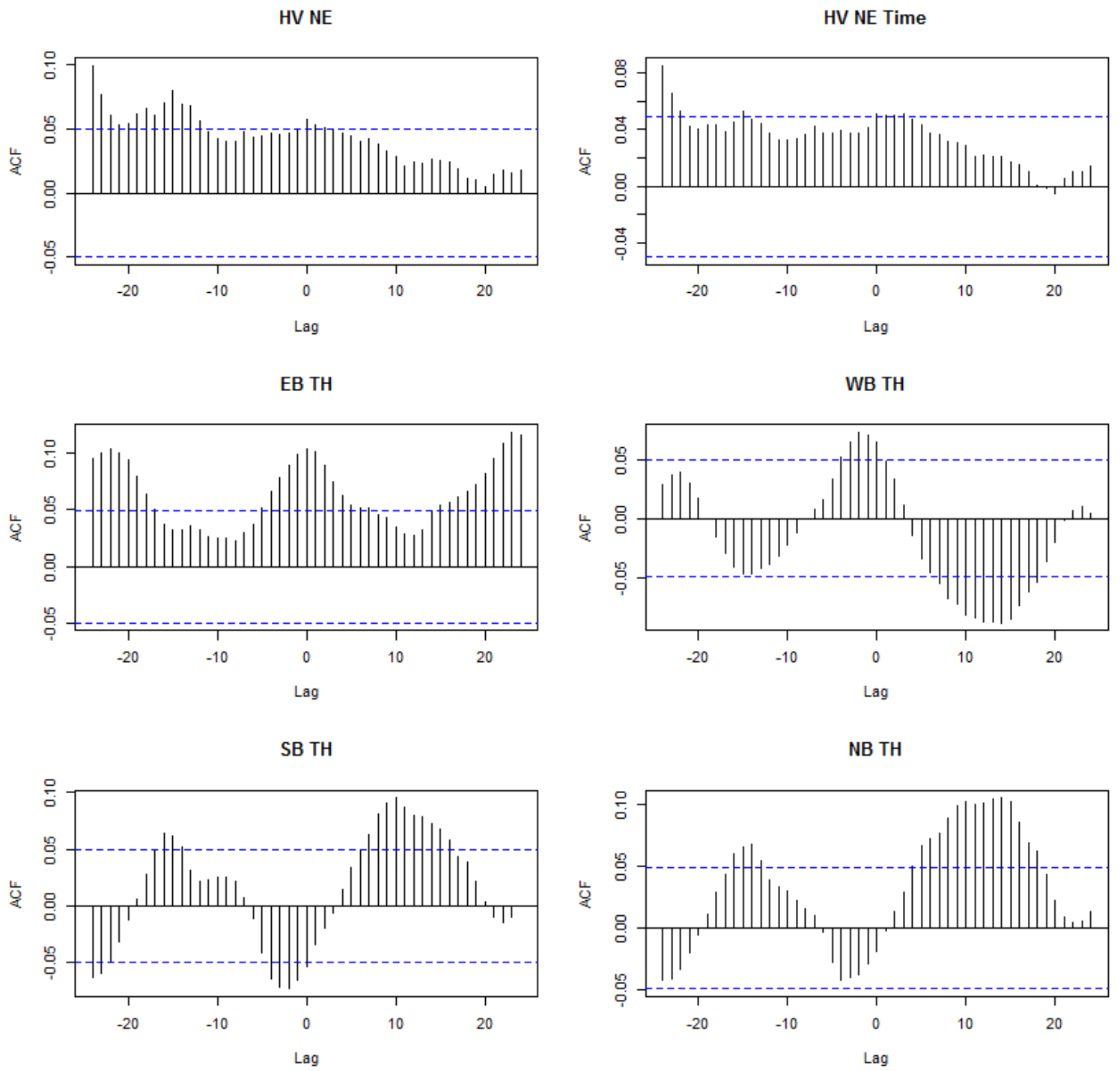

Figure 27. Cross Correlation Plots - UFP NE B

The cross correlation plots show the cyclic nature of the vehicle movements through the intersection. A cycle is about two minutes long, which is the amount that the plots are lagged. For the plots of eastbound, westbound, southbound, and northbound through volumes, from lag 24 to time zero, the correlations are equal. During the cycle, as various movements have their turn to go through the intersection, the correlation with the pollutant changes, but returns back to the same value at the end of the cycle. These plots 
help to understand the nature of the relationship between vehicle movements and pollutant levels. The remaining cross correlation plots for $\mathrm{PM}_{2.5}, \mathrm{CO}$, and $\mathrm{CO}_{2}$ at the $\mathrm{NE}$ corner are included in Figure 39 through Figure 44, and UFP and $\mathrm{PM}_{2.5}$ at the NW corner are included in Figure 45 through Figure 48.

The model results for UFP at the NE corner including lagged traffic variables is shown in Table 49. This table includes the regression coefficients, standard errors, and p-values for each predictor. For the lagged variables, the number of lags, in seconds and minutes is included to show how far back the impact is extended.

Table 49. UFP NE Lagged AR1 Model

\begin{tabular}{|c|c|c|c|c|c|c|}
\hline & & & & \multicolumn{3}{|c|}{ ARIMA $(1,0,0)$} \\
\hline \multicolumn{4}{|l|}{$\mathrm{R}^{2}$} & \multicolumn{3}{|c|}{$88.31 \%$} \\
\hline \multicolumn{4}{|l|}{ Sigma $^{2}$} & \multicolumn{3}{|c|}{0.02123} \\
\hline \multicolumn{4}{|c|}{ Log Likelihood } & \multicolumn{3}{|c|}{764.14} \\
\hline \multicolumn{4}{|l|}{ AIC } & \multicolumn{3}{|c|}{-1472.27} \\
\hline \multicolumn{4}{|l|}{ Durbin Watson } & \multicolumn{3}{|c|}{1.797104} \\
\hline & & & & $\mathrm{B}$ & $\mathrm{SE}_{\mathrm{B}}$ & P-Value \\
\hline \multicolumn{4}{|l|}{ ar1 } & 0.9035 & 0.0113 & 0.0000 \\
\hline \multicolumn{4}{|l|}{ intercept } & 2.1191 & 1.9645 & 0.0702 \\
\hline \multicolumn{4}{|l|}{ RH } & 0.0955 & 0.0251 & 0.0000 \\
\hline \multicolumn{4}{|l|}{ BusRedLight } & 0.0046 & 0.0017 & 0.0015 \\
\hline \multicolumn{4}{|l|}{$H V N E$} & 0.0805 & 0.0359 & 0.0062 \\
\hline \multicolumn{4}{|l|}{ WBTH } & 0.0098 & 0.0043 & 0.0056 \\
\hline & Lags & Secs. & Mins. & & & \\
\hline BusRedLight & 13 & 65 & 1.08 & 0.0040 & 0.0017 & 0.0045 \\
\hline BusRedLight & 18 & 90 & 1.50 & 0.0028 & 0.0017 & 0.0234 \\
\hline$E M P$ & 9 & 45 & 0.75 & -0.0694 & 0.0550 & 0.0517 \\
\hline$E M P$ & 12 & 60 & 1.00 & -0.1089 & 0.0541 & 0.0110 \\
\hline$E M P$ & 13 & 65 & 1.08 & -0.0713 & 0.0538 & 0.0464 \\
\hline$E M P$ & 22 & 110 & 1.83 & -0.0824 & 0.0538 & 0.0314 \\
\hline$D P F$ & 7 & 35 & 0.58 & -0.0569 & 0.0311 & 0.0167 \\
\hline
\end{tabular}




\begin{tabular}{|l|r|r|r|rrr|}
\hline & Lags & Secs. & Mins. & & & \\
\hline$H V N E$ & 13 & 65 & 1.08 & 0.0731 & 0.0367 & 0.0116 \\
$H V N E$ & 15 & 75 & 1.25 & 0.1587 & 0.0366 & 0.0000 \\
$H V N E$ & 18 & 90 & 1.50 & 0.0625 & 0.0360 & 0.0207 \\
$H V N E$ & 19 & 95 & 1.58 & 0.0716 & 0.0377 & 0.0144 \\
WBTH & 2 & 10 & 0.17 & 0.0089 & 0.0043 & 0.0095 \\
VolCycle & 4 & 20 & 0.33 & 0.0020 & 0.0008 & 0.0023 \\
VolCycle & 8 & 40 & 0.67 & 0.0012 & 0.0008 & 0.0273 \\
VolCycle & 13 & 65 & 1.08 & 0.0013 & 0.0008 & 0.0204 \\
VolCycle & 26 & 130 & 2.17 & 0.0012 & 0.0007 & 0.0258 \\
VolCycle & 36 & 180 & 3.00 & 0.0012 & 0.0008 & 0.0253 \\
VolCycle & 37 & 185 & 3.08 & 0.0016 & 0.0007 & 0.0071 \\
VolCycle & 44 & 220 & 3.67 & 0.0012 & 0.0007 & 0.0277 \\
VolCycle & 49 & 245 & 4.08 & 0.0010 & 0.0007 & 0.0469 \\
VolCycle & 59 & 295 & 4.92 & 0.0011 & 0.0007 & 0.0344 \\
VolCycle & 60 & 300 & 5.00 & 0.0014 & 0.0007 & 0.0126 \\
\hline
\end{tabular}

The following Table 50 is a summary table of the $\%$ change in UFP NE per unit change in predictor, $\%$ change in UFP NE per $1 \%$ change in predictor and the $\%$ average contribution to the baseline condition, including the lagged variables.

Table 50. UFP NE Lagged AR1 Model Interpretation

\begin{tabular}{|c|c|c|c|c|c|c|}
\hline & & & & $\begin{array}{c}\text { \% Change } \\
\text { per Unit } \\
\text { Change in } \mathrm{X} \\
\end{array}$ & $\begin{array}{c}\% \text { Change } \\
\text { per } 1 \% \\
\text { Change in } \mathrm{X}\end{array}$ & $\begin{array}{l}\text { \% Average } \\
\text { Contribution } \\
\text { to Baseline* }\end{array}$ \\
\hline RH & & & & $10.02 \%$ & $7.833 \%$ & \\
\hline BusRedLight & & & & $0.46 \%$ & $0.004 \%$ & $0.40 \%$ \\
\hline$H V N E$ & & & & $8.38 \%$ & & $0.25 \%$ \\
\hline WBTH & & & & $0.99 \%$ & $0.019 \%$ & $1.95 \%$ \\
\hline & Avg. Lag & Secs. & Mins. & & & \\
\hline BusRedLight & 15.1 & 75 & 1.26 & $0.68 \%$ & $0.006 \%$ & $0.59 \%$ \\
\hline$E M P$ & 14.1 & 70 & 1.17 & $-31.82 \%$ & & $-0.66 \%$ \\
\hline$D P F$ & 7 & 35 & 0.58 & $-5.53 \%$ & & $-0.28 \%$ \\
\hline HVNE & 15.9 & 80 & 1.32 & $38.66 \%$ & & $1.12 \%$ \\
\hline WBTH & 2 & 10 & 0.17 & $0.90 \%$ & $0.018 \%$ & $1.77 \%$ \\
\hline VolCycle & 31.8 & 159 & 2.65 & $1.33 \%$ & $1.275 \%$ & $136.33 \%$ \\
\hline
\end{tabular}


In terms of the lagged effect, bus presence that occurred a minute and half beforehand for a bus with an engine cooling system reduces UFP levels by $32 \%$ compared to a backwards oriented tailpipe. Heavy vehicle presence on the NE corner a minute and a half earlier on average increased UFP by $39 \%$. For every additional volume per cycle tow and a half minutes earlier, there is an increase in UFP levels of $1 \%$. The bus and heavy vehicle related lagged variables have less than a $1 \%$ average contribution compared to the baseline, whereas volume per cycle contributes $136 \%$, having a much larger impact on UFP at the NE corner.

The model results for $\mathrm{PM}_{2.5}$ at the NE corner including lagged traffic variables is shown in Table 51. This table includes the regression coefficients, standard errors, and p-values for each predictor. For the lagged variables, the number of lags, in seconds and minutes is included to show how far back the impact is extended.

Table 51. $\mathrm{PM}_{2.5}$ NE Lagged AR1 Model

\begin{tabular}{|c|c|c|c|}
\hline & \multicolumn{3}{|c|}{ ARIMA $(1,0,0)$} \\
\hline $\mathrm{R}^{2}$ & \multicolumn{3}{|c|}{$78.45 \%$} \\
\hline Sigma $^{2}$ & \multicolumn{3}{|c|}{0.00555} \\
\hline Log Likelihood & \multicolumn{3}{|c|}{1780.55} \\
\hline AIC & \multicolumn{3}{|c|}{-3471.10} \\
\hline Durbin Watson & \multicolumn{3}{|c|}{2.1838} \\
\hline & $\mathrm{B}$ & $\mathrm{SE}_{\mathrm{B}}$ & P-Value \\
\hline ar1 & 0.7873 & 0.0181 & 0.0000 \\
\hline intercept & 7.9895 & 1.3125 & 0.0000 \\
\hline RH & 0.0163 & 0.0093 & 0.0200 \\
\hline Temp & -0.1425 & 0.0293 & 0.0000 \\
\hline wsSE & -0.0313 & 0.0202 & 0.0304 \\
\hline wsS & -0.0277 & 0.0157 & 0.0193 \\
\hline wsSW & -0.0301 & 0.0135 & 0.0065 \\
\hline$E M P$ & -0.0408 & 0.0272 & 0.0332 \\
\hline
\end{tabular}




\begin{tabular}{|c|c|c|c|c|c|c|}
\hline & & & & B & $\mathrm{SE}_{\mathrm{B}}$ & P-Value \\
\hline PowellVol & & & & 0.0044 & 0.0017 & 0.0021 \\
\hline GreenA & & & & -0.0020 & 0.0007 & 0.0008 \\
\hline GreenE & & & & 0.0020 & 0.0013 & 0.0332 \\
\hline GreenD & & & & 0.0033 & 0.0011 & 0.0005 \\
\hline & Lags & Secs. & Mins. & & & \\
\hline BusRedLight & 1 & 5 & 0.08 & 0.0019 & 0.0008 & 0.0048 \\
\hline BusRedLight & 10 & 50 & 0.83 & 0.0036 & 0.0008 & 0.0000 \\
\hline BusRedLight & 17 & 85 & 1.42 & 0.0010 & 0.0008 & 0.0569 \\
\hline$E M P$ & 8 & 40 & 0.67 & -0.0501 & 0.0273 & 0.0167 \\
\hline TPAngled & 6 & 30 & 0.50 & -0.1346 & 0.0670 & 0.0111 \\
\hline TPAngled & 10 & 50 & 0.83 & -0.1320 & 0.0790 & 0.0237 \\
\hline TPAngled & 14 & 70 & 1.17 & -0.1910 & 0.0820 & 0.0050 \\
\hline TPAngled & 18 & 90 & 1.50 & -0.2732 & 0.0795 & 0.0001 \\
\hline TPAngled & 22 & 110 & 1.83 & -0.1654 & 0.0686 & 0.0040 \\
\hline HVNETime & 18 & 90 & 1.50 & 0.0013 & 0.0007 & 0.0151 \\
\hline ЕВТН & 2 & 10 & 0.17 & 0.0131 & 0.0040 & 0.0002 \\
\hline EBTH & 5 & 25 & 0.42 & 0.0075 & 0.0041 & 0.0164 \\
\hline EBTH & 12 & 60 & 1.00 & 0.0103 & 0.0033 & 0.0004 \\
\hline EBTH & 14 & 70 & 1.17 & 0.0089 & 0.0041 & 0.0077 \\
\hline EBTH & 17 & 85 & 1.42 & 0.0096 & 0.0042 & 0.0053 \\
\hline EBTH & 19 & 95 & 1.58 & 0.0078 & 0.0041 & 0.0142 \\
\hline EBTH & 20 & 100 & 1.67 & 0.0053 & 0.0041 & 0.0482 \\
\hline EBTH & 23 & 115 & 1.92 & 0.0084 & 0.0042 & 0.0104 \\
\hline WBTH & 2 & 10 & 0.17 & -0.0061 & 0.0028 & 0.0079 \\
\hline WBTH & 5 & 25 & 0.42 & -0.0058 & 0.0029 & 0.0109 \\
\hline WBTH & 9 & 45 & 0.75 & -0.0030 & 0.0024 & 0.0522 \\
\hline WBTH & 11 & 55 & 0.92 & -0.0054 & 0.0024 & 0.0057 \\
\hline WBTH & 14 & 70 & 1.17 & -0.0056 & 0.0029 & 0.0138 \\
\hline WBTH & 15 & 75 & 1.25 & -0.0049 & 0.0023 & 0.0087 \\
\hline WBTH & 17 & 85 & 1.42 & -0.0079 & 0.0029 & 0.0016 \\
\hline WBTH & 19 & 95 & 1.58 & -0.0036 & 0.0029 & 0.0532 \\
\hline WBTH & 20 & 100 & 1.67 & -0.0056 & 0.0029 & 0.0135 \\
\hline WBTH & 22 & 110 & 1.83 & -0.0032 & 0.0024 & 0.0471 \\
\hline WBTH & 23 & 115 & 1.92 & -0.0054 & 0.0029 & 0.0158 \\
\hline WBTH & 24 & 120 & 2.00 & -0.0095 & 0.0024 & 0.0000 \\
\hline SBTH & 3 & 15 & 0.25 & -0.0172 & 0.0071 & 0.0039 \\
\hline VolCycle & 32 & 160 & 2.67 & 0.0007 & 0.0003 & 0.0123 \\
\hline VolCycle & 56 & 280 & 4.67 & 0.0007 & 0.0003 & 0.0085 \\
\hline
\end{tabular}


The following Table 52 is a summary table of the \% change in $\mathrm{PM}_{2.5}$ NE per unit change in predictor, \% change in $\mathrm{PM}_{2.5} \mathrm{NE}$ per $1 \%$ change in predictor and the $\%$ average contribution to the baseline condition, including the lagged variables.

Table 52. $\mathrm{PM}_{2.5}$ NE Lagged AR1 Model Interpretation

\begin{tabular}{|c|c|c|c|c|c|c|}
\hline & & & & $\begin{array}{c}\% \text { Change } \\
\text { per Unit } \\
\text { Change in } \mathrm{X}\end{array}$ & $\begin{array}{c}\% \text { Change } \\
\text { per } 1 \% \\
\text { Change in } \mathrm{X}\end{array}$ & $\begin{array}{l}\text { \% Average } \\
\text { Contribution } \\
\text { to Baseline* }\end{array}$ \\
\hline \multicolumn{4}{|l|}{ RH } & $1.65 \%$ & $1.299 \%$ & \\
\hline \multicolumn{4}{|l|}{ Temp } & $-13.28 \%$ & $-5.530 \%$ & \\
\hline \multicolumn{4}{|l|}{ wsSE } & $-3.08 \%$ & $-0.001 \%$ & $-0.11 \%$ \\
\hline \multicolumn{4}{|l|}{ wsS } & $-2.74 \%$ & $-0.002 \%$ & $-0.18 \%$ \\
\hline \multicolumn{4}{|l|}{ wsSW } & $-2.96 \%$ & $-0.002 \%$ & $-0.15 \%$ \\
\hline \multicolumn{4}{|l|}{$E M P$} & $-4.00 \%$ & & $-0.08 \%$ \\
\hline \multicolumn{4}{|l|}{ PowellVol } & $0.44 \%$ & $0.014 \%$ & $1.41 \%$ \\
\hline \multicolumn{4}{|l|}{ GreenA } & $-0.20 \%$ & $-0.143 \%$ & $-13.31 \%$ \\
\hline \multicolumn{4}{|l|}{ GreenE } & $0.20 \%$ & $0.004 \%$ & $0.37 \%$ \\
\hline \multicolumn{4}{|l|}{ GreenD } & $0.33 \%$ & $0.097 \%$ & $10.20 \%$ \\
\hline & Avg. Lag & Secs. & Mins. & & & \\
\hline BusRedLight & 8.4 & 42 & 0.70 & $0.66 \%$ & $0.006 \%$ & $0.58 \%$ \\
\hline$E M P$ & 8 & 40 & 0.67 & $-4.88 \%$ & & $-0.10 \%$ \\
\hline TPAngled & 14.9 & 75 & 1.24 & $-81.50 \%$ & & $-0.23 \%$ \\
\hline HVNETime & 18 & 90 & 1.50 & $0.13 \%$ & $0.001 \%$ & $0.11 \%$ \\
\hline EBTH & 13 & 65 & 1.09 & $7.13 \%$ & $0.089 \%$ & $8.92 \%$ \\
\hline WBTH & 15.4 & 77 & 1.28 & $-6.58 \%$ & $-0.130 \%$ & $-12.95 \%$ \\
\hline SBTH & 3 & 15 & 0.25 & $-1.71 \%$ & $-0.004 \%$ & $-0.39 \%$ \\
\hline VolCycle & 54.1 & 280 & 4.67 & $0.14 \%$ & $0.130 \%$ & $13.44 \%$ \\
\hline
\end{tabular}

About one minute previously, buses present with an angled tailpipe reduced $\mathrm{PM}_{2.5}$ levels by $82 \%$ compared to a backwards oriented tailpipe. Eastbound through volume on Powell from a minute before increases pollutant levels, while westbound through volume on Powell a minute earlier decreases pollutant levels. Three lagged variables an average 
contribution relative to the baseline over $5 \%$, including eastbound and westbound traffic along with volume per cycle.

The model results for $\mathrm{CO}$ at the $\mathrm{NE}$ corner including lagged traffic variables is shown in Table 53Table 26. This table includes the regression coefficients, standard errors, and pvalues for each predictor. For the lagged variables, the number of lags, in seconds and minutes is included to show how far back the impact is extended.

Table 53. CO NE Lagged AR 2 Model

\begin{tabular}{|c|c|c|c|c|c|c|}
\hline \multicolumn{4}{|l|}{ 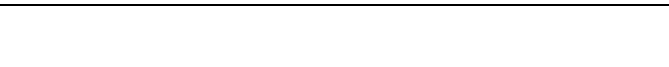 } & \multicolumn{3}{|c|}{ ARIMA $(2,0,0)$} \\
\hline \multicolumn{4}{|l|}{$\overline{\mathrm{R}^{2}}$} & \multicolumn{3}{|c|}{$99.08 \%$} \\
\hline \multicolumn{4}{|l|}{ Sigma $^{2}$} & \multicolumn{3}{|c|}{0.00214} \\
\hline \multicolumn{4}{|l|}{ Log Likelihood } & \multicolumn{3}{|c|}{2516.79} \\
\hline \multicolumn{4}{|l|}{ AIC } & \multicolumn{3}{|c|}{-4949.58} \\
\hline \multicolumn{4}{|l|}{ Durbin Watson } & \multicolumn{3}{|c|}{2.1575} \\
\hline & & & & $\mathrm{B}$ & $\mathrm{SE}_{\mathrm{B}}$ & P-Value \\
\hline \multicolumn{4}{|l|}{ ar1 } & 1.4537 & 0.0232 & 0.0000 \\
\hline \multicolumn{4}{|l|}{$\operatorname{ar} 2$} & -0.4639 & 0.0232 & 0.0000 \\
\hline \multicolumn{4}{|l|}{ intercept } & -1.5171 & 0.7432 & 0.0103 \\
\hline \multicolumn{4}{|l|}{ RH } & 0.0137 & 0.0093 & 0.0348 \\
\hline \multicolumn{4}{|l|}{ wsSW } & -0.0089 & 0.0054 & 0.0248 \\
\hline \multicolumn{4}{|l|}{ EBTH } & 0.0043 & 0.0021 & 0.0093 \\
\hline \multicolumn{4}{|l|}{ WBTH } & -0.0044 & 0.0015 & 0.0007 \\
\hline \multicolumn{4}{|l|}{ GreenA } & -0.0006 & 0.0005 & 0.0488 \\
\hline \multicolumn{4}{|l|}{ GreenE } & 0.0021 & 0.0012 & 0.0186 \\
\hline \multicolumn{4}{|l|}{ GreenF } & 0.0021 & 0.0010 & 0.0081 \\
\hline \multicolumn{4}{|l|}{ GreenC } & 0.0020 & 0.0010 & 0.0087 \\
\hline & Lags & Secs. & Mins. & & & \\
\hline BusRedLight & 18 & 90 & 1.50 & 0.0007 & 0.0005 & 0.0395 \\
\hline$D P F$ & 12 & 60 & 1.00 & -0.0255 & 0.0087 & 0.0008 \\
\hline$D P F$ & 14 & 70 & 1.17 & -0.0130 & 0.0086 & 0.0329 \\
\hline$D P F$ & 17 & 85 & 1.42 & -0.0148 & 0.0094 & 0.0286 \\
\hline$D P F$ & 18 & 90 & 1.50 & -0.0281 & 0.0098 & 0.0010 \\
\hline TPAngled & 8 & 40 & 0.67 & -0.0631 & 0.0305 & 0.0097 \\
\hline TPAngled & 22 & 110 & 1.83 & -0.0613 & 0.0306 & 0.0112 \\
\hline
\end{tabular}




\begin{tabular}{|l|r|r|r|rrr|}
\hline & Lags & Secs. & Mins. & & & \\
\hline EBTH & 14 & 70 & 1.17 & 0.0040 & 0.0020 & 0.0112 \\
EBTH & 23 & 115 & 1.92 & 0.0028 & 0.0022 & 0.0482 \\
WBTH & 23 & 115 & 1.92 & -0.0022 & 0.0015 & 0.0374 \\
SBTH & 3 & 15 & 0.25 & 0.0054 & 0.0037 & 0.0367 \\
SBTH & 9 & 45 & 0.75 & 0.0085 & 0.0053 & 0.0281 \\
SBTH & 10 & 50 & 0.83 & 0.0111 & 0.0057 & 0.0125 \\
SBTH & 11 & 55 & 0.92 & 0.0080 & 0.0052 & 0.0322 \\
SBTH & 14 & 70 & 1.17 & 0.0110 & 0.0045 & 0.0035 \\
SBTH & 15 & 75 & 1.25 & 0.0129 & 0.0046 & 0.0013 \\
SBTH & 16 & 80 & 1.33 & 0.0088 & 0.0048 & 0.0162 \\
SBTH & 17 & 85 & 1.42 & 0.0125 & 0.0042 & 0.0008 \\
SBTH & 21 & 105 & 1.75 & 0.0067 & 0.0041 & 0.0241 \\
SBTH & 22 & 110 & 1.83 & 0.0056 & 0.0042 & 0.0472 \\
SBTH & 24 & 120 & 2.00 & 0.0079 & 0.0038 & 0.0100 \\
NBTH & 9 & 45 & 0.75 & -0.0189 & 0.0139 & 0.0432 \\
NBTH & 10 & 50 & 0.83 & -0.0273 & 0.0148 & 0.0162 \\
NBTH & 11 & 55 & 0.92 & -0.0180 & 0.0137 & 0.0475 \\
VolCycle & 8 & 40 & 0.67 & 0.0004 & 0.0002 & 0.0192 \\
VolCycle & 13 & 65 & 1.08 & 0.0004 & 0.0002 & 0.0139 \\
VolCycle & 21 & 105 & 1.75 & 0.0004 & 0.0002 & 0.0114 \\
VolCycle & 30 & 150 & 2.50 & 0.0004 & 0.0002 & 0.0259 \\
VolCycle & 35 & 175 & 2.92 & 0.0004 & 0.0002 & 0.0106 \\
VolCycle & 45 & 225 & 3.75 & 0.0006 & 0.0002 & 0.0038 \\
VolCycle & 46 & 230 & 3.83 & 0.0005 & 0.0002 & 0.0081 \\
\hline
\end{tabular}

The following Table 54 is a summary table of the \% change in CO NE per unit change in predictor, $\%$ change in $\mathrm{CO} \mathrm{NE}$ per $1 \%$ change in predictor and the $\%$ average contribution to the baseline condition, including the lagged variables. 
Table 54. CO NE Lagged AR 2 Model Interpretation

\begin{tabular}{|c|c|c|c|c|c|c|}
\hline & & & & $\begin{array}{c}\text { \% Change } \\
\text { per Unit } \\
\text { Change in X }\end{array}$ & $\begin{array}{c}\% \text { Change } \\
\text { per } 1 \% \\
\text { Change in } \mathrm{X}\end{array}$ & $\begin{array}{l}\% \text { Average } \\
\text { Contribution } \\
\text { to Baseline* }\end{array}$ \\
\hline \multicolumn{4}{|l|}{ RH } & $1.38 \%$ & $1.091 \%$ & \\
\hline \multicolumn{4}{|l|}{ wsSW } & $-0.88 \%$ & $0.000 \%$ & $-0.04 \%$ \\
\hline \multicolumn{4}{|l|}{ EBTH } & $0.43 \%$ & $0.005 \%$ & $0.54 \%$ \\
\hline \multicolumn{4}{|l|}{ WBTH } & $-0.43 \%$ & $-0.009 \%$ & $-0.85 \%$ \\
\hline \multicolumn{4}{|l|}{ GreenA } & $-0.06 \%$ & $-0.042 \%$ & $-4.13 \%$ \\
\hline \multicolumn{4}{|l|}{ GreenE } & $0.21 \%$ & $0.004 \%$ & $0.38 \%$ \\
\hline \multicolumn{4}{|l|}{ GreenF } & $0.21 \%$ & $0.014 \%$ & $1.38 \%$ \\
\hline \multicolumn{4}{|l|}{ GreenC } & $0.20 \%$ & $0.012 \%$ & $1.17 \%$ \\
\hline & Avg. Lag & Secs. & Mins. & & & \\
\hline BusRedLight & 18 & 90 & 1.50 & $0.07 \%$ & $0.001 \%$ & $0.06 \%$ \\
\hline$D P F$ & 15.3 & 77 & 1.24 & $-8.06 \%$ & & $-0.40 \%$ \\
\hline TPAngled & 14.9 & 75 & 1.24 & $-12.05 \%$ & & $-0.04 \%$ \\
\hline ЕВТН & 17.7 & 89 & 1.48 & $0.69 \%$ & $0.009 \%$ & $0.86 \%$ \\
\hline WBTH & 23 & 115 & 1.92 & $-0.22 \%$ & $-0.004 \%$ & $-0.43 \%$ \\
\hline SBTH & 14.7 & 74 & 1.22 & $9.88 \%$ & $0.023 \%$ & $2.25 \%$ \\
\hline NBTH & 10 & 50 & 0.83 & $-6.35 \%$ & $-0.005 \%$ & $-0.49 \%$ \\
\hline VolCycle & 29.7 & 149 & 2.47 & $0.31 \%$ & $0.301 \%$ & $30.77 \%$ \\
\hline
\end{tabular}

One minute earlier, buses present with an angled tailpipe reduced CO levels by $12 \%$ compared to a backwards oriented tailpipe. Southbound through volume on Powell a minute before increases $\mathrm{CO}$ by $10 \%$. Lagged volume per cycle had the largest $\%$ average contribution relative to the baseline, and was the only one over $3 \%$, with $31 \%$ at a weighted average lag of two and a half minutes.

The model results for $\mathrm{CO}_{2}$ at the $\mathrm{NE}$ corner including lagged traffic variables is shown in Table 55Table 26. This table includes the regression coefficients, standard errors, and pvalues for each predictor. For the lagged variables, the number of lags, in seconds and minutes is included to show how far back the impact is extended. 
Table 55. $\mathrm{CO}_{2} \mathrm{NE}$ Lagged AR 1 Model

\begin{tabular}{|c|c|c|c|c|c|c|}
\hline & & & & & IMA $(1,0$ & \\
\hline $\mathrm{R}^{2}$ & & & & & $90.86 \%$ & \\
\hline Sigma $^{2}$ & & & & & 0.00302 & \\
\hline Log Likelihoo & & & & & 2243.13 & \\
\hline AIC & & & & & -4420.25 & \\
\hline Durbin Watsor & & & & & 2.1992 & \\
\hline & & & & B & $\mathrm{SE}_{\mathrm{B}}$ & P-Value \\
\hline ar1 & & & & 0.9267 & 0.0104 & 0.0000 \\
\hline intercept & & & & 0.8760 & 0.7973 & 0.0680 \\
\hline RH & & & & 0.0325 & 0.0101 & 0.0003 \\
\hline wsS & & & & -0.0121 & 0.0086 & 0.0407 \\
\hline SBTH & & & & -0.0083 & 0.0063 & 0.0474 \\
\hline NBTH & & & & 0.0413 & 0.0166 & 0.0032 \\
\hline GreenA & & & & -0.0006 & 0.0006 & 0.0757 \\
\hline & Lags & Secs. & Mins. & & & \\
\hline BusRedLight & 5 & 25 & 0.42 & 0.0009 & 0.0007 & 0.0467 \\
\hline BusRedLight & 6 & 30 & 0.50 & 0.0009 & 0.0007 & 0.0374 \\
\hline BusRedLight & 11 & 55 & 0.92 & 0.0009 & 0.0007 & 0.0410 \\
\hline BusRedLight & 16 & 80 & 1.33 & 0.0014 & 0.0006 & 0.0062 \\
\hline BusRedLight & 21 & 105 & 1.75 & 0.0012 & 0.0007 & 0.0144 \\
\hline$D P F$ & 3 & 15 & 0.25 & -0.0185 & 0.0116 & 0.0279 \\
\hline$D P F$ & 5 & 25 & 0.42 & -0.0168 & 0.0122 & 0.0415 \\
\hline$D P F$ & 10 & 50 & 0.83 & -0.0295 & 0.0116 & 0.0028 \\
\hline$D P F$ & 11 & 55 & 0.92 & -0.0329 & 0.0121 & 0.0016 \\
\hline$D P F$ & 13 & 65 & 1.08 & -0.0156 & 0.0116 & 0.0452 \\
\hline$D P F$ & 19 & 95 & 1.58 & -0.0176 & 0.0117 & 0.0334 \\
\hline$D P F$ & 20 & 100 & 1.67 & -0.0301 & 0.0117 & 0.0025 \\
\hline$D P F$ & 23 & 115 & 1.92 & -0.0172 & 0.0117 & 0.0353 \\
\hline HVNETime & 1 & 5 & 0.08 & 0.0006 & 0.0005 & 0.0462 \\
\hline HVNETime & 5 & 25 & 0.42 & 0.0010 & 0.0005 & 0.0123 \\
\hline HVNETime & 14 & 70 & 1.17 & 0.0007 & 0.0005 & 0.0317 \\
\hline EBTH & 19 & 95 & 1.58 & -0.0058 & 0.0023 & 0.0030 \\
\hline WBTH & 13 & 65 & 1.08 & 0.0023 & 0.0016 & 0.0380 \\
\hline VolCycle & 13 & 65 & 1.08 & 0.0008 & 0.0003 & 0.0023 \\
\hline VolCycle & 27 & 135 & 2.25 & 0.0004 & 0.0003 & 0.0515 \\
\hline VolCycle & 33 & 165 & 2.75 & 0.0004 & 0.0003 & 0.0504 \\
\hline VolCycle & 36 & 180 & 3.00 & 0.0004 & 0.0003 & 0.0339 \\
\hline VolCycle & 37 & 185 & 3.08 & 0.0008 & 0.0003 & 0.0015 \\
\hline
\end{tabular}




\begin{tabular}{|l|r|r|r|rrr|}
\hline & Lags & Secs. & Mins. & & & \\
\hline VolCycle & 46 & 230 & 3.83 & 0.0004 & 0.0003 & 0.0302 \\
VolCycle & 50 & 250 & 4.17 & 0.0004 & 0.0003 & 0.0305 \\
VolCycle & 55 & 275 & 4.58 & 0.0005 & 0.0003 & 0.0197 \\
\hline
\end{tabular}

The following Table 56 is a summary table of the $\%$ change in $\mathrm{CO}_{2} \mathrm{NE}$ per unit change in predictor, $\%$ change in $\mathrm{CO}_{2} \mathrm{NE}$ per $1 \%$ change in predictor and the $\%$ average contribution to the baseline condition, including the lagged variables.

Table 56. $\mathrm{CO}_{2} \mathrm{NE}$ Lagged $\mathrm{AR} 1$ Model Interpretation

\begin{tabular}{|c|c|c|c|c|c|c|}
\hline & & & & $\begin{array}{c}\text { \% Change per } \\
\text { Unit Change in } \\
\mathrm{X}\end{array}$ & $\begin{array}{c}\% \text { Change } \\
\text { per } 1 \% \\
\text { Change in } \mathrm{X}\end{array}$ & $\begin{array}{l}\text { \% Average } \\
\text { Contribution } \\
\text { to Baseline* }\end{array}$ \\
\hline $\mathrm{RH}$ & & & & $3.30 \%$ & $2.600 \%$ & \\
\hline wsS & & & & $-1.20 \%$ & $-0.001 \%$ & $-0.08 \%$ \\
\hline SBTH & & & & $-0.83 \%$ & $-0.002 \%$ & $-0.19 \%$ \\
\hline NBTH & & & & $4.21 \%$ & $0.003 \%$ & $0.32 \%$ \\
\hline GreenA & & & & $-0.06 \%$ & $-0.041 \%$ & $-4.00 \%$ \\
\hline & Avg. Lag & Secs. & Mins. & & & \\
\hline BusRedLight & 12.8 & 64 & 1.06 & $0.54 \%$ & $0.005 \%$ & $0.47 \%$ \\
\hline$D P F$ & 13.1 & 65 & 1.09 & $-17.60 \%$ & & $-0.87 \%$ \\
\hline HVNETime & 6.8 & 34 & 0.56 & $0.23 \%$ & $0.002 \%$ & $0.21 \%$ \\
\hline EBTH & 19 & 95 & 1.58 & $-0.58 \%$ & $-0.007 \%$ & $-0.72 \%$ \\
\hline WBTH & 13 & 65 & 1.08 & $0.23 \%$ & $0.005 \%$ & $0.46 \%$ \\
\hline VolCycle & 35.7 & 179 & 2.98 & $0.40 \%$ & $0.390 \%$ & $40.03 \%$ \\
\hline
\end{tabular}

Buses from two minutes ago with a particulate filter reduce $\mathrm{CO}_{2}$ levels by $18 \%$. The largest mean contribution was from lagging volume per cycle at a three minute lag, with an overall contribution of $40 \%$.

The model results for UFP at the NW corner including lagged traffic variables is shown in Table 57. This table includes the regression coefficients, standard errors, and p-values 
for each predictor. For the lagged variables, the number of lags, in seconds and minutes is included to show how far back the impact is extended.

Table 57. UFP NW Lagged AR1 Model

\begin{tabular}{|c|c|c|c|c|c|c|}
\hline & \multicolumn{3}{|c|}{ ARIMA $(1,0,0)$} \\
\hline \multicolumn{4}{|l|}{$\mathrm{R}^{2}$} & \multicolumn{3}{|c|}{$83.07 \%$} \\
\hline \multicolumn{4}{|l|}{ Sigma $^{2}$} & \multicolumn{3}{|c|}{0.03888} \\
\hline \multicolumn{4}{|c|}{ Log Likelihood } & \multicolumn{3}{|c|}{300.66} \\
\hline \multicolumn{4}{|l|}{ AIC } & \multicolumn{3}{|c|}{-551.32} \\
\hline \multicolumn{4}{|c|}{ Durbin Watson } & \multicolumn{3}{|c|}{1.7444} \\
\hline & & & & B & $\mathrm{SE}_{\mathrm{B}}$ & P-Value \\
\hline \multicolumn{4}{|l|}{ ar1 } & 0.8856 & 0.0127 & 0.0000 \\
\hline & 7.1784 & 2.5937 & 0.0014 \\
\hline \multicolumn{4}{|l|}{$\mathrm{RH}$} & 0.0320 & 0.0332 & 0.0838 \\
\hline \multicolumn{4}{|l|}{$D P F$} & -0.0625 & 0.0422 & 0.0346 \\
\hline \multicolumn{4}{|l|}{$H V N W$} & 0.0324 & 0.0246 & 0.0470 \\
\hline \multicolumn{4}{|l|}{ WBTH } & -0.0085 & 0.0061 & 0.0396 \\
\hline \multicolumn{4}{|l|}{ GreenA } & -0.0030 & 0.0020 & 0.0319 \\
\hline \multicolumn{4}{|l|}{ GreenE } & 0.0095 & 0.0041 & 0.0052 \\
\hline \multicolumn{4}{|l|}{ GreenF } & 0.0087 & 0.0030 & 0.0009 \\
\hline \multicolumn{4}{|l|}{ VolCycle } & 0.0016 & 0.0010 & 0.0318 \\
\hline & Lags & Secs. & Mins. & & & \\
\hline BusRedLight & 19 & 95 & 1.58 & 0.0035 & 0.0023 & 0.0317 \\
\hline EBTH & 4 & 20 & 0.33 & 0.0143 & 0.0087 & 0.0251 \\
\hline EBTH & 6 & 30 & 0.50 & 0.0235 & 0.0086 & 0.0015 \\
\hline EBTH & 7 & 35 & 0.58 & 0.0170 & 0.0087 & 0.0126 \\
\hline EBTH & 8 & 40 & 0.67 & 0.0154 & 0.0086 & 0.0185 \\
\hline EBTH & 16 & 80 & 1.33 & 0.0115 & 0.0087 & 0.0461 \\
\hline EBTH & 18 & 90 & 1.50 & 0.0159 & 0.0087 & 0.0165 \\
\hline WBTH & 1 & 5 & 0.08 & -0.0123 & 0.0060 & 0.0101 \\
\hline WBTH & 12 & 60 & 1.00 & -0.0099 & 0.0059 & 0.0236 \\
\hline WBTH & 13 & 65 & 1.08 & -0.0080 & 0.0061 & 0.0473 \\
\hline VolCycle & 12 & 60 & 1.00 & 0.0023 & 0.0010 & 0.0065 \\
\hline VolCycle & 18 & 90 & 1.50 & 0.0021 & 0.0010 & 0.0089 \\
\hline VolCycle & 22 & 110 & 1.83 & 0.0015 & 0.0010 & 0.0326 \\
\hline VolCycle & 39 & 195 & 3.25 & 0.0022 & 0.0010 & 0.0070 \\
\hline VolCycle & 56 & 280 & 4.67 & 0.0021 & 0.0010 & 0.0077 \\
\hline
\end{tabular}


The following Table 58 is a summary table of the \% change in UFP NW per unit change in predictor, $\%$ change in UFP NW per $1 \%$ change in predictor and the $\%$ average contribution to the baseline condition, including the lagged variables.

Table 58. UFP NW Lagged AR 1 Model Interpretation

\begin{tabular}{|c|c|c|c|c|c|c|}
\hline & & & & $\begin{array}{c}\text { \% Change } \\
\text { per Unit } \\
\text { Change in } \mathrm{X} \\
\end{array}$ & $\begin{array}{c}\% \text { Change } \\
\text { per } 1 \% \\
\text { Change in } \mathrm{X} \\
\end{array}$ & $\begin{array}{l}\% \text { Average } \\
\text { Contribution } \\
\text { to Baseline* }\end{array}$ \\
\hline \multicolumn{4}{|l|}{ RH } & $3.26 \%$ & $2.562 \%$ & \\
\hline \multicolumn{4}{|l|}{$D P F$} & $-6.06 \%$ & & $-0.31 \%$ \\
\hline \multicolumn{4}{|l|}{$H V N W$} & $3.30 \%$ & & $1.30 \%$ \\
\hline \multicolumn{4}{|l|}{ WBTH } & $-0.85 \%$ & $-0.017 \%$ & $-1.67 \%$ \\
\hline \multicolumn{4}{|l|}{ GreenA } & $-0.30 \%$ & $-0.215 \%$ & $-19.38 \%$ \\
\hline \multicolumn{4}{|l|}{ GreenE } & $0.96 \%$ & $0.018 \%$ & $1.77 \%$ \\
\hline \multicolumn{4}{|l|}{ GreenF } & $0.87 \%$ & $0.058 \%$ & $5.93 \%$ \\
\hline \multicolumn{4}{|l|}{ VolCycle } & $0.16 \%$ & $0.150 \%$ & $16.22 \%$ \\
\hline & Avg. Lag & Secs. & Mins. & & & \\
\hline BusRedLight & 19 & 95 & 1.58 & $0.35 \%$ & $0.003 \%$ & $0.30 \%$ \\
\hline EBTH & 9.3 & 47 & 0.78 & $9.84 \%$ & $0.122 \%$ & $12.33 \%$ \\
\hline WBTH & 7.8 & 39 & 0.65 & $-3.01 \%$ & $-0.059 \%$ & $-5.89 \%$ \\
\hline VolCycle & 29.5 & 148 & 2.46 & $1.02 \%$ & $0.984 \%$ & $108.79 \%$ \\
\hline
\end{tabular}

Each additional eastbound through vehicle per five second period adds $10 \%$ to UFP a minute earlier. The largest average contribution is from volume per cycle at two and half minutes with $109 \%$. The next largest is from eastbound with $12 \%$ and westbound with a reduction of $6 \%$.

The model results for $\mathrm{PM}_{2.5}$ at the NW corner including lagged traffic variables is shown in Table 59. This table includes the regression coefficients, standard errors, and p-values for each predictor. For the lagged variables, the number of lags, in seconds and minutes is included to show how far back the impact is extended. 
Table 59. PM $_{2.5}$ NW Lagged AR 1 Model

\begin{tabular}{|c|c|c|c|c|c|c|}
\hline & & & & & IMA $(1,0$ & \\
\hline $\mathrm{R}^{2}$ & & & & & $69.22 \%$ & \\
\hline Sigma $^{2}$ & & & & & 0.01014 & \\
\hline Log Likelihoo & & & & & 1290.84 & \\
\hline AIC & & & & & -2499.68 & \\
\hline Durbin Watsor & & & & & 2.0702 & \\
\hline & & & & $\mathrm{B}$ & $\mathrm{SE}_{\mathrm{B}}$ & P-Value \\
\hline ar1 & & & & 0.7467 & 0.0178 & 0.0000 \\
\hline intercept & & & & 10.3897 & 1.3679 & 0.0000 \\
\hline Temp & & & & -0.1678 & 0.0344 & 0.0000 \\
\hline wsSE & & & & -0.0527 & 0.0265 & 0.0118 \\
\hline wsS & & & & -0.0228 & 0.0187 & 0.0559 \\
\hline wsNW & & & & 0.0138 & 0.0108 & 0.0501 \\
\hline TPAngled & & & & -0.1200 & 0.0884 & 0.0436 \\
\hline$H V N W$ & & & & 0.0185 & 0.0119 & 0.0301 \\
\hline ЕВТН & & & & 0.0091 & 0.0057 & 0.0274 \\
\hline WBTH & & & & -0.0058 & 0.0039 & 0.0351 \\
\hline GreenA & & & & -0.0031 & 0.0008 & 0.0000 \\
\hline GreenD & & & & 0.0038 & 0.0013 & 0.0010 \\
\hline & Lags & Secs. & Mins. & & & \\
\hline BusRedLight & 19 & 95 & 1.58 & 0.0023 & 0.0011 & 0.0087 \\
\hline TPAngled & 4 & 20 & 0.33 & -0.1880 & 0.1026 & 0.0167 \\
\hline TPAngled & 8 & 40 & 0.67 & -0.2243 & 0.1060 & 0.0086 \\
\hline TPAngled & 12 & 60 & 1.00 & -0.2653 & 0.1053 & 0.0029 \\
\hline TPAngled & 16 & 80 & 1.33 & -0.2385 & 0.1016 & 0.0047 \\
\hline TPAngled & 20 & 100 & 1.67 & -0.1214 & 0.0888 & 0.0429 \\
\hline EBTH & 6 & 30 & 0.50 & 0.0089 & 0.0056 & 0.0286 \\
\hline EBTH & 11 & 55 & 0.92 & 0.0072 & 0.0056 & 0.0503 \\
\hline EBTH & 14 & 70 & 1.17 & 0.0093 & 0.0056 & 0.0242 \\
\hline ЕВТН & 15 & 75 & 1.25 & 0.0104 & 0.0056 & 0.0165 \\
\hline ЕВТН & 16 & 80 & 1.33 & 0.0194 & 0.0056 & 0.0001 \\
\hline ЕВТН & 18 & 90 & 1.50 & 0.0074 & 0.0056 & 0.0464 \\
\hline ЕВТН & 19 & 95 & 1.58 & 0.0126 & 0.0057 & 0.0070 \\
\hline EBTH & 24 & 120 & 2.00 & 0.0130 & 0.0057 & 0.0057 \\
\hline WBTH & 6 & 30 & 0.50 & -0.0069 & 0.0039 & 0.0204 \\
\hline WBTH & 9 & 45 & 0.75 & -0.0092 & 0.0033 & 0.0013 \\
\hline WBTH & 10 & 50 & 0.83 & 0.0059 & 0.0032 & 0.0160 \\
\hline WBTH & 11 & 55 & 0.92 & -0.0050 & 0.0039 & 0.0502 \\
\hline
\end{tabular}




\begin{tabular}{|l|r|r|r|rrr|}
\hline & Lags & Secs. & Mins. & & & \\
\hline WBTH & 12 & 60 & 1.00 & -0.0042 & 0.0032 & 0.0457 \\
WBTH & 14 & 70 & 1.17 & -0.0068 & 0.0039 & 0.0205 \\
WBTH & 15 & 75 & 1.25 & -0.0061 & 0.0040 & 0.0312 \\
WBTH & 16 & 80 & 1.33 & -0.0099 & 0.0040 & 0.0031 \\
WBTH & 18 & 90 & 1.50 & -0.0082 & 0.0040 & 0.0098 \\
WBTH & 19 & 95 & 1.58 & -0.0069 & 0.0040 & 0.0217 \\
WBTH & 21 & 105 & 1.75 & -0.0076 & 0.0032 & 0.0046 \\
WBTH & 22 & 110 & 1.83 & -0.0059 & 0.0033 & 0.0191 \\
WBTH & 24 & 120 & 2.00 & -0.0070 & 0.0040 & 0.0207 \\
VolCycle & 21 & 105 & 1.75 & 0.0011 & 0.0004 & 0.0015 \\
VolCycle & 43 & 215 & 3.58 & 0.0013 & 0.0004 & 0.0006 \\
\hline
\end{tabular}

The following Table 60 is a summary table of the $\%$ change in $\mathrm{PM}_{2.5} \mathrm{NW}$ per unit change in predictor, \% change in $\mathrm{PM}_{2.5} \mathrm{NW}$ per $1 \%$ change in predictor and the $\%$ average contribution to the baseline condition, including the lagged variables.

Table 60. PM P..5 NW Lagged AR 1 Model Interpretation

\begin{tabular}{|c|c|c|c|c|c|c|}
\hline & & & & $\begin{array}{c}\% \text { Change } \\
\text { per Unit } \\
\text { Change in X }\end{array}$ & $\begin{array}{c}\% \text { Change } \\
\text { per } 1 \% \\
\text { Change in } \mathrm{X} \\
\end{array}$ & $\begin{array}{l}\text { \% Average } \\
\text { Contribution } \\
\text { to Baseline* }\end{array}$ \\
\hline \multicolumn{4}{|l|}{ Temp } & $-15.45 \%$ & $-6.481 \%$ & \\
\hline \multicolumn{4}{|l|}{ wsSE } & $-5.13 \%$ & $-0.002 \%$ & $-0.19 \%$ \\
\hline \multicolumn{4}{|l|}{ wsS } & $-2.25 \%$ & $-0.002 \%$ & $-0.15 \%$ \\
\hline \multicolumn{4}{|l|}{ wsNW } & $1.39 \%$ & $0.001 \%$ & $0.10 \%$ \\
\hline \multicolumn{4}{|l|}{ TPAngled } & $-11.31 \%$ & & $-0.04 \%$ \\
\hline \multicolumn{4}{|l|}{$H V N W$} & $1.87 \%$ & & $0.91 \%$ \\
\hline \multicolumn{4}{|l|}{ EBTH } & $0.91 \%$ & $0.011 \%$ & $1.14 \%$ \\
\hline \multicolumn{4}{|l|}{ WBTH } & $-0.58 \%$ & $-0.011 \%$ & $-1.13 \%$ \\
\hline \multicolumn{4}{|l|}{ GreenA } & $-0.31 \%$ & $-0.222 \%$ & $-19.91 \%$ \\
\hline \multicolumn{4}{|l|}{ GreenD } & $0.38 \%$ & $0.113 \%$ & $11.96 \%$ \\
\hline & Avg. Lag & Secs. & Mins. & & & \\
\hline BusRedLight & 19 & 95 & 1.58 & $0.23 \%$ & $0.002 \%$ & $0.20 \%$ \\
\hline TPAngled & 11.5 & 58 & 0.96 & $-93.19 \%$ & & $-0.27 \%$ \\
\hline ЕВТН & 16 & 80 & 1.34 & $8.86 \%$ & $0.110 \%$ & $11.10 \%$ \\
\hline WBTH & 16.1 & 80 & 1.34 & $-7.74 \%$ & $-0.153 \%$ & $-15.20 \%$ \\
\hline VolCycle & 32.6 & 163 & 2.72 & $0.24 \%$ & $0.233 \%$ & $24.73 \%$ \\
\hline
\end{tabular}


In terms of the lagged effect, a minute beforehand when the bus tailpipe is angled during bus presence, $\mathrm{PM}_{2.5}$ at the NW corner is $93 \%$ lower than other orientations. In terms of mean contributions, volume per cycle is the largest with $25 \%$, westbound is $-15 \%$ and eastbound is $11 \%$.

To check the accuracy and fit of the final lagged models, plots of the observed vs. fitted values were made. The following in Figure 28 is for UFP at the NE corner, with an rsquare of $88 \%$ when fitting a linear trend to the observed vs. fitted values.

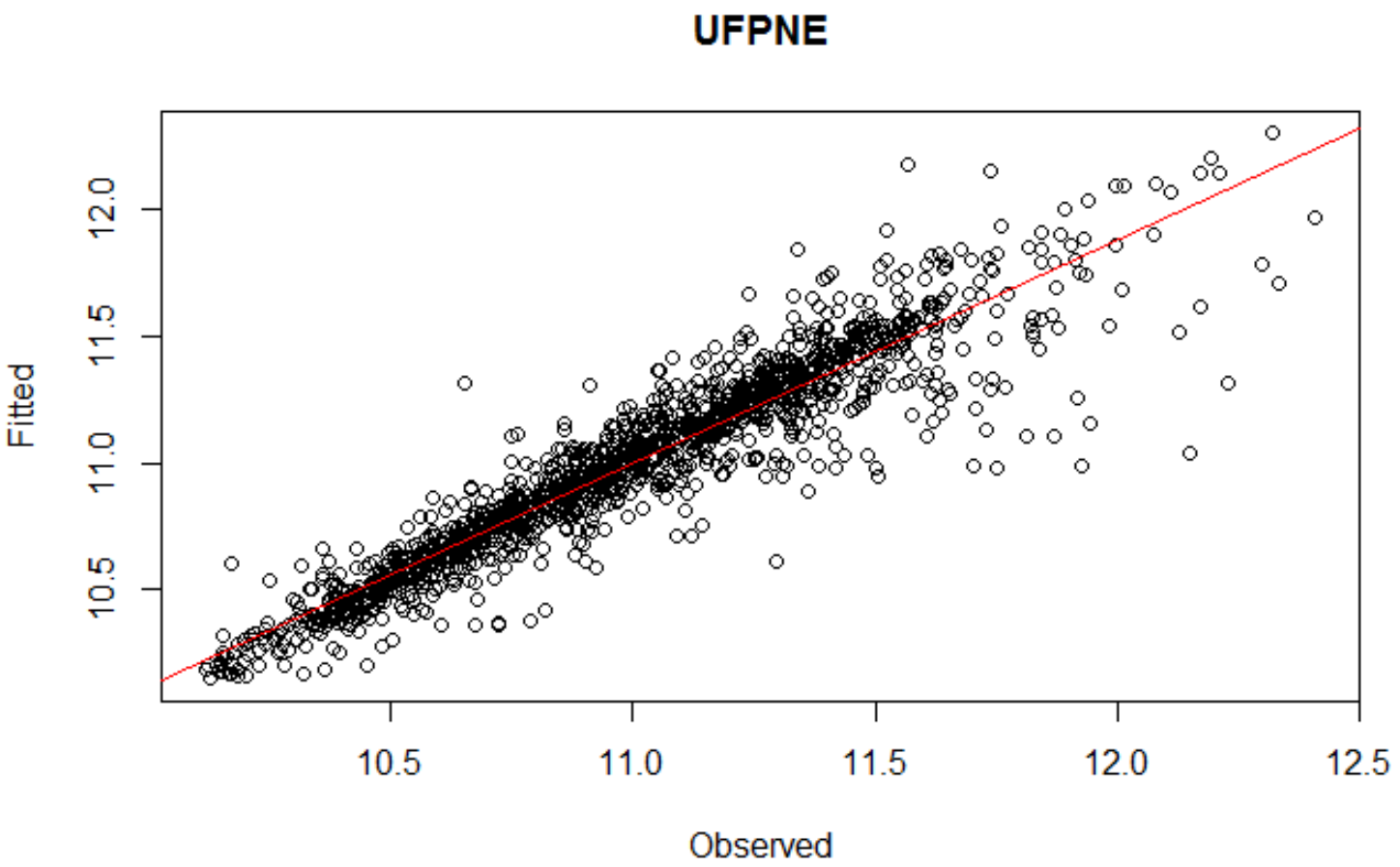

Figure 28. Fitted vs. Observed Plot

Regression models of the log-linear form have been presented in addition to autoregressive models including lagged traffic variables. The results of this statistical analysis will be further tied together through comparisons and summaries in the following discussion chapter. 


\subsection{Discussion}

The following chapter will summarize the results presented in this thesis and will quantify exposure to air pollution at an urban intersection. To provide a brief background, the study intersection (Powell Boulevard and $26^{\text {th }}$ Avenue) is located on Powell Boulevard, a key arterial in Portland, Oregon, connecting the downtown to suburbs to the east. The study intersection is surrounded by a variety of land uses, including a fast food restaurant, a high school, city park, and retailers, as shown in Figure 29. The data collection setup included simultaneous measurements of pollutant concentration levels, weather, transit buses, heavy vehicles, signal timing, and traffic volumes.

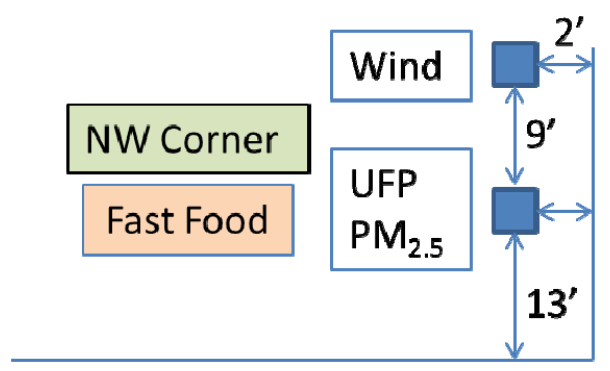

Powell Blvd.

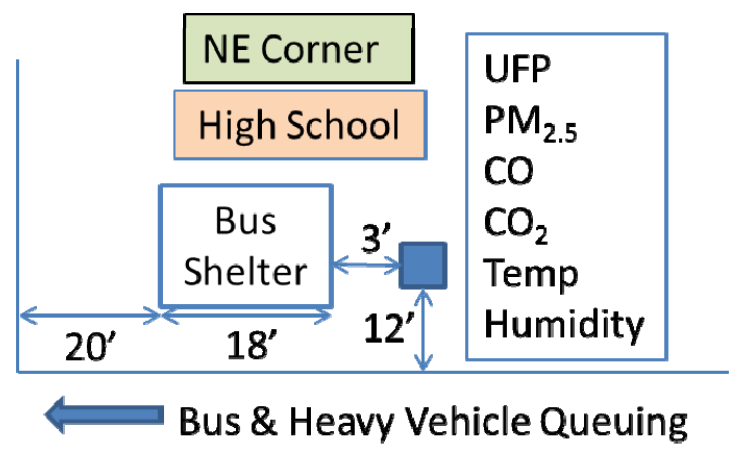

SE Corner

Retailers

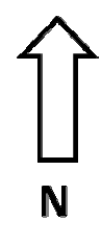

Note: Vehicles measured by loop detectors

Figure 29. Data Collection Layout 
This discussion chapter will draw conclusions on the measured pollutant concentration levels at the NE and NW corners of the intersection. The discussion will include five sections: a comparison of the four pollutants at the NE Corner (UFP, $\mathrm{PM}_{2.5}, \mathrm{CO}$ and $\mathrm{CO}_{2}$ ), a comparison of particulate matter (UFP and $\mathrm{PM}_{2.5}$ ) between the NE and NW Corners, vehicle impacts, signal timing impacts, and policy implications. All traffic related impacts were assessed to understand their contribution to pollutant levels.

\subsection{Comparison of Pollutants at NE Corner}

Four pollutants including UFP, $\mathrm{PM}_{2.5}, \mathrm{CO}$ and $\mathrm{CO}_{2}$ were measured at the NE Corner of the intersection. Autoregressive models were made for each pollutant using weather and traffic related variables to explain the variation in pollutant levels. The following summary table shows the elasticities for each significant input variable for the four pollutants at the NE Corner, shown in Table 61.

Table 61. NE Corner Elasticities

\begin{tabular}{|l|cccc|}
\hline Model Input & UFP & $\mathrm{PM}_{2.5}$ & $\mathrm{CO}$ & $\mathrm{CO}_{2}$ \\
\hline R & $87.00 \%$ & $76.38 \%$ & $98.95 \%$ & $89.97 \%$ \\
Log Likelihood & 741.90 & 1803.34 & 2510.57 & 2280.26 \\
AIC & -1469.80 & -3576.68 & -4997.13 & -4542.53 \\
\hline \multicolumn{5}{|c}{ Elasticities - NE Corner } \\
\hline RH & $\mathbf{5 . 7 2 1 \%}$ & $\mathbf{1 . 3 8 1 \%}$ & $\mathbf{1 . 1 6 7 \%}$ & $\mathbf{2 . 5 5 5 \%}$ \\
Temp & $\mathbf{- 4 . 0 8 8 \%}$ & & $-0.000 \%$ \\
wsE & & $-0.001 \%$ & $-0.000 \%$ & $-0.001 \%$ \\
wsSE & & $-0.002 \%$ & & $-0.001 \%$ \\
wsS & & $-0.001 \%$ & $-0.000 \%$ & \\
wsSW & $-0.001 \%$ & & & \\
wsNW & $0.004 \%$ & $0.001 \%$ & & \\
BusRedLight & $0.017 \%$ & & $-0.007 \%$ & \\
WBTH & & & & \\
\hline
\end{tabular}




\begin{tabular}{|l|cccc|}
\hline & UFP & $\mathrm{PM}_{2.5}$ & $\mathrm{CO}$ & $\mathrm{CO}_{2}$ \\
\hline EBTH & & & $0.004 \%$ & \\
PowellVol & & $0.011 \%$ & & \\
NBTH & & & & $0.004 \%$ \\
SBTH & & & $-0.002 \%$ \\
GreenA & & $-0.122 \%$ & $-0.041 \%$ & $-0.074 \%$ \\
GreenE & $0.005 \%$ & & \\
GreenF & & $0.010 \%$ & $0.006 \%$ & \\
GreenC & & & $0.007 \%$ & \\
GreenD & & $0.079 \%$ & & \\
VolCycle & & $0.051 \%$ & & \\
\hline
\end{tabular}

For all four pollutants either relative humidity or temperature were significant and had high elasticities, meaning that pollutant levels are sensitive to changes in these variables. Since relative humidity and temperature are correlated with each other, it's not surprising that in most cases only one of the two was necessary. The elasticities for all wind variables were small negative numbers in all cases. Bus related variables were only significant for UFP, $\mathrm{PM}_{2.5}$ and $\mathrm{CO}$, including bus red light time and an engine cooling system. Heavy vehicle presence was only significant for UFP. Each pollutant had different traffic variables that were significant. Green time for Phase A was significant in all cases except for UFP, where none of the traffic signal timing parameters were significant.

Additionally, a summary table is provided for the mean contributions for each significant input variable for the four pollutants at the NE Corner, shown in Table 62. 
Table 62. NE Corner Mean Contributions

\begin{tabular}{|c|c|c|c|c|}
\hline Model Input & UFP & $\mathrm{PM}_{2.5}$ & $\mathrm{CO}$ & $\mathrm{CO}_{2}$ \\
\hline $\mathrm{R}^{2}$ & $87.00 \%$ & $76.38 \%$ & $98.95 \%$ & $89.97 \%$ \\
\hline Log Likelihood & 741.90 & 1803.34 & 2510.57 & 2280.26 \\
\hline AIC & -1469.80 & -3576.68 & -4997.13 & -4542.53 \\
\hline & \multicolumn{4}{|c|}{ Mean Contribution - NE Corner } \\
\hline wsE & & & & $-0.05 \%$ \\
\hline wsSE & & $-0.09 \%$ & $-0.03 \%$ & $-0.06 \%$ \\
\hline wsS & & $-0.18 \%$ & & $-0.10 \%$ \\
\hline wsSW & & $-0.13 \%$ & $-0.04 \%$ & \\
\hline wsNW & $-0.13 \%$ & & & \\
\hline BusRedLight & $0.45 \%$ & $0.11 \%$ & & \\
\hline$E M P$ & & $-0.08 \%$ & $-0.04 \%$ & \\
\hline$H V N E$ & $0.23 \%$ & & & \\
\hline WBTH & $1.73 \%$ & & $-0.73 \%$ & \\
\hline EBTH & & & $0.36 \%$ & \\
\hline PowellVol & & $1.09 \%$ & & \\
\hline NBTH & & & & $0.36 \%$ \\
\hline SBTH & & & & $-0.18 \%$ \\
\hline GreenA & & $-11.47 \%$ & $-4.04 \%$ & $-7.10 \%$ \\
\hline GreenE & & $0.54 \%$ & & \\
\hline GreenF & & $1.04 \%$ & $0.58 \%$ & \\
\hline GreenC & & & $0.66 \%$ & \\
\hline GreenD & & $8.25 \%$ & & \\
\hline VolCycle & & $5.26 \%$ & & \\
\hline
\end{tabular}

All four pollutants are affected by the wind speed and direction. Longer bus idling time increased UFP and $\mathrm{PM}_{2.5}$. Buses equipped with an engine cooling system reduced $\mathrm{PM}_{2.5}$ and CO. Heavy vehicle presence was only significant for UFP. Each pollutant had different traffic variables that were significant. Green time for Phase A was significant in all cases except for UFP, where none of the traffic signal timing parameters were significant. Using mean values for all inputs, green time for Phase A reduced $\mathrm{PM}_{2.5}$ by $11.5 \%$, $\mathrm{CO}$ by $4 \%$ and $\mathrm{CO}_{2}$ by $7.1 \%$. 
After including the lagged traffic variables, another summary table is provided for the elasticities for each significant input variable for the four pollutants at the NE Corner, as shown in Table 63.

Table 63. NE Corner Lagged Elasticities

\begin{tabular}{|l|cccc|}
\hline Model Input & UFP & $\mathrm{PM}_{2.5}$ & $\mathrm{CO}$ & $\mathrm{CO}_{2}$ \\
\hline R & $88.31 \%$ & $78.45 \%$ & $99.08 \%$ & $90.86 \%$ \\
Log Likelihood & 764.14 & 1780.55 & 2516.79 & 2243.13 \\
AIC & -1472.27 & -3471.10 & -4949.58 & -4420.25 \\
\hline & \multicolumn{5}{|c|}{ Elasticities - NE Corner } \\
\hline RH & $\mathbf{7 . 8 3 3 \%}$ & $\mathbf{1 . 2 9 9 \%}$ & $\mathbf{1 . 0 9 1 \%}$ & $\mathbf{2 . 6 0 0 \%}$ \\
Temp & & $\mathbf{- 5 . 5 3 0 \%}$ & & \\
wsSE & & $-0.001 \%$ & & $-0.001 \%$ \\
wsS & & $-0.002 \%$ & & \\
wsSW & & $-0.002 \%$ & $0.000 \%$ & \\
BusRedLight & $0.004 \%$ & & & \\
WBTH & $0.019 \%$ & & $-0.009 \%$ & \\
EBTH & & & $0.005 \%$ & \\
PowellVol & & $0.014 \%$ & & $-0.002 \%$ \\
SBTH & & & & $0.003 \%$ \\
NBTH & & & & $-0.041 \%$ \\
GreenA & & $-0.143 \%$ & $-0.042 \%$ & $0.007 \%$ \\
GreenE & & $0.004 \%$ & $0.004 \%$ & \\
GreenF & & & $0.014 \%$ & \\
GreenC & & & $0.012 \%$ & \\
GreenD & & $0.097 \%$ & & \\
\hline Lagged Variables & & & & \\
\hline BusRedLight & $0.006 \%$ & $0.006 \%$ & $0.001 \%$ & $0.005 \%$ \\
HVNETime & & $0.001 \%$ & & $0.002 \%$ \\
WBTH & $0.018 \%$ & $0.089 \%$ & $-0.004 \%$ & $0.005 \%$ \\
EBTH & & $-0.130 \%$ & $0.009 \%$ & $-0.007 \%$ \\
SBTH & & $-0.004 \%$ & $0.023 \%$ & \\
NBTH & & & $-0.005 \%$ & \\
VolCycle & $\mathbf{1 . 2 7 5 \%}$ & $0.130 \%$ & $0.301 \%$ & $0.390 \%$ \\
\hline
\end{tabular}


Most of the elasticities remain the same for the non-lagged variables after adding lagged variables. For those variables that are lagged, the highest elasticity is volume per cycle for UFP. Volume per cycle is significant once it has been lagged for all four pollutants, whereas it was not in the original models. Heavy vehicles were not significant in the original models, but are in the lagged versions for $\mathrm{PM}_{2.5}$ and $\mathrm{CO}_{2}$.

After including the lagged traffic variables, another summary table is provided for the mean contributions for each significant input variable for the four pollutants at the $\mathrm{NE}$ Corner, as shown in Table 64.

Table 64. NE Corner Lagged Mean Contributions

\begin{tabular}{|c|c|c|c|c|}
\hline Model Input & UFP & $\mathrm{PM}_{2.5}$ & $\mathrm{CO}$ & $\mathrm{CO}_{2}$ \\
\hline $\mathrm{R}^{2}$ & $88.31 \%$ & $78.45 \%$ & $99.08 \%$ & $90.86 \%$ \\
\hline Log Likelihood & 764.14 & 1780.55 & 2516.79 & 2243.13 \\
\hline \multirow[t]{2}{*}{ AIC } & -1472.27 & -3471.10 & -4949.58 & -4420.25 \\
\hline & \multicolumn{4}{|c|}{ Mean Contribution - NE Corner } \\
\hline wsSE & & $-0.11 \%$ & & \\
\hline wsS & & $-0.18 \%$ & & $-0.08 \%$ \\
\hline wsSW & & $-0.15 \%$ & $-0.04 \%$ & \\
\hline BusRedLight & $0.40 \%$ & & & \\
\hline$E M P$ & & $-0.08 \%$ & & \\
\hline$H V N E$ & $0.25 \%$ & & & \\
\hline WBTH & $1.95 \%$ & & $-0.85 \%$ & \\
\hline ЕВТН & & & $0.54 \%$ & \\
\hline PowellVol & & $1.41 \%$ & & \\
\hline SBTH & & & & $-0.19 \%$ \\
\hline NBTH & & & & $0.32 \%$ \\
\hline GreenA & & $-13.31 \%$ & $-4.13 \%$ & $-4.00 \%$ \\
\hline GreenE & & $0.37 \%$ & $0.38 \%$ & \\
\hline GreenF & & & $1.38 \%$ & \\
\hline GreenC & & & $1.17 \%$ & \\
\hline GreenD & & $10.20 \%$ & & \\
\hline
\end{tabular}




\begin{tabular}{|c|c|c|c|c|}
\hline \multicolumn{5}{|c|}{ Lagged Variables } \\
\hline & UFP & $\mathrm{PM}_{2.5}$ & $\mathrm{CO}$ & $\mathrm{CO}_{2}$ \\
\hline BusRedLight & $0.59 \%$ & $0.58 \%$ & $0.06 \%$ & $0.47 \%$ \\
\hline$E M P$ & $-0.66 \%$ & $-0.10 \%$ & & \\
\hline$D P F$ & $-0.28 \%$ & & $-0.40 \%$ & $-0.87 \%$ \\
\hline TPAngled & & $-0.23 \%$ & $-0.04 \%$ & \\
\hline$H V N E$ & $1.12 \%$ & & & \\
\hline HVNETime & & $0.11 \%$ & & $0.21 \%$ \\
\hline WBTH & $1.77 \%$ & $8.92 \%$ & $-0.43 \%$ & $0.46 \%$ \\
\hline EBTH & & $-12.95 \%$ & $0.86 \%$ & $-0.72 \%$ \\
\hline SBTH & & $-0.39 \%$ & $2.25 \%$ & \\
\hline NBTH & & & $-0.49 \%$ & \\
\hline VolCycle & $136.33 \%$ & $13.44 \%$ & $30.77 \%$ & $40.03 \%$ \\
\hline
\end{tabular}

After lagging the traffic variables, wind in the east direction became insignificant, where it was included in the original $\mathrm{CO}_{2}$ model. Bus red light time was only included in the original models for UFP and $\mathrm{PM}_{2.5}$, but is significant for all pollutants once it has been lagged. Heavy vehicles are significant for all pollutants except for CO. The highest mean contribution in the original models was around $11 \%$, whereas with the lagged variables it has increased to $136 \%$ from lagged volume per cycle. The high mean contributions for many of the lagged traffic variables confirms higher explanatory power for the lagged models compared to the original ones.

\subsection{Comparison of Particulate Matter Between NE \& NW Corners}

Two pollutants were measured at both the NE and NW Corners of the intersection, including UFP and $\mathrm{PM}_{2.5}$. Autoregressive models were made for each pollutant using weather and traffic related variables to explain the variation in pollutant levels. The 
following summary table shows the elasticities for each significant input variable for UFP and $\mathrm{PM}_{2.5}$, at both the NE and NW Corners, as shown in Table 65 .

Table 65. NE \& NW Corners Elasticities

\begin{tabular}{|c|c|c|c|c|}
\hline Model Input & UFP NE & UFP NW & $\mathrm{PM}_{2.5} \mathrm{NE}$ & $\mathrm{PM}_{2.5} \mathrm{NW}$ \\
\hline $\mathrm{R}^{2}$ & $87.00 \%$ & $82.36 \%$ & $76.38 \%$ & $67.32 \%$ \\
\hline Log Likelihood & 741.90 & 270.45 & 1803.34 & 1246.76 \\
\hline \multirow[t]{2}{*}{$\mathrm{AIC}$} & -1469.80 & -524.90 & -3576.68 & -2471.51 \\
\hline & \multicolumn{4}{|c|}{ Elasticities - NE \& NW Corners } \\
\hline $\mathrm{RH}$ & $8.721 \%$ & $5.584 \%$ & $1.381 \%$ & \\
\hline Temp & & & $-4.088 \%$ & $-4.855 \%$ \\
\hline wsSE & & & $-0.001 \%$ & $-0.002 \%$ \\
\hline wsS & & & $-0.002 \%$ & \\
\hline wsSW & & & $-0.001 \%$ & \\
\hline wsNW & $-0.001 \%$ & & & $0.001 \%$ \\
\hline BusRedLight & $0.004 \%$ & & $0.001 \%$ & \\
\hline WBTH & $0.017 \%$ & $-0.019 \%$ & & $-0.011 \%$ \\
\hline EBTH & & & & $0.010 \%$ \\
\hline PowellVol & & & $0.011 \%$ & \\
\hline GreenA & & $-0.207 \%$ & $-0.122 \%$ & $-0.219 \%$ \\
\hline GreenE & & $0.019 \%$ & $0.005 \%$ & \\
\hline GreenF & & $0.070 \%$ & $0.010 \%$ & $0.018 \%$ \\
\hline GreenD & & & $0.079 \%$ & $0.158 \%$ \\
\hline VolCycle & & $0.203 \%$ & $0.051 \%$ & \\
\hline
\end{tabular}

Between the NE and NW Corners, UFP is being explained by many different variables. The two variables that are the same between the corners for UFP are relative humidity and westbound volumes. At the NE corner, bus presence and wind are significant, where they are not at the NW corner. However, at the NW corner signal timing parameters are included, that are not at the $\mathrm{NE}$ corner. $\mathrm{PM}_{2.5}$ has many more variables in common between the two locations at the intersection, such as temperature, wind in the southeast 
direction, and green time for Phase A, F, and D. At both locations, weather has the highest elasticity, followed by volume per cycle and green time for Phase A.

The following summary table shows the mean contributions for each significant input variable for UFP and $\mathrm{PM}_{2.5}$, at both the NE and NW Corners, as shown in Table 66.

Table 66. NE \& NW Corners Mean Contributions

\begin{tabular}{|c|c|c|c|c|}
\hline Model Input & UFP NE & UFP NW & $\mathrm{PM}_{2.5} \mathrm{NE}$ & $\mathrm{PM}_{2.5} \mathrm{NW}$ \\
\hline $\mathrm{R}^{2}$ & $87.00 \%$ & $82.36 \%$ & $76.38 \%$ & $67.32 \%$ \\
\hline Log Likelihood & 741.90 & 270.45 & 1803.34 & 1246.76 \\
\hline AIC & -1469.80 & -524.90 & -3576.68 & -2471.51 \\
\hline & \multicolumn{4}{|c|}{ Mean Contribution - NE \& NW Corners } \\
\hline wsSE & & & $-0.09 \%$ & $-0.17 \%$ \\
\hline wsS & & & $-0.18 \%$ & \\
\hline wsSW & & & $-0.13 \%$ & \\
\hline wsNW & $-0.13 \%$ & & & $0.11 \%$ \\
\hline BusRedLight & $0.45 \%$ & & $0.11 \%$ & \\
\hline$E M P$ & & & $-0.08 \%$ & \\
\hline$H V N E$ & $0.23 \%$ & & & \\
\hline$H V N W$ & & & & $0.05 \%$ \\
\hline WBTH & $1.73 \%$ & $-1.88 \%$ & & $-1.08 \%$ \\
\hline EBTH & & & & $1.03 \%$ \\
\hline PowellVol & & & $1.09 \%$ & \\
\hline GreenA & & $-18.73 \%$ & $-11.47 \%$ & $-19.67 \%$ \\
\hline GreenE & & $1.89 \%$ & $0.54 \%$ & \\
\hline GreenF & & $7.21 \%$ & $1.04 \%$ & $1.78 \%$ \\
\hline GreenD & & & $8.25 \%$ & $17.06 \%$ \\
\hline VolCycle & & $22.46 \%$ & $5.26 \%$ & \\
\hline
\end{tabular}

The highest mean contributions are signal timing parameters and volume per cycle. It is interesting to note that the additional green time given to Phase $\mathrm{A}$, which helps reduce queuing on Powell Boulevard, has the same impact at the NW as well as the NE location. 
After including the lagged traffic variables, the following summary table shows the elasticities for each significant input variable for UFP and $\mathrm{PM}_{2.5}$, at both the NE and NW Corners, as shown in Table 67.

Table 67. NE \& NW Corners Lagged Elasticities

\begin{tabular}{|c|c|c|c|c|}
\hline Model Input & UFP NE & UFP NW & $\mathrm{PM}_{2.5} \mathrm{NE}$ & $\mathrm{PM}_{2.5} \mathrm{NW}$ \\
\hline $\mathrm{R}^{2}$ & $88.31 \%$ & $83.07 \%$ & $78.45 \%$ & $69.22 \%$ \\
\hline Log Likelihood & 764.14 & 300.66 & 1780.55 & 1290.84 \\
\hline \multirow[t]{2}{*}{ AIC } & -1472.27 & -551.32 & -3471.10 & -2499.68 \\
\hline & \multicolumn{4}{|c|}{ Elasticities - NE \& NW Corners } \\
\hline RH & $7.833 \%$ & $2.562 \%$ & $1.299 \%$ & \\
\hline Temp & & & $-5.530 \%$ & $-6.481 \%$ \\
\hline wsSE & & & $-0.001 \%$ & $-0.002 \%$ \\
\hline wsS & & & $-0.002 \%$ & $-0.002 \%$ \\
\hline wsSW & & & $-0.002 \%$ & \\
\hline wsNW & & & & $0.001 \%$ \\
\hline BusRedLight & $0.004 \%$ & & & \\
\hline WBTH & $0.019 \%$ & $-0.017 \%$ & & $-0.011 \%$ \\
\hline EBTH & & & & $0.011 \%$ \\
\hline PowellVol & & & $0.014 \%$ & \\
\hline GreenA & & $-0.215 \%$ & $-0.143 \%$ & $-0.222 \%$ \\
\hline GreenE & & $0.018 \%$ & $0.004 \%$ & \\
\hline GreenF & & $0.058 \%$ & & \\
\hline GreenD & & & $0.097 \%$ & $0.113 \%$ \\
\hline VolCycle & & $0.150 \%$ & & \\
\hline \multicolumn{5}{|l|}{ Lagged Variables } \\
\hline BusRedLight & $0.006 \%$ & $0.003 \%$ & $0.006 \%$ & $0.002 \%$ \\
\hline HVNETime & & & $0.001 \%$ & \\
\hline WBTH & $0.018 \%$ & $-0.059 \%$ & $0.089 \%$ & $-0.153 \%$ \\
\hline EBTH & & $0.122 \%$ & $-0.130 \%$ & $0.110 \%$ \\
\hline SBTH & & & $-0.004 \%$ & \\
\hline VolCycle & $1.275 \%$ & $0.984 \%$ & $0.130 \%$ & $0.233 \%$ \\
\hline
\end{tabular}

With the original models, the highest elasticities belonged only to weather related variables, however with the lagged models, the lagged version of volume per cycle has a 
high elasticity as well. UFP at both corners has a similar elasticity for volume per cycle as well as bus red light time. For $\mathrm{PM}_{2.5}$, the elasticity for volume per cycle is higher at the NW corner than the NE.

After including the lagged traffic variables, the following summary table shows the mean contributions for each significant input variable for UFP and $\mathrm{PM}_{2.5}$, at both the NE and NW Corners, as shown in Table 68.

Table 68. NE \& NW Corners Lagged Mean Contributions

\begin{tabular}{|c|c|c|c|c|}
\hline Model Input & UFP NE & UFP NW & $\mathrm{PM}_{2.5} \mathrm{NE}$ & $\mathrm{PM}_{2.5} \mathrm{NW}$ \\
\hline $\mathrm{R}^{2}$ & $88.31 \%$ & $83.07 \%$ & $78.45 \%$ & $69.22 \%$ \\
\hline Log Likelihood & 764.14 & 300.66 & 1780.55 & 1290.84 \\
\hline \multirow{2}{*}{ AIC } & -1472.27 & -551.32 & -3471.10 & -2499.68 \\
\hline & \multicolumn{4}{|c|}{ Mean Contribution - NE Corner } \\
\hline wsSE & & & $-0.11 \%$ & $-0.19 \%$ \\
\hline wsS & & & $-0.18 \%$ & $-0.15 \%$ \\
\hline wsSW & & & $-0.15 \%$ & \\
\hline wsNW & & & & $0.10 \%$ \\
\hline BusRedLight & $0.40 \%$ & & & \\
\hline EMP & & & $-0.08 \%$ & \\
\hline$D P F$ & & $-0.31 \%$ & & \\
\hline TPAngled & & & & $-0.04 \%$ \\
\hline$H V N E$ & $0.25 \%$ & & & \\
\hline$H V N W$ & & $1.30 \%$ & & $0.91 \%$ \\
\hline WBTH & $1.95 \%$ & $-1.67 \%$ & & $-1.13 \%$ \\
\hline EBTH & & & & $1.14 \%$ \\
\hline PowellVol & & & $1.41 \%$ & \\
\hline SBTH & & & & \\
\hline NBTH & & & & \\
\hline GreenA & & $-19.38 \%$ & $-13.31 \%$ & $-19.91 \%$ \\
\hline GreenE & & $1.77 \%$ & $0.37 \%$ & $11.96 \%$ \\
\hline GreenF & & $5.93 \%$ & & \\
\hline GreenD & & & $10.20 \%$ & \\
\hline VolCycle & & $16.22 \%$ & & \\
\hline
\end{tabular}




\begin{tabular}{|l|rrrr|}
\hline \multicolumn{2}{|l|}{ Lagged Variables } & \multicolumn{4}{l|}{} \\
\hline & UFP NE & UFP NW & $\mathrm{PM}_{2.5} \mathrm{NE}$ & $\mathrm{PM}_{2.5} \mathrm{NW}$ \\
\hline BusRedLight & $0.59 \%$ & $0.30 \%$ & $0.58 \%$ & $0.20 \%$ \\
EMP & $-0.66 \%$ & & $-0.10 \%$ & \\
DPF & $-0.28 \%$ & & & \\
TPAngled & & & $-0.23 \%$ & $-0.27 \%$ \\
HVNE & $1.12 \%$ & & & \\
HVNETime & & & $0.11 \%$ & \\
WBTH & $1.77 \%$ & $\mathbf{- 5 . 8 9 \%}$ & $\mathbf{8 . 9 2 \%}$ & $\mathbf{- 1 5 . 2 0 \%}$ \\
EBTH & & $\mathbf{1 2 . 3 3 \%}$ & $\mathbf{- 1 2 . 9 5 \%}$ & $\mathbf{1 1 . 1 0 \%}$ \\
SBTH & & & $-0.39 \%$ & \\
VolCycle & $\mathbf{1 3 6 . 3 3 \%}$ & $\mathbf{1 0 8 . 7 9 \%}$ & $\mathbf{1 3 . 4 4 \%}$ & $\mathbf{2 4 . 7 3 \%}$ \\
\hline
\end{tabular}

For UFP, the highest mean contributions (over 100\%) came from the lagged version of volume per cycle at both corners of the intersection. For $\mathrm{PM}_{2.5}$, the lagged version of volume per cycle has a mean contribution of around $13 \%$ at the NE corner and $25 \%$ at the NW corner.

\subsection{Vehicle Related Impacts}

Vehicle related impacts were assessed in three ways: (1) calculating transit bus vehicle equivalencies, (2) calculating heavy vehicle equivalencies, and (3) summing vehicle related impacts for an overall vehicular contribution. Vehicle equivalencies were calculated for each pollutant to understand the number of vehicles that has the same impact on pollutant levels as one bus or one heavy vehicle. Vehicle movements were summed to show the traffic volume impact compared to other types of impacts.

\subsubsection{Transit Bus Impacts}

Transit buses were significant factors in explaining air pollutant levels for UFP, $\mathrm{PM}_{2.5}$, $\mathrm{CO}$ and $\mathrm{CO}_{2}$, at both the NE and NW corners of the intersection. The duration of time 
spent waiting at a red light after serving passengers was significant in explaining pollutant levels. There is potential to reduce the amount of time that a bus is forced to wait after having closed its doors with responsive signal timing and transit signal priority (TSP). These strategies can have a significant impact on exposure for pedestrians and transit users. Additionally, characteristics specific to each bus are significant, such as being equipped with a diesel particulate filter, an engine cooling system, and the orientation of the tailpipe. Buses equipped with any of the following: diesel particulate filters (DPF), a specific engine cooling system (EMP), and tailpipes that are angled instead of straight back; pollute less than buses without these characteristics.

Bus queuing is important to pedestrian and transit user exposure, due to the amount of time spent time waiting at the bus stop, typically located near an intersection. The number of equivalent vehicles to a transit bus, in terms of each pollutant, was calculated to quantify the impact of a bus compared to vehicles from the general traffic stream. The results of the lagged autoregressive models were used for a bus with the worst case scenario for characteristics (no diesel particulate filter, no engine cooling system, and a tailpipe oriented back) that waits at the red light the average amount of time, to determine the equivalency, shown in Table 69.

\section{Table 69. Bus Equivalencies}

\begin{tabular}{|l|c|c|c|c|c|c|}
\hline \multirow{2}{*}{$\begin{array}{l}\text { Number of } \\
\text { equivalent } \\
\text { vehicles }\end{array}$} & \multicolumn{4}{|c|}{ NE Corner } & \multicolumn{2}{c|}{ NW Corner } \\
\cline { 2 - 7 } & $\mathrm{UFP}$ & $\mathrm{PM}_{2.5}$ & $\mathrm{CO}$ & $\mathrm{CO}_{2}$ & UFP & $\mathrm{PM}_{2.5}$ \\
\cline { 2 - 7 } & 13 & 174 & 4 & 6 & 1 & 72 \\
\hline
\end{tabular}


One worst case bus presence is equivalent to having 174 vehicles in terms of $\mathrm{PM}_{2.5}$ at the NE corner and 72 at the NW corner. $\mathrm{PM}_{2.5}$ has the highest bus equivalencies, whereas UFP, $\mathrm{CO}$, and $\mathrm{CO}_{2}$ are equivalent to less than 15 vehicles.

Bus presence can have a large impact (the same as up to 174 vehicles) especially on $\mathrm{PM}_{2.5}$, demonstrating the importance of fleet management and operations for transit agencies. Fleet management could aim at installing technologies, such as diesel particulate filters, and engine cooling systems, on more of the bus fleet. One of the limitations of implementing these technologies is the budget. However, changing the tailpipe orientation is a cost effective way to reduce pollutant levels without a large investment. Beyond traits specific to each bus, operations play a key role in pollutant levels. Additional time spent idling at the intersection increases pollutant levels, indicating that the time buses are stopped is a pivotal time. Methods to serve passengers more quickly (electronic ticketing) and to reduce red light time (transit signal priority), could play a significant role in reducing air pollution exposure for pedestrians, bicyclists, and transit users.

\subsubsection{Heavy Vehicle Impacts}

Heavy vehicle presence was significant in explaining pollutant levels for all pollutants except for CO. The impact of heavy vehicles was quantified using the autoregressive lagged models and an average amount of heavy vehicle idling time. The contribution of queued heavy vehicles relative to the general traffic stream, was calculated as shown in Table 70, excluding CO (since heavy vehicles were not significant in explaining CO). 
Table 70. Heavy Vehicle Equivalencies

\begin{tabular}{|l|c|c|c|c|c|c|}
\hline \multirow{2}{*}{$\begin{array}{l}\text { Number of } \\
\text { equivalent } \\
\text { vehicles }\end{array}$} & \multicolumn{4}{|c|}{ NE Corner } & \multicolumn{2}{c|}{ NW Corner } \\
\cline { 2 - 7 } & $\mathrm{UFP}$ & $\mathrm{PM}_{2.5}$ & $\mathrm{CO}$ & $\mathrm{CO}_{2}$ & UFP & $\mathrm{PM}_{2.5}$ \\
\cline { 2 - 7 } & 14 & 1 & - & 1 & 1 & 2 \\
\hline
\end{tabular}

One heavy vehicle idling for the average length of time is equivalent to having 14 vehicles in terms of UFP at the NE corner. UFP has the highest heavy vehicle equivalencies, whereas $\mathrm{PM}_{2.5}, \mathrm{CO}$, and $\mathrm{CO}_{2}$ are equivalent to less than 2 vehicles.

Heavy vehicle presence can have a large impact (the same as up to 14 vehicles) especially on UFP, demonstrating the importance of strategies to reduce heavy vehicle queuing, such as truck signal priority. Additional time spent idling at the intersection increases pollutant levels, indicating that the time heavy vehicles are stopped is a pivotal time. Methods to reduce red light time (truck signal priority), could play a significant role in reducing air pollution exposure for pedestrians, bicyclists, and transit users.

\subsubsection{Overall Traffic Impacts}

To understand the total impact from traffic volumes, the mean contributions from traffic volumes were summed from the lagged autoregressive models. The results of this are shown in Table 71, where traffic volumes significantly contribute to pollutant levels at both the NE and NW corners of the intersection for all pollutants.

Table 71. Traffic Impact on Pollutants

\begin{tabular}{|l|c|c|c|c|c|c|}
\hline \multirow{2}{*}{$\begin{array}{l}\text { Traffic Impact } \\
\text { Mean }\end{array}$} & \multicolumn{4}{|c|}{ NE Corner } & \multicolumn{2}{c|}{ NW Corner } \\
\cline { 2 - 7 } Contribution & UFP & $\mathrm{PM}_{2.5}$ & $\mathrm{CO}$ & $\mathrm{CO}_{2}$ & UFP & $\mathrm{PM}_{2.5}$ \\
\cline { 2 - 7 } & $140.05 \%$ & $10.43 \%$ & $117.79 \%$ & $39.9 \%$ & $129.78 \%$ & $20.64 \%$ \\
\hline
\end{tabular}


UFP is highly affected by traffic volumes, much more so than $\mathrm{PM}_{2.5}$. Recall, one heavy vehicle was equivalent to 14 vehicles for UFP, while one bus was equivalent to 174 vehicles for $\mathrm{PM}_{2.5}$. UFP is most responsive to general traffic volumes and heavy vehicles, while $\mathrm{PM}_{2.5}$ is most responsive to transit buses.

\subsection{Traffic Signal Timing Impacts}

The effect from the change in traffic signal timing from time of day plans to an adaptive system can be quantified using results from the autoregressive models. The average percent contributions from the models are summarized for the traffic signal timing parameters using mean values for time of day (TOD) plans and for the adaptive signal timing system (SCATS). The traffic signal timing impact was assessed for all pollutants at both the NE corner NW corners, where a negative change is associated with SCATS reducing the pollutant levels compared to TOD, whereas positive changes indicate the opposite. The results are shown in Table 72, where UFP at the NE corner is not included because none of the traffic signal timing parameters were significant. Additionally, the total traffic signal timing impact is included, which is a multiplicative effect from all phase green time differences. 
Table 72. Impact of Traffic Signal Timing on Pollutant Levels

\begin{tabular}{|l|l|c|c|c|c|c|c|}
\hline & & GreenA & GreenE & GreenF & GreenC & GreenD & Total \\
\hline \multirow{2}{*}{$\begin{array}{l}\text { Mean } \\
\text { Value }\end{array}$} & TOD & 60 & 0 & 20 & 0 & 32 & 112 \\
\cline { 2 - 8 } & DCATS & 72 & 2 & 7 & 6 & 29 & 116 \\
\hline Impact & $\mathrm{PM}_{2.5}$ & $-2.28 \%$ & $0.38 \%$ & & & $-0.95 \%$ & $\mathbf{- 2 . 8 4 \%}$ \\
at NE & $\mathrm{CO}$ & $-0.68 \%$ & $0.40 \%$ & $-2.57 \%$ & $1.17 \%$ & & $\mathbf{1 . 7 1 \%}$ \\
Corner & $\mathrm{CO}_{2}$ & $-0.66 \%$ & & & & & $\mathbf{- 0 . 6 6 \%}$ \\
\hline Impact & $\mathrm{UFP}_{\text {at NW }}$ & $-3.41 \%$ & $1.86 \%$ & $-10.33 \%$ & & & $\mathbf{- 1 1 . 7 8 \%}$ \\
Corner & $\mathrm{PM}_{2.5}$ & $-3.52 \%$ & & & & $-1.11 \%$ & $\mathbf{- 4 . 5 9 \%}$ \\
\hline
\end{tabular}

The additional green time for Phase A resulted in lower pollutant levels in all cases, ranging from a $0.6 \%$ to a $3.5 \%$ reduction, which is slightly less at the NE corner. The reduction in green time for Phase $\mathrm{F}$ also resulted in reductions in pollutant levels in most cases. It was not significant for UFP and $\mathrm{CO}_{2}$ at the NE corner, but had a reduction of 1$10 \%$ in other cases. The largest difference was for UFP at the NW corner with a $10 \%$ reduction from green time for Phase $\mathrm{F}$. The reduction in green time for left turning had a distinct reduction.

Overall, the NW corner had the largest improvements from the change in signalization. UFP at the NW corner was most affected by the changes in signal timing at the intersection with a $12 \%$ reduction. $\mathrm{PM}_{2.5}$ at the $\mathrm{NW}$ corner had an $5 \%$ reduction followed by $\mathrm{PM}_{2.5}$ at the $\mathrm{NE}$ corner with $3 \%$. Both $\mathrm{CO}$ and $\mathrm{CO}_{2}$ only were reduced by $1-2 \%$. UFP at the NE corner was directly unaffected by the changes in signal timing at the intersection. 
According to Slavin, Feng, and Figliozzi (2012), the traffic conditions before and after SCATS was implemented are significantly different both in terms of speed and volume. Traffic data was compared at Powell Boulevard and $26^{\text {th }}$ Avenue before and after the traffic signal timing was changed. The results showed that during the morning and afternoon peak periods, there were both speed improvements and higher traffic volumes after SCATS was installed. The SCATS system favors or gives priority to the main line, which in this case is Powell Boulevard, over a secondary street such as $26^{\text {th }}$ (Slavin, Feng, \& Figliozzi, 2012).

For example, Figure 30 shows the volume before SCATS was implemented, afterwards, and the difference, for the morning peak period at Powell Boulevard and $26^{\text {th }}$ Avenue. The volume is consistently higher after SCATS was implemented, resulting in three additional vehicles per cycle. 

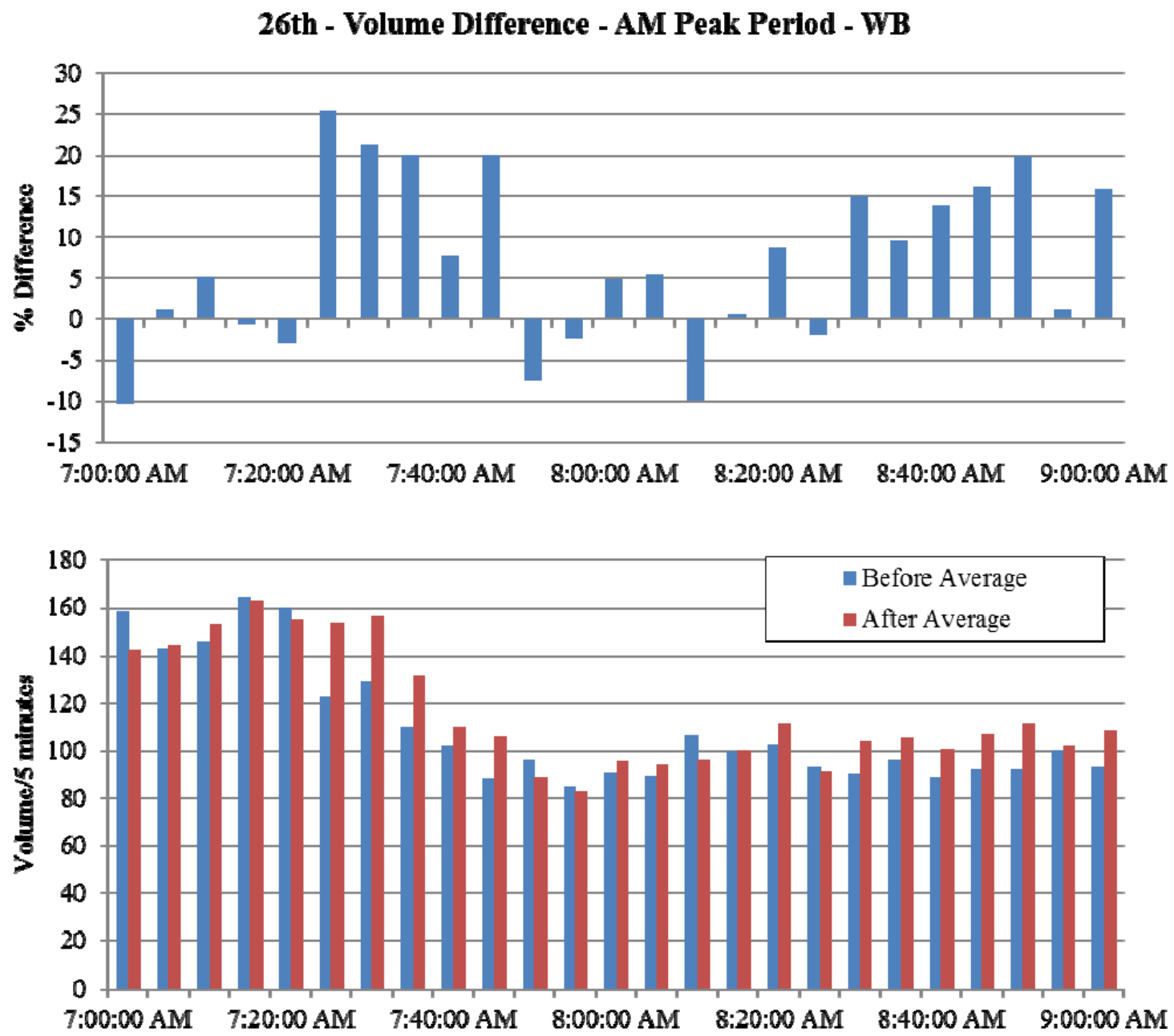

Figure 30. Volume Before and After SCATS

The SCATS implementation has been able to improve the speed at Powell Boulevard \& $26^{\text {th }}$ Avenue along with reducing air pollution. This system has been behaving in this way even with higher volumes on the roadway. From the autoregressive models we have concluded that even after controlling for other vehicles, there is an effect from the green time due to queuing. There are large impacts from queuing at the intersection between the before and after conditions. The results of this thesis have indicated that the operation of 
an adaptive traffic signal system has improved performance and resulted in reduced exposure for pedestrians, bicyclists, and transit users at the intersection level.

Anecdotally, from field observations it was noted that after the adaptive system was implemented, queuing along Powell Boulevard reduced significantly. Although queuing at $26^{\text {th }}$ Avenue appeared slightly worse afterwards, it did not seem to be as crucial to exposure.

\subsection{Policy Implications}

So far, this discussion chapter has aimed at summarizing the results and highlighting important relationships. Recall, there is a significant relationship between traffic signal timing parameters and pollutant levels, which varies by type of air pollutant and by the corner of the intersection. There are many policy implications that come from the results of this thesis. The most relevant policies related to outcomes from this research includes:

- Transit agency fleet management

- Transit signal priority

- Truck signal priority

- Operational strategies

Transit agency fleet management is often doing using basic guidelines, such as replacing buses every 10 years, or using optimization models to minimize overall cost over a specific time period. These optimization models can help fleet managers decide when to replace buses and what type to purchase. Bus fleet characteristics, which have been identified from this research as significant factors in explaining pollutant levels, are not currently considered in fleet management decisions. Characteristics, such as a diesel particulate filter, an engine cooling system, and the orientation of the tailpipe, make a 
large difference in the amount of pollution that a bus is emitting. These type of retrofits should be included in transit agencies' fleet management decisions, if they are not already.

In addition aiming towards a lower emitting bus fleet, bus operations are an important consideration. Often in urban areas, buses must navigate congested corridors and accrue delay throughout their trip. Transit signal priority, a system that allows late buses to request priority at a signalized intersection, changes traffic signal timing to reduce the amount of time buses are waiting at red lights at intersections. The main motivation behind transit signal priority is to reduce the wait time for transit users because buses carry a much greater passenger load than a passenger car. The additional benefit of reducing the bus wait time at a stop is a reduction in transit bus related emissions.

Heavy vehicles produce more emissions than passenger cars (14 times as much UFP). Truck signal priority, which works similarly to transit signal priority, can be used to reduce the wait time for trucks. The main motivation behind this is to reduce emissions. However, there is not the added benefit of reducing wait time for as many people, as there is with transit signal priority. Therefore it is not as commonly used in practice.

There are operational strategies that can be used to reduce the number of stops and queuing along a corridor. These strategies can minimize the amount of time spend in acceleration, which produces more emissions than cruising and idling based on results from emissions modeling (Papson, Hartley, \& Kuo, 2011). Signal retiming and responsive signal timing are commonly used to improve operations. 
Beyond the general policy implications and strategies that can be employed to reduce emissions, this thesis resulted in autoregressive models that can be applied to similar intersections. Future research efforts can explore similar models but with data collected at different times or weather conditions in intersections with different geometric design, traffic signal timing, and traffic volumes. 


\subsection{Conclusions}

This work is unique in the way that data were collected and analyzed. Data were collected simultaneously from various agencies and organizations to make this research possible. Pairing measured air quality data with detailed traffic signal timing plans has never been done. The way that the data were collected made it possible to create a link between all of the data sources. Because this type of work has not been done by other researchers, the methods of analysis also had to be developed. Previous studies examining the effect of traffic signal timing on air quality took in vehicle measurements and focused on driver exposure. However, this research aimed to assess pedestrian, bicyclist, and transit user exposure on an urban arterial. It is common for roadways to be multimodal in nature, therefore all modes should be considered. Pedestrians, bicyclists, and transit users waiting for the bus have no control over the air that they breathe. Their exposure level depends on outside factors that affect air quality. This research quantified which variables play a significant role in contributing to or reducing air pollution levels, and to what extent. The differences in exposure even within one intersection were examined and was able to be quantified since air quality measurements were taken at more than one corner of the intersection. Most users of the transportation system travel in various modes within urban areas. The results of this research are relevant to all users of the transportation system, not just drivers.

\subsection{Limitations}

There were a couple of limitations to this research. First, it was a challenge being able to obtain simultaneous data from all of the sources used in the analysis. The sample size was 
limited to one day due to data availability reasons. The second limitation addresses the issue of application of this model. These models that explain exposure at various corners of an intersection cannot be applied in every situation. They must only be applied at locations with similar geometric and operational characteristics. The model is most accurate when all predictors are around their mean values. However, it can be applied for the range of values that each predictor had in the model, so from the minimum to maximum values. The validity of the model is based applying it to a reasonable range of input values.

\subsection{Future Work}

The data collected at the southeast corner of the intersection could be incorporated in the analysis and compared to other corners of the intersection. This analysis was limited to using one day from the data that were collected due to data availability. In the future, it would be beneficial to add more days to the analysis using the same methods. The wind speed and direction was measured at only one corner of the intersection and used to represent the entire intersection, however in the future having an anemometer setup at each corner would provide more detailed wind data. Measurements could be taken at all four corners of the intersection instead of three to account for possible differences in how air quality is affected through the intersection environment.

Additionally, this analysis was based on a database that used a 5-second period for each row of data. This was selected based on keeping the finest level of detail possible. However, the same models could be created using an aggregation by cycle instead of a 
five second period. This would be helpful for the traffic and signal timing variables, but would lose some of the detail from the way that it was done. 


\subsection{References}

Ballester, F., Medina, S., Boldo, E., Goodman, P., Neuberger, M., Iniguez, C., et al. (2008). Reducing ambient levels of fine particulates could substantially improve health: a mortality impact assessment for 26 European cities. 62(2).

Bedada, G., Heinrich, J., Gotschi, T., Downs, S., Forsberg, B., Jarvis, D., et al. (2007). Urban background particulate matter and allergic sensitization in adults of ECRHS II. 210(6).

Bigazzi, A., \& Figliozzi, M. (2012). The Impact of Freeway Traffic Conditions on inVehicle Exposure to Ultrafine Particulate Matter. Atmospheric Environment.

Carslaw, D. (2012). The openair manual. London: King's College London.

Charron, A., \& Harrison, R. (2003). Primary particle formation from vehicle emissions during exhaust dilution in the roadside atmosphere. 37(29).

City of Portland. (2008, June 30). Oregon Department of Transportation: Transportation Operations Innovation \& Demonstration Program. 2008-2011 STIP Application US 26 Adaptive Signal System.

Claggett, M. (2010). Implications of the MOVES2010 Model on Mobile Source Emission Estimates. EM : Air \& Waste Management Association's magazine for environmental managers, 10-15.

Dutta, U. (2008). Evaluation of the SCATS Control System Final Report. Michigan Ohio University Transportation Center. 
EPA. (2007, July 9). Mobile Source Emissions - Past, Present, and Future: Pollutants. Retrieved November 5, 2011, from United States Environmental Protection Agency: http://www.epa.gov/otaq/invntory/overview/pollutants/index.htm

EPA. (2011, August 15). Modeling and Inventories. (Environmental Protection Agency) Retrieved December 29, 2011, from http://www.epa.gov/otaq/models.htm

EPA. (2011, November 8). National Ambient Air Quality Standards. (EPA) Retrieved December 29, 2011, from http://www.epa.gov/air/criteria.html

EPA. (2012, June 14). Environmental Protection Agency. Retrieved July 9, 2012, from Carbon Dioxide Emissions - Greenhouse Gas Emissions: http://www.epa.gov/climatechange/ghgemissions/gases/co2.html\#Trends

EPA. (2012, June 29). Federal Register Proposed Rules. Retrieved from National Ambient Air Quality Standards for Particulate Matter: http://www.gpo.gov/fdsys/pkg/FR-2012-06-29/pdf/2012-15017.pdf

EPA. (2012, June 28). Particulate Matter: Air \& Radiation. (US EPA) Retrieved July 2, 2011, from http://www.epa.gov/oar/particlepollution/

Hagler, G., Baldauf, R., Thoma, E., Long, T., Snow, R., Kinsey, J., et al. (2009). Ultrafine particles near a major roadway in Raleigh, North Carolina: Downwind attenuation and correlation with traffic-related pollutants. 43(6). 
Holmes, N. (2007). A review of particle formation events and growth in the atmosphere in the various environments and discussion of mechanistic implications. Atmospheric Environment, 2183-2201.

Kergaye, C., Stevanovic, A., \& Martin, P. (2010). Comparative Evaluation of Adaptive Traffic Control System Assessments Through Field and Microsimulation. Journal of Intelligent Transportation Systems, 109-124.

Kittelson \& Associates, Inc. (2008). Traffic Signal Timing Manual. US Department of Transportation Federal Highway Administration.

Li, J.-Q., Wu, G., \& Zou, N. (2011). Investigation of the impacts of signal timing on vehicle emissions at an isolated intersection. Transportation Research Part D, 16, 409-414.

Li, X., Li, G., Pang, S.-S., Yang, X., \& Tian, J. (2004). Signal timing of intersections using integrated optimization of traffic quality, emissions and fuel consumption: a note. Transportation Research, Part D(9), 401-407.

Morawska, L., Moore, M., \& Ristovski, Z. (2004). Health impacts of ultrafine particles: Desktop literature review and analysis. Report to the Australian Department of the Environment and Heritage.

Nguyen, V. N. (1994). A Comparison of SCATS Adaptive and Fixed-Time Traffic Control Techniques. Second International Symposium on Highway Capacity, 1932. 
Pandian, S., Gokhale, S., \& Ghoshal, A. (2009). Evaluating effects of traffic and vehicle characteristics on vehicular emissions near traffic intersections. 14(3).

Papson, A., Hartley, S., \& Kuo, K.-L. (2011). Analysis of Emissions at Congested and Uncongested Intersections using MOVES2010. Transportation Research Board. Washington DC.

Parikh, R. I. (2006). Effectiveness of Signal Coordination as an Emission Reduction Measure for Vehicles. University of Texas at Arlington - Masters Thesis Dissertation.

Peters, J., McCourt, R., \& Hurtado, R. (2009). Reducing Carbon Emissions and Congestion by Coordinating Traffic Signals. ITE Journal, 79(4), 25-29.

Pindyck, R., \& Rubinfeld, D. (1998). Econometric Models and Economic Forecasts - 4th Edition. Boston, Massachusetts: Irwin/McGraw-Hill.

Portland Public Schools. (2010). About Cleveland. Retrieved February 15, 2012, from Cleveland High School: http://www.pps.k12.or.us/schools/cleveland/194.htm

Slavin, C., Feng, W., \& Figliozzi, M. (2012). An Evaluation of the Impacts of an Adaptive Coordinated Traffic Signal System on Transit Performance. Conference on Advanced Systems for Public Transport. Santiago, Chile.

Stevanovic, A., Kergaye, C., \& Stevanovic, J. (2012). Environmental Benefits of an Adaptive Traffic Control System: Assessment of Fuel Consumption and 
Vehicular Emissions. Transportation Research Board Annual Meeting. Washington, DC.

Sunkari, S. (2004). The Benefits of Retiming Traffic Signals. ITE Journal, 74(4), 26-29.

Tao, F., Shi, Q., \& Yu, L. (2011). Evaluation of Effectiveness of Coordinated Signal Control on Reducing Vehicle Emissions during Peak Hours vs. Non-peak Hours. Transportation Research Board. Washington DC.

TransCore. (2011). SCATS Adaptive Traffic Control System. Retrieved November 15, 2011, from ATMS Downloadable Literature: http://www.transcore.com/IA/traffic\%20management\%20systems/atms-download.shtml

Unal, A., Rouphail, N. M., \& Frey, H. C. (2003). Effect of Arterial Signalization and Level of Service on Measured Vehicle Emissions. Transportation Research Record, 1842, 47-56.

Vallero, D. (2008). Fundamentals of air pollution. Academic press.

WHO. (1999). Environmental Health Criteria 213: Carbon Monoxide (second edition). Geneva: World Health Organization.

Zhu, Y., Hinds, W., Kim, S., Shen, S., \& Sioutas, C. (2002). Study of ultrafine particles near a major highway with heavy-duty diesel traffic. 36(27).

Zhu, Y., Kuhn, T., Mayo, P., \& Hinds, W. (2006). Comparison of daytime and nighttime concentration profiles and size distributions of ultrafine particles near a major highway. 40(8). 


\subsection{Appendix A: Exploratory Data Analysis}

Table 73. All Correlations Between Weather, Traffic and Pollutant Levels

\begin{tabular}{|c|c|c|c|c|c|c|}
\hline & \multicolumn{4}{|c|}{ NE Corner } & \multicolumn{2}{|c|}{ NW Corner } \\
\hline & UFP & $\mathrm{PM}_{2.5}$ & $\mathrm{CO}$ & $\mathrm{CO}_{2}$ & UFP & $\mathrm{PM}_{2.5}$ \\
\hline RH & 0.53 & 0.16 & 0.58 & 0.55 & 0.34 & 0.11 \\
\hline Temp & 0.06 & -0.19 & 0.18 & 0.31 & 0.12 & -0.20 \\
\hline wsN & 0.08 & 0.21 & 0.17 & 0.10 & 0.23 & 0.20 \\
\hline wsNE & 0.07 & 0.20 & 0.09 & 0.08 & 0.16 & 0.12 \\
\hline wsE & -0.03 & 0.07 & 0.04 & 0.02 & 0.03 & 0.06 \\
\hline wsSE & -0.26 & -0.22 & -0.33 & -0.25 & -0.25 & -0.17 \\
\hline wsS & -0.09 & -0.33 & -0.24 & -0.18 & -0.32 & -0.24 \\
\hline wsSW & -0.03 & -0.18 & -0.11 & -0.05 & -0.18 & -0.15 \\
\hline wsW & -0.02 & 0.08 & 0.02 & -0.01 & 0.04 & 0.04 \\
\hline wsNW & 0.07 & 0.16 & 0.12 & 0.08 & 0.12 & 0.13 \\
\hline BusNE & 0.07 & 0.04 & -0.03 & 0.04 & 0.03 & 0.00 \\
\hline BusRedLight & 0.15 & 0.18 & 0.07 & 0.08 & 0.07 & 0.03 \\
\hline TPAngled & -0.04 & -0.06 & -0.06 & -0.04 & -0.01 & -0.05 \\
\hline EMP & -0.02 & -0.08 & 0.00 & 0.06 & 0.06 & 0.01 \\
\hline DPF & 0.06 & 0.06 & -0.03 & 0.03 & 0.06 & 0.02 \\
\hline HVNE & 0.05 & 0.07 & 0.10 & 0.12 & -0.02 & -0.03 \\
\hline HVNETime & 0.05 & 0.09 & 0.12 & 0.11 & -0.04 & -0.03 \\
\hline HVNW & 0.19 & 0.05 & 0.15 & 0.13 & 0.19 & 0.04 \\
\hline ЕВТН & 0.11 & 0.12 & 0.09 & 0.03 & 0.08 & 0.05 \\
\hline WBTH & 0.06 & -0.06 & -0.03 & -0.05 & -0.09 & -0.08 \\
\hline SBTH & -0.06 & 0.02 & 0.02 & 0.02 & 0.07 & 0.05 \\
\hline NBTH & 0.01 & 0.05 & 0.04 & 0.09 & 0.05 & 0.00 \\
\hline GreenA & -0.01 & -0.24 & -0.09 & -0.08 & -0.18 & -0.23 \\
\hline GreenC & -0.03 & -0.23 & -0.17 & -0.10 & -0.19 & -0.17 \\
\hline GreenF & 0.09 & 0.11 & 0.13 & 0.10 & 0.20 & 0.15 \\
\hline GreenE & 0.02 & 0.21 & 0.08 & 0.05 & 0.18 & 0.14 \\
\hline GreenD & 0.16 & 0.21 & 0.25 & 0.11 & 0.21 & 0.14 \\
\hline ActualCL & 0.10 & -0.09 & 0.05 & 0.00 & 0.02 & -0.08 \\
\hline VolCycle & 0.24 & 0.13 & 0.31 & 0.24 & 0.15 & 0.08 \\
\hline
\end{tabular}




\subsection{Appendix B: Exploratory Linear Regression Analysis}

Table 74. UFP NE Lagged Log Linear Model Interpretation All Lags

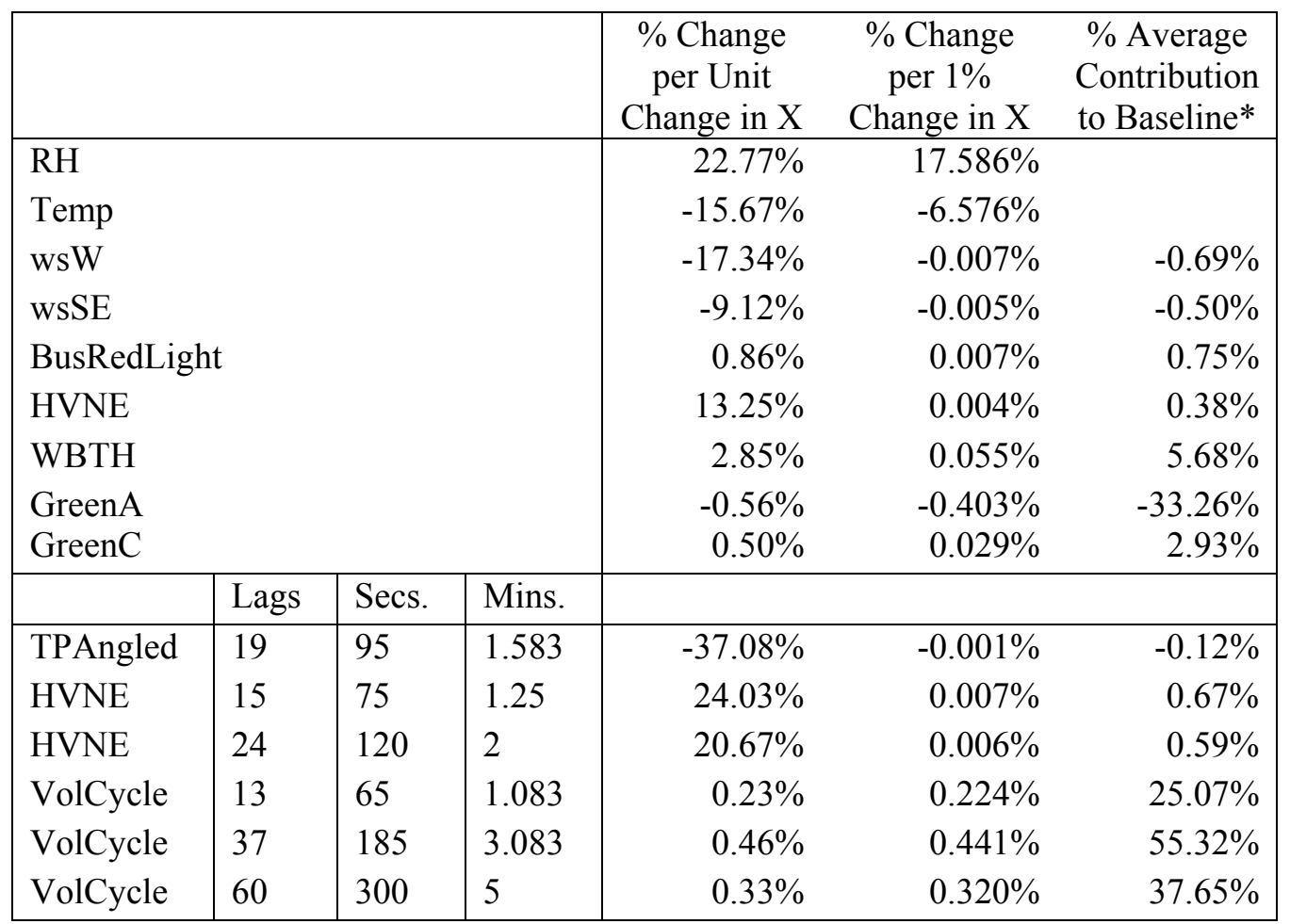

*Baseline is the sum of constant, $\mathrm{RH}$, and temp

Table 75. $\mathrm{PM}_{2.5}$ NE Lagged Log Linear Model Interpretation All Lags

\begin{tabular}{|l|rrr|}
\hline & $\begin{array}{r}\text { \% Change per } \\
\text { Unit Change } \\
\text { in X }\end{array}$ & $\begin{array}{c}\text { \% Change } \\
\text { per } 1 \% \\
\text { Change in X }\end{array}$ & $\begin{array}{c}\text { \% Average } \\
\text { Contribution } \\
\text { to Baseline* }\end{array}$ \\
\hline RH & $0.94 \%$ & $0.741 \%$ & \\
Temp & $-12.00 \%$ & $-4.975 \%$ & \\
wsN & $4.83 \%$ & $0.008 \%$ & $0.79 \%$ \\
wsNE & $11.72 \%$ & $0.006 \%$ & $0.58 \%$ \\
wsSE & $-15.62 \%$ & $-0.006 \%$ & $-0.61 \%$ \\
wsS & $-18.35 \%$ & $-0.013 \%$ & $-1.34 \%$ \\
wsSW & $-11.66 \%$ & $-0.006 \%$ & $-0.62 \%$ \\
wsNW & $5.96 \%$ & $0.004 \%$ & $0.42 \%$ \\
BusRedLight & $0.35 \%$ & $0.003 \%$ & $0.30 \%$ \\
TPAngled & $-16.79 \%$ & $0.000 \%$ & $-0.05 \%$ \\
EMP & $-7.57 \%$ & $-0.002 \%$ & $-0.16 \%$ \\
HVNETime & $0.19 \%$ & $0.002 \%$ & $0.17 \%$ \\
GreenA & $-0.22 \%$ & $-0.155 \%$ & $-14.34 \%$
\end{tabular}




\begin{tabular}{|l|l|l|l|lrr|} 
GreenE \\
GreenD
\end{tabular}

*Baseline is the sum of constant, RH, and temp

Table 76. CO NE Lagged Log Linear Model Interpretation All Lags

\begin{tabular}{|l|rrr|}
\hline \multicolumn{1}{|c}{} & $\begin{array}{c}\text { \% Change } \\
\text { per Unit } \\
\text { Change in X }\end{array}$ & $\begin{array}{c}\text { \% Change } \\
\text { per 1\% } \\
\text { Change in X }\end{array}$ & $\begin{array}{c}\text { \% Average } \\
\text { Contribution } \\
\text { to Baseline* }\end{array}$ \\
\hline RH & $22.68 \%$ & $17.518 \%$ & \\
wsW & $-8.36 \%$ & $-0.005 \%$ & $-0.46 \%$ \\
wSSW & $-20.44 \%$ & $-0.012 \%$ & $-1.14 \%$ \\
wSS & $-36.37 \%$ & $-0.030 \%$ & $-2.96 \%$ \\
WSSE & $-42.29 \%$ & $-0.020 \%$ & $-1.97 \%$ \\
TPAngled & $-55.58 \%$ & $-0.002 \%$ & $-0.21 \%$ \\
DPF & $-9.24 \%$ & $-0.005 \%$ & $-0.47 \%$ \\
HVNETime & $0.82 \%$ & $0.007 \%$ & $0.73 \%$ \\
GreenA & $-0.80 \%$ & $-0.576 \%$ & $-43.85 \%$ \\
GreenF & $-0.66 \%$ & $-0.044 \%$ & $-4.31 \%$
\end{tabular}




\begin{tabular}{|c|c|c|c|c|c|c|}
\hline \multicolumn{4}{|l|}{ VolCycle } & \multirow[t]{2}{*}{$0.20 \%$} & \multirow[t]{2}{*}{$0.196 \%$} & \multirow[t]{2}{*}{$21.67 \%$} \\
\hline & Lags & Secs. & Mins. & & & \\
\hline BusNE & 24 & 120 & 2 & $16.47 \%$ & $0.011 \%$ & $1.15 \%$ \\
\hline TPAngled & 4 & 20 & 0.33 & $-59.11 \%$ & $-0.002 \%$ & $-0.23 \%$ \\
\hline TPAngled & 17 & 85 & 1.417 & $-38.90 \%$ & $-0.001 \%$ & $-0.13 \%$ \\
\hline TPAngled & 21 & 105 & 1.75 & $-31.93 \%$ & $-0.001 \%$ & $-0.10 \%$ \\
\hline HVNETime & 6 & 30 & 0.5 & $0.67 \%$ & $0.006 \%$ & $0.61 \%$ \\
\hline ЕВТН & 24 & 120 & 2 & $2.04 \%$ & $0.025 \%$ & $2.53 \%$ \\
\hline NBTH & 5 & 25 & 0.417 & $-14.77 \%$ & $-0.012 \%$ & $-1.22 \%$ \\
\hline NBTH & 12 & 60 & 1 & $-21.02 \%$ & $-0.018 \%$ & $-1.74 \%$ \\
\hline VolCycle & 15 & 75 & 1.25 & $0.44 \%$ & $0.428 \%$ & $53.26 \%$ \\
\hline VolCycle & 34 & 170 & 2.83 & $0.26 \%$ & $0.247 \%$ & $27.97 \%$ \\
\hline VolCycle & 39 & 195 & 3.25 & $0.38 \%$ & $0.365 \%$ & $43.92 \%$ \\
\hline VolCycle & 60 & 300 & 5 & $0.10 \%$ & $0.092 \%$ & $9.67 \%$ \\
\hline
\end{tabular}

*Baseline is the sum of constant, $\mathrm{RH}$, and temp

Table 77. $\mathrm{CO}_{2} \mathrm{NE}$ Lagged Log Linear Model Interpretation All Lags

\begin{tabular}{|c|c|c|c|c|c|c|}
\hline & & & & $\begin{array}{l}\text { \% Change per } \\
\text { Unit Change } \\
\text { in X }\end{array}$ & $\begin{array}{l}\% \text { Change per } \\
1 \% \text { Change in } \\
X\end{array}$ & $\begin{array}{l}\text { \% Average } \\
\text { Contribution } \\
\text { to Baseline* }\end{array}$ \\
\hline \multicolumn{4}{|l|}{$\mathrm{RH}$} & $9.80 \%$ & $7.663 \%$ & \\
\hline \multicolumn{4}{|l|}{ wsS } & $-7.67 \%$ & $-0.005 \%$ & $-0.53 \%$ \\
\hline \multicolumn{4}{|l|}{ wsSE } & $-5.87 \%$ & $-0.002 \%$ & $-0.22 \%$ \\
\hline \multicolumn{4}{|l|}{ HVNE } & $10.62 \%$ & $0.003 \%$ & $0.31 \%$ \\
\hline \multicolumn{4}{|l|}{ GreenA } & $-0.35 \%$ & $-0.252 \%$ & $-22.28 \%$ \\
\hline \multicolumn{4}{|l|}{ GreenE } & $-0.16 \%$ & $-0.003 \%$ & $-0.30 \%$ \\
\hline \multicolumn{4}{|l|}{ GreenF } & $-0.27 \%$ & $-0.018 \%$ & $-1.78 \%$ \\
\hline \multicolumn{4}{|l|}{ VolCycle } & $0.06 \%$ & $0.058 \%$ & $5.93 \%$ \\
\hline & Lags & Secs. & Mins. & & & \\
\hline BusRedLight & 16 & 80 & 1.33 & $0.19 \%$ & $0.002 \%$ & $0.17 \%$ \\
\hline BusRedLight & 24 & 120 & 2 & $0.20 \%$ & $0.002 \%$ & $0.18 \%$ \\
\hline EMP & 24 & 120 & 2 & $8.02 \%$ & $0.002 \%$ & $0.16 \%$ \\
\hline HVNETime & 5 & 25 & 0.417 & $0.24 \%$ & $0.002 \%$ & $0.21 \%$ \\
\hline HVNETime & 9 & 45 & 0.75 & $0.18 \%$ & $0.002 \%$ & $0.17 \%$ \\
\hline EBTH & 15 & 75 & 1.25 & $1.01 \%$ & $0.012 \%$ & $1.26 \%$ \\
\hline NBTH & 8 & 40 & 0.67 & $-7.00 \%$ & $-0.006 \%$ & $-0.55 \%$ \\
\hline VolCycle & 13 & 65 & 1.083 & $0.10 \%$ & $0.095 \%$ & $9.93 \%$ \\
\hline VolCycle & 37 & 185 & 3.083 & $0.18 \%$ & $0.172 \%$ & $18.78 \%$ \\
\hline VolCycle & 46 & 230 & 3.83 & $0.05 \%$ & $0.051 \%$ & $5.28 \%$ \\
\hline
\end{tabular}

*Baseline is the sum of constant, $\mathrm{RH}$, and temp 
Table 78. UFP NW Lagged Log Linear Model Interpretation All Lags

\begin{tabular}{|c|c|c|c|c|c|c|}
\hline & & & & $\begin{array}{c}\text { \% Change per } \\
\text { Unit Change } \\
\text { in X }\end{array}$ & $\begin{array}{l}\text { \% Change per } \\
1 \% \text { Change in } \\
X\end{array}$ & $\begin{array}{l}\text { \% Average } \\
\text { Contribution } \\
\text { to Baseline* }\end{array}$ \\
\hline $\mathrm{RH}$ & & & & $13.22 \%$ & $10.304 \%$ & \\
\hline wsNE & & & & $20.61 \%$ & $0.010 \%$ & $0.99 \%$ \\
\hline wsN & & & & $9.82 \%$ & $0.016 \%$ & $1.57 \%$ \\
\hline wsSW & & & & $-29.77 \%$ & $-0.018 \%$ & $-1.76 \%$ \\
\hline wsS & & & & $-40.22 \%$ & $-0.034 \%$ & $-3.36 \%$ \\
\hline wsSE & & & & $-33.85 \%$ & $-0.015 \%$ & $-1.48 \%$ \\
\hline HVNW & & & & $13.55 \%$ & $0.051 \%$ & $5.19 \%$ \\
\hline GreenA & & & & $-0.47 \%$ & $-0.338 \%$ & $-28.70 \%$ \\
\hline GreenD & & & & $0.77 \%$ & $0.226 \%$ & $25.39 \%$ \\
\hline GreenE & & & & $0.90 \%$ & $0.016 \%$ & $1.66 \%$ \\
\hline GreenF & & & & $0.48 \%$ & $0.031 \%$ & $3.19 \%$ \\
\hline VolCycle & & & & $0.11 \%$ & $0.107 \%$ & $11.24 \%$ \\
\hline & Lags & Secs. & Mins. & & & \\
\hline BusRedLight & 24 & 120 & 2.00 & $0.37 \%$ & $0.003 \%$ & $0.33 \%$ \\
\hline EBTH & 9 & 45 & 0.75 & $4.05 \%$ & $0.050 \%$ & $5.07 \%$ \\
\hline EBTH & 18 & 90 & 1.50 & $3.73 \%$ & $0.046 \%$ & $4.66 \%$ \\
\hline EBTH & 24 & 120 & 2.00 & $2.97 \%$ & $0.036 \%$ & $3.67 \%$ \\
\hline WBTH & 9 & 45 & 0.75 & $-2.98 \%$ & $-0.060 \%$ & $-5.78 \%$ \\
\hline WBTH & 12 & 60 & 1.00 & $-3.07 \%$ & $-0.062 \%$ & $-5.97 \%$ \\
\hline WBTH & 15 & 75 & 1.25 & $-3.53 \%$ & $-0.071 \%$ & $-6.86 \%$ \\
\hline WBTH & 19 & 95 & 1.58 & $-4.03 \%$ & $-0.081 \%$ & $-7.80 \%$ \\
\hline WBTH & 22 & 110 & 1.83 & $-2.67 \%$ & $-0.053 \%$ & $-5.19 \%$ \\
\hline WBTH & 24 & 120 & 2.00 & $-4.59 \%$ & $-0.093 \%$ & $-8.85 \%$ \\
\hline
\end{tabular}

*Baseline is the sum of constant, $\mathrm{RH}$, and temp

Table 79. $\mathrm{PM}_{2.5}$ NW Lagged Log Linear Model Interpretation All Lags

\begin{tabular}{|l|rrr|}
\hline & \multicolumn{1}{l}{ B } & \multicolumn{1}{l}{$\mathrm{SE}_{\mathrm{B}}$} & P-Value \\
\hline Constant & 8.9669 & 0.6068 & 0.0000 \\
RH & 0.0289 & 0.0056 & 0.0000 \\
Temp & -0.1809 & 0.0135 & 0.0000 \\
wsN & 0.0554 & 0.0126 & 0.0000 \\
wsNE & 0.0573 & 0.0239 & 0.0167 \\
wsSE & -0.1319 & 0.0361 & 0.0003 \\
wsS & -0.1430 & 0.0278 & 0.0000 \\
wsSW & -0.1050 & 0.0270 & 0.0001 \\
wsNW & 0.0622 & 0.0183 & 0.0007
\end{tabular}




\begin{tabular}{|l|l|l|l|rrr|} 
BusRedLight \\
GreenA \\
GreenD
\end{tabular}

*Baseline is the sum of constant, $\mathrm{RH}$, and temp 


\subsection{Appendix C: Time Series Analysis}

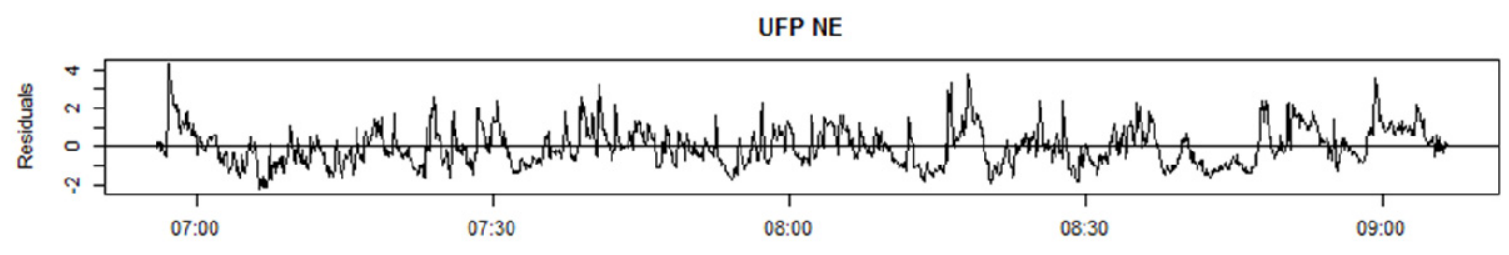

PM2.5 NE

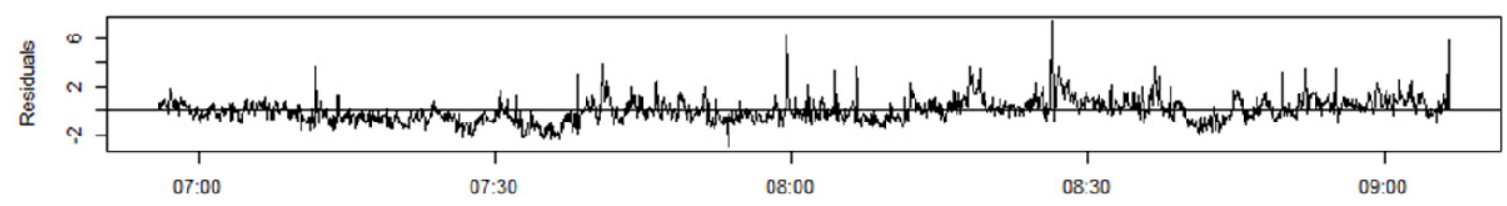

CO NE
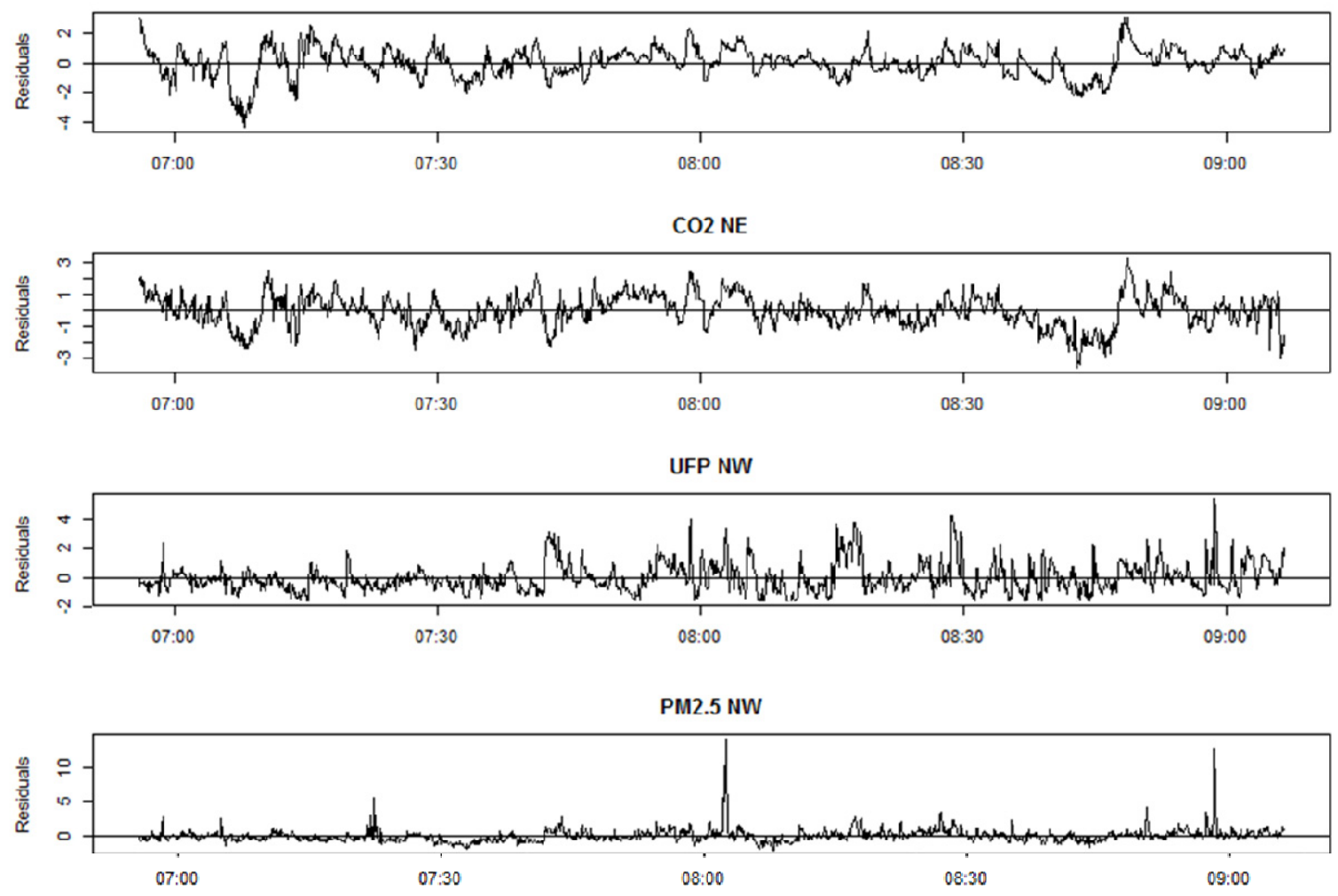

Figure 31. Residual Plots - Log Linear Models 

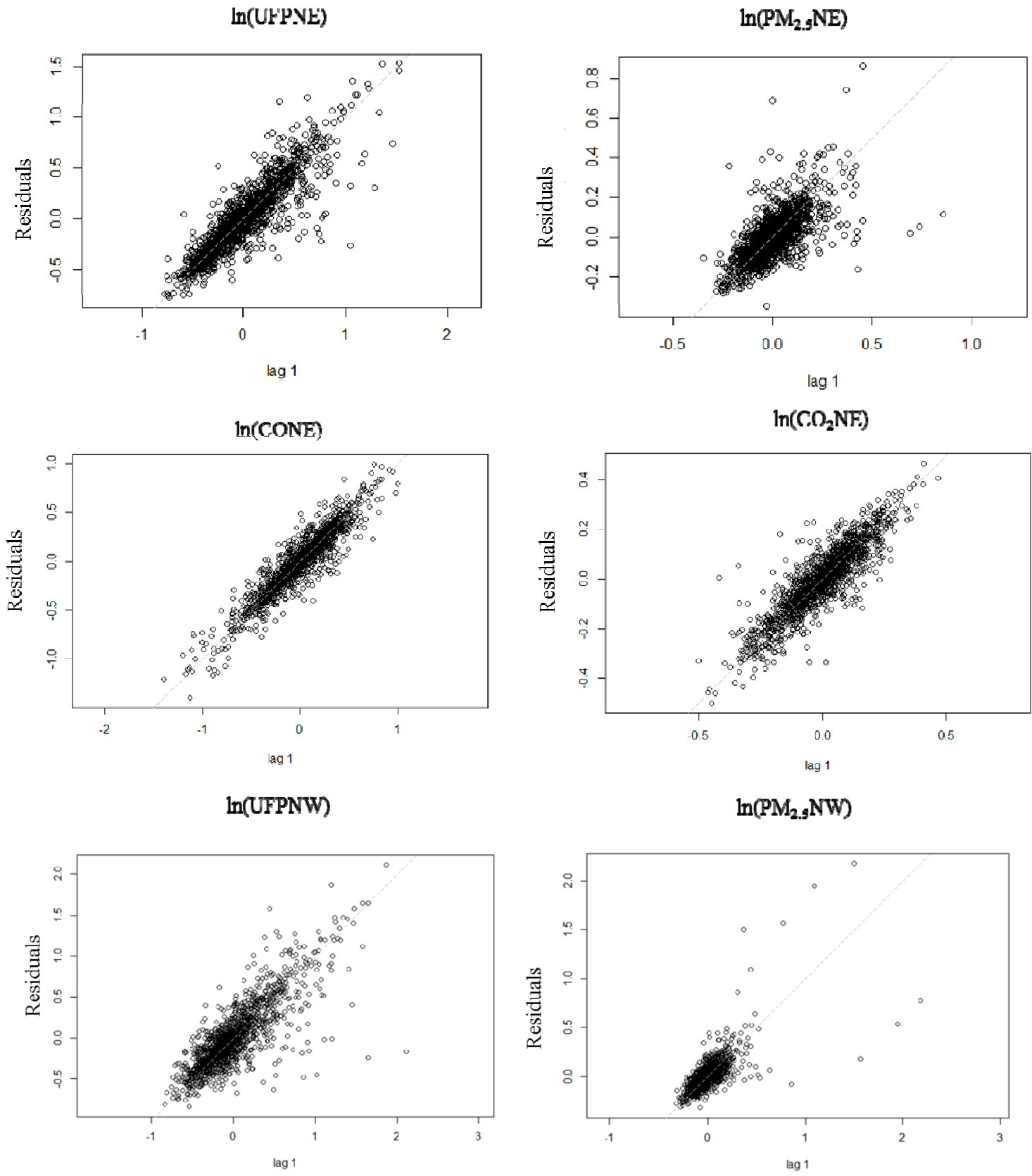

Figure 32. Lag Plots - Log Linear Models 
In(UFP NE)
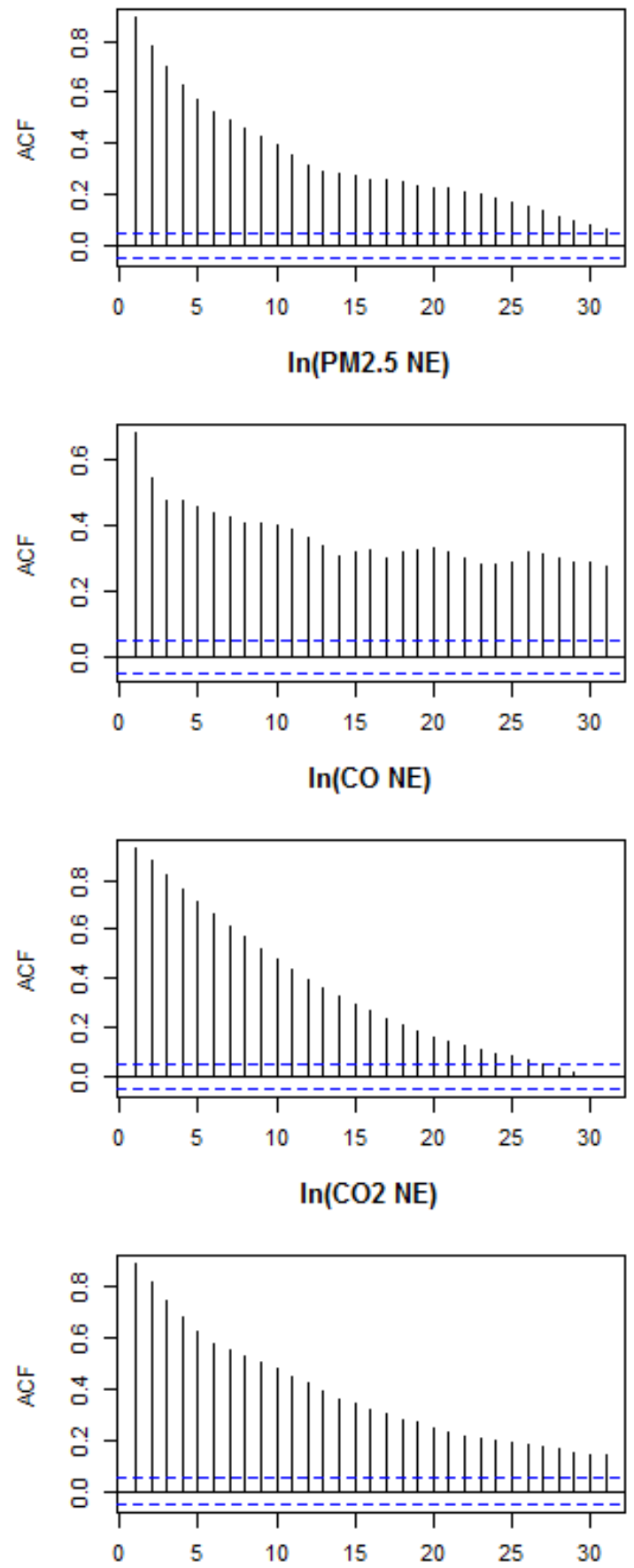

In(UFP NE)
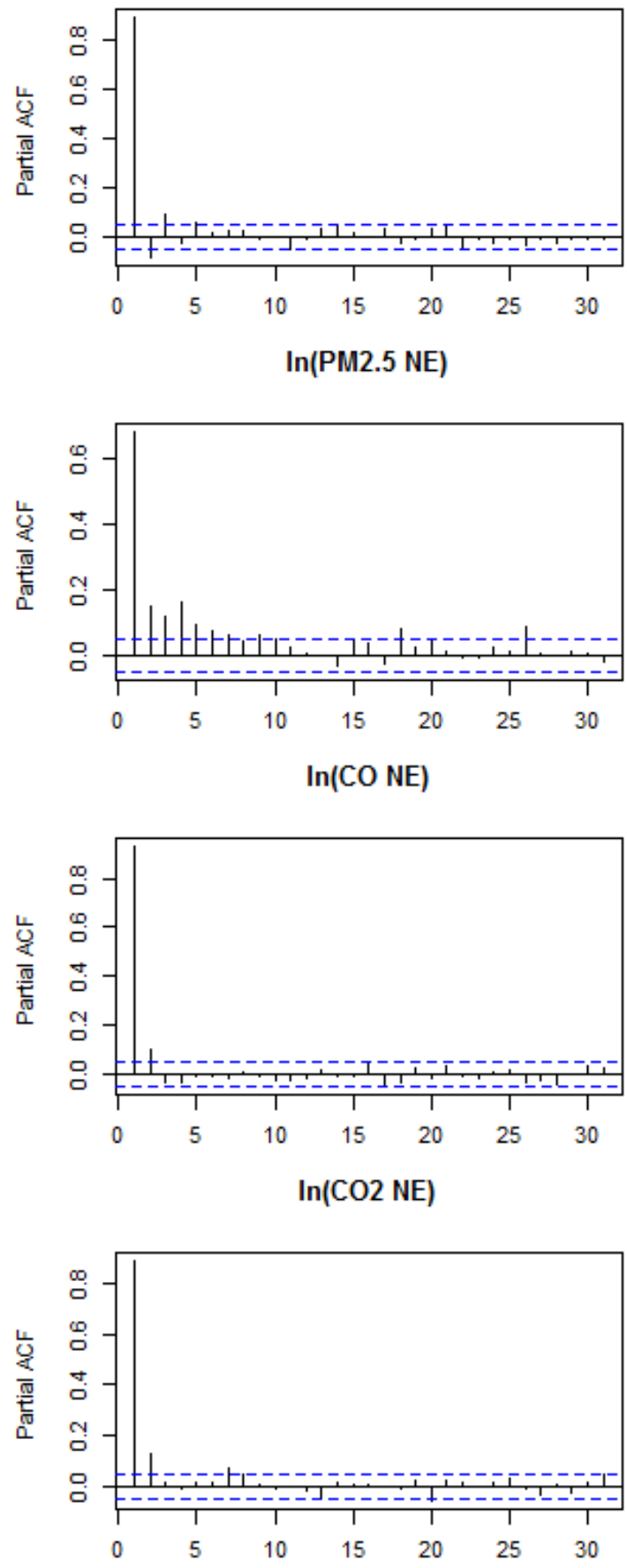

Figure 33. ACF \& PACF Plots - Log Linear Models NE Corner 
In(UFP NW)
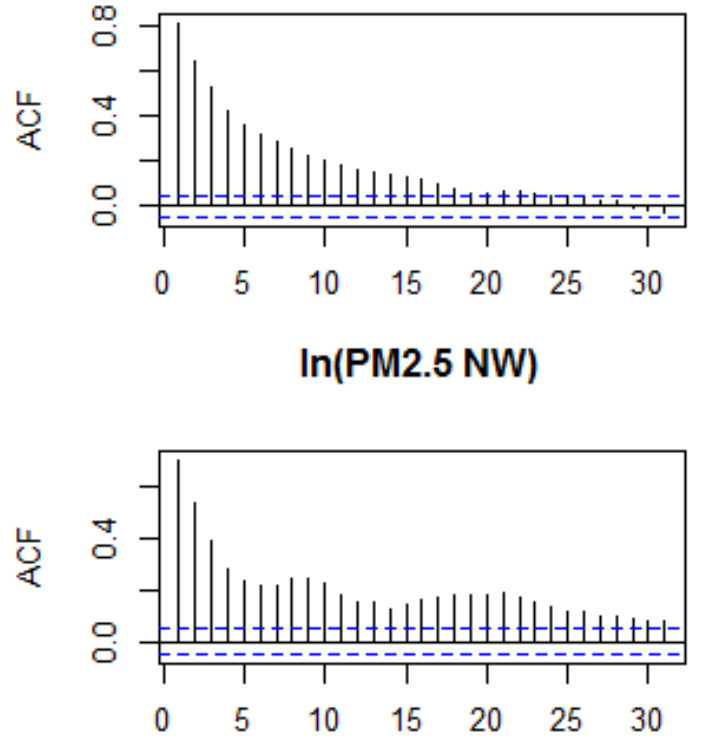

In(UFP NW)
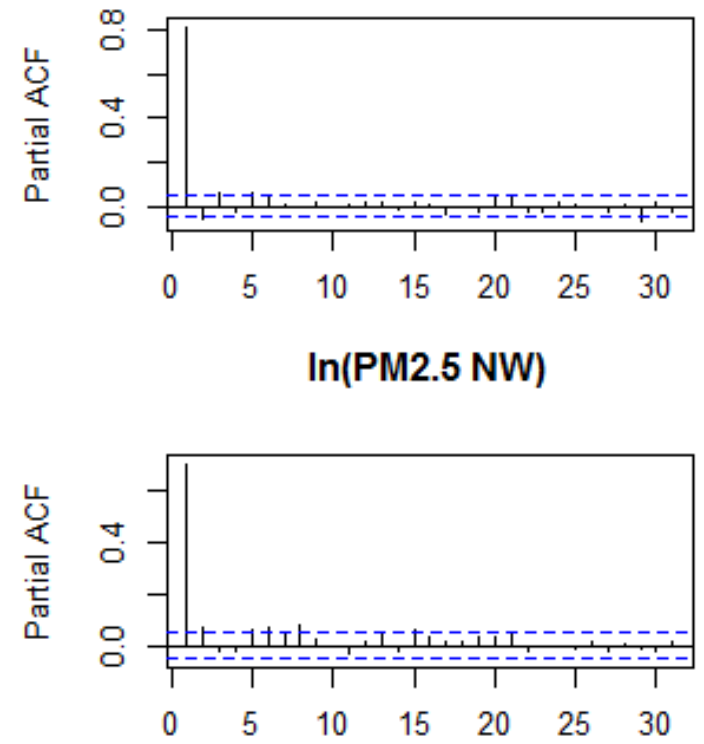

Figure 34. ACF\& PACF Plots - Log Linear Models NW Corner 
In(UFPNE)

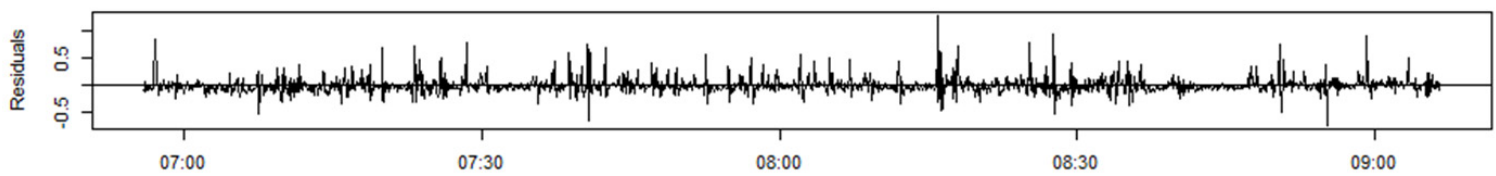

In(PM2.5NE)

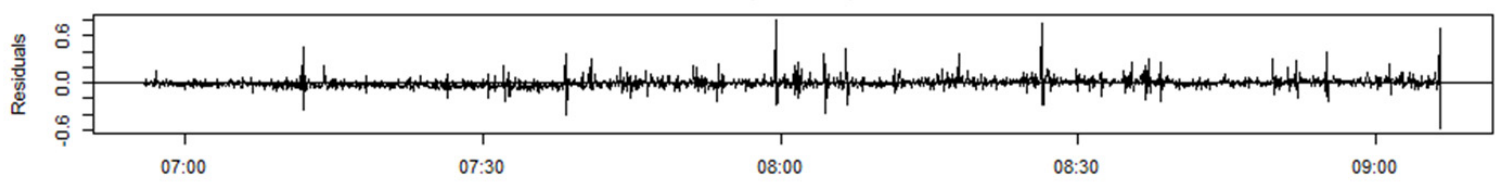

$\ln ($ CONE)

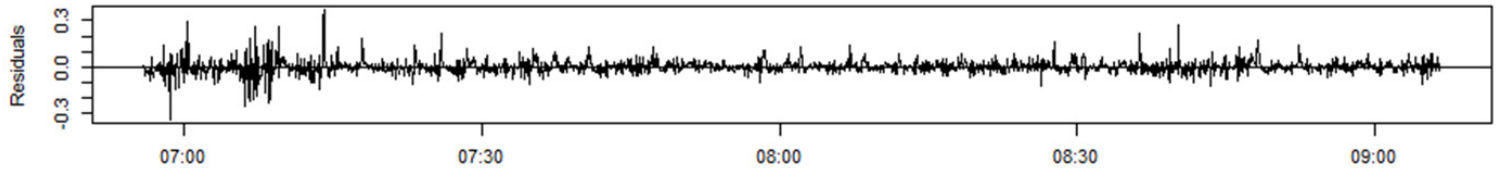

$\ln (\mathrm{CO} 2 \mathrm{NE})$

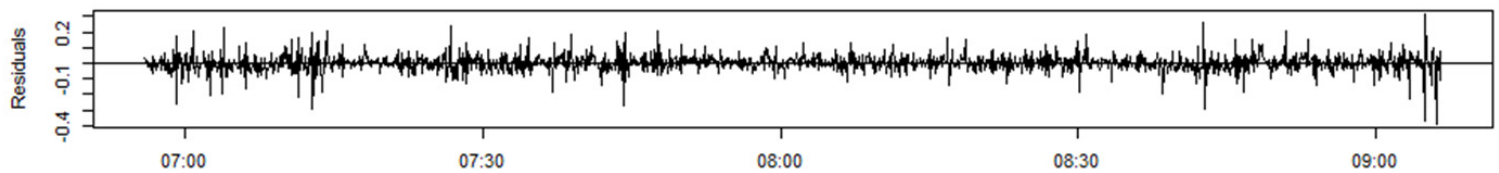

In(UFPNW)

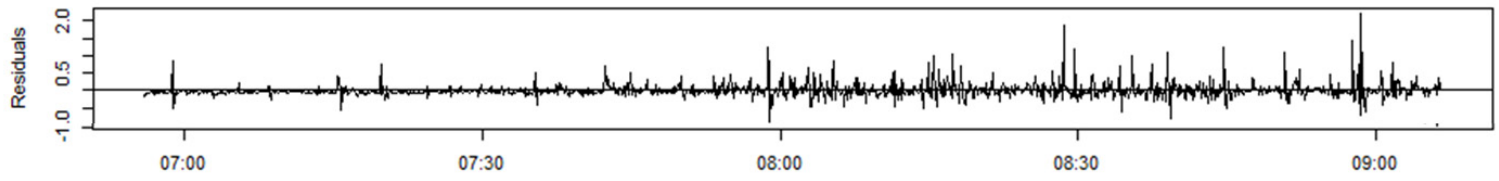

$\ln (\mathrm{PM} 2.5 \mathrm{NW})$

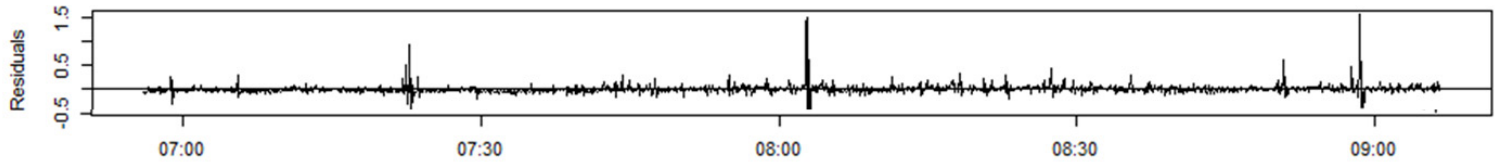

Figure 35. Residual Plots - Autoregressive Models 

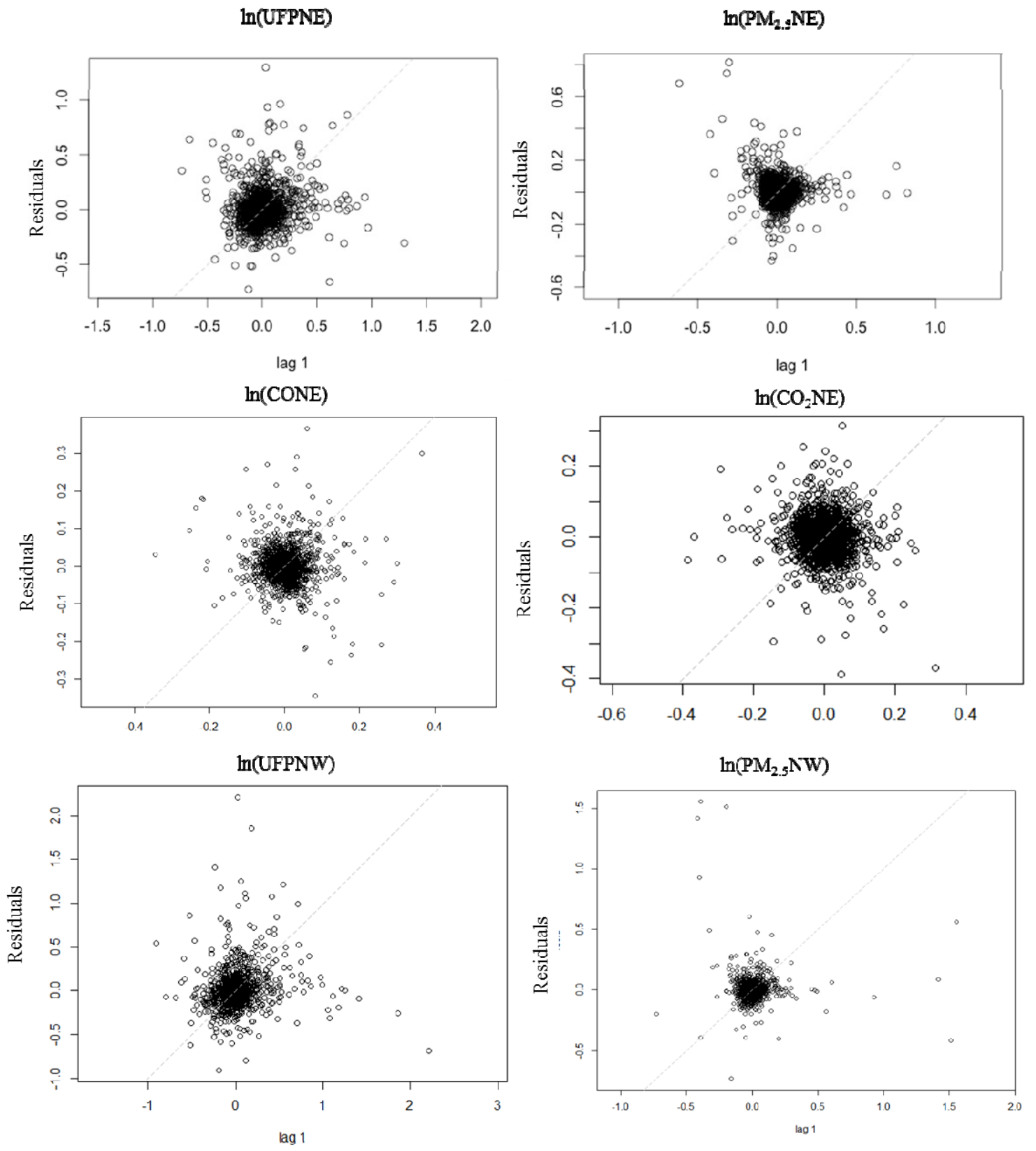

Figure 36. Lag Plots - Autoregressive Models 
In(UFP NE)
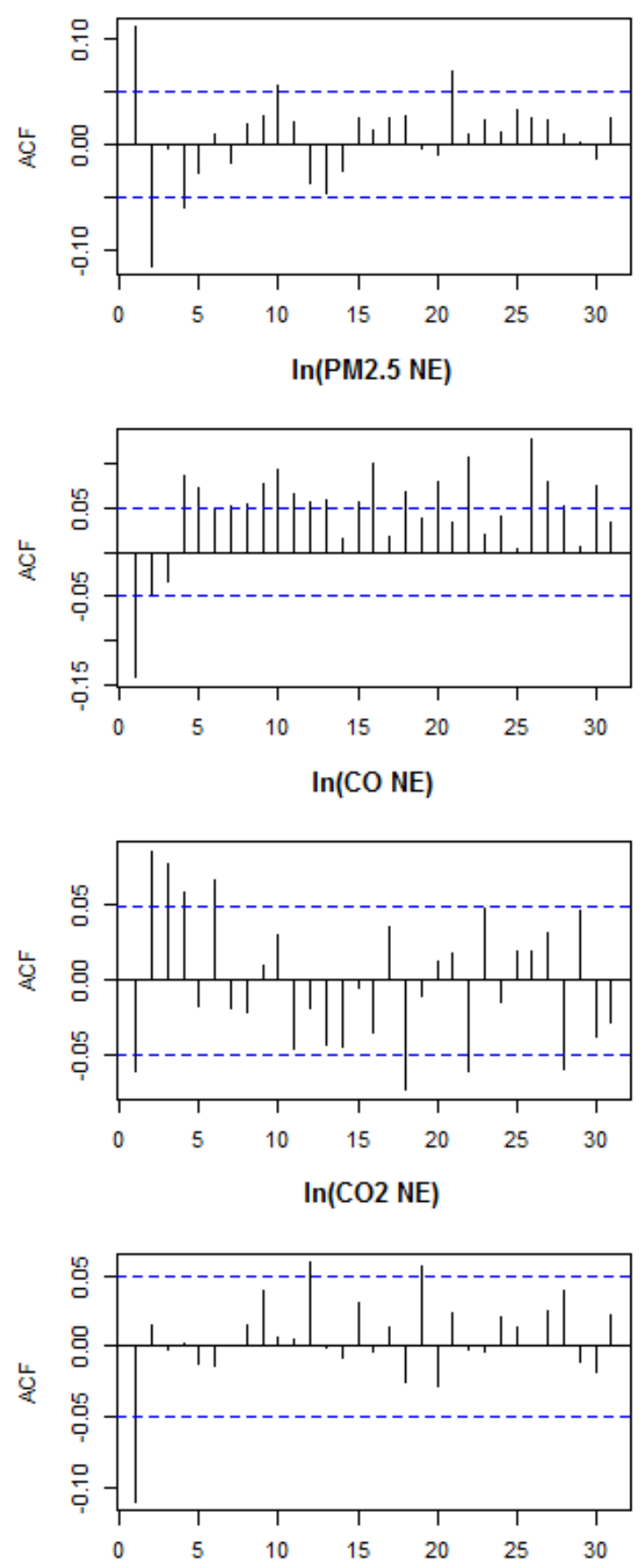

In(UFP NE)
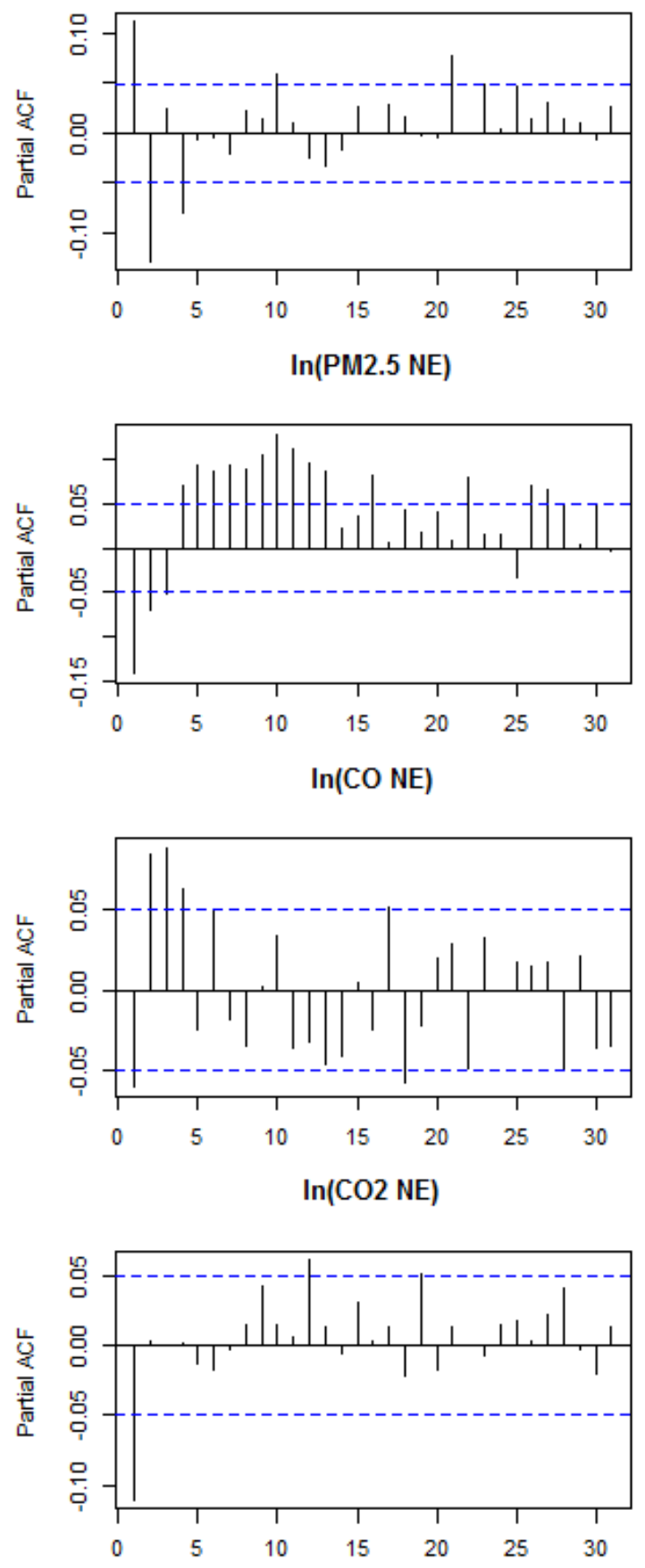

Figure 37. ACF\& PACF Plots - Autoregressive Models NE Corner 
In(UFP NW)

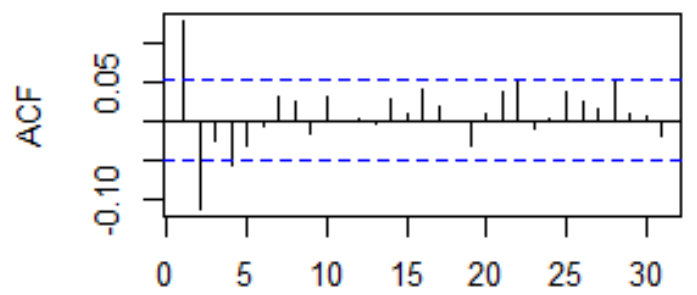

In(PM2.5 NW)

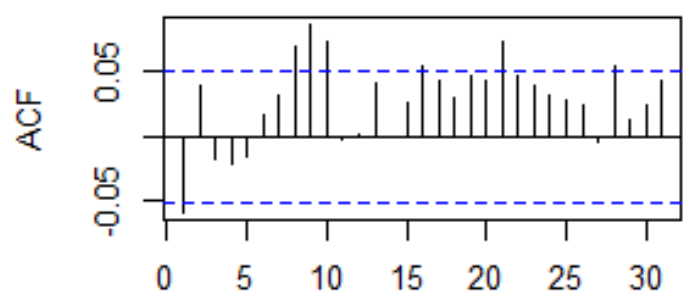

In(UFP NW)
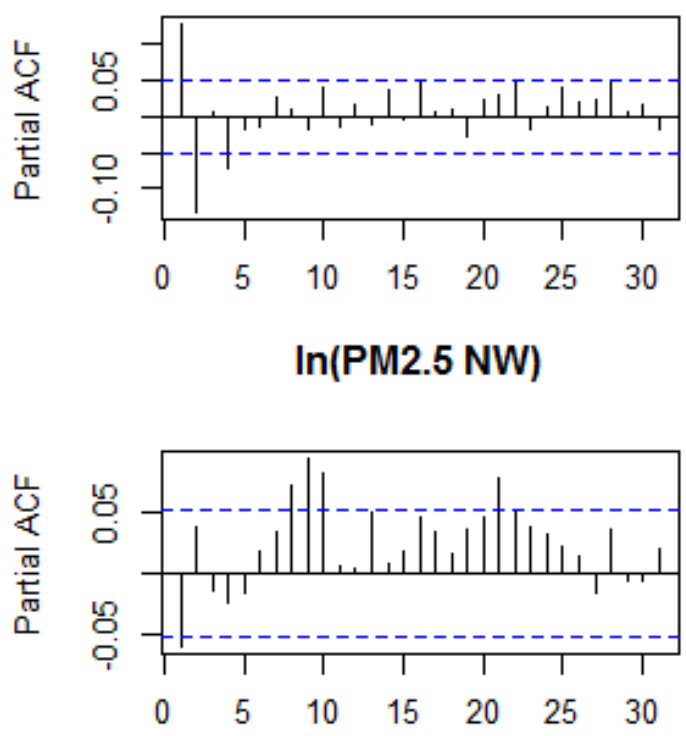

Figure 38. ACF \& PACF Plots - Autoregressive Models NW Corner 

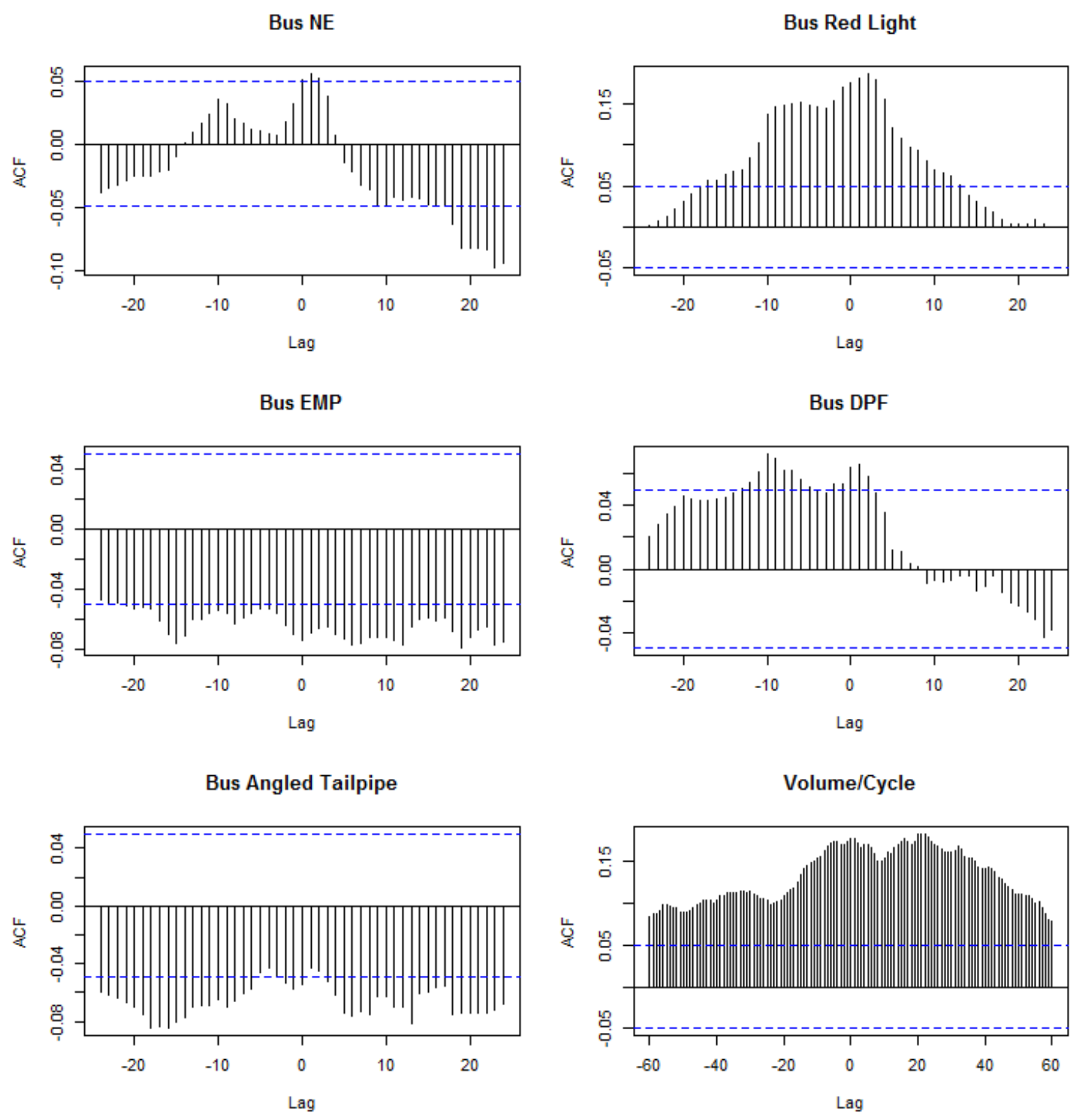

Figure 39. Cross Correlation Plots - $\mathrm{PM}_{2.5} \mathrm{NE} A$ 

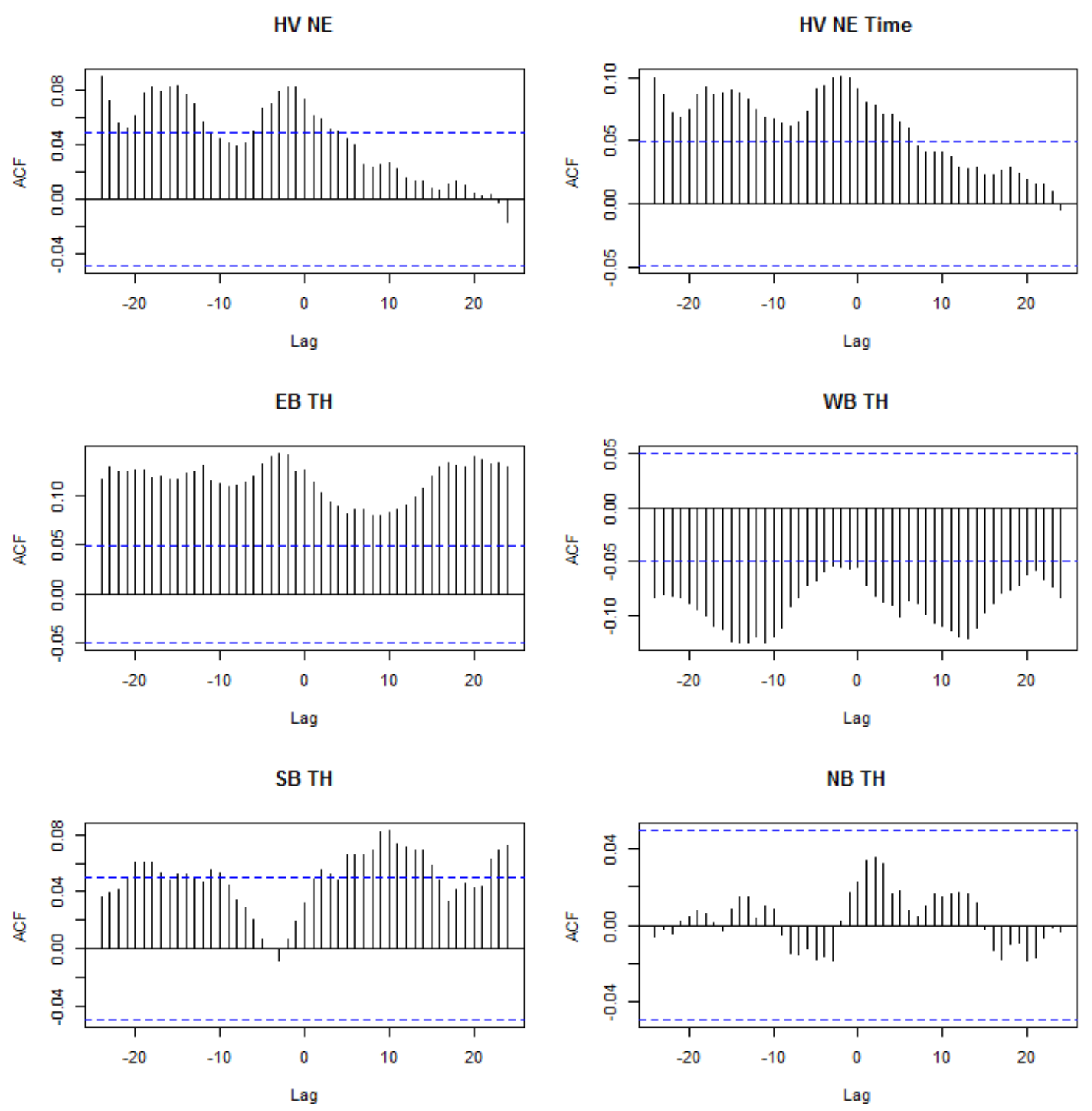

Figure 40. Cross Correlation Plots - $\mathrm{PM}_{2.5} \mathrm{NE} B$ 

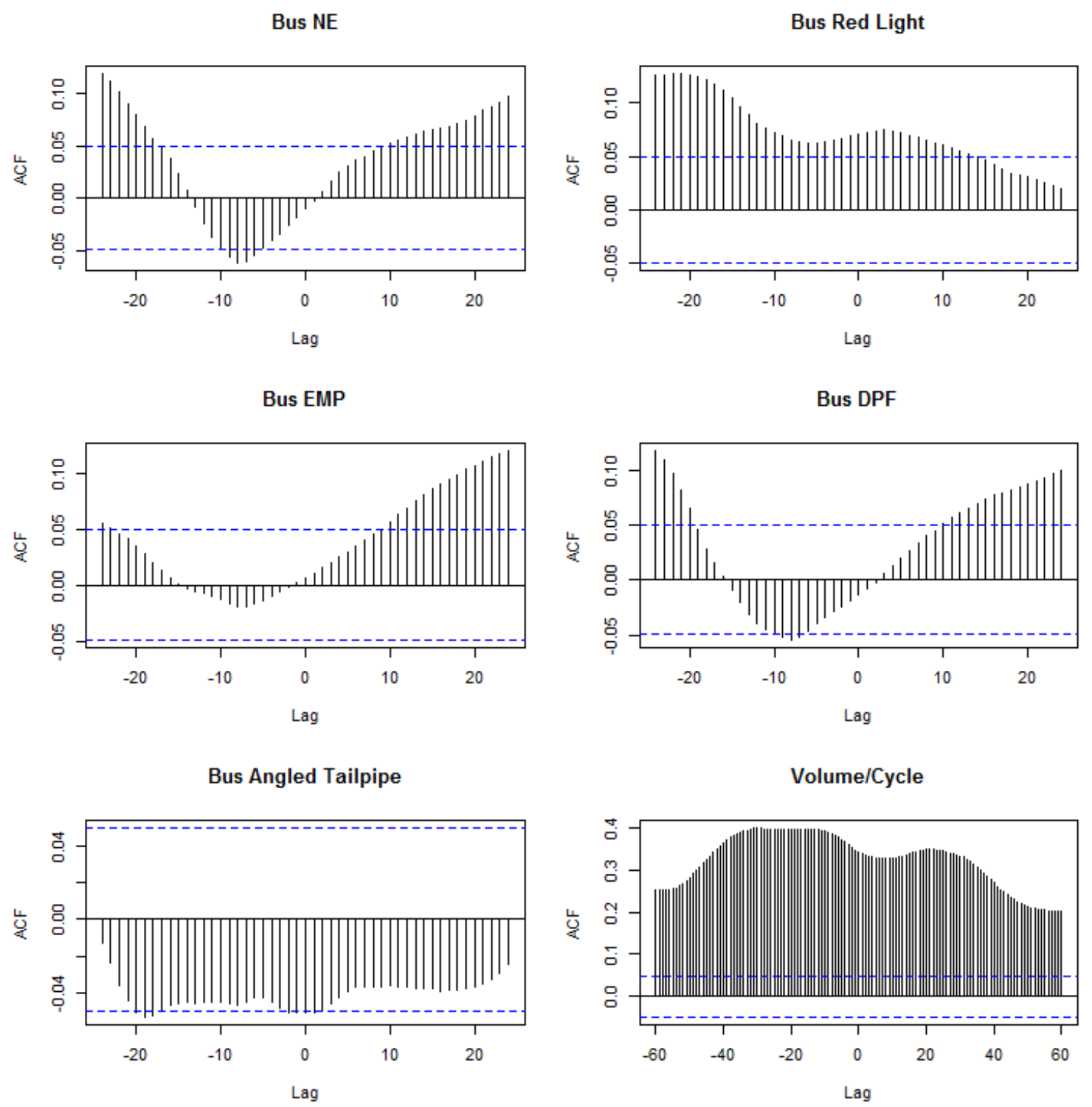

Figure 41. Cross Correlation Plots - CO NE A 

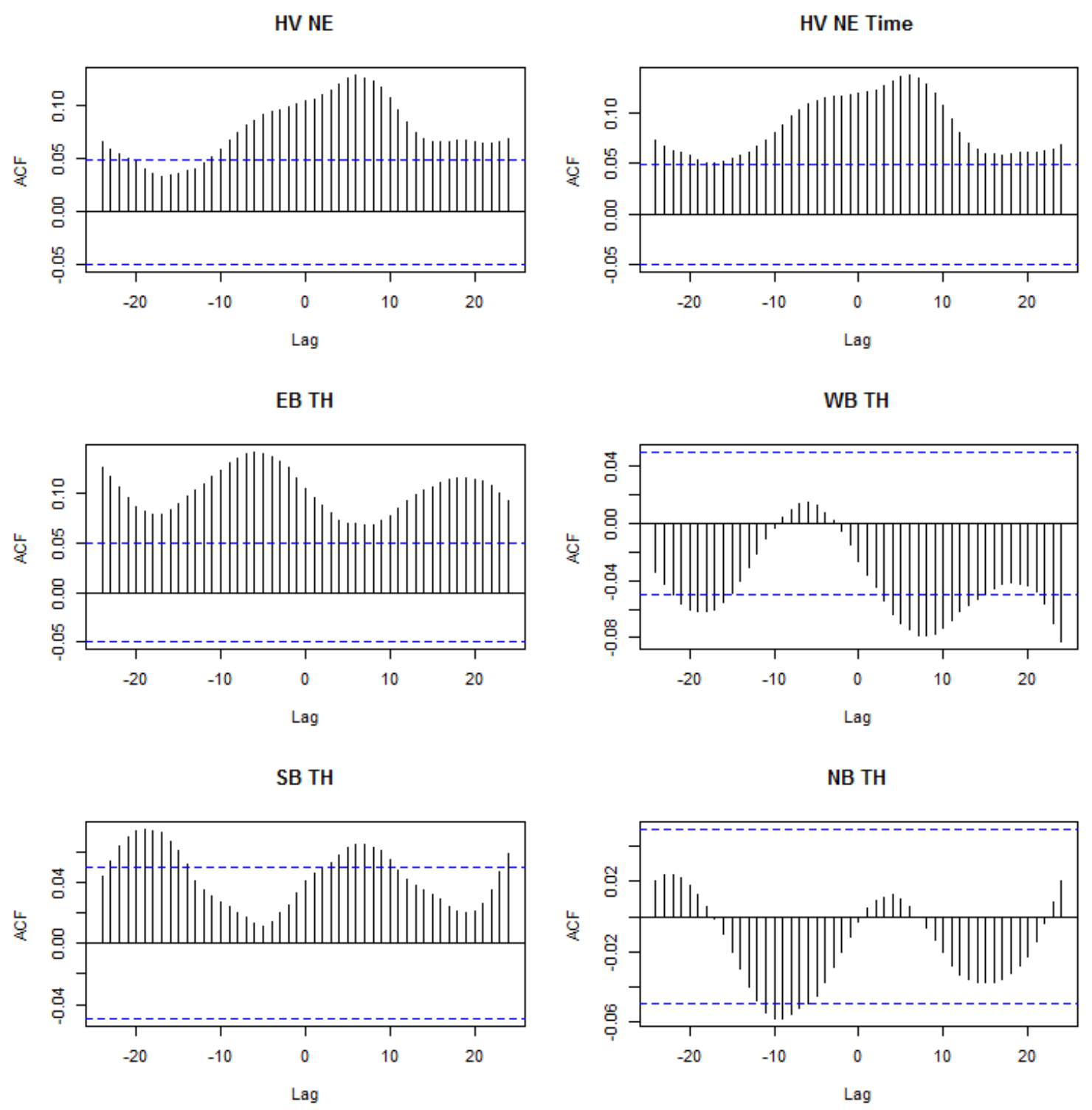

Figure 42. Cross Correlation Plots - CO NE B 

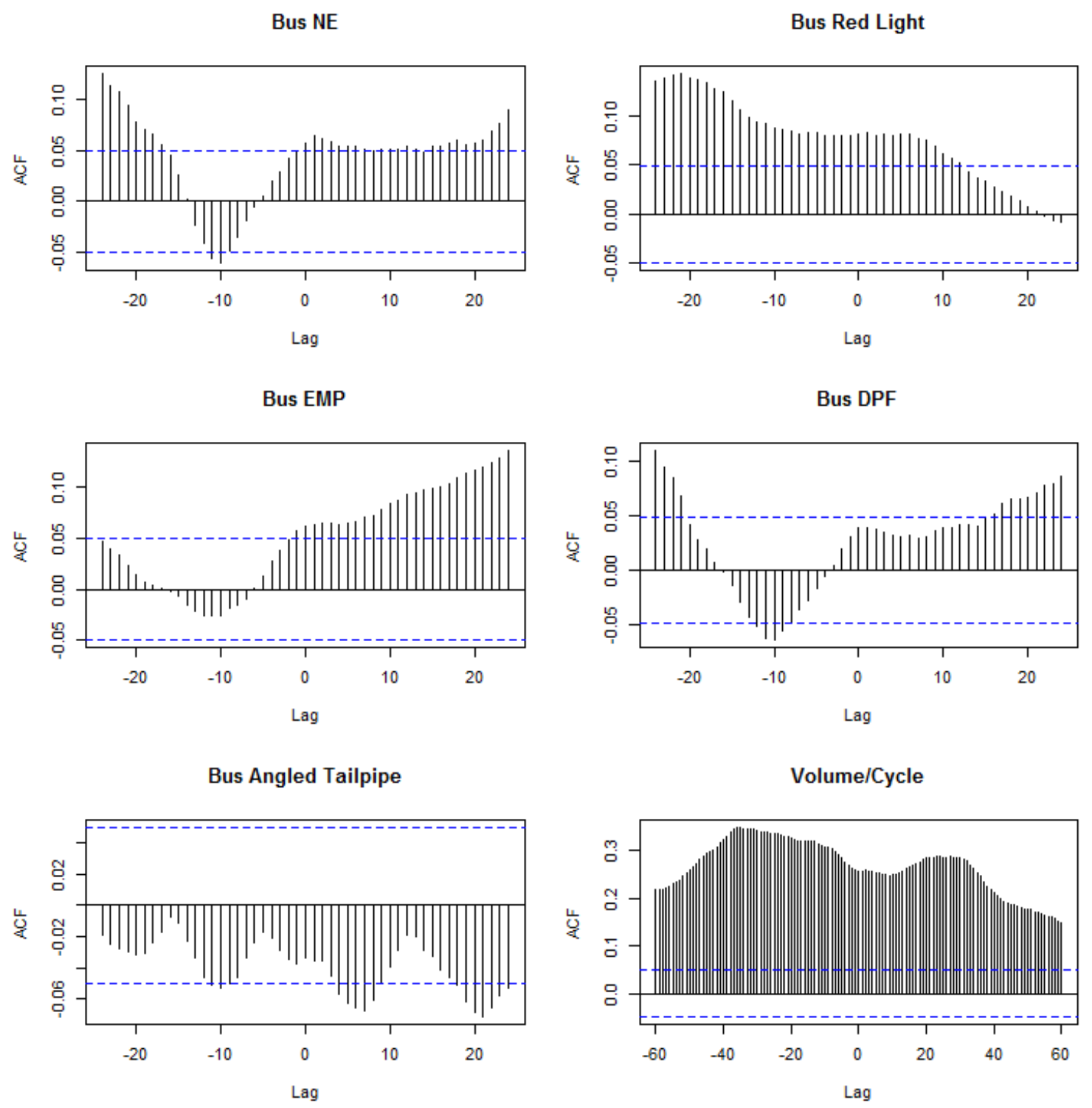

Figure 43. Cross Correlation Plots - $\mathrm{CO}_{2} \mathrm{NE} \mathrm{A}$ 

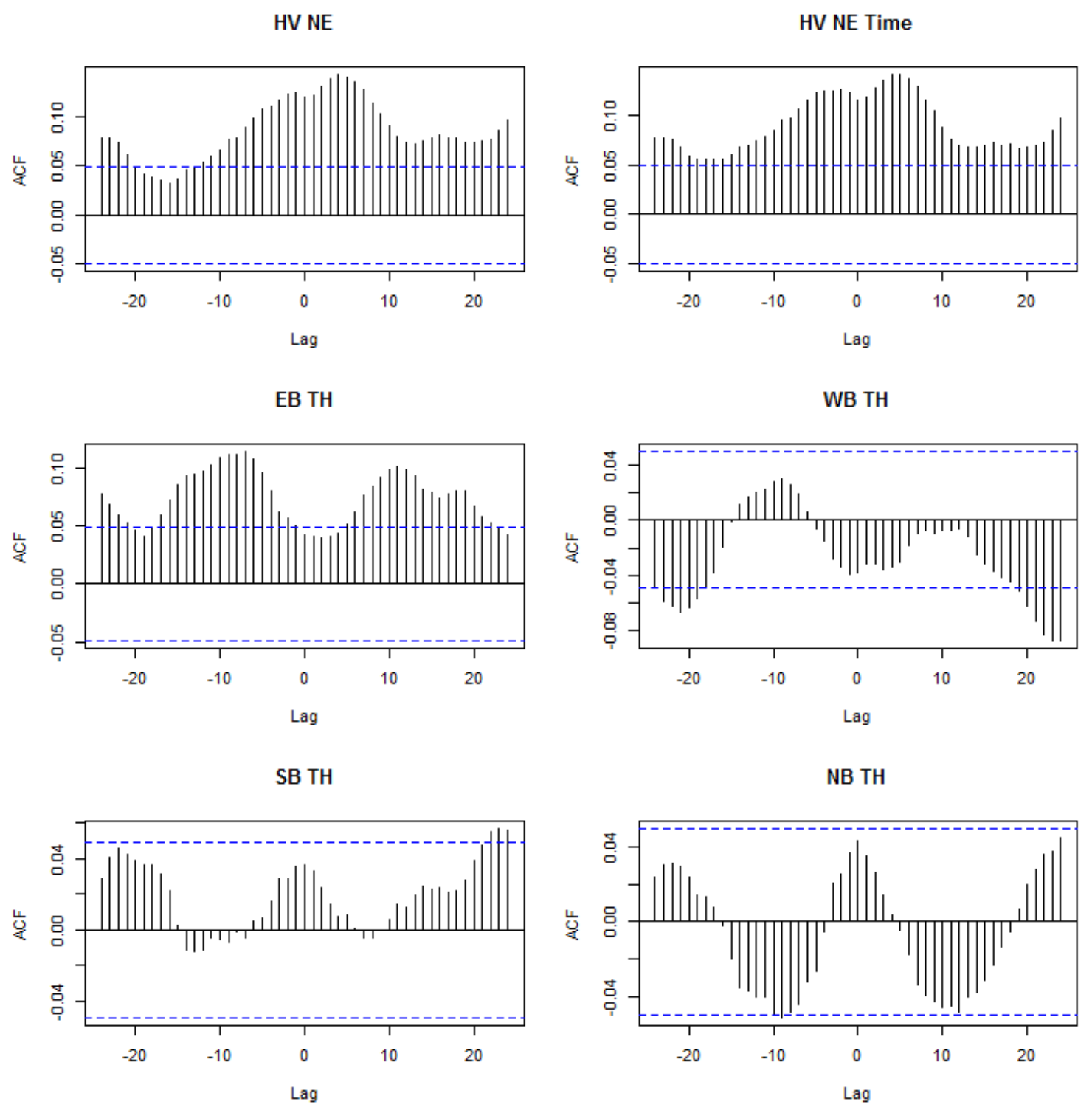

Figure 44. Cross Correlation Plots - $\mathrm{CO}_{2} \mathrm{NE} \mathrm{B}$ 

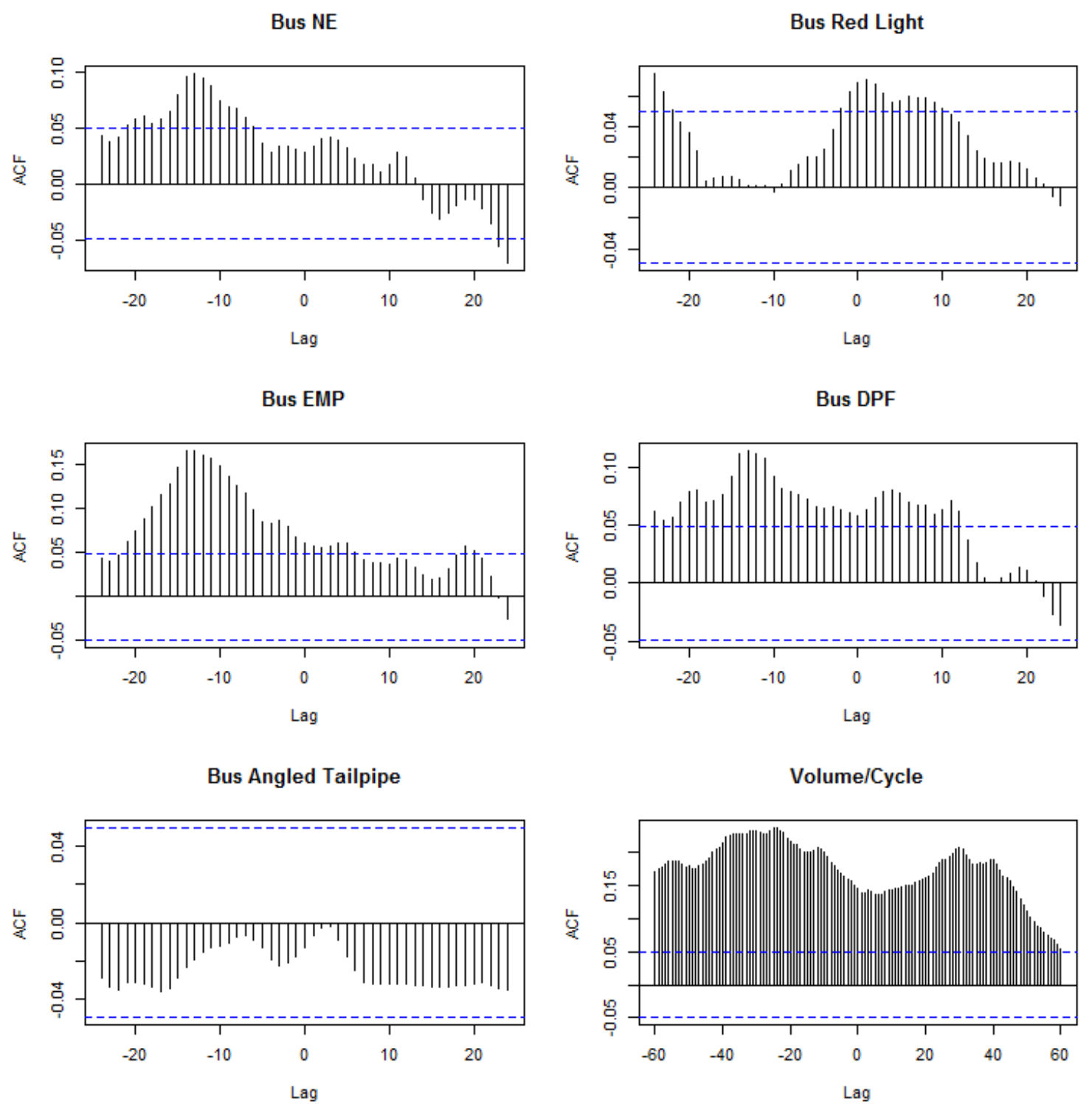

Figure 45. Cross Correlation Plots - UFP NW A 

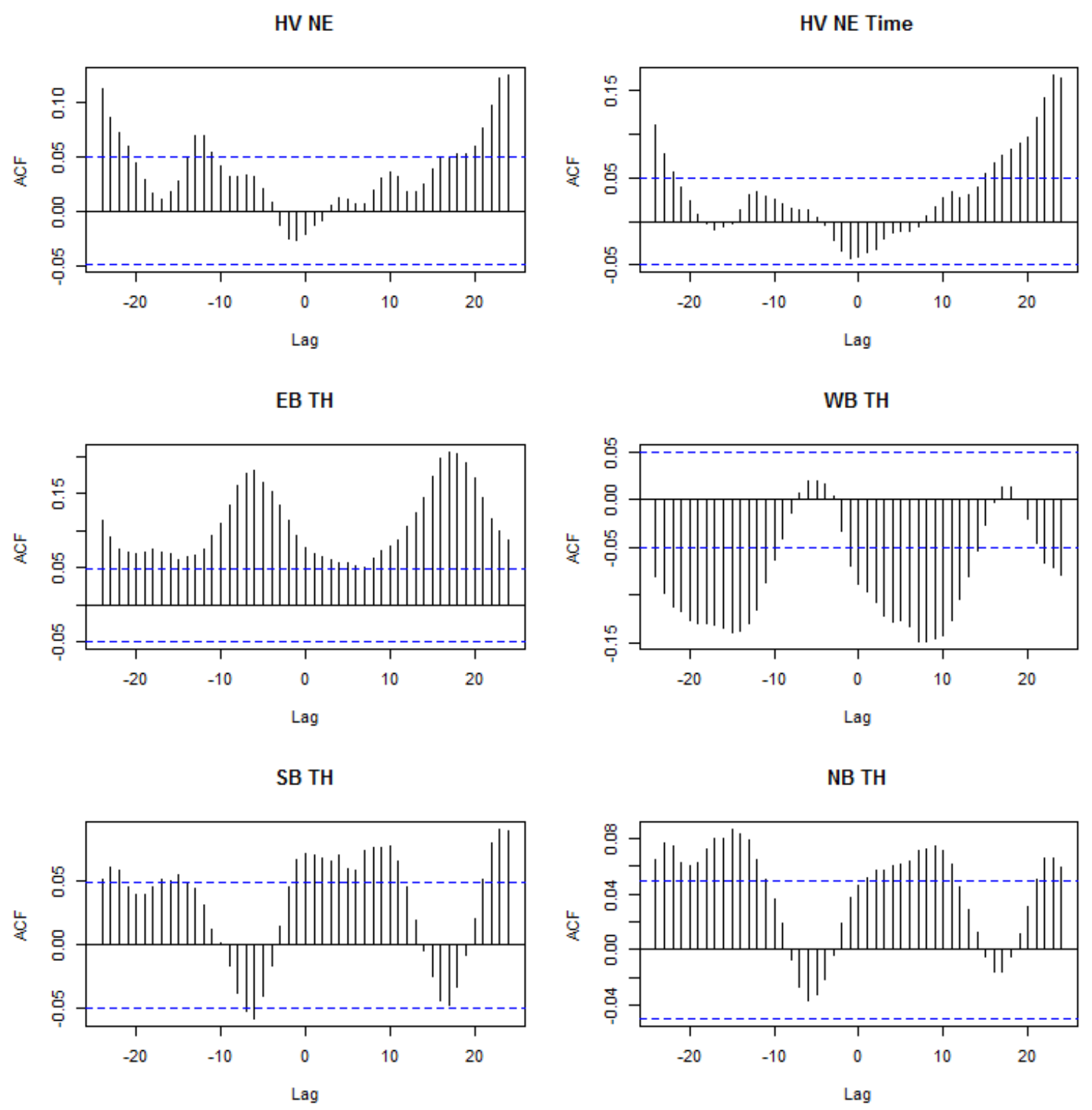

Figure 46. Cross Correlation Plots - UFP NW B 

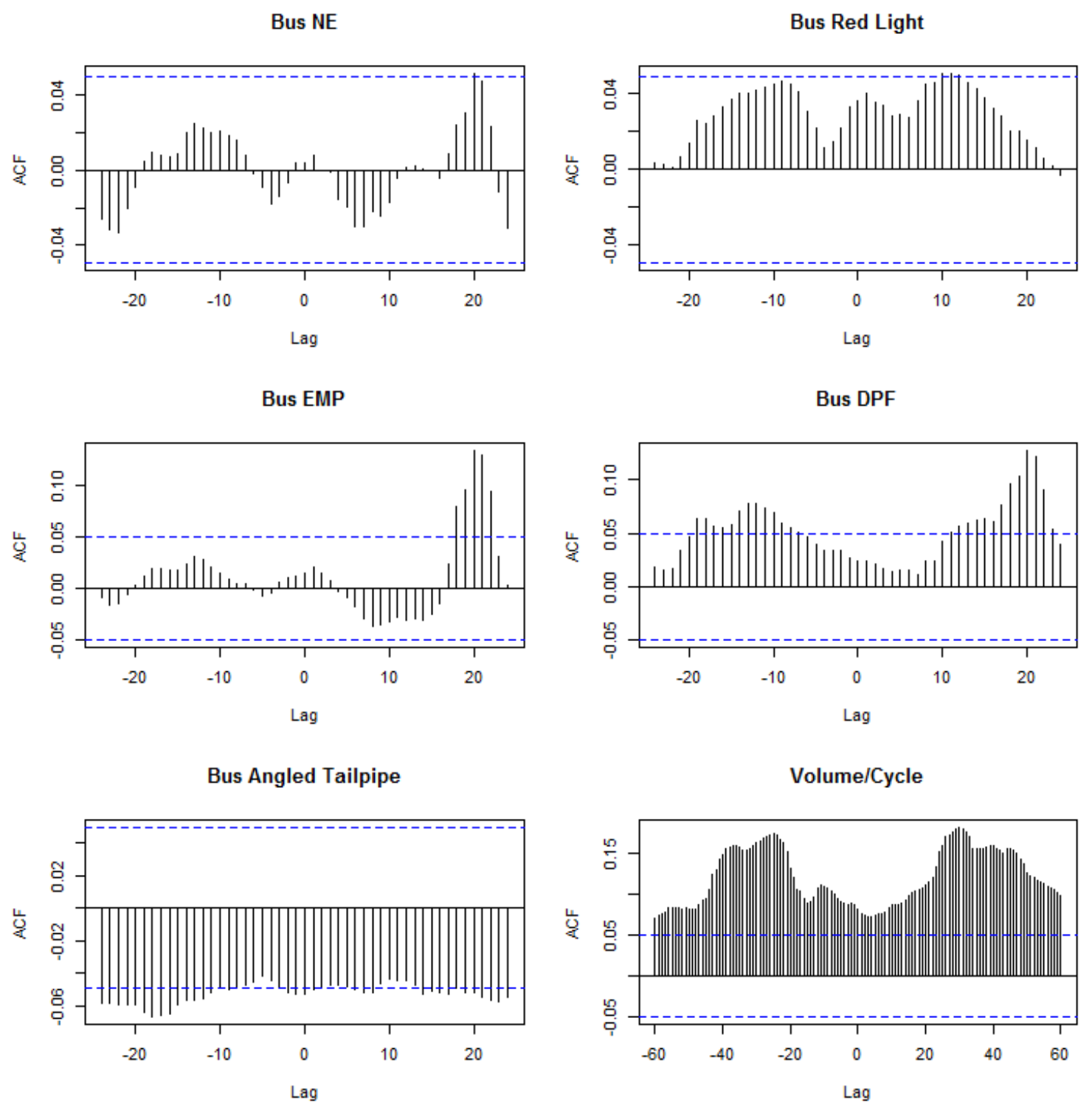

Figure 47. Cross Correlation Plots - $\mathbf{P M}_{2.5}$ NW A 

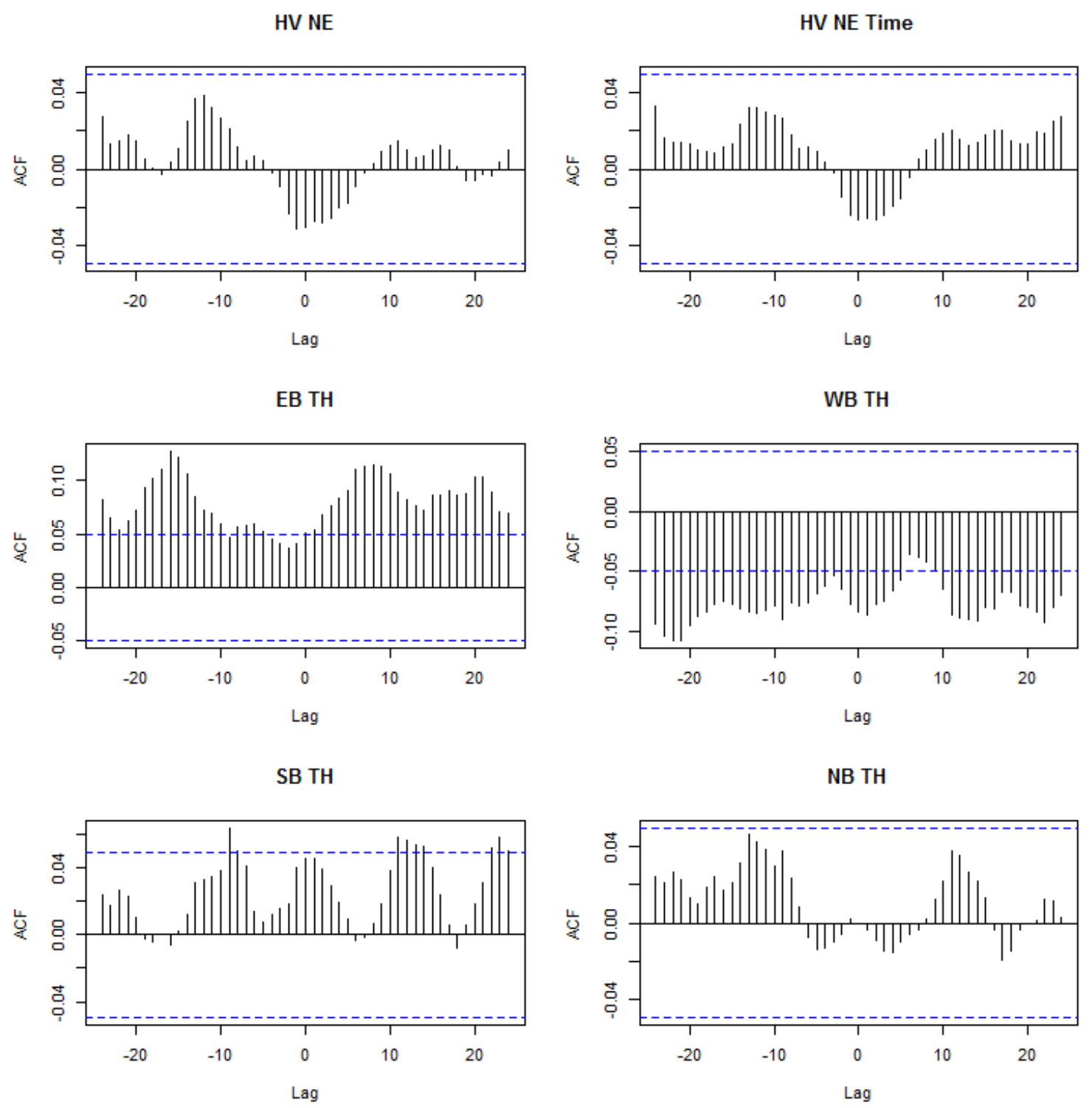

Figure 48. Cross Correlation Plots - $\mathrm{PM}_{2.5}$ NW B

Table 80. UFP NE Lagged AR1 Model Interpretation All Lags

\begin{tabular}{|c|c|c|c|}
\hline & $\begin{array}{c}\% \text { Change } \\
\text { per Unit } \\
\text { Change in X }\end{array}$ & $\begin{array}{c}\% \text { Change } \\
\text { per } 1 \% \\
\text { Change in } \mathrm{X}\end{array}$ & $\begin{array}{l}\% \text { Average } \\
\text { Contribution } \\
\text { to Baseline* }\end{array}$ \\
\hline $\mathrm{RH}$ & $10.02 \%$ & $7.833 \%$ & \\
\hline BusRedLight & $0.46 \%$ & $0.004 \%$ & $0.40 \%$ \\
\hline
\end{tabular}




\begin{tabular}{|c|c|c|c|c|c|c|}
\hline \multirow{2}{*}{\multicolumn{4}{|c|}{$\begin{array}{l}\text { HVNE } \\
\text { WBTH }\end{array}$}} & \multirow{3}{*}{$\begin{array}{l}8.38 \% \\
0.99 \% \\
\end{array}$} & \multirow{3}{*}{$\begin{array}{l}0.002 \% \\
0.019 \% \\
\end{array}$} & \multirow{3}{*}{$\begin{array}{l}0.25 \% \\
1.95 \% \\
\end{array}$} \\
\hline & & & & & & \\
\hline & Lags & Secs. & Mins. & & & \\
\hline BusRedLight & 13 & 65 & 1.08 & $0.40 \%$ & $0.003 \%$ & $0.35 \%$ \\
\hline BusRedLight & 18 & 90 & 1.50 & $0.28 \%$ & $0.002 \%$ & $0.25 \%$ \\
\hline EMP & 9 & 45 & 0.75 & $-6.71 \%$ & $-0.001 \%$ & $-0.14 \%$ \\
\hline EMP & 12 & 60 & 1.00 & $-10.32 \%$ & $-0.002 \%$ & $-0.22 \%$ \\
\hline EMP & 13 & 65 & 1.08 & $-6.88 \%$ & $-0.001 \%$ & $-0.14 \%$ \\
\hline EMP & 22 & 110 & 1.83 & $-7.91 \%$ & $-0.002 \%$ & $-0.16 \%$ \\
\hline DPF & 7 & 35 & 0.58 & $-5.53 \%$ & $-0.003 \%$ & $-0.28 \%$ \\
\hline HVNE & 13 & 65 & 1.08 & $7.59 \%$ & $0.002 \%$ & $0.22 \%$ \\
\hline HVNE & 15 & 75 & 1.25 & $17.20 \%$ & $0.005 \%$ & $0.49 \%$ \\
\hline HVNE & 18 & 90 & 1.50 & $6.45 \%$ & $0.002 \%$ & $0.19 \%$ \\
\hline HVNE & 19 & 95 & 1.58 & $7.42 \%$ & $0.002 \%$ & $0.22 \%$ \\
\hline WBTH & 2 & 10 & 0.17 & $0.90 \%$ & $0.018 \%$ & $1.77 \%$ \\
\hline VolCycle & 4 & 20 & 0.33 & $0.20 \%$ & $0.189 \%$ & $20.75 \%$ \\
\hline VolCycle & 8 & 40 & 0.67 & $0.12 \%$ & $0.116 \%$ & $12.32 \%$ \\
\hline VolCycle & 13 & 65 & 1.08 & $0.13 \%$ & $0.127 \%$ & $13.53 \%$ \\
\hline VolCycle & 26 & 130 & 2.17 & $0.12 \%$ & $0.117 \%$ & $12.38 \%$ \\
\hline VolCycle & 36 & 180 & 3.00 & $0.12 \%$ & $0.119 \%$ & $12.61 \%$ \\
\hline VolCycle & 37 & 185 & 3.08 & $0.16 \%$ & $0.157 \%$ & $16.93 \%$ \\
\hline VolCycle & 44 & 220 & 3.67 & $0.12 \%$ & $0.114 \%$ & $12.12 \%$ \\
\hline VolCycle & 49 & 245 & 4.08 & $0.10 \%$ & $0.093 \%$ & $9.77 \%$ \\
\hline VolCycle & 59 & 295 & 4.92 & $0.11 \%$ & $0.105 \%$ & $11.11 \%$ \\
\hline VolCycle & 60 & 300 & 5.00 & $0.14 \%$ & $0.138 \%$ & $14.80 \%$ \\
\hline
\end{tabular}

Table 81. $\mathrm{PM}_{2.5}$ NE Lagged AR1 Model Interpretation All Lags

\begin{tabular}{|l|rrr|}
\hline & $\begin{array}{c}\text { \% Change per } \\
\text { Unit Change } \\
\text { in X }\end{array}$ & $\begin{array}{c}\text { \% Change } \\
\text { per 1\% } \\
\text { Change in X }\end{array}$ & $\begin{array}{c}\text { \% Average } \\
\text { Contribution } \\
\text { to Baseline* }\end{array}$ \\
\hline RH & $1.65 \%$ & $1.299 \%$ & \\
Temp & $-13.28 \%$ & $-5.530 \%$ & \\
wSSE & $-3.08 \%$ & $-0.001 \%$ & $-0.11 \%$ \\
wSS & $-2.74 \%$ & $-0.002 \%$ & $-0.18 \%$ \\
wSSW & $-2.96 \%$ & $-0.002 \%$ & $-0.15 \%$ \\
EMP & $-4.00 \%$ & $-0.001 \%$ & $-0.08 \%$ \\
PowellVol & $0.44 \%$ & $0.014 \%$ & $1.41 \%$ \\
GreenA & $-0.20 \%$ & $-0.143 \%$ & $-13.31 \%$ \\
GreenE & $0.20 \%$ & $0.004 \%$ & $0.37 \%$ \\
GreenD & $0.33 \%$ & $0.097 \%$ & $10.20 \%$ \\
\hline
\end{tabular}




\begin{tabular}{|l|l|l|l|lrr|}
\hline & Lags & Secs. & Mins. & & & \\
\hline BusRedLight & 1 & 5 & 0.08 & $0.19 \%$ & $0.002 \%$ & $0.17 \%$ \\
BusRedLight & 10 & 50 & 0.83 & $0.36 \%$ & $0.003 \%$ & $0.32 \%$ \\
BusRedLight & 17 & 85 & 1.42 & $0.10 \%$ & $0.001 \%$ & $0.09 \%$ \\
EMP & 8 & 40 & 0.67 & $-4.88 \%$ & $-0.001 \%$ & $-0.10 \%$ \\
TPAngled & 6 & 30 & 0.50 & $-12.60 \%$ & $0.000 \%$ & $-0.03 \%$ \\
TPAngled & 10 & 50 & 0.83 & $-12.37 \%$ & $0.000 \%$ & $-0.03 \%$ \\
TPAngled & 14 & 70 & 1.17 & $-17.38 \%$ & $0.000 \%$ & $-0.05 \%$ \\
TPAngled & 18 & 90 & 1.50 & $-23.91 \%$ & $-0.001 \%$ & $-0.07 \%$ \\
TPAngled & 22 & 110 & 1.83 & $-15.24 \%$ & $0.000 \%$ & $-0.04 \%$ \\
HVNETime & 18 & 90 & 1.50 & $0.13 \%$ & $0.001 \%$ & $0.11 \%$ \\
EBTH & 2 & 10 & 0.17 & $1.31 \%$ & $0.016 \%$ & $1.65 \%$ \\
EBTH & 5 & 25 & 0.42 & $0.75 \%$ & $0.009 \%$ & $0.94 \%$ \\
EBTH & 12 & 60 & 1.00 & $1.03 \%$ & $0.013 \%$ & $1.29 \%$ \\
EBTH & 14 & 70 & 1.17 & $0.90 \%$ & $0.011 \%$ & $1.12 \%$ \\
EBTH & 17 & 85 & 1.42 & $0.96 \%$ & $0.012 \%$ & $1.20 \%$ \\
EBTH & 19 & 95 & 1.58 & $0.78 \%$ & $0.010 \%$ & $0.98 \%$ \\
EBTH & 20 & 100 & 1.67 & $0.54 \%$ & $0.007 \%$ & $0.67 \%$ \\
EBTH & 23 & 115 & 1.92 & $0.85 \%$ & $0.011 \%$ & $1.06 \%$ \\
WBTH & 2 & 10 & 0.17 & $-0.61 \%$ & $-0.012 \%$ & $-1.20 \%$ \\
WBTH & 5 & 25 & 0.42 & $-0.58 \%$ & $-0.012 \%$ & $-1.15 \%$ \\
WBTH & 9 & 45 & 0.75 & $-0.30 \%$ & $-0.006 \%$ & $-0.60 \%$ \\
WBTH & 11 & 55 & 0.92 & $-0.53 \%$ & $-0.011 \%$ & $-1.05 \%$ \\
WBTH & 14 & 70 & 1.17 & $-0.56 \%$ & $-0.011 \%$ & $-1.10 \%$ \\
WBTH & 15 & 75 & 1.25 & $-0.49 \%$ & $-0.010 \%$ & $-0.97 \%$ \\
WBTH & 17 & 85 & 1.42 & $-0.79 \%$ & $-0.016 \%$ & $-1.55 \%$ \\
WBTH & 19 & 95 & 1.58 & $-0.36 \%$ & $-0.007 \%$ & $-0.70 \%$ \\
WBTH & 20 & 100 & 1.67 & $-0.56 \%$ & $-0.011 \%$ & $-1.10 \%$ \\
WBTH & 22 & 110 & 1.83 & $-0.32 \%$ & $-0.006 \%$ & $-0.63 \%$ \\
WBTH & 23 & 115 & 1.92 & $-0.53 \%$ & $-0.011 \%$ & $-1.05 \%$ \\
WBTH & 24 & 120 & 2.00 & $-0.94 \%$ & $-0.019 \%$ & $-1.85 \%$ \\
SBTH & 3 & 15 & 0.25 & $-1.71 \%$ & $-0.004 \%$ & $-0.39 \%$ \\
VolCycle & 32 & 160 & 2.67 & $0.07 \%$ & $0.063 \%$ & $6.53 \%$ \\
VolCycle & 56 & 280 & 4.67 & $0.07 \%$ & $0.067 \%$ & $6.92 \%$ \\
\hline
\end{tabular}

Table 82. CO NE Lagged AR 2 Model Interpretation All Lags

\begin{tabular}{|l|ccc|}
\hline & $\begin{array}{c}\text { \% Change } \\
\text { per Unit } \\
\text { Change in X }\end{array}$ & $\begin{array}{c}\% \text { Change per } \\
1 \% \text { Change in } \\
\text { X }\end{array}$ & $\begin{array}{c}\text { \% Average } \\
\text { Contribution } \\
\text { to Baseline* }\end{array}$ \\
\hline RH & $1.38 \%$ & $1.091 \%$
\end{tabular}




\begin{tabular}{|c|c|c|c|c|c|c|}
\hline \multicolumn{4}{|l|}{ wsSW } & $-0.88 \%$ & $0.000 \%$ & $-0.04 \%$ \\
\hline \multicolumn{4}{|l|}{ ЕВТН } & $0.43 \%$ & $0.005 \%$ & $0.54 \%$ \\
\hline \multicolumn{4}{|l|}{ WBTH } & $-0.43 \%$ & $-0.009 \%$ & $-0.85 \%$ \\
\hline \multicolumn{4}{|l|}{ GreenA } & $-0.06 \%$ & $-0.042 \%$ & $-4.13 \%$ \\
\hline \multicolumn{4}{|l|}{ GreenE } & $0.21 \%$ & $0.004 \%$ & $0.38 \%$ \\
\hline \multicolumn{4}{|l|}{ GreenF } & $0.21 \%$ & $0.014 \%$ & $1.38 \%$ \\
\hline \multicolumn{4}{|l|}{ GreenC } & $0.20 \%$ & $0.012 \%$ & $1.17 \%$ \\
\hline & Lags & Secs. & Mins. & & & \\
\hline BusRedLight & 18 & 90 & 1.50 & $0.07 \%$ & $0.001 \%$ & $0.06 \%$ \\
\hline DPF & 12 & 60 & 1.00 & $-2.52 \%$ & $-0.001 \%$ & $-0.12 \%$ \\
\hline DPF & 14 & 70 & 1.17 & $-1.29 \%$ & $-0.001 \%$ & $-0.06 \%$ \\
\hline DPF & 17 & 85 & 1.42 & $-1.47 \%$ & $-0.001 \%$ & $-0.07 \%$ \\
\hline DPF & 18 & 90 & 1.50 & $-2.78 \%$ & $-0.001 \%$ & $-0.14 \%$ \\
\hline TPAngled & 8 & 40 & 0.67 & $-6.11 \%$ & $0.000 \%$ & $-0.02 \%$ \\
\hline TPAngled & 22 & 110 & 1.83 & $-5.94 \%$ & $0.000 \%$ & $-0.02 \%$ \\
\hline ЕВТН & 14 & 70 & 1.17 & $0.40 \%$ & $0.005 \%$ & $0.50 \%$ \\
\hline ЕВТН & 23 & 115 & 1.92 & $0.29 \%$ & $0.004 \%$ & $0.36 \%$ \\
\hline WBTH & 23 & 115 & 1.92 & $-0.22 \%$ & $-0.004 \%$ & $-0.43 \%$ \\
\hline SBTH & 3 & 15 & 0.25 & $0.54 \%$ & $0.001 \%$ & $0.12 \%$ \\
\hline SBTH & 9 & 45 & 0.75 & $0.85 \%$ & $0.002 \%$ & $0.19 \%$ \\
\hline SBTH & 10 & 50 & 0.83 & $1.12 \%$ & $0.003 \%$ & $0.26 \%$ \\
\hline SBTH & 11 & 55 & 0.92 & $0.80 \%$ & $0.002 \%$ & $0.18 \%$ \\
\hline SBTH & 14 & 70 & 1.17 & $1.11 \%$ & $0.003 \%$ & $0.25 \%$ \\
\hline SBTH & 15 & 75 & 1.25 & $1.30 \%$ & $0.003 \%$ & $0.30 \%$ \\
\hline SBTH & 16 & 80 & 1.33 & $0.89 \%$ & $0.002 \%$ & $0.20 \%$ \\
\hline SBTH & 17 & 85 & 1.42 & $1.26 \%$ & $0.003 \%$ & $0.29 \%$ \\
\hline SBTH & 21 & 105 & 1.75 & $0.68 \%$ & $0.002 \%$ & $0.15 \%$ \\
\hline SBTH & 22 & 110 & 1.83 & $0.56 \%$ & $0.001 \%$ & $0.13 \%$ \\
\hline SBTH & 24 & 120 & 2.00 & $0.79 \%$ & $0.002 \%$ & $0.18 \%$ \\
\hline NBTH & 9 & 45 & 0.75 & $-1.88 \%$ & $-0.001 \%$ & $-0.15 \%$ \\
\hline NBTH & 10 & 50 & 0.83 & $-2.69 \%$ & $-0.002 \%$ & $-0.21 \%$ \\
\hline NBTH & 11 & 55 & 0.92 & $-1.78 \%$ & $-0.001 \%$ & $-0.14 \%$ \\
\hline VolCycle & 8 & 40 & 0.67 & $0.04 \%$ & $0.037 \%$ & $3.80 \%$ \\
\hline VolCycle & 13 & 65 & 1.08 & $0.04 \%$ & $0.041 \%$ & $4.15 \%$ \\
\hline VolCycle & 21 & 105 & 1.75 & $0.04 \%$ & $0.043 \%$ & $4.42 \%$ \\
\hline VolCycle & 30 & 150 & 2.50 & $0.04 \%$ & $0.034 \%$ & $3.49 \%$ \\
\hline VolCycle & 35 & 175 & 2.92 & $0.04 \%$ & $0.042 \%$ & $4.32 \%$ \\
\hline VolCycle & 45 & 225 & 3.75 & $0.06 \%$ & $0.055 \%$ & $5.63 \%$ \\
\hline VolCycle & 46 & 230 & 3.83 & $0.05 \%$ & $0.049 \%$ & $4.97 \%$ \\
\hline
\end{tabular}


Table 83. $\mathrm{CO}_{2} \mathrm{NE}$ Lagged $\mathrm{AR} 1$ Model Interpretation All Lags

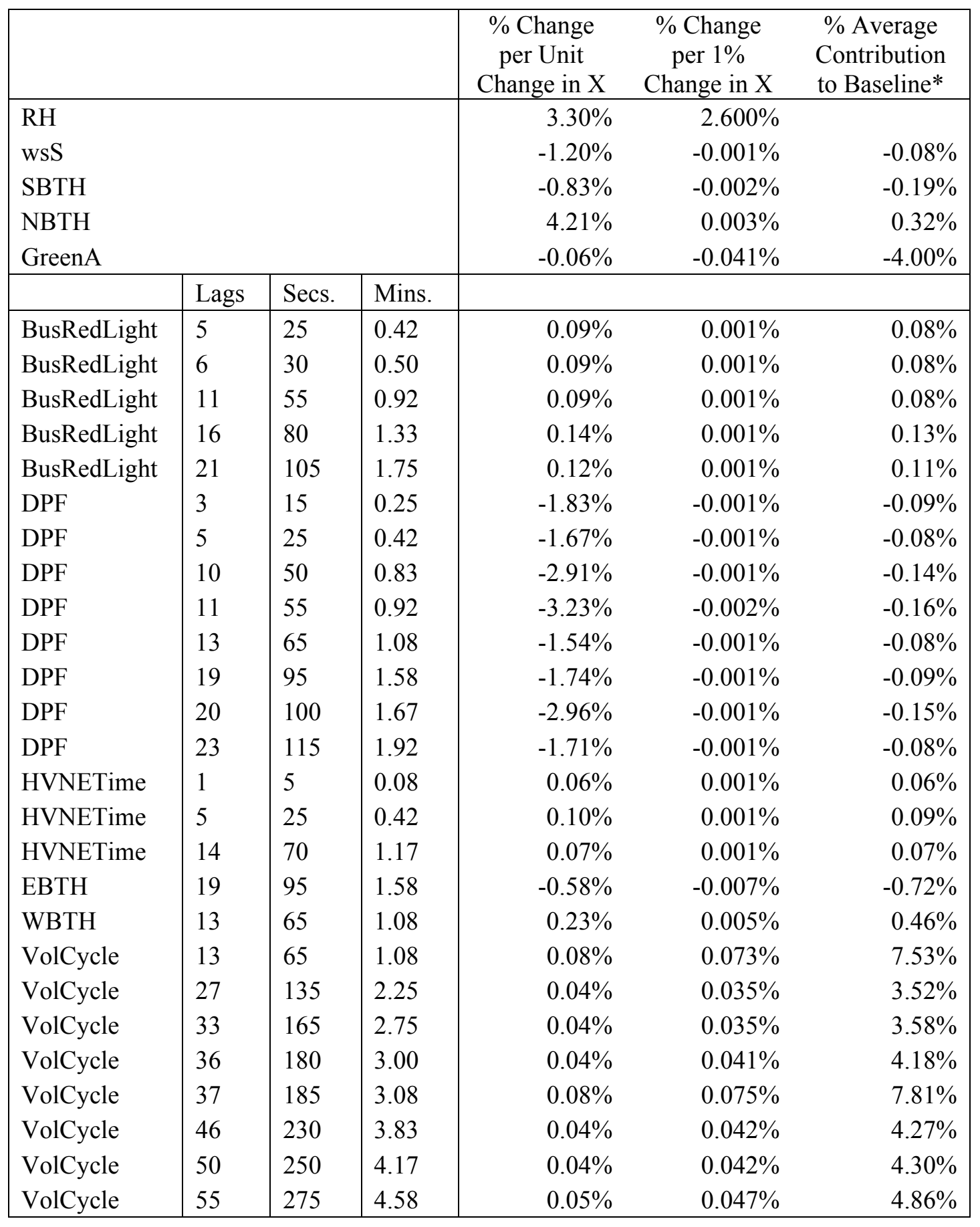


Table 84. UFP NW Lagged AR1 Model Interpretation All Lags

\begin{tabular}{|c|c|c|c|c|c|c|}
\hline & & & & $\begin{array}{c}\% \text { Change } \\
\text { per Unit } \\
\text { Change in X }\end{array}$ & $\begin{array}{c}\% \text { Change } \\
\text { per } 1 \% \\
\text { Change in } \mathrm{X}\end{array}$ & $\begin{array}{l}\text { \% Average } \\
\text { Contribution } \\
\text { to Baseline* }\end{array}$ \\
\hline \multicolumn{4}{|l|}{ RH } & $3.26 \%$ & $2.562 \%$ & \\
\hline \multicolumn{4}{|l|}{ DPF } & $-6.06 \%$ & $-0.003 \%$ & $-0.31 \%$ \\
\hline \multicolumn{4}{|l|}{ HVNW } & $3.30 \%$ & $0.013 \%$ & $1.30 \%$ \\
\hline \multicolumn{4}{|l|}{ WBTH } & $-0.85 \%$ & $-0.017 \%$ & $-1.67 \%$ \\
\hline \multicolumn{4}{|l|}{ GreenA } & $-0.30 \%$ & $-0.215 \%$ & $-19.38 \%$ \\
\hline \multicolumn{4}{|l|}{ GreenE } & $0.96 \%$ & $0.018 \%$ & $1.77 \%$ \\
\hline \multicolumn{4}{|l|}{ GreenF } & $0.87 \%$ & $0.058 \%$ & $5.93 \%$ \\
\hline \multicolumn{4}{|l|}{ VolCycle } & $0.16 \%$ & $0.150 \%$ & $16.22 \%$ \\
\hline & Lags & Secs. & Mins. & & & \\
\hline BusRedLight & 19 & 95 & 1.58 & $0.35 \%$ & $0.003 \%$ & $0.30 \%$ \\
\hline EBTH & 4 & 20 & 0.33 & $1.44 \%$ & $0.018 \%$ & $1.80 \%$ \\
\hline EBTH & 6 & 30 & 0.50 & $2.38 \%$ & $0.029 \%$ & $2.99 \%$ \\
\hline EBTH & 7 & 35 & 0.58 & $1.71 \%$ & $0.021 \%$ & $2.14 \%$ \\
\hline EBTH & 8 & 40 & 0.67 & $1.55 \%$ & $0.019 \%$ & $1.94 \%$ \\
\hline EBTH & 16 & 80 & 1.33 & $1.16 \%$ & $0.014 \%$ & $1.45 \%$ \\
\hline ЕВТН & 18 & 90 & 1.50 & $1.60 \%$ & $0.020 \%$ & $2.01 \%$ \\
\hline WBTH & 1 & 5 & 0.08 & $-1.23 \%$ & $-0.024 \%$ & $-2.40 \%$ \\
\hline WBTH & 12 & 60 & 1.00 & $-0.99 \%$ & $-0.020 \%$ & $-1.93 \%$ \\
\hline WBTH & 13 & 65 & 1.08 & $-0.79 \%$ & $-0.016 \%$ & $-1.56 \%$ \\
\hline VolCycle & 12 & 60 & 1.00 & $0.23 \%$ & $0.218 \%$ & $24.32 \%$ \\
\hline VolCycle & 18 & 90 & 1.50 & $0.21 \%$ & $0.206 \%$ & $22.91 \%$ \\
\hline VolCycle & 22 & 110 & 1.83 & $0.15 \%$ & $0.148 \%$ & $15.99 \%$ \\
\hline VolCycle & 39 & 195 & 3.25 & $0.22 \%$ & $0.209 \%$ & $23.18 \%$ \\
\hline VolCycle & 56 & 280 & 4.67 & $0.21 \%$ & $0.202 \%$ & $22.40 \%$ \\
\hline
\end{tabular}

Table 85. $\mathrm{PM}_{2.5} \mathrm{NW}$ Lagged AR 1 Model Interpretation All Lags

\begin{tabular}{|l|rrr|}
\hline & $\begin{array}{c}\text { \% Change } \\
\text { per Unit } \\
\text { Change in X }\end{array}$ & $\begin{array}{c}\text { \% Change per } \\
1 \% \text { Change in } \\
\text { Xemp }\end{array}$ & $\begin{array}{c}\text { \% Average } \\
\text { Contribution } \\
\text { to Baseline* }\end{array}$ \\
\hline wSSE & $-15.45 \%$ & $-6.481 \%$ & \\
wSS & $-5.13 \%$ & $-0.002 \%$ & $-0.19 \%$ \\
wSNW & $-2.25 \%$ & $-0.002 \%$ & $-0.15 \%$ \\
TPAngled & $1.39 \%$ & $0.001 \%$ & $0.10 \%$ \\
HVNW & $-11.31 \%$ & $0.000 \%$ & $-0.04 \%$ \\
EBTH & $1.87 \%$ & $0.009 \%$ & $0.91 \%$ \\
& $0.91 \%$ & $0.011 \%$ & $1.14 \%$
\end{tabular}




\begin{tabular}{|c|c|c|c|c|c|c|}
\hline \multirow{3}{*}{\multicolumn{4}{|c|}{$\begin{array}{l}\text { WBTH } \\
\text { GreenA } \\
\text { GreenD }\end{array}$}} & \multirow{4}{*}{$\begin{array}{r}-0.58 \% \\
-0.31 \% \\
0.38 \% \\
\end{array}$} & \multirow{4}{*}{$\begin{array}{c}-0.011 \% \\
-0.222 \% \\
0.113 \% \\
\end{array}$} & \multirow{4}{*}{$\begin{array}{r}-1.13 \% \\
-19.91 \% \\
11.96 \% \\
\end{array}$} \\
\hline & & & & & & \\
\hline & & & & & & \\
\hline & Lags & Secs. & Mins. & & & \\
\hline BusRedLight & 19 & 95 & 1.58 & $0.23 \%$ & $0.002 \%$ & $0.20 \%$ \\
\hline TPAngled & 4 & 20 & 0.33 & $-17.14 \%$ & $0.000 \%$ & $-0.05 \%$ \\
\hline TPAngled & 8 & 40 & 0.67 & $-20.09 \%$ & $-0.001 \%$ & $-0.06 \%$ \\
\hline TPAngled & 12 & 60 & 1.00 & $-23.30 \%$ & $-0.001 \%$ & $-0.07 \%$ \\
\hline TPAngled & 16 & 80 & 1.33 & $-21.22 \%$ & $-0.001 \%$ & $-0.06 \%$ \\
\hline TPAngled & 20 & 100 & 1.67 & $-11.44 \%$ & $0.000 \%$ & $-0.03 \%$ \\
\hline ЕВТН & 6 & 30 & 0.50 & $0.89 \%$ & $0.011 \%$ & $1.11 \%$ \\
\hline EBTH & 11 & 55 & 0.92 & $0.72 \%$ & $0.009 \%$ & $0.90 \%$ \\
\hline ЕВТН & 14 & 70 & 1.17 & $0.94 \%$ & $0.012 \%$ & $1.17 \%$ \\
\hline ЕВТН & 15 & 75 & 1.25 & $1.04 \%$ & $0.013 \%$ & $1.31 \%$ \\
\hline ЕВТН & 16 & 80 & 1.33 & $1.96 \%$ & $0.024 \%$ & $2.45 \%$ \\
\hline EBTH & 18 & 90 & 1.50 & $0.74 \%$ & $0.009 \%$ & $0.93 \%$ \\
\hline ЕВТН & 19 & 95 & 1.58 & $1.27 \%$ & $0.016 \%$ & $1.59 \%$ \\
\hline ЕВТН & 24 & 120 & 2.00 & $1.31 \%$ & $0.016 \%$ & $1.63 \%$ \\
\hline WBTH & 6 & 30 & 0.50 & $-0.68 \%$ & $-0.014 \%$ & $-1.34 \%$ \\
\hline WBTH & 9 & 45 & 0.75 & $-0.91 \%$ & $-0.018 \%$ & $-1.80 \%$ \\
\hline WBTH & 10 & 50 & 0.83 & $0.60 \%$ & $0.012 \%$ & $1.18 \%$ \\
\hline WBTH & 11 & 55 & 0.92 & $-0.50 \%$ & $-0.010 \%$ & $-0.99 \%$ \\
\hline WBTH & 12 & 60 & 1.00 & $-0.42 \%$ & $-0.008 \%$ & $-0.83 \%$ \\
\hline WBTH & 14 & 70 & 1.17 & $-0.68 \%$ & $-0.013 \%$ & $-1.33 \%$ \\
\hline WBTH & 15 & 75 & 1.25 & $-0.61 \%$ & $-0.012 \%$ & $-1.20 \%$ \\
\hline WBTH & 16 & 80 & 1.33 & $-0.99 \%$ & $-0.020 \%$ & $-1.93 \%$ \\
\hline WBTH & 18 & 90 & 1.50 & $-0.81 \%$ & $-0.016 \%$ & $-1.60 \%$ \\
\hline WBTH & 19 & 95 & 1.58 & $-0.69 \%$ & $-0.014 \%$ & $-1.35 \%$ \\
\hline WBTH & 21 & 105 & 1.75 & $-0.76 \%$ & $-0.015 \%$ & $-1.49 \%$ \\
\hline WBTH & 22 & 110 & 1.83 & $-0.59 \%$ & $-0.012 \%$ & $-1.15 \%$ \\
\hline WBTH & 24 & 120 & 2.00 & $-0.69 \%$ & $-0.014 \%$ & $-1.36 \%$ \\
\hline VolCycle & 21 & 105 & 1.75 & $0.11 \%$ & $0.110 \%$ & $11.63 \%$ \\
\hline VolCycle & 43 & 215 & 3.58 & $0.13 \%$ & $0.123 \%$ & $13.10 \%$ \\
\hline
\end{tabular}

